\title{
ASPECTS OF ROMAN POTTERY IN \\ CANTON TICINO (SWITZERLAND)
}

\author{
Volume I
}

by

Christiane M. A. De Micheli Schulthess

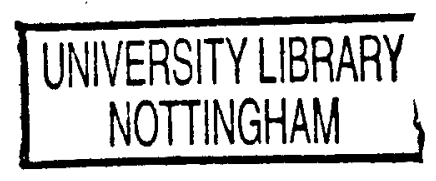

Thesis submitted to the University of Nottingham for the degree of Doctor of Philosophy

May 2001 
Ai miei genitori 


\section{Contents}

\section{SECTION I : INTRODUCTION}

Chapter 1 : Introduction

1.1. Aims of the Thesis

1.2. Structure

1.3. Methodology

1.4. Definition of Coarse Pottery 6

1.5. History of Research on Roman Coarse Pottery 8

1.6. History of Research on Thin walled Pottery 14

$\begin{array}{lll}\text { 1.7. Acknowledgements } & 16\end{array}$

Chapter 2 : The Geography and Archaeology of Canton Ticino

2.1. Introduction

2.2. Geography of Canton Ticino

Geomorphology

Soils

Climate 
$\begin{array}{ll}\text { Vegetation } & 32\end{array}$

$\begin{array}{ll}\text { Natural Resources } & 40\end{array}$

$\begin{array}{ll}\text { Communications } & 48\end{array}$

2.3. Archaeology of Canton Ticino 54

History of Research $\quad 54$

Native Background of Canton Ticino (Iron Age) : $\quad 60$

Golasecca and La Tène

Outline of later Prehistory $\quad 71$

The Romanization of Canton Ticino 78

Chapter 3 : Cemeteries and Settlements 89

3.1. Introduction and Methodology of Dating 89

$\begin{array}{ll}\text { 3.2. The Sites } & 95\end{array}$

$\begin{array}{ll}\text { Ascona } & 95\end{array}$

$\begin{array}{ll}\text { Avegno } & 100\end{array}$

$\begin{array}{ll}\text { Cavigliano } & 101\end{array}$

$\begin{array}{ll}\text { Gambarogno } & 104\end{array}$

$\begin{array}{ll}\text { Gordola } & 106\end{array}$

$\begin{array}{ll}\text { Locarno } & 109\end{array}$

$\begin{array}{ll}\text { Locarno-Muralto } & 111\end{array}$

$\begin{array}{ll}\text { Locarno-Solduno } & 130\end{array}$

$\begin{array}{ll}\text { Losone } & 139\end{array}$ 
$\begin{array}{ll}\text { Maggia } & 151\end{array}$

Minusio 152

$\begin{array}{ll}\text { Moghegno } & 158\end{array}$

$\begin{array}{ll}\text { Riazzino } & 162\end{array}$

$\begin{array}{ll}\text { Tegna } & 163\end{array}$

$\begin{array}{ll}\text { Tenero } & 164\end{array}$

$\begin{array}{lll}\text { 3.3. Vertical Stratigraphy } & 173\end{array}$

$\begin{array}{ll}\text { 3.4. Date-range of Coins } & 175\end{array}$

SECTION II : THE MATERIAL

Chapter 4 : The Forms

4.1. Introduction and Methodology

4.2. The Forms 182

$\begin{array}{ll}\text { 4.2.1. Cups } & 182\end{array}$

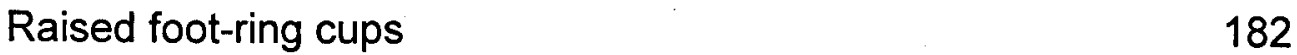

$\begin{array}{ll}\text { Thin walled cups } & 191\end{array}$

$\begin{array}{ll}\text { Cups with globular body } & 191\end{array}$

$\begin{array}{ll}\text { Cups with hemispherical body } & 196\end{array}$

Cups with conical body $\quad 208$

$\begin{array}{ll}\text { Carinated cups } & 211\end{array}$ 
Cups with cylindrical body $\quad 224$

Handled cups $\quad 226$

$\begin{array}{ll}\text { Cups with globular body } & 226\end{array}$

4.2.2. Beakers $\quad 230$

$\begin{array}{ll}\text { Beakers with globular body } & 230\end{array}$

Beakers with ovoid body $\quad 242$

Beakers with conical body 265

Beakers with cylindrical body 269

$\begin{array}{ll}\text { 4.2.3. Balsamaria } & 279\end{array}$

Balsamaria with ovoid body 279

4.2.4. Dishes 282

Dishes with inturned or out-turned rim $\quad 282$

Rim rounded in section $\quad 282$

$\begin{array}{ll}\text { Rim triangular in section } & 288\end{array}$

Dishes with straight or slightly inturned wall 292

Rim rounded in section $\quad 292$

Rim triangular in section $\quad 299$

Summary $\quad 300$

4.2.5. Bowls 304

Bowls with globular or hemispherical body 304

$\begin{array}{ll}\text { Bowls with conical body } & 315\end{array}$

Bowls with low conical body $\quad 315$

$\begin{array}{ll}\text { Bowls with high conical body } & 337\end{array}$ 
4.2.6. Jars

Jars with ovoid body

Jars with out-turned rounded rim

Jars with out-turned rim triangular or rectangular in section 365

Jars with rim with internal lid seating

Jars with horizontal rim

Jars with barrel-shaped body

Jars with cylindrical body

Jars with globular body

Handled jars

4.2.7. Lids

396

Lids with conical body

Lids with straight wall

Lids with curved wall 403

4.2.8. Flagons \& Jugs

Flagons with biconical body

Flagons with biconical to pyriform body

Flagons with pyriform body

Flagons with pyriform to globular body

Flagons with globular body

Flagons with globular flattened body

Flagons with onion-shaped body

Flagons with ovoid body

Flagons with barrel-shaped body 
Flanged Flagons

Flagons with biconical body 460

Flagons with globular body 468

Flagons with globular flattened body 473

Flagons with onion-shaped body 476

Flagons with ovoid body 481

Flagons with barrel-shaped body 481

Jugs 482

Jugs with ovoid body 482

Jugs with biconical body 483

4.3. Functions, Latin Names and Graffiti 485

4.3.1. Historical Evidence 485

4.3.2. Epigraphical Evidence 499

Chapter 5 : The Fabrics

5.1. Classification and Analysis

5.1.1. Dark Fabrics

5.1.2. Light Fabrics

510

5.2. Histograms and Chronology 
Chapter 6 : Decoration

6.1. Classification and Analysis 520

$\begin{array}{ll}\text { 6.1.1. Cups } & 521\end{array}$

6.1.2. Beakers 542

6.1.3. Balsamaria

6.1.4. Flagons, Flanged Flagons, Jugs 551

6.1.5. Jars, Two-handled Jars, Bowls 556

6.1.6. Dishes 563

$\begin{array}{ll}\text { 6.1.7. Lids } & 565\end{array}$

SECTION III : CONCLUSIONS

Chapter 7 : Chronology

$\begin{array}{ll}\text { 7.1. Introduction } & 566\end{array}$

$\begin{array}{ll}\text { 7.2. Internal Chronology } & 567\end{array}$

7.2.1. Single Forms 568

7.2.2. Histograms 581

$\begin{array}{ll}\text { 7.2.3. Summary } & 582\end{array}$

7.3. External Chronology 583

$\begin{array}{lll}\text { 7.4. Summary } & 596\end{array}$ 
Chapter 8 : Trade, External Relations and

\section{Other Influences}

8.1. Introduction

8.2. Production Areas 627

8.3. Local and Imported Products 637

8.3.1. Local Products $\quad 641$

8.3.2. Imported Products $\quad 650$

8.4. Trade and Connexions 655

8.5. Summary of the Origin of Other Selected Classes of Material for Comparison : Sigillata Ware and Glass

8.6. Summary of Local and Imported Products 672

Chapter 9 : Summary and Conclusions

9.1. Thin Walled and Coarse Pottery as Grave-goods 686

9.2. Conclusions

702

9.3. Future Work

708 
Chapter 10 : Bibliography and Appendices

10.1. Bibliography

10.2 Appendices

794

Appendix I : Catalogue of Thin Walled and Coarse Pottery

794

Appendix II : Drawings (Pls. 1-158)

1073

Appendix III : Concordance List between Thesis Catalogue and Drawing Numbers, and Museum Inventory Numbers

Appendix IV : List of Graves and Principal Grave-Contents

Appendix $\mathrm{V}$ : List of Fabrics

1464

Appendix VI : Histograms to Section 9.1.'Thin Walled and

Coarse Pottery as Grave-Goods

Appendix VII : Analysis of the Pottery by Periods 


\section{Abstract}

This work deals with the classification and further study of Roman coarse and thin walled pottery from the Locarno region of Canton Ticino, a district of Switzerland on the southern side of Central Alps, in order to establish a reference typology and chronology which may have wider value in Ticino and the nearer regions of northern Italy. The considered pottery comes from the cemeteries and, to a lesser extent, the settlements of the Locarno region, which contains by far the largest number of burials with datable grave-goods in the Canton. The Roman graves from the region range from the beginning of the 1st century $A D$ to the end of the 4th century $A D$, with a concentration during the 1 st and 2 nd centuries AD.

The analysis of coarse and thin walled pottery has highlighted the potential of information of these materials, considering various aspects such as forms, fabrics, decoration, chronology, origin and distribution. The analysis of the coarse pottery in the grave-goods, in association with sigillata and glass wares, and with coins, seems to suggest centres with stronger Roman influence and centres with stronger native background linked to the settlement of Locarno-Muralto.

Parallels with finds from the Verbano region and western Lombardy-eastern Piemonte, in particular the area between the rivers Sesia, Po and Adda were highlighted. Lakes Verbano and Lario lead to the alpine passes and linked the Verbano area to the Raetic and Rhine regions. The same area was easily linked to main centres of the eastern Po region as far as Aquileia and Ravenna by the river Po. 
The present work is not only intended to fulfil the requirement of a British doctoral thesis, but also to satisfy current approaches in Switzerland and complement the systematic studies of other Roman artefacts of the region. 


\section{SECTION I : INTRODUCTION}




\section{ChAPTER 1}

\section{Introduction}

\subsection{AIMS OF THE THESIS}

Aims of the thesis are the classification and further study of Roman coarse and thin walled pottery from the cemeteries and, to a lesser extent, the settlements of the Locarno region of Canton Ticino, in order to establish a reference typology and chronology which may have wider value in Ticino and the nearer parts of northern Italy. The study area was chosen because it contains by far the largest number of burials with datable grave-goods in the Canton. Moreover, vessels from graves have more complete profiles and come from better datable contexts than vessels from settlements.

These main aims involve the following procedures :

1. To study and include in a single work both published and unpublished items, in order to build a picture as complete as possible of the coarse and thin walled pottery in a defined area. Unassociated vessels are also included. Vessels, even if already published, if they could not be checked by the author, have been omitted.

2. To catalogue the vessels according to form, fabric and decoration, in order to compare them with pottery from other nearby regions and define possible links. 
3. To analyse the presence of coarse and thin walled pottery in the cemeteries of the study area and define their relationship to other grave-goods.

4. To analyse external relations and influences in connexion with the history of the region and highlight possible local or imported classes of material.

5. To develop an internal chronology, in order to suggest a possible dating for vessels from unknown contexts.

Purpose of this work is not only to fulfil the requirement of a British doctoral thesis, but also to satisfy current approaches in Switzerland. The present work is therefore intended to complement the systematic study of Roman glass ware (e.g. Biaggio Simona 1991) and other Roman artefacts such as metalwork (Bonzanigo, M. L. Unpublished). In case of the present work, however, the study area does not include all Canton Ticino, but has been restricted to the Locarno region. The main reasons for limiting the study area are the quantity of material and the geographical difference between the regions of Ticino, in particular landscape and communication routes. Moreover, the borders between Ticino and the other Swiss Cantons or Italy are merely the result of recent political events. The study area is therefore defined by its geographical position as the northern end of the natural waterway of lake Verbano and the starting point for routes leading over the Alps. It includes the area from Ascona to Tenero and from Locarno to Moghegno. This area includes cemeteries and settlements situated at the lake's shore, cemeteries lying on the plain but at the foot of the mountains, and cemeteries situated in the lower half of the Valle Maggia. 


\subsection{STRUCTURE}

The thesis has been structured into nine Chapters and five Appendices.

The first Chapter deals with aims and methodology, definition of study area and study material, and the history of research on coarse and thin walled pottery.

In Chapter 2 are considered natural components and history of Canton Ticino, to assist the understanding of the study area and the comprehension of the other Chapters.

Chapter 3 deals with the sites within the study area, described with details summarizing location, size, type and chronology of the cemeteries, and history of archaeological research, in form of a catalogue of cemeteries and graves and of settlements. In Appendix IV, related to Chapter 3, is listed coarse and thin walled pottery from each context along with all other associated datable grave-goods. Other non-datable grave-goods are omitted. The analysis and discussion of the associations in the graves and the suggestion of an internal chronology, are considered as the basis for the present study.

In Chapter 4, coarse and thin walled vessels are divided into Forms. In the same chapter are discussed chronology of the forms, relationship with similar forms from the neighbouring areas, functions and relationship with the other grave-goods.

In Chapter 5 are highlighted and discussed the fabrics; in Chapter 6 decoration and surface treatments.

Chapter 7 includes the sections on chronology. Chapter 8 deals with manufacture, trade, external relations and influences, in order to suggest 
possible production areas and local or imported material. Chapter 9 deals with the conclusions.

The Appendices include the catalogue of coarse and thin walled pottery (Appendix I), the drawings (Appendix II), the concordance list between catalogue and inventory numbers (Appendix III), the list of graves and principal grave-contents (Appendix IV), the list of fabrics (Appendix V), the histograms related to the section 'Thin walled and coarse pottery as gravegoods' in Chapter 9 (Appendix VI), and the analysis of the pottery by periods (Appendix VII).

\subsection{Methodology}

All sources of information about the sites and their excavation have been examined. Natural components and history of Canton Ticino have been outlined in order to enhance knowledge of the study area and the comprehension of the other Chapters. Relevant published and unpublished material has been investigated. This material is held in the following institutions and museums: Ufficio dei Beni Culturali, Bellinzona; Museo Civico Castello di Montebello, Bellinzona; Museo Civico Castello Visconteo, Locarno ; Landesmuseum, Zürich ; Historisches Museum, Bern. Material from private collections is also investigated. In a small number of cases, however, it was not possible to gain access to material. A catalogue of drawings, descriptions, contexts and other details was built up, from which key information could be abstracted for the thesis and its Appendices. All data 
have been processed by computer (Apple-Macintosh at the beginning, then personal computer). The texts have been written with Microsoft Word. Histograms and maps have been worked out with Microsoft Excel and respectively Adobe Photoshop, and both paged with Adobe PageMaker. Plates have been paged with Quark-X-Press. The details of coarse and thin walled pottery have been recorded with FileMaker Pro in files with 30 main fields, enabling a quick search by single or composite features. Each file has been successively summarized into a text for the catalogue in Appendix I, where the vessels are listed according to their provenance and their museum inventory numbers. The vessels discussed in the thesis are displayed in Appendix II.

In the thesis, each vessel bears a catalogue number that corresponds with the drawing number. A concordance list between the author's catalogue and drawing numbers, and museum inventory numbers is provided in Appendix III. The drawing numbers consist of the catalogue numbers preceded by site codes. Both catalogue and drawing numbers occur in the catalogue besides the museum inventory numbers if a vessel has been further discussed and displayed in the thesis.

Of the 1373 vessels or vessel fragments examined, 918 are considered in the thesis. Of these, 594 were drawn or re-drawn by the author; all others were drawn by Nevio Quadri (Ufficio dei Beni Culturali, Bellinzona) and checked by the author for accuracy. All drawings were then re-drawn, computerized and paged by Alessandro Zara, Fabrizio Argiola and Ivano Rosso with a CAD (Computer-Aided Design) program (ArchiCAD). The purpose was to avoid the very time-consuming task of inking drawings and, in particular, to facilitate 
changes of scale and line thickness in accordance with the requirements of different illustrations. The drawings are included in Appendix II and displayed at $1: 3$ scale, according to continental standards. Type specimens were chosen for the summary in Chapter 7, standing for all other vessels of the same Form, and displayed at 1:6 scale.

The work was done on a part-time basis, starting in 1991. Progress depended upon the exigencies of various full-time jobs.

\subsection{Definition of CoARse Pottery}

The term 'coarse pottery' is not well defined. Scarcity of detailed studies and lack of precise definition make some preliminary remarks necessary to understand the limits of the study material.

Italian studies of Roman pottery mention 'ceramica comune' (common pottery), meaning all pottery of everyday use (kitchen, cooking, storage and table ware), in contrast to 'ceramica fine' (fine wares, table wares only) such as Campanian and sigillata ware and thin walled pottery (Carandini 1979, 108; Lavizzari Pedrazzini 1985a, 329). Moreover, sometimes in Roman but especially in Medieval studies, other terms are used: 'ceramica grezza' (coarse pottery) indicates vessels in contact with fire, whereas 'ceramica acroma' (unpainted pottery) denominates vessels not in contact with fire (Brogiolo \& Gelichi 1986, 293ff.). French studies deal, as Italian do, with the term 'commune' (common) to indicate pottery of everyday use (i. e. Sénéchal 1975; Thiriot 1986; Alcamo 1985). German scholars prefer the term 
'Gebrauchskeramik' (i. e. Schindler-Kaudelka 1989) ; Americans have used 'utilitarian pottery' (Dyson 1976). In any case, the use of 'coarse pottery' as contrary of 'fine ware' does not indicate at all which classes of types of pottery are considered.

Riley $(1981,69 \mathrm{ff}$.$) uses 'coarse ware' for household pottery without any slip or$ wash and includes table and kitchen ware, and mortaria. Paunier (1981) highlights the importance of distinguishing, according to the firing techniques, between light fabrics of Mediterranean tradition and local grey/black fabrics. Alarcâo $(1975,27)$ considers 'coarse' the pottery of local manufacture. Except in the presence of kilns or petrographical analysis, however, it is extremely difficult to apply this definition to the pottery from a site. A general meaning, unfortunately still very deep-rooted among many scholars, is to consider pottery without any particular aesthetic or technical value as manufactured where it was found. The assumption of local manufacture because of the 'coarse' appearance of a ware or of high percentages of it on a site, is arbitrary and not supported by scientific evidence. Some pottery from Albintimilium/Nentimilia for example in coarse fabric, used for cooking and spread over all areas of the ancient town, consisted of imports (Olcese 1993, 44).

Carandini (Carandini et al. 1973, 409) defines 'coarse' pottery according to technical features of execution and local manufacture. On the contrary, Massari \& Ratti (Frova 1977, 595-7) and Olcese $(1993,44-5)$ allow that pottery of the same class can be either local or imported.

Mannoni $(1970,297 f f)$, Olcese $(1993,44-5)$ and Carandini \& Ricci $(1985,93-$ 107) consider coarse pottery vessels answering functional criteria (table, 
kitchen, storage, cooking), where aesthetic criteria have a secondary rôle. The function of a vessel, however, is usually a matter of conjecture and I prefer not to use it as a defining criterion. For example, a supposed cooking jar could have been in reality a funerary jar and a sigillata dish could be used as a lid in the kitchen rather than as a dish in fine ware on the table. Moreover, vessels considered as coarse in Roman archaeology because of aesthetic criteria could be considered fine ware in prehistoric archaeology.

Therefore, in this work the term 'coarse pottery' is only related to Roman archaeology and used to make a contrast with as Campanian, sigillata and glazed wares.

Thin walled pottery is here also considered together with coarse wares, whereas other scholars (i.e. Lavizzari Pedrazzini 1985a, 329) list it within fine wares. The reasons are the similarity of some fabrics with coarse pottery and the occurrence of some forms in both classes.

\subsection{HISTORY OF RESEARCH ON ROMAN COARSE POTTERY}

This Section is not intended to be a complete paper on the history of research on Roman coarse pottery. Its purpose is to highlight the significant phases in the study of Roman coarse pottery in Italy and in Canton Ticino.

Coarse pottery in Italy and Ticino has been neglected in pottery studies until recently. In the first half of this century, the study of clay artefacts was based exclusively on aesthetic criteria. Unattractive pottery, recovered during the excavations, was usually thrown away or exceptionally only listed but not 
studied. This appears clearly from excavation reports published in the Italian periodical 'Notizie degli Scavi di Antichità', where only fine wares are studied.

The scarcity of works on coarse pottery is therefore mainly due to the following elements:

1. A tradition of studies that elevated aesthetically fine pottery which was easier to classify;

2. The scarcity of morphological and stylistical changes on coarse pottery over time, making such pottery difficult to date.

Today the relevance of coarse pottery is clear. It constitutes usually the majority of pottery from a site, and modern scientific analysis allows the scholar to gain further information about manufacture and distribution, adding new elements to understanding the past.

A revolution in the approach of the material from northern Italy occurred in $\mathbf{N}$. Lamboglia's publication Gli scavi di Albintimilium e la cronologia della ceramica romana (1950). Lamboglia highlighted the importance of stratigraphic excavation and detailed publication of all associated materials, even if fragmentary and apparently insignificant: ' $\mathrm{Ci}$ siamo scostati dai procedimenti consueti dell'archeologia classica e monumentale, per applicare alla storia quelli dell'archeologia preistorica e provinciale; preoccupandoci soprattutto di fruttare sino in fondo il terreno scavato e di dare valore al frammento e al particolare senza alcun preconcetto d'ordine estetico.' (Lamboglia 1950, preface).

Many scholars followed Lamboglia's example for material from Italy and the Mediterranean area, as it appears from excavation reports in 'Notizie degli 
Scavi di Antichità' or other publications (i.e. Duncan 1964 and 1965; Carandini et al. 1968).

Pottery studies increased in the seventies because of the new interest in material culture ('cultura materiale') and its socio-economical implications (Carandini 1979, 108). Progress in stratigraphical excavation highlighted the need to improve methodology of studying pottery. In particular coarse pottery, according to Carandini, assumed importance as everyday ware, used by the masses, in contrast to fine, luxury wares, which were the prerogative of the few.

M. Vegas published in 1973 an important study of Roman coarse pottery from the western Mediterranean regions. The author compared pottery from many sites and distinguished materials according to their functions: kitchen, table, storage, cult wares and varia. She excluded sigillata ware and local productions, to obtain a classification of coarse pottery over wider areas. Also in 1973 appeared the third volume on the excavations at Ostia (Carandini et al. 1973), with some innovations on methodology. In particular, there was proposed a definition for coarse pottery: the term, inaccurate and conventional, indicated groups of vessels which did not have constant features of clay and surface treatment. It was therefore used to classify all material which did not belong to precise typologies and included everyday ware of local manufacture. In this publication (Carandini et al. 1973, 409; 421) 'coarse pottery' indicated local productions with bright and refined clay, without any coat. In the following study (Carandini et al. 1977a) the data were elaborated as quantitative schedules. 
R. Sénéchal published in 1975 a study on the coarse pottery from Alesia (Sénéchal 1975). The author compared the study material with that from Vindonissa and from some Rhineland regions and explained the similarity assuming common manufacture techniques in western Roman world. He considered as impossible, however, the exportation of coarse pottery from its production centres.

In 1976 appeared S.L. Dyson's work on coarse pottery excavated at Cosa (Dyson 1976). Of particular interest, is the study of pottery from a kiln, and parallels established with the pottery from Albintimilium.

The publication of the material from Luni (Cavalieri Manasse 1977) represented a further evolution in the study of coarse pottery. Besides the typological classification of the material, T. Mannoni executed petrological analysis on thin sections. The resulting morphological types were associated with different fabrics and grouped according to provenance. These analyses also highlighted the fact that some coarse pottery consisted of imports from other production centres. The results of this study were later improved and the provenance of some pottery types were definitively determined (Ratti Squellati 1987).

In 1979 appeared the work on the Gallo-Roman coarse pottery from Aquitania (Santrot \& Santrot 1979). The study, partly supported by laboratory analysis, highlighted the most frequent problems in approaching coarse pottery: large quantities of material, the difficulty of building up pottery groups, and the insufficiency of similar studies as reference. The authors also could distinguish pottery of Celtic tradition, associated to Roman pottery or local imitations. 
In the 1980s modern technologies and investigation methods were more and more applied to pottery studies. Pottery was not only considered for its dating evidence, but also as a source of information about production, manufacture techniques, trade and their socio-economical implications (Anderson 1984; Peacock 1982). New exigences of specification, quantification and qualification were requested for the reconstruction of the economic of history of the Ancient World (Finley 1977, 30; Arthur \& Ricci 1981; Shennan 1988; Orton 1989; Oxford 1989). Mathematics and computing were currently applied to archaeology (Doran \& Hodson 1975; Riley 1981; Riley 1984; Orton 1980). Laboratory analysis became frequent in archaeological publications. Lithic inclusions and chemical composition of the fabrics were related to local geology and quantitative analysis of the pottery in archaeological deposits (Cavalieri Manasse 1977, 590-595; Carandini \& Ricci 1985; Paunier 1981; Schindler-Kaudelka 1989).

Many Italian studies of Roman coarse ware still lack of petrological analysis, although the situation varies from region to region. Genoa and Liguria (Mannoni 1972; Mannoni 1974; Mannoni 1975; Mannoni 1985 ; Olcese 1993) and Lombardy (Brogiolo 1988 ; Sfrecola 1991) have many examples. It is important to consider, however, the limits of such analysis. Often the identification of the exact provenance of the elements contained in the fabrics is impossible because many inclusions belong to rocks or soils spread over wide areas by glacial or fluvial movements.

In 1984 was published a study on the pottery from Carthage (Fulford \& Peacock 1984). The authors carried out typological and chronological classifications and petrological analysis. The fabrics of the main groups, 
previously defined according to function, were further separated according to petrological features. The result was a catalogue of forms and types grouped according to mineralogical, technical and functional criteria and associated to morphological and chronological parallels. Among the coarse pottery, it was possible to distinguish local products from imports and quantify their relationships.

In 1991 appeared the study on the material found at Milan during work for the tube line MM3. The coarse pottery was divided into forms, according to the function, and types within a form, with common morphological and technical features as fabric, firing, manufacture (Guglielmetti et. al. 1991, 132ff.). Further, there were identified some 'productions' indicating vessels of different form but identical fabric and manufacturing techniques. On the basis of these results, it is necessary to re-examine all products identified at Milan in fabric groups rather than formal groups.

In 1993 G. Olcese published a new classification of the coarse pottery from AlbintimiliumNentimilia according to typology and fabrics (Olcese 1993). Laboratory analysis was employed to group the pottery. Clay analysis allowed the author to identify production areas and to quantify local products and imports.

In Ticino, the scientific approach to ceramic artifacts is still totally lacking. Moreover, the few publications on Roman material are very general ones. Except for Roman glass, object of a doctoral thesis (Biaggio Simona 1991), and thin walled and coarse pottery, with which this work is concerned, no ware has been studied in detail. There also persists the idea of coarse pottery as 
chronologically and typologically less relevant and as essentially local product. Laboratory analyses of samples from different regions are needed in order to distinguish between local products and imports, and to establish where the imports came from. It is important to consider, however, that the morphology of Canton Ticino is due to the action of glaciers, moving southwards scouring the valleys. This movement, taking material from upper Ticino southwards, might not allow one to obtain clear results from the analyses. Geologicalpetrological criteria indicating the same compositional components in the pottery and in the area may not result in any useful evidence. Moreover, no pottery kilns have been found so far in Ticino or in the neighbouring areas. It is therefore impossible to analyse kiln wasters to define local vessels and establish groups of reference (for the methods, also see Olcese 1993, 70ff.).

\subsection{HISTORY OF RESEARCH ON THIN WALLED POTTERY}

This ware consists of drinking vessels (cups, beakers, tankards), characterized by the extreme thinness of the wall $(0.1$ to 3 or $5 \mathrm{~mm})$. Unlike Campanian and sigillata wares, this class is very heterogeneous: some items are close to sigillata pottery of Italian manufacture, other items resemble the coarse pottery. The forms reflect Hellenistic and Iron Age (Golasecca, La Tène and Este cultures) influences.

The main studies on thin walled pottery are those by Marabini Moeus (1973) on material from Cosa and by Mayet (1975) on material from Iberia. Marabini Moeus's work consisted of a typology according to forms, but did not consider 
distribution patterns. Mayet's study, on the other hand, was based upon thin walled pottery from Spain and, when possible, the author tried to identify production centres.

Another study, by Ricci (1985), defines types connected with standardized products mainly from central Italy.

Recently knowledge of materials from Cisalpina has been enlarged by works on the cemetery and the settlement at Angera (Sena Chiesa \& Lavizzari Pedrazzini 1985; Sena Chiesa \& Lavizzari Pedrazzini 1995), on the thin walled pottery in the museums of western Lombardy (Treggiari 1986-87) and on the Roman cemeteries of Milan (Bolla 1988).

Although these studies represent a valid contribution to the knowledge of this class of material, the general problem of studying thin walled pottery from Cisalpina is the lack of a systematic classification of its products, facilitating the recognition of local products and an understanding of their production and movements. 


\subsection{ACKNOWLEDGEMENTS}

I am indebted to a large number of people who made this thesis possible.

Dr. Jeffrey May (University of Nottingham) stimulated and constantly made clear the aims of the thesis, supporting me for both archaeological and linguistic aspects. He and his wife Brenda made my many supervisions in Nottingham easier and more pleasant with their hospitality.

The late Pier Angelo Donati, Dr. Giuseppe Chiesi, dott. Rossana Cardani Vergani, Nevio Quadri and the staff of the Ufficio dei Beni Culturali, Bellinzona, gave me access to the study material kept in Bellinzona and the relative documentation.

Riccardo Carazzetti, Keeper of the Museo Archeologico, Locarno, made the access to the archaeological collections in both museum and deposits and my many visits to Locarno easier.

The access to material and documentation outside Canton Ticino were possible thanks to Rudolph Degen, Keeper of Roman Archaeology by the Landesmuseum Zürich, and Elena Corvi, and to Karl Zimmermann, Keeper of the Historisches Museum Bern, and Felix Müller.

Many scholars and colleagues enriched the thesis with their useful suggestions and information. For interesting discussion on Roman pottery I am grateful to dott. Isabella Nobile and dott. Marina Uboldi (Museo Civico Giovio, Como), Prof. Roger J.A. Wilson (University of Nottingham), Dr. Andrew G. Poulter (University of Nottingham), and Dr. Mark Pearce (University of Nottingham). Alfio Martinelli (Castel San Pietro) provided me with information about the history of research in Canton Ticino and helped the comprehension 
of the later prehistory of Ticino. Dr. Markus Felber (Museo Cantonale di Storia Naturale, Lugano), dott. Lanfredo Castelletti and dott. Alfio Maspero (Museo Civico Giovio, Como) helped with information about geomorphology of Canton Ticino. Sacha De Micheli (London) and Alessandro Zara (Chiasso) helped with solutions of problems linked to data processing.

The Associazione Archeologica Ticinese (AAT), Lugano, supported financially the very first steps of this research.

My husband, Pierre Schulthess, substained and encouraged me by throughout this work with the greatest forbearance. 


\section{ChAPTER 2}

\section{The Geography and Archaeology of Canton Ticino}

\subsection{INTRODUCTION}

Chapter 2 deals with natural components and history of Canton Ticino (fig.

2.1). Its substance and extent are intended to enhance knowledge of the study area and the comprehension of the other Chapters, e.g. the problem of fabric analysis depending upon the mixed soil due to the action of the glaciers (Chapter 5), the lack of human or food remains due to the acid soil (Chapter 4), trading and other connections suggested by imports and exports (Chapter 8).

The natural components of Canton Ticino are considered in Section 2.2 under the headings Geomorphology, Soils, Climate, Vegetation, Natural Resources and Communications. Geomorphology and Soils analyse the nature of the territory and its origins. Climate highlights the particularly favourable conditions of the area of pre-alpine lakes, called Insubria and including Verbano and Ceresio. Similar climatic conditions occurred in Ticino in Roman times, with increasing warmth from the 1st century $B C$ to the 4 th century $A D$ and consequent repercussions on agriculture and the practicability of alpine passes. Vegetation considers the evolution from the end of the last glaciation to modern times, with particular reference to the Roman period and the 


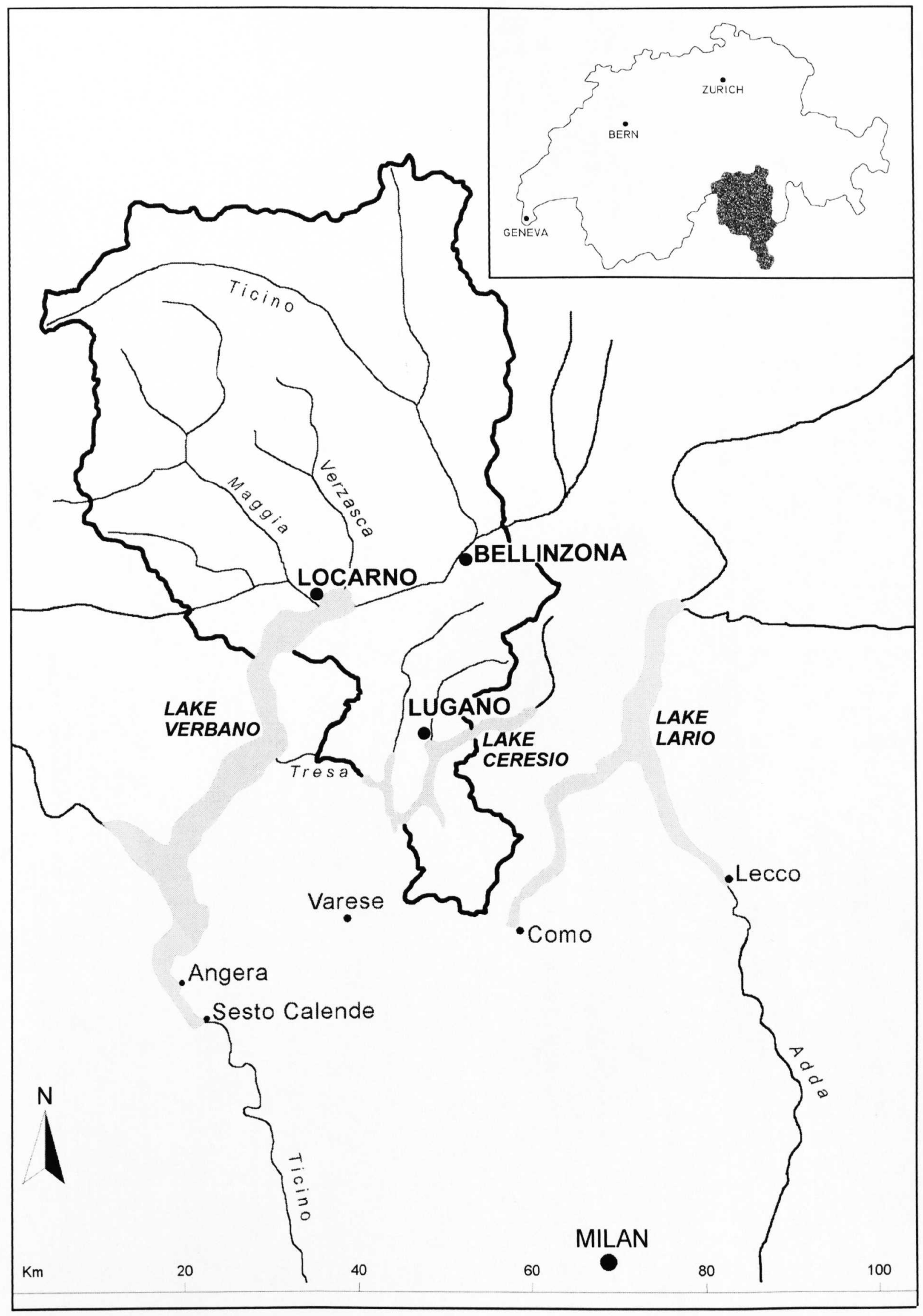

Fig. 2.1. Canton Ticino. Location map. 
analysis of pollens from marshes in Ticino. Natural Resources highlights the richness of the Canton in stones, quartz and iron. Communications, closely linked to Geomorphology and Climate, considers the natural routes and the function of Ticino as passage between the Po plain and the Central Alps.

The cultural development of Canton Ticino is considered in Section 2.3. The first sub-section, History of Research, analyses chronology and methods of approach of archaeological research in Ticino. The other sub-sections are concerned with the evidence of cultural development from the Bronze Age to the Lombard invasion in Ticino. Native Background of Canton Ticino considers the broad evolution of the region from the Bronze Age to the end of La Tène according to archaeological evidence. Outline of Later Prehistory analyses the 2nd and 1st centuries BC and in particular the evolution of the pottery and the passage to the Roman period. Romanization of Canton Ticino investigates Roman expansion and influence, life under Roman rule in Ticino according to archaeological and historical sources. 


\subsection{Geography of Canton Ticino}

\section{Geomorphology (fig. 2.2)}

Canton Ticino is a mountainous district on the southern side of Lepontic or Central Alps. It occupies an area of 2850 square kilometres, to the south nearly reaching the plain of the Po, to the north Cantons Wallis, Uri and Grigioni, to the east Calanca and Mesolcina valleys also in Canton Grigioni. In Italy to the south and west are the provinces of Lombardy and Piemonte.

About half of the territory of Ticino is situated over $1500 \mathrm{~m}$ asl. The district is naturally divided by the Monte Ceneri (554 m asl) into two parts: to the north is the Sopraceneri and to the south is the Sottoceneri. 54.2 percent of Sopraceneri lies over $1500 \mathrm{~m}$ asl with only 20 percent under $900 \mathrm{~m}$ asl. Only 5.2 percent of Sottoceneri is over $1500 \mathrm{~m}$ asl and 66 percent is under $900 \mathrm{~m}$ asl. Sopraceneri is thus part of Switzerland's alpine and mountainous region, Sottoceneri is part of the southern foothills of the Alps (Cotti 1990, 110ff.).

The geography of Ticino is dominated by the presence of two lakes, partly situated in Italy: Verbano or Lago Maggiore in Sopraceneri and Ceresio or Lago di Lugano in Sottoceneri ${ }^{1}$. The main river is the Ticino, which gives its name to the canton. The river rises on the southern side of the San Gottardo and flows through the Leventina and Riviera valleys towards the Verbano, joined by the Brenno at Biasca and the Moesa at Arbedo-Castione. The Ticino continues south from the Verbano from Sesto Calende to Pavia (the Roman Ticinum), where it joins the river Po. Two other considerable rivers flow into the northern end of the Verbano: the Verzasca and the Maggia. On the west 
the Toce, rising in Passo San Giacomo, flows into the Verbano at Fondotoce, where its glaciers joined the Ticino glacier.

Unlike Verbano, Ceresio in Sottoceneri has a centripetal drainage basin with small and short watercourses as affluents. On the north the Vedeggio flows from Rivera to Agno and the Magliasina to Magliaso, on the east the Cassarate from Val Colla and the Cuccio from Cavagna to Porlezza, on the south the Laveggio from Stabio to Riva San Vitale and the Bollettaccia from Valle Cavallizza to Porto Ceresio. Ceresio forms a catchment basin for the surrounding Val Colla, Malcantone and Mendrisiotto as result of a pre-glacial drainage and there is no significant outflow as there is with the Verbano. Only the small river Tresa links Ceresio and Verbano, flowing from Ponte Tresa to Luino.

The actual aspect of the Ticino region is the result of a series of natural phenomena from the Tertiary period onwards and is due in particular to the intense action of rivers and glaciers connected to the progressive alpine lifting. Today the region's main river Ticino is confined to Sopraceneri. The morphology of Sottoceneri and of the Lugano region in particular proves that until the Quaternary period the Ticino did not bend at Giubiasco to flow into the Verbano, but continued directly southwards to the Ceresio (Campana 1988, 245-50). During the Würm glaciation, the southern end of the glaciers reached nearly the Po plain and covered the Ticino valley entirely. A rise in temperature at the end of this period started melting the ice sheet and allowed one to distinguish the main glaciers. As far as Giubiasco the Ticino glacier occupied Leventina and Riviera valleys, that show today the usual post-glacial

\footnotetext{
${ }^{1}$ Both names of the lakes are currently used. The shorter versions of Verbano and Ceresio are preferred in the thesis.
} 
U-shaped profiles. Near Giubiasco, where the ice sheet was about $1500 \mathrm{~m}$ high, there occurred the phenomenon of diffluence. The passage over Monte Ceneri was too narrow for the ice mass, and the glacier split into two arms. Instead of continuing to flow southwards, the main arm changed its course, with an angle of about ninety degrees, to move towards the Verbano. A minor arm passed over Monte Ceneri and flowed southwards scouring the Vedeggio valley, and the western arm of the Ceresio between Agno and Porto Ceresio. The Porlezza-Capolago arm of the Ceresio is the result of the movement of the Adda glacier. Rising in the Raetic Alps, its mass became bigger than the Ticino glacier because of its affluents from Val San Giacomo, Val Bregaglia and Valtellina. By the same phenomenon of diffluence as the Ticino glacier at Giubiasco, the Adda glacier split at Menaggio-Bellagio into three arms. The first arm continued southwards to Como, the second to Lecco. From Lecco, the river Adda flows southwards, joining the Po between Piacenza and Cremona. A third arm of the glacier bent to the west, scouring the Porlezza arm of the Ceresio and flowing southwards to Capolago and Riva San Vitale (Hantke 1983, 368; 370).

The Ticino glacier reached its maximum thickness of about $2000 \mathrm{~m}$ in the Magadino plain and at the north end of the actual lake, after the junction of the Verzasca and Maggia glaciers. The glacier's weight and the amount of rocky material pushed forward slowed down its movement making its erosional force very intense (1-2mm/year) and digging deep depressions in the rocky bottom. Most of these depressions, representing the initial phase of the actual lake, descend under sea level to a maximum depth of $350 \mathrm{~m}$ at Remedello, on the axis Cugnasco-Contone. When the glacier reached Sesto Calende, the 
climate changed and became milder. The glacier started melting, leaving its terminal moraine near Sesto Calende. It became thinner and lost some of its erosional force. Therefore, the rocky bottom was higher at the south end and together with the moraine constituted a natural barrier for the water. The terraces of the Magadino plain show the lake's dimensions in the different periods (fig. 2.3 ; Hantke 1983, 434-8). During late Würm, the lake occupied the plain as far as Sementina and Giubiasco to the north, producing a terrace at $220 \mathrm{~m}$ asl, and reached Ponte Brolla in the lower Valle Maggia. Morainal material and material carried down by the Ticino reduced the dimensions of the lake. The Holocene level appears in a terrace at $207 \mathrm{~m}$ asl on the axis Gudo-Cadenazzo. In Roman times the northern shore reached Quartino and Cugnasco with a terrace at $200 \mathrm{~m}$ asl. The toponym 'Il Porto', south-west of Cugnasco, indicates an ancient port. In the area of Locarno, the Roman finds closest to the lake are at Ascona-San Materno, Solduno, Muralto and Minusio at $205-210 \mathrm{~m}$ asl. The next lake level at $197 \mathrm{~m}$ asl, dating from Medieval times, is between Riazzino and Quartino-Castellaccio. In this period, Magadino and Gordola were ports and frontier stations for the region of Locarno (Wielich 1970, 73 and note 283). The lake's shore moved quickly southwards especially after the Brenno overflow through the Büza of Biasca in 1512. After 1711 the Ticino mouth reached the Bolette ( $194.3 \mathrm{~m}$ asl), north-west of Magadino. The irregular course of the Ticino became canalized in 1888-1895 with a new mouth about one kilometre to the south, at 180m asl (Hantke 1983, 449).

The Ticino was not the only river that carried material into the lake. The Verzasca, and especially the Maggia, are responsible to the lake's filling from 
the west (fig. 2.4). At Tegna the Maggia is also joined by the Melezza, that flows from the west. Before 1907 the Maggia flowed freely through its delta, carrying down every year about 500'000 cubic metres of material, and divided itself into two main arms: one towards Locarno and the other towards Ascona. After the canalization of the river in 1890-1907 and the harnessing of the water for hydroelectric purposes the amount of material is now reduced to 200 '000 cubic metres a year (Hantke 1983, 490).

The occupation of an area and its settlement's distribution are closely linked to the morphology of its territory. The Ticino valley south of the natural narrowing of Arbedo-Gorduno has a wide river floor and steep sides as result of the $\mathrm{U}$ shaped cut of the glacier. Over the valley, a series of terraces on different levels show the pre-glacial modelling of the territory (Campana 1988, 195ff.). The steep sides in Riviera and Magadino plain are also cut by deep valleys, whose rivers or streams flow into the Ticino. The debris carried down by these watercourses during the centuries constituted alluvial cones, on which were built most of the settlements. This allowed the population to live near the tillable soils but sheltered from the intense river floods of the uncanalized Ticino. The different occupation of the two sides of Verbano is the direct consequence of its morphology. On its northern end the Gambarogno on the east consists of steep and narrow glacial terraces, whereas the Locarnese on the west shows alluvial terracings indicating the lake's levels in different times. On both sides of the lake the first big settlements are possible first on the axis Verbania-Laveno. From Laveno southwards, on the west side, the territory shows the same characteristics as the Po plain and, consequently, is more suitable for settlements (Ispra, Angera, Sesto Calende). 


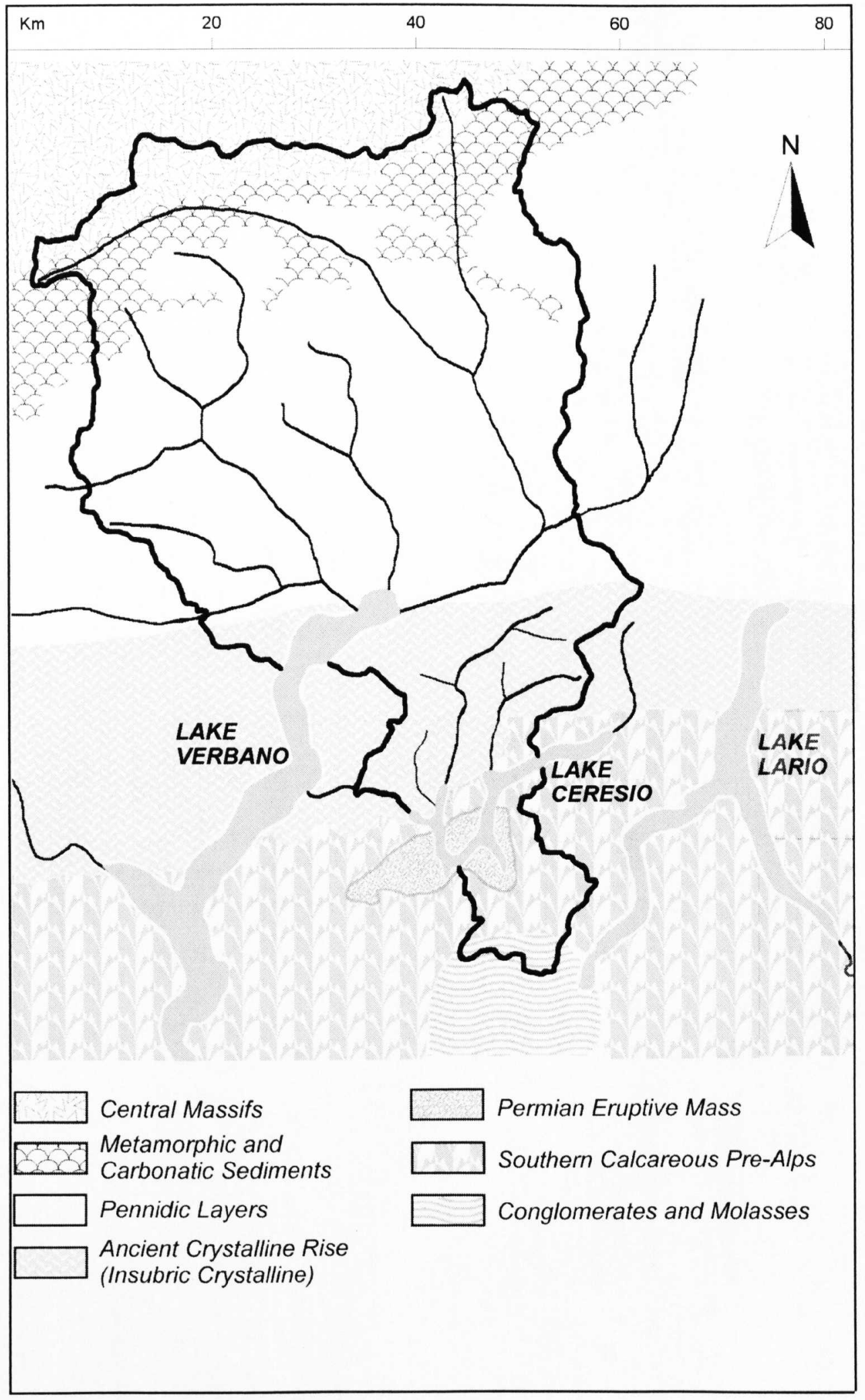

Fig. 2.2. Geomorphology of Canton Ticino (from Aguardi et al. 1984, 32; modified by the author). 


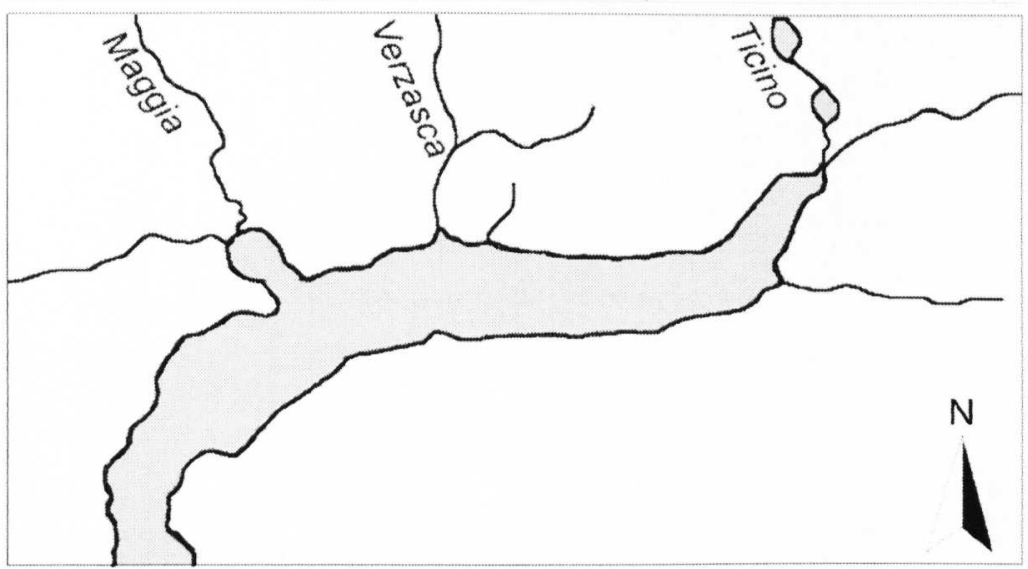

Lake Verbano during the early post-glacial period

$\mathrm{Km}$

10

20

30

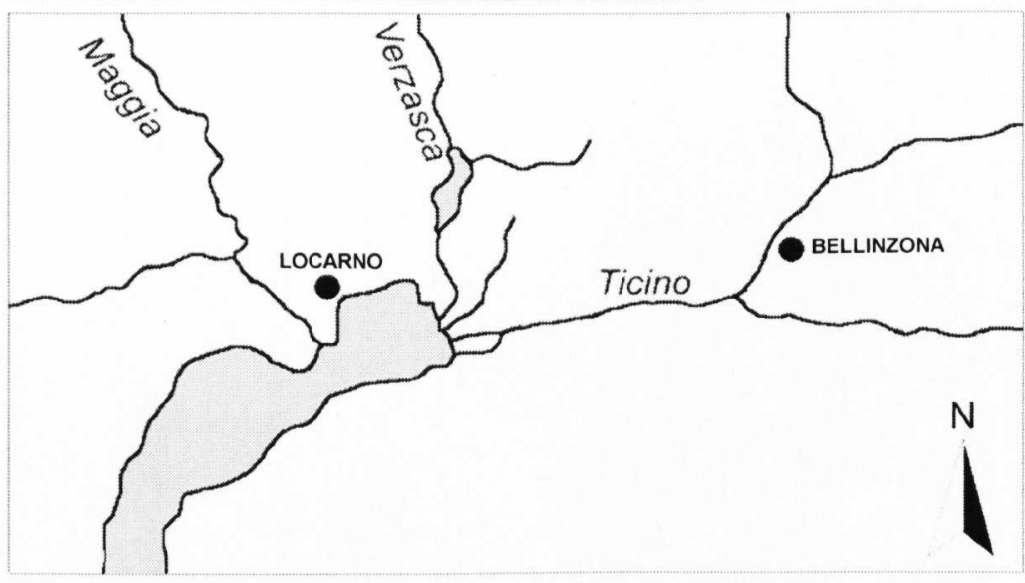

Lake Verbano today

Fig. 2.3. Dimensions of the northern end of lake Verbano in different periods (from Aguardi et al. 1986, 17; modified by the author).

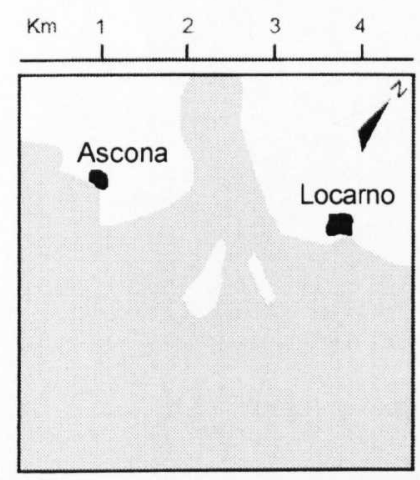

Later prehistoric period

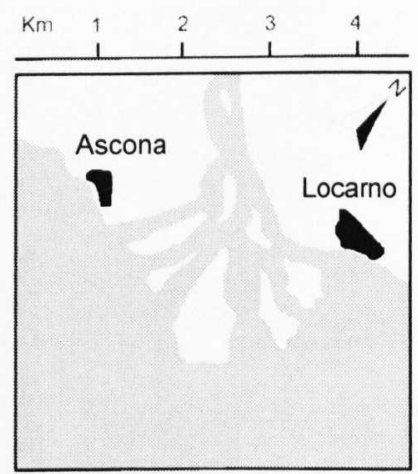

Middle Ages

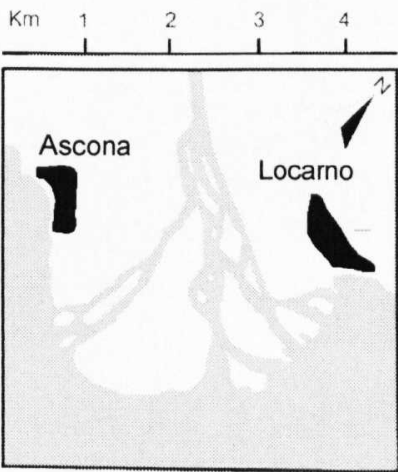

C. 1890

Before the alteration of river Maggia's course

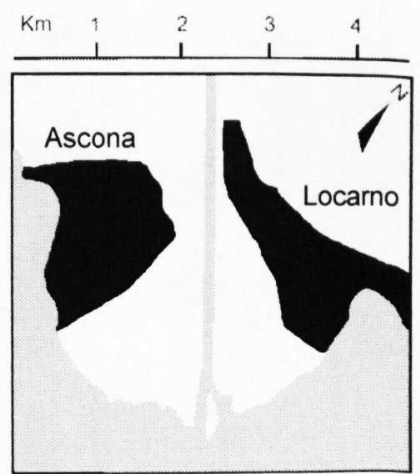

1980s.

Fig. 2.4. Dimensions of the delta of river Maggia in different periods (from Cotti 1990, 132; modified by the author). 
The region of the lakes including Verbano, Ceresio and Lago di Como (also called Lario), dominated by the presence of rivers with a wide and flat river floor, constituted a transit area linking the rich Po plain (and the Adriatic Sea) and the regions north of the Alps. The big lakes in particular, always on the north-south axis, were the more convenient routes for people and goods.

\section{Soils}

Except for a narrow band to the north, Switzerland is dominated by the Alps, a molassic basin in the Swiss Plateau and their ramifications in the Jura. The phenomenon creating the Alps occurred mainly during the first half of the Tertiary period, when the European plate to the north-west collided with the Adriatic-Apulian plate to the south-east. The Southern Alps, where Canton Ticino is situated, range from the Sesia region to the west to the Austroalpine area to the east and show a series of folds and thrusts (Trümpy 1965-1978, pl. 4).

The political and geographical subdivision of Canton Ticino into Sopraceneri and Sottoceneri corresponds roughly to an important geological division. The fracture called 'Linea del Tonale' or Insubric line runs from DomodossolaLocarno through the Valtellina to Passo del Tonale and continues as Linea di Canavese to the south-east. The Insubric line separates the area of Pennidic layers, pushed against the San Gottardo Massif during the alpine folding, north of Monte Ceneri, from the area of the ancient crystalline of Southern Alps or Insubric crystalline (Antonietti 1968, 88-90). Successive modifications of the territory carried new materials into the Alpine thrusts and created the actual geotectonic unities. They are mainly disposed in transverse zones as 
result of the same compression on the north-south axis due to the movement of the rocky rise that created the Alpine mountain range.

The geological substratum of the southern end of Ticino, in the region of Chiasso, consists of conglomerates and molasses dating from the Tertiary period. South of the line Caslano-Lugano, the Insubric crystalline disappears under Mesozoic sedimentary layers with limestone, flint limestone, dolomite and marls. They form the southern calcareous Pre-Alps and are confined mainly to Medrisiotto because of the presence around Ceresio of the Permian eruptive mass with porphyrite, porphyry, vulcanic tuff, red conglomerates and sandstones. South of the Insubric line and as far as Lugano appears the ancient crystalline rise with different gneiss, amphibolites, schists and micaschists.

North of the Insubric line, the main part of Sopraceneri occupies the area of the Pennidic layers, with different gneiss, amphibolites and green rocks. To the northern end of Ticino metamorphic and carbonatic sediments with dolomitic marbles, dolomites and limestone schists are spread on a narrow band, including Val Bedretto, Val Piora and Campolungo. This band borders on the area of the Central Massifs with granites and granitic gneiss. Therefore, most of the rocky substratum of Canton Ticino consists of siliceous rocks, with acid reaction and poor in carbonates. Only the calcareous southern Pre-Alps in Sottoceneri and the narrow band of metamorphic and carbonatic sediments in Sopraceneri have a substratum with alkaline reaction, rich in carbonates (Bär 1984, 14; Jäckly 1965-1978, pl. 16; Spicher 1965-1978, pl. 5; Aguardi et al. 1984, 31-4; Aguardi et al. 1985, 11ff.). 
The fluvio-glacial formations of the Quaternary completed the pedogenetic aspect of the territory. The glaciers carried big quantities of loose material, forming lateral and ground moraines in the valleys. When the ice mass started melting, the terminal moraines constituted natural barriers for the water. North of these barriers were created the post-glacial lakes. In the meantime, the post-glacial rivers washed away the morainic rocks from the steep sides of the valleys and deposited them in the plains. The same rivers filled in the following periods part of the lakes, creating alluvial plains. The predominant gneiss structure of the moraines explains the soils with acid reaction of the valley floors and the surrounding areas. The distribution of different soils in Canton Ticino and in the neighbouring Moesano can be summarized as follows: alluvial sandy brown soil, acid and rich in humus, is distributed in the flat valley floors of Valle Maggia from Bignasco, Leventina from Giornico, Riviera from Malvaglia, Mesolcina from Lostallo and in the alluvial plains of the Maggia's delta, Magadino and the plain south of Mendrisio. Low acid or neutral brown soil, rich in humus, occupies low valleys, hill areas or terraces. It originated from moraines or a substratum rich in gneiss. In Sopraceneri this soil appears mainly along the main rivers and plains in Centovalli; in Sottoceneri in Valle del Vedeggio from Monte Ceneri to Agno and south of Ceresio, except for the region of Monte Generoso. This area is characterized by calcareous brown soil rich in carbonates.

Acid brown soil, mixed with podzol and rich in humus, originated from a gneiss substratum and appears on slopes (up to $1300 \mathrm{~m}$ asl) or big rocky surfaces: in Valcolla and Malcantone in Sottoceneri; in Gambarogno, on the east side of middle and upper Valle Maggia, on the east side of middle and lower 
Leventina and the west side and north end of Riviera. The remaining areas along the valleys (from over 1300 up to $2900 \mathrm{~m}$ asl) are occupied by podzol with acid brown soil and humus, originating from silicate rocks. A narrow band, following the east boundary of Canton Ticino and Moesano and ranging from Monte Generoso to San Bernardino, shows a pebbles and rocky soil, rich in carbonates and silicates (Frei \& Peyer 1965-1978, pl. 7a).

\section{Climate}

The geographic position of Canton Ticino at the foot of the Alps determines its climatic conditions, which differ from those north of the Alps or those of the Po plain. The geographic structure of the district, with mountains sloping quickly down southwards and valleys with wide openings to the south, also contributes to determine its climate (Aguardi et al. 1984, 20-30; Antonietti 1968, 91-5).

Particularly favourable conditions appear in the area of the pre-alpine lakes, from Lago d'Orta to the west to Lago di Garda to the east, including Verbano, Ceresio, Lario and Lago d'Iseo. This area is also called 'Insubria' and its 'Insubric climate' is one of its peculiar features. Geographically, the Insubric territory of Canton Ticino includes the whole Sottoceneri, except for its southern end which feels the influence of the Po plain, and the areas around the Swiss arm of lake Verbano. The influence of Insubric climate reaches, although attenuated, the lower valleys of the Ticino as far as Biasca, of the

Riviera as far as Acquarossa, of the Moesa as far as Mesocco and of the Maggia as far as Bignasco. 
In comparison with the middle-European continental climate north of the Alps and the alpine climate, the Insubric climate differs because of a higher annual average temperature and a lower temperature range, conditioned by the influence of the lakes moderating the temperature. The relatively high annual average temperature is the consequence of a milder winter climate due to the clear sky with more sunny days and rarely fog, and is determined by dry air masses from the north that become warmer in the valleys south of the Alps. The southern end of Canton Ticino feels the influence of the continental climate of the Po plain, with higher temperature in summer and a lower one in winter. These conditions depend on the massive presence of fog and are due to the stagnation of cold air masses.

The rainfall in Canton Ticino occurs mainly from May until October with higher frequency during the summer, whereas the winter is usually dryer. In comparison with the rainfalls north of the Alps, those in Ticino are characterized by double intensity and lower frequency. They are caused by warm and moist winds blowing from the south and south-east, that ascend the Alps quickly and undergo a sudden cooling. The consequences are condensation, abundant rainfalls and frequent storms.

In antiquity, the warmest post-glacial level in Europe occurred between about 4000 and $2400 \mathrm{BC}$. During this period the upper tree line in the Swiss and Austrian Alps reached $2100 \mathrm{~m}$ asl. At the edges of the lakes at Burgäschisee and Thayngen in Switzerland and Federsee in the Alpen foreland settlements were built on piles, which were later abandoned because of floods. There followed a warmer period between 1100 and $800 \mathrm{BC}$, when new lake 
settlements were built in the Alpine regions and farming activitiy reached the Alpine forest limit.

H.H. Lamb (1985, 132ff.), quoting H. Gams (1937), suggested that during the 7th to 4th century BC the climate became colder again. The lakes rose again (c. $500 \mathrm{BC}$ the Bodensee rose by about 10 metres) and flooded the surrounding lake settlements. The upper tree limit in the Central Alps reached a minimum in c. $400 \mathrm{BC}$ at $1980 \mathrm{~m}$ asl. Civilizations of the Mediterranean may have been favoured by frequent winter rains, which increased soil fertility in Greece, southern Italy and northern Africa and allowed the development of their cultures. During the 1 st century $B C$ and the 1 st century $A D$, horticultural writers such as Pliny (Naturalis Historia XIV, 3-27; XV, 1) refer to the cultivation and wine and olive farther north in Italy, whereas in previous centuries the climate was too cold. The continued recovery of warmth continued through Roman times, reaching its maximum in the 4th century AD. The spread of wine cultivation continued northwards until the late 1st century AD, when Domitian's edict prohibited vineyards north and west of the Alps. Probus revoked this edict in $280 A D$ and wine was grown in Germany and Britain. Around AD 300 wine production in Britain may have become sufficient to diminish or even stop the importation of foreign wine.

The variations of climate in Europe known from documentary sources from $400 \mathrm{BC}$ to $A D 1300$ demonstrate that the situation in Italy did not differ from that in the Mediterranean or in Central Asia. Particularly wet years occurred in Italy in about $200 \mathrm{BC}$ and around the turn of the millennium. From the beginning of our age onwards, the climate became progressively dryer, reaching its peak between soon after $A D 300$ and after $A D$ 400. The 
migrations of late Roman times and afterwards seem to coincide with this change of climatic conditions. From $150 \mathrm{BC}$ to $A D 300$ is attested the use of the Great Silk Road across Asia to China. By the 4th century AD drought developed and stopped the traffic along this route. In the meantime, the drying up of nomads' pastures had as a probable consequence the migration westwards of many Asiatic people. A similar massive migration in one direction occurred during the last millennium $\mathrm{BC}$, with a great movement of peoples from northern Europe to the south. In this case the probable reason was the progressive deterioration in climatic conditions.

Wet years returned c. $A D 600$, increased down to $A D 800$ and reached another maximum $c$. $A D 900$. From about $A D 1000$ until $A D 1300$ the wet years frequency increased strongly again (Lamb 1985, 153-4 fig. 59 ; 157-8).

The upper tree line in the Central Alps was lowered to $1970 \mathrm{~m}$ asl in c. AD 500. In the following centuries the climate improved progressively and the upper tree line reached a maximum at $2040 \mathrm{~m}$ asl in $\mathrm{C}$. AD 1000 . It followed again a sharp cooling of the climate with a minimum in $\mathrm{C} . A D 1600$, when the tree line did not reach 1950m asl (Lamb 1985, 134 fig. 53).

The progressive cooling of central Europe after AD 400 has been examined by the Geographisches Institut of the University of Zürich (Röthlisberger \& Schneebeli 1976). Radiocarbon dating of the moraines in the Val de Baignes, south-western Switzerland, showed that around AD 600-700 the glaciers reached further limits, as they did during the Little Ice Age between 15501850. These glaciers also cut a Roman road leading to Italy through the mountains. Dendrochonological studies on larches growing near the upper tree line at Zermatt (Lamb 1985, fig. 61) indicate an increasing warmth of the 
climate during the late 4 th century $A D$, followed by sharp variations during the first decades of the 5th century AD and cold periods afterwards.

The warmth during the Roman period helped the contacts from both sides of the Alps. Canton Ticino is the direct link to central Switzerland for people and goods coming from Italy. Many of the passes used today were not used as carriage roads, but were simple paths (see Communications, p. 48). Milder climatic conditions, however, made easier to cross the Alps. Apart from the problem of snow in winter, a dryer climate may have diminished rushing watercourses, making them easier to cross.

\section{Vegetation}

During the Würm glaciation, only areas over $1100-1200 \mathrm{~m}$ asl emerged from the ice sheet, but even these were mainly covered with permanent snow. Therefore, the pre-existing flora and fauna were forced to migrate southwards. After the end of the glaciation the region was for long without vegetation. The first traces of vegetal life consisted in algae and lichens, followed by moss. These plants contributed to the crumbling of the rocks and prepared the soil for more exigent species. In the meantime, small lakes were created in the rocky valley bottoms and in the moraines. These lakes were later filled with argillaceous and turfy sediments and became marshes. The importance of these sediments depends on their inclusions of such organic material as pollen, wood, leaves and seeds. They allow one to reconstruct the development of the vegetation and, through pollen analysis, to date precisely the successive phases of change (Aguardi et al. 1985, 23-7; Zoller 1987, 123ff.). 
The history of the return of forest vegetation in Canton Ticino has been outlined by Zoller $(1961,263 \mathrm{ff}$.$) on the basis of the analysis of pollens from$ moss layers. In particular, Zoller studied cores from the Bedrina marsh (1235 $\mathrm{m}$ asl) by Dalpe in Leventina (Sopraceneri) and the small lake of Origlio ( $421 \mathrm{~m}$ asl) north of Lugano (Sottoceneri). In both marshes, the coring met sediments dating from the late-glacial period $(14000-8300 \mathrm{BC})$. The pollen diagrams confirmed the reappearance of vegetation in Sopra- and Sottoceneri during this period and showed until c. $7500 \mathrm{BC}$ the same evolution north of the Alps. The first traces of vegetation belonged to the tundra horizon. Between 11300 and $10400 \mathrm{BC}$ trees appeared in southern Ticino, around the Insubric lakes, as isolated groups of birches. The real reafforestation occurred between 9800 and $8800 \mathrm{BC}$ with forests of birches and pinetrees, that reached Leventina soon afterwards (Bedrina, c. $9000 \mathrm{BC}$ ).

At the beginning of the post-glacial period (c. $7500 \mathrm{BC}$ ) particular climatic conditions allowed the vegetation of Ticino to differ from that north of the Alps. In southern Ticino appeared black hornbeam, oak, maple, and later alder, elm, ash and lime. In the meantime, in the mountainous and subalpine areas of Leventina, pine gave way for silver fir coming from the south in $7600 \mathrm{BC}$. This transformation changed the forest vegetation of Ticino from 7500 until $4000 \mathrm{BC}$ : in the mountainous regions silver fir took the place of pine; in the lower areas the pine was replaced by mixed forest of oak and alder. The aspect of Ticino changed again in $4000 \mathrm{BC}$ with the appearance of the Norway spruce. Coming probably from the north, through the Lucomagno pass, it occupied Riviera and Leventina and soon confined the silver fir to the lower regions. Pliny (Naturalis Historia XVI, 18-9, 76, 82) mentioned the 
Norway spruce from Subalpine Italy for the construction of ships and the production of resin, and the larch as valuable wood.

The next event, changing once more the general aspect of the forest, was the introduction of agriculture. Its direct consequences were the partial destruction of wide areas of forest, the forests' shifting, and the appearance of wild shrubs. Pollen diagrams attested the appearance of cereals and of weeds of cultivation.

Similar analysis north of the Alps gave the same results in relationship to the introduction of agriculture. $\mathrm{A} \mathrm{C}_{14}$ - dating of the corresponding layer at Origlio dated the event to $2750 \mathrm{BC}$ (+- 100 years). This date coincides with those of the oldest traces of agriculture in Denmark and in Central Switzerland: 2740 BC (+- 90 years) by Wauwilermoos in Canton Luzern, and 2620 BC (+- 80 years) on the island of Seeland in Canton Bern.

The composition of the forest vegetation of Ticino did not undergo a considerable change from the Neolithic to the Iron Age, except for the areas close to settlements. Until the diffusion of the chestnut, the spectrum of pollens in plains and hills is dominated by the presence of alder and oak. Nevertheless, some new plants appeared in the Insubric region after the beginning of agriculture. The birch (Betula pendula) seems to grow in larger numbers on areas freed from the forest and is one of the commonest trees in the chestnut wood still today. Other plants also common today, such as heather (Calluna vulgaris) and bracken (Pteridium aquilinum), already existed before the Neolithic. During this period and in the Bronze Age their pollens achieved their maximal expansion. 
Another important pollen, characterized by its massive presence in prehistoric layers, is that of the vine (Vitis). Pollen analysis shows an expansion of the vine in Leventina during the Iron Age wider than that of today. It has still not been possible to define whether to begin with the vine was the wild one (Vitis silvestris) or the domestic one (Vitis vinifera). However, the viticulture in Ticino was important already before the appearance of the chestnut. Pliny (Naturalis Historia XIV $, 3-4,25,27$ ) mentioned the viticulture in the areas to the north of Po and in the alpine regions. Deposits of pollens deriving from agriculture and viticulture are associated with elements indicating sheep farming and wild fruits gathering.

Typical for the Insubric region is chestnut woodland. The chestnut (Castanea sativa) grows mainly on soils poor in carbonates, with acid reaction, that constitute the main group of soils in Ticino. Thanks to its particular adaptability, the chestnut also spread on alluvial deposits and soils rich in carbonates, if they are rich in humus. Growing between 200 and 900-1'100 m asl, it provided fruits, wood and fodder and replaced forests of oak, alder and ash (Aguardi et al. 1985, 29ff.).

The origin of the chestnut is still not completely clear. Probably coming from Sardi, in Asia Minor (Pliny, Naturalis Historia XV, 25), its general diffusion in southern Europe seems to be due to cultural influences during antiquity. Since Marcus Porcio Cato (234-149 BC) did not mention the chestnut in his $\mathrm{De} R e$ Rustica and Marcus Terentius Varro (116-27 BC) in his De re Rustica only spoke of it as fodder, its presence in the Roman world was considerable only after the end of the Republic (Zoller 1961, 276-7). Pliny (Naturalis Historia XV, 25) spoke of the chestnuts as a fruit of little value. They might be eaten boiled 
or roast, or ground as dried fruit to obtain chestnut flour. There existed many types of chestnut-trees. The chestnuts of poor quality were used as fodder and grown for their wood. Pliny (Naturalis Historia XVII, 34) mentioned the turnip as the third most important product from the areas north of Po, after wine and crops.

In Ticino, pollen analysis at Dalpe, Origlio, Pian di Stignano $(1540 \mathrm{~m}$ asl, by Grono in Misox) and Losone-Arcegno (350 m asl, north of Ascona) showed the complete absence of chestnut pollen in layers dating from the Neolithic and the Bronze Age. The diagrams of the Bedrina by Dalpe and of Pian di Stignano also prove that agriculture and the establishment of settlements appeared in the upper valleys much later than in southern Ticino, at the beginning of the Iron Age.

Traces of chestnut in pollen diagrams at Origlio are dated c. $810 \mathrm{BC}(+-120$ years). Since this layer was $240-250 \mathrm{~cm}$ below the surface and the corresponding chestnut curve began at $230 \mathrm{~cm}$, it is not clear if this tree had already been grown during the Iron Age or if it had been introduced by the Romans (Zoller 1961, 271-2 ; Castelletti 1985, 591-95; Sena Chiesa \& Lavizzari Pedrazzini 1995, 500-508). Analyses on the wood used for the funerary bed of cremation graves at Angera attest the presence of the chestnut from Augustan-Tiberian times (Castelletti 1985, 592-4). The time of the first chestnut maximum, however, at Losone-Arcegno (AD 530, +- 70 years) and at Origlio ( $A D 470,+-70$ years), was towards the end of the Roman period.

With the chestnut also appeared walnut (Junglans regia), although during Roman and late Roman times walnut never occurred in large numbers, 
chestnut pollen constituting 60 percent of the whole spectrum at Origlio and 50 percent at Losone-Arcegno. Against the chestnut's maximum between $A D$ 450 and $A D 550$, in both sites the values of cereals and vine reached their minimum at the end of the Roman period as consequence of the massive presence of chestnut woods in the surrounding areas.

Suddenly, after the late Roman maximum, the chestnut curve decreased, reaching its minimum (10-20 percent of the whole spectrum). $\mathrm{A} \mathrm{C}_{14^{-}}$- dating of the layers links the event to the Lombard invasion of Ticino (AD 565). The consequences were the increase of cereals and vine pollens at the expense of chestnut, whose forests were partly destroyed to gain wider areas for agriculture and viticulture.

At Origlio and Losone-Arcegno the chestnut values rose again to a second maximum after $A D 1000$, reaching 70 percent and 35 percent respectively of the whole spectrum. In the meantime, cereals and vine pollens became less relevant, showing another change in cultivation. New chestnut trees seems to have been planted in areas previously occupied by agriculture and viticulture.

A sudden decrease of the chestnut, with consequent increase of vine and cereals, occurred at Origlio during the 14th and 15th centuries. The corresponding layer of the marsh attests a deforestated area near the lake. With this exception, however, the massive presence of chestnut woods in the region continued until the 18th century. On the contrary, at Losone-Arcegno the values of cereals and vine increased quickly after the Medieval regression and continued until recent times because of the intense agricultural activity on the terraces. 
The maximal concentrations of chestnut pollen in the marshes seem to correspond roughly to the warmest and dryest periods in Europe: the end of the 4th century $A D$ and the turn of the first millennium $A D$. On the contrary, during the 6th century $A D$ and the 14th and 15th centuries $A D$, vine and cereals pollens increased at the expense of chestnut. These changes in cultivation depend partly on historical-cultural reasons, but also and especially on climatic conditions. Chestnut is a spontaneous and tough species, which expands naturally. Vine and cereals need favourable climatic conditions and particular care. It is therefore possible that during the periods of warmth the climate became to dry for vine and cereals in this region. This had as consequence the natural expansion of the chestnut in the areas once freed for agriculture. As soon as the climate again became wet enough, vine and cereals reappeared.

The last important change in the diagrams of both sites corresponds to the introduction of the maize (Zea mays) and other cereals during the 18th and 19th centuries and the consequent reduction of the chestnut woods.

Today the flora of the Insubric chestnut region belongs to the Atlantic, westEuropean group growing on acid soils. The natural oak forests were reduced by agriculture and viticulture, new species were introduced and the upper tree line was lowered to gain more areas for grazing. Therefore, the middleEuropean features of the original vegetation became less evident than the Atlantic features (Antonietti 1968, 81-226).

In the upper valleys of Ticino the chestnut appeared only during the early Middle Ages. Since both diagrams at Dalpe and Pian di Stignano date the first chestnut maximum to the 11 th century, the tree appeared probably at the 
beginning of the deforestation. Unlike the southern regions, the values of cereals and vine in lower Leventina and Mesolcina increased together with those of the chestnut.

Today Ticino has a tree density of 47.4 percent and is the most densely wooded canton of Switzerland (Bettelini 1993, 7ff.). This density rate, however, corresponds to a high concentration on the slopes of the mountains and a low concentration in valley floors and plains.

Differences in altitude, exposure to the sun and gradient of the slopes, geological substratum and climates ranging from oceanic to subcontinental are reflected in the variety of forest formation typical of the region to the south of the Alps. Moreover, the features of the actual forest areas depend upon human activities, such as diffusion of chestnut-trees, tillage of areas suitable for agriculture or settlement, lowering of the forests upper limit due to the need for grazing land.

In the alpine region (Sopraceneri) the upper limit of the forests reaches 1900$2000 \mathrm{~m}$ asl. This limit reaches $1600 \mathrm{~m}$ asl in the subalpine region (Sottoceneri), characterized by the almost exclusive presence of hardwood forests.

The submontane horizon extends from the lake shores to $700-900 \mathrm{~m}$ asl and is characterized by a clear distinction of the forest, depending on the substratum. Areas with basic soils (calcareous rocks) bear mixed hardwood forests, whereas on sour soils (siliceous rocks) the chestnut forest dominates with associated trees as oak, birch, ash, cherry tree, alder and linden. The robinia appears today especially in southern Ticino in the areas once occupied by the chestnut tree. 
The montane horizon of Sottoceneri extends from $700-900$ to $1600 \mathrm{~m}$ als and is dominated by the beech. In the Sopraceneri, this horizon reaches 1400 $1700 \mathrm{~m}$ asl and shows a variety of species. The oceanic climate in Valle Maggia, Valle Verzasca and the Ticino valley as far as Biasca favours the presence of beech and silver fir. The subcontinental climate of Val di Blenio and Leventina is hostile to these species, with Scotch pine and Norway spruce growing instead.

In the subalpine horizon, that reaches the forest limit, the larch appears everywhere.

The forests in valley floors, with exception of those on the alluvial cones, do usually not show the species typical in the corresponding altitude zones. In the plains there is no trace of chestnut tree. Over $500-600 \mathrm{~m}$ asl, the presence of alder is almost exclusive. On lower altitude the forests consist of hardwood.

\section{Natural resources}

The natural resources of Canton Ticino include building stone, and its granitic gneiss is considered one of the best building materials in Europe. The most important freestone quarries lay in Leventina and Riviera. There are minor quarries also in Val di Blenio, Val Verzasca, Valle Maggia, at the Monte Ceneri and in the Sottoceneri (Schneiderfranken 1943, 55ff.). These granites are used in the building industry, and for paving, fencing and sculpture. Slabs of gneiss are also used as flag stones in rural Leventina, Valle Maggia and Verzasca. During the Iron Age and Roman periods, stone slabs were used in the funerary architecture as walls and covers for graves. Therefore, it seems that granitic gneiss was used as a building material also in ancient times. It 
has not been possible, however, to define which quarries were in use in antiquity. Because of their structure, the gneiss from the region between Bellinzona and Locarno and Val Onsernone is exploited today only as rough building stone and crushed stone. The presence of gneiss in these areas, rich in Iron Age and Roman cemeteries, strengthens the convinction of the exploitation of quarries in ancient times.

In the central area of Ceresio, between Monte Generoso, Monte Arbostora and Brusino-Arsizio, lies an important layer of porphyry (Schneiderfranken $1943,69 \mathrm{ff}$.$) . Black porphyry is used today as crushed stone for roads and$ railways. Red porphyry is used as building material or, cut into cubes, for paving. There is no evidence of the use porphyry during Roman times.

Sandstone occurs in Sottoceneri, at Mendrisio, Stabio and Pazzallo. It was used to produce hones, slabs for ovens and sand for degreasing the clay. Calctufa occurs at Rancate, on the slope of Monte Generoso, between Mendrisio and Meride.

Siliceous rocks of the Lias formation form the group of mountains to the east of Ceresio, between Monte Generoso and Monte Brè. Because of their good structure, they are mainly used as building materials. The quarries, however, are relatively recent and again there is no evidence for use of these stones in antiquity.

The area of San Salvatore, Monte Caslano and San Giorgio is characterized by the massive presence of dolomite and limestone. Because of their irregular structure, making them difficult to cut, they were not exploited as building materials, but as crushed stone for gardens and roads, or as sand. Therefore, they were probably not used in Roman times. 
At Arzo, in Sottoceneri, Castione and Val di Peccia in Sopraceneri, lay the most important marble quarries of Ticino. Petrographically, these rocks are not real marble but conglomerates and breccia with microcrystalline structure (Schneiderfranken 1943, 63ff.). The marbles of Arzo, in three coloured variants, were first exploited during the 16 th century AD. The layers of greywhite marble at Castione continue northwards in two directions: to Gnosca, Ticino, and San Vittore, Mesolcina. The quarries in Val di Peccia were opened after the Second World War and provide six variants of coloured marble. None of these marble quarries was exploited during Roman times.

Canton Ticino is also rich in gravel-pits and sand deposits dating from the glacial period. They lie in the valley floors of Ticino, Brenno, Moesa, Maggia, Melezza, Vedeggio, Cassarate and in the region between Mendrisio and Chiasso, once occupied by the Ceresio. These rivers contain mainly gneiss with a low percentage of amphibolites and eruptive rocks (5-10\%), and sand of quarz, feldspar and mica. No other Swiss region bears the same homogeneity in gravel and sand as the rivers of Ticino. These materials are used today as additives for cement, crushed stone in road building and fill. The use of Roman opus caementicium in Ticino was favoured by the presence of good building materials in both Sopra- and Sottoceneri in areas with many Roman remains. In Sottoceneri, the Mendrisio region bears important Roman sites such as Stabio and Riva San Vitale; the river Vedeggio flows from Monte Ceneri to Agno and the river Cassarate intersects the area of Lugano. In Sopraceneri, the Brenno and the Moesa join the Ticino at Biasca, and at Arbedo-Castione respectively. Along the Brenno is the road to the pass of Lucomagno and at Malvaglia there was a Medieval castle to 
control the passage. Today there is no archaeological evidence of Roman presence except for a Roman coin hoard (Crivelli 1943, 75), but no archaeological investigation has been executed yet. Some Roman coins were also discovered at Biasca, at the foot of the valley (Crivelli 1943, 75). Val di Blenio was strongly occupied by the Lombards. It is seems that the valley was already occupied by romanized people. River Moesa joins the Ticino in the area of maximal concentration of Iron Age cemeteries of the Canton: from Gnosca to Giubiasco cemeteries were discovered at Gorduno, ArbedoCerinasca and Arbedo-Molinazzo, Castione, Daro, Carasso, Sementina, Giubiasco. Some of these cemeteries had Roman grave-goods in their latest graves, as for example Giubiasco, indicating continued occupation of the area. River Melezza flows along Cavigliano and Tegna, and joins the Maggia at Ponte Brolla. The Roman presence in these areas in attested by the presence of cemeteries. The Maggia flows into the Verbano, passing between Losone and Ascona, and Solduno and Locarno.

Ticino, in particular Valle Maggia, Verzasca and Centovalli, is rich in Lavezrocks, which are rich in talc, which appears in lenses. Lavez-rocks occur in two varieties. The first one has a fine structure and is suitable for lathe-turning. It occurs in particular from Valle di Peccia, Valle Lavizzara and Valle di Campo (Valle Maggia). The second variety has a coarser structure and was exploited to produce stone slabs. Because Lavez-rock absorbs heat and cools slowly, these slabs were used in the construction of stoves in Valle Maggia, Verzasca, Leventina and Val di Blenio (Schneiderfranken 1943, 123-32). Lavez-rocks were used in the production of cooking wares because of their fire resistenace, high heat capacity and easy working in rough state (Pliny, 
Naturalis Historia XXXIV, 44). If these rocks are heated at $800^{\circ}-1000^{\circ} \mathrm{C}$, they lose their water content and become hard and difficult to work. Lavez-rock vessels, especially jars, were very common in Roman Ticino. Whereas early Roman vessels were handcut, Lavez-ware was usually lathe turned. The forms were limited to cup, beaker, bowl, jar and bucket. From the 3rd century AD Lavez-ware became common in the areas north of the Alps. In particular between the 4th and the 7th century $A D$ this ware and wooden vessels replaced the more expensive imported pottery (Pauli 1981, 295-6). Some quarries in Ticino were used from Roman times onwards. Only petrological analysis of Lavez-vessels, however, can indicate the origin of the rocks. At Piano di Peccia, in upper Valle Maggia, the industry of Lavez-working is attested since late Medieval times and thrived until 1850, but lost importance at the beginning of the 20th century. Probably these quarries also provided rocks for Roman vessels.

Cretaceous marls ('biancone') exist in Ticino only in the Breggia valley. They are used as cement rock or as dressed stone for altars and chimneys. In Leventina (Airolo, Valle Bedretto) and Valle di Blenio (Olivone) in Sopraceneri, and at Meride and Arogno (Valle Mara) in Sottoceneri, are deposits of gypsum. Rocks rich in pegmatite in the area between Bellinzona, Locarno and Centovalli are today exploited because of their content in feldspar, used in the production of porcelain. There is no evidence of the exploitation of these materials in Roman times.

On Monte Generoso are superficial boulders of flint-stone, but they are of poor-quality. Therefore, flint-stone was probably never exploited and had to be imported from neighbouring areas. 
Many deposits of clay are situated in Sottoceneri. At Caslano there is a deposit of 'argilla smectica' used for degreasing wool and in the production of pottery. This material, however, in the second half of the 19th century was sent to manufacturing centres at Como and Campione d'Italia (Lavizzari 1863, 298). Diluvial clay deposits are in Mendrisiotto (Vacallo, Balerna, Mendrisio) and at Noranco-Figino in Luganese. Morainal deposits are situated at Canobbio, Riva San Vitale and minor sites in Sottoceneri. These deposits were surely exploited during Roman times. In addition to the pottery, in Sottoceneri stone slabs were soon replaced by flat tiles in the funerary architecture, and at Riva San Vitale was found a Roman factory of tiles (Macchi 1987, 8). During the first half of the 19th century, brickworks were also situated in Malcantone and Val Colla, but the kilns were in use only when necessary. In Sopraceneri clay deposits are not as many and important as in Sottoceneri. They are situated at Airolo, Robasacco, Sementina, Palagnedra, Giubiasco, Campo Vallemaggia and the Locarno area (brickworks at Locarno, Muralto and Giubiasco). Some of these deposits were exploited until the end of last century and many kilns were in use (Schneiderfranken 1943, 90-93). It is possible that some of these deposits in Sopraceneri were already exploited in Roman times. Unlike in Sottoceneri, however, flat tiles did not replace stone slabs in the funerary architecture.

Conspicuous veins of pure quartz lay in Leventina, Riviera, Val di Blenio and in the area between Monte Ceneri and Tamaro. Pure silicic acid, contained in the quartz, is today used in electrochemistry, glass making, and the production of fireproof building material and detergents (de Quervain 1965-78, Foglio 58; de Quervain 1969, 1ff.). In Roman Ticino glass factories existed, as 
demonstrated by the remains at Locarno-Muralto in the area called ParkHotel. Silicon comes from quartz veins or from some fluvial deposits, such as those of river Ticino. It was used in Roman times as basis for the production of glass. In more recent times, these deposits were also exploited to produce glass. There was a glass factory at Locarno in 1586, and during the 18th century new factories appeared at Lodrino and Personico which were in use until the second half of the 19th century (Schneiderfranken 1943, 144-47).

The region of San Gottardo is rich in rock crystal, as Pliny mentions (Naturalis Historia XXXVII, 10). The oldest find in Ticino is an arrowhead, found in the Neolithic layers at Castel Grande, Bellinzona (Donati 1986a, 102). Other rock crystals appeared at Tremona associated with prehistoric pottery, in Roman graves at Losone-Arcegno and in the Roman settlement of Muralto. Rock crystals were used in antiquity for weapons, jewellery and as simple goods for exchange. From the Alps also came wood for buildings and resin, used as a combustible for torches or as glue. The scarcity of oil-lamps among the gravegoods of Roman graves results from the absence in Ticino of olive trees and oil. Other means of lighting were therefore necessary, for example torches or candles.

Switzerland has the richest deposit of vein ores ('minerali di fessura') of alpine type in the world. Some of these ores are considered precious stones. An important deposit lies in Ticino, in the region of Campolungo (Leventina). It does not seem, that this deposit was exploited already in the Roman period.

Pliny (Naturalis Historia XXXIV, 41) referred to iron in northern Italy. Important veins of ore lay in Valle Morobbia. Their exploitation is documented from the 15th century (Schneiderfranken 1943, 150ff.), but probably began in the Iron 
Age. In Valle Morobbia, is situated the big cemetery of Pianezzo, dating from the Iron Age. The area between Giubiasco and Gnosca, in the immediate neighbourhood, bore the maximal concentration of Iron Age cemeteries of Ticino. Other veins of iron ore are situated in Val Mesolcina and Val Calanca. The important Iron Age cemeteries of Castaneda and Santa Maria (Canton Grigioni) and along the river Ticino as far as Claro demonstrated the presence of iron in the area. Iron ore veins also exist in Locarnese and in Val Colla at Bogno (Sottoceneri). They were exploited until the end of the Second World War. In Sottoceneri iron ores are known in Val d'Iseo, but their exploitation is modern.

Gold and silver occur in Switzerland only in small deposits. In Ticino these lay in Malcantone (Sottoceneri), in particular at Astano-Costa. Other reefs in Malcantone have been located at Sessa, Fescoggia, Miglieglia, Novaggio and Breno. These reefs were exploited during the second half of the 19th century $A D$, but the quantities of precious metals were very low. The mine at AstanoCosta is interesting because it shows traces of activities in several periods, probably from Roman times onwards (Bazzurri 1990,6). The first report about the discovery of the reefs date to 1795 . They were exploited until the 1940 s and contained about $34 \mathrm{~g}$. gold and $525 \mathrm{~g}$. silver per tonne. Silver reefs were also discovered in the region of Ritom (Leventina) and were exploited from the end of last century until the end of the Second World War. Some rivers of Ticino carried alluvial gold as result of the erosion of the reefs: Magliasina, Vedeggio and Breggia in Sottoceneri, and, in lower quantities, Ticino and Melezza in Sopraceneri. The extraction of alluvial gold was easier than the mining of gold. The high specific weight of gold allowed it to be deposited in 
the slower sections of rivers (Hoffmann 1991, 35-9). Modern alterations of the courses of rivers and the construction of artificial lakes, however, caused a reduction of the supply of gold debris.

A report dating from the beginning of the 17 th century $A D$ mentions wood and charcoal, rock crystal and building stones as products of the exploitation of natural resources from the Verbano area, and fish, cheese, chestnuts and vine as natural products (Morigia 1603). Similar products were probably traded during the Iron Age and in Roman times, if not before.

\section{Communications}

Contacts between people living in Central Europe and the Italian peninsula have always been difficult because of the natural barrier of the Alps. The earliest finds on the mountain passes date to the end of Neolithic and the beginning of the Bronze Age (Pauli 1981, 181ff.). The discovery of copper, associated with favourable climatic conditions, gave the first impulse for more frequent traffic. People started settling in the alpine regions rich in copper. The export of this metal to the neighbouring areas stimulated new commercial and cultural contacts and made evident the necessity of communication routes. There is evidence of the use of all mountain passes during the Bronze Age (Wyss 1971, 130-45; Primas 1970, 109).

The Laugen culture, whose centre is situated in the Etsch valley, occupied Eastern Alps during the late Bronze Age. The distribution of Laugen ware ranges from the Etsch valley to the Eisack to the north, the Inn and the Rhine to the west and, more isolatedly, the Drau to the east. The presence of Laugen ware in this area demonstrates the use of many mountain passes, 
such as Brenner, Julier, Stelvio, Maloja and Splügen (Stauffer 1979, 130-7; Lunz 1974, pl. 90 B). In the same period, Western Alps did not constitute a cultural unity. Imports from Italy, however, reached the Swiss Mittelland and Savoy and attested the importance of transalpine contacts (Pauli 1981, 30-40, fig. 130).

From the Iron Age the trade between north and south of the Alps followed two main lines. Greek colonists founded Massalia/Marseille c. 600 BC, opening the Rhône route. During the 6th century BC the Etruscans reached northern Italy and fixed their capital at Felsina/Bologna. In the 5th century BC they founded the port of Spina for their trade with Greece. The transalpine contacts between Central Europe and the Mediterranean were guaranteed by the Rhône route to the west and the Adriatic route to the east.

Trade was not the only reason pushing people to cross the Alps. In 387 BC Celtic tribes reached and sacked Rome. Livy (Ab Urbe Condita V 33ff.), writing about this event, refers to the pass of Mons Poeninus/Gran San Bernardo. Some modern scholars do not exclude the passage of minor groups on more direct ways through Canton Ticino. Evidence of this passage is the bronze hoard found at Arbedo, interpreted as the attempt to hide precious items during the passage of Celtic tribes (Crivelli 1946a, 59-79; Primas 1972, 7693). The second danger for Rome came also from the north. According to Polybios (Historiai III 47-60) and Livy (Ad Urbe Condita XXI 31-38), Hannibal crossed the Alps on Col du Clapier, a minor pass to the south of Mont-Cénis, or on Mont-Genèvre.

Other peoples from the north crossed the Alps. Cimbres and Teutones reached the Carnic Alps through the Brenner or Pustertal passes and 
defeated the Romans first at Noreia. They crossed the Alps again to move to Gaul but there is no evidence of the route they followed. They were defeated finally at Aquae Sextiae/Aix-en-Provence in 102-101 BC.

The evidence of the passage of people and goods across the Alps already in prehistoric times does not prove the existence of roads. The routes consisted only of paths. Metalled roads across the Alps are to be credited to the Romans and connected with the need to move the army. The history of their construction began with the military expedition of Drusus and Tiberius. After the submission of the alpine tribes in $\mathrm{c} .7 / 6 \mathrm{BC}$ and the conquest of northern Pre-Alps, new roads were necessary to guarantee the passage also in winter.

To the east, already under Augustus the Via Julia Augusta linked Aquileia to the Magdalensberg in Noricum through the Plöckenpass. This road followed part of the prehistoric amber route from the Mediterranean to the Baltic sea. The Via Claudia Augusta is dated to AD $46-47$ (CIL V 8002, 8003). It originally consisted of two roads, because the passage of the Kuntersschlucht near Bolzano was impossible. The main road from Verona led to the Reschen and to Augusta Vindelicum/Augsburg, reaching the Danube. The other road from the Piave valley led to the Pustertal and, through the Brenner, to the Inn valley. Only during the 2 nd century $A D$ the Kuntersschlucht was surmounted and the Brenner became the main route (de Bon 1938; Nierhaus 1950, 17788).

To the west, after the defeat of the Salassi (25 BC) and the foundation of Augusta Preatoria/Aosta, the passes over Mons Poeninus/Gran San Bernardo and Piccolo San Bernardo were free for the Romans. The first led from Aosta to Octodurus/Martigny and from there to Augusta Raurica/Augst near Basel, 
through the Swiss Plateau. The second led to the territory of the Ceutrones and to Lugdunum/Lyon. Archaeological and historical evidence prove the use of both passes. Remains of a temple, a hospice and a sentry post appeared on both Summus Poeninus/Gran San Bernardo and In Alpe Graia/Piccolo San Bernardo. Fifty-three bronze plaques with votive inscriptions for Jupiter Poeninus were found in the temple area on Gran San Bernardo. An inscription mentioning repairs to the route of Piccolo San Bernardo is dated to AD 163 (CIL XII 107). Another inscription attests the same for Gran San Bernardo and is dated to AD $308-312$ (Bender $1979,2 \mathrm{ff}$. ). Good evidence is also given on the Tabula Peutingeriana and the Antonini Augusti itineraria provinciarum et maritimum. The Tabula Peutingeriana is the 13th century copy of a Roman road map dated between the 3rd and the 5th century AD. The Antonini Augusti itineraria is also a road map, dated to Caracalla's times (AD 280). Both maps contain names of sites and the relative distances. Form Aosta a road passed in summo poenino and reached Martigny, another went to the west towards the Cottius region. Ancient authors such as Caesar, Strabo and Tacitus also mention the passes. Another passage to the west is over MontGenèvre. Evidence of the use of this pass in Roman times is given by the triumphal arch, erected by Cottius for Augustus and dated to $8 \mathrm{BC}$.

Some of the passes used today as main links between the north and the south were not in use in Roman times as carrage roads. Epigraphical and archaeological evidence is given for Plöcken, Reschen and Brenner, Radstädter Tauern, Septimer and Julier with Maloja to the east, and MontGenèvre, Piccolo and Gran San Bernardo to the west. 
Direct links to central Switzerland are today possible over Simplon, San Gottardo, Lucomagno, San Bernardino and Splügen. The access from the south to all these passes is through Canton Ticino or Misox. Imports and finds along these roads attest their use already in pre-Roman times (Donati 1979, 131-42). The lack of buildings or dedicatory hoards on the passes, as well as the absence of traces of wheels in the rocks, make it difficult to consider these roads as Roman (Wielich 1970, 67ff.; Planta 1979, 15ff.). Excavations in Misox have brought to light parts of a steep and narrow road built with Roman techniques and possibly leading to San Bernardino (Erb \& Schwarz 1969; Planta 1975, 32-44). The absence of this road on the Tabula Peutingeriana and the Antonini Augusti itineraria dates the road after AD 280 or indicates a secondary route, which did not appear among the imperial roads. Therefore, the road on the maps from Como to Chiavenna and to Chur passed over the Splügen or, according to other scholars, over the Julier (Wielich 1970, 67ff. ).

Another passage across the Alps from Canton Ticino is Lucomagno, leading from Olivone to Disentis and from there to the Vorderrheintal. Latin toponyms and Roman coins dating from the 1 st to 3 rd centuries $A D$ and found at Malvaglia do not prove the existence of a main route. Roman structures and other finds are lacking on the pass and the road over Lucomagno does not appear on the ancient maps. As for other alpine passes, the absence of a carriage road does not exclude the use of the pass. The first evidence for the Rhône route over the Simplon, linking Verbano to Brig, is an inscription dated to AD 196 (Crivelli 1964, 189). Also this road is not mentioned in the ancient road maps. 
The road over the San Gottardo constitutes the quickest passage from Ticino to the regions north of the Alps. The first road dates to the end of the 12th century $A D$, when the Schollenschlucht was crossed.

In Ticino the existence of Roman roads is attested by the presence of Medieval roads and settlements along the road. Communication routes usually followed natural routes. In particular in a region such as Ticino, the easiest routes were courses of rivers and basins of lakes. Travellers coming to Bellinzona from the north had two possibilities to continue southwards (Schäfer 1954, 159ff.; Wielich 1970, 72-74). The lacustrine route of Verbano led from the ports of Magadino and Gordola to Sesto Calende and from there to Varese, Milan and Pavia. Important Roman finds along the shores of Verbano attest its occupation in Roman times. The other main route ascended Monte Ceneri and reached Sottoceneri. From Monte Ceneri the road went southwards along the Vedeggio valley. About two kilometres south of Tabernae/Taverne, at the bridge of Grumo, the road split in two arms. The first descended to Agno and crossed the river Tresa. The other continued to Lugano, became a lacustrine one as far as Capolago and Riva San Vitale, and reached Como. The road from Taverne to Blitio/Bellinzona was called in Medieval times Strata Francisca and followed the modern road along the valley floor (Chiesi \& Zappa 1991, 3-35). Archaeological evidence of Roman presence is spread all along the Vedeggio valley. Two Roman inscriptions were found at Mezzovico and Gravesano and finds dating from the Iron Age and the Roman period come from Monte Ceneri, Rivera, Torricella and Taverne. Besides these main roads, there existed minor routes linking the settlements, whose traces are today almost disappeared. 


\subsection{ARchaEology of Canton ticino}

\section{History of research}

The first attempt made in Ticino to regulate the protection of historical monuments dates to 1905 . This date, however, does not coincide with the begin of systematic archaeological research. Before 1905 there were no laws concerning the protection and conservation of historical or archaeological monuments. Therefore, written reports or documents about excavations or discoveries were due exclusively to the interest of private people.

The first news about archaeological finds in Ticino appeared in a chronicle of 1609 and are written by $\mathrm{G}$. Borsieri. He reported the discovery of a hoard of bronze tools, made by a farmer working in a field at Sagno.

The next written record about archaeological remains is due to the shoemaker Giovanni Bagutti from Rovio. During tillage works in his meadow in 1805, the workers discovered some graves containing jars with bones inside and bronze items. This report is full of grammar and interpretation mistakes, but is the first document about the discovery of the Bronze Age cemetery at Rovio. Dr. L. Lavizzari from Mendrisio wrote in 1846 in his memories 'Rovio and its mineral water' and 'Excursions' about the discovery of several graves during deforestation works and described their content. He also reported that near the village, in 1846, was found a bronze 'jar'. In 1873 Dr. Lavizzari reported about several other graves found at Rovio (Lavizzari 1873, 428). The first scientific report about the graves from Rovio was published in 1876 by $P$. Castelfranco. This report is also the first scientific one written in Canton Ticino. 
In 1896-7 a carpenter from Arbedo, D. Pini, excavated the cemetery of Cerinasca d'Arbedo together with I. Migliorati from Arbedo-Castione. Before 1905, Migliorati also investigated Iron Age cemeteries at Arbedo-Molinazzo, Castione-Bergàmo, Claro alla Monda, Giubiasco and Stabio. Both Pini and Migliorati were, in effect, tombs-robbers and excavated without any archaeological knowledge. The grave goods were regularly sold to museums all over Europe and frequently, to make grave contents more attactive, items from different graves were mixed. Material from these sites has been identified at Bern, Solothurn, Basel, Chur, Zürich and the British Museum in London. There also exist records for sales to museums in Berlin and Washington D.C. The excavation of part of the cemetery of Giubiasco before 1905 caused a huge loss of information about the European chronology. The six-hundred or more graves ranged from the late Bronze Age to the 2 nd century AD. The first graves were found in 1900. Immediately D. Pini rented the ground and started the excavation, discovering graves 1 to 105 . The items were sold to the Landesmuseum in Zürich. In 1901 the directors of the Landesmuseum decided to send to Giubiasco Dr. Zeller to check the objects purchased by the Landesmuseum, and the draughtsman F. Corradi to draw the plan of the cemetery and to carry on the excavation of graves 106 to 233. In November 1901 Corradi went back to Zürich and Pini continued the excavation. He dug graves $234-298$, telling to Corradi that they lay on the north side of the cemetery. Corradi checked the statement, discovering that the northern part of the cemetery had not been excavated. It is still unknown where these graves were located. 
Dr. D. Viollier, who later excavated the cemetery, suggested that they were from Pianezzo. Pini had an agreement with the Landesmuseum to sell items from Giubiasco, but not from Pianezzo. Pini finally sold these graves for 6'500.- Swiss francs.

Graves 299-472 were also excavated by Pini, but under supervision of Corradi. He tried to document the excavation as well as he could and gave the items grave numbers. It appears clear from the plans, however, that although the excavation must have been carried on by trenches, they did not concentrate on an area in order to recover all graves.

In 1905 appeared the first laws to control excavations in Ticino. The Landesmuseum decided to carry on the investigation with a further campaign under the direction of Prof. Dr. Viollier. He published in 1905-1906 the results of the investigation of graves $473-540$. Unfortunately, he did not draw a plan and the drawings published of the graves were made from excavation photographs. Only in 1927 did Viollier publish the first chronological subdivision of the items from Giubiasco.

In the same years, Migliorati excavated hundred and sixty-seven graves at Cerinasca d'Arbedo under supervision of the Landesmuseum that purchased the items.

In 1899 Pini started the excavation of the cemetery of Pianezzo at the localities 'Alle Piazze', 'Carabella' and 'Motta'. Migliorati carried on the excavation in 1903, selling the grave contents to the Landesmuseum. The cemetery 'Alle Piazze' was later excavated by a labourer paid by a Mr. Jorio. The same Jorio discovered some graves in 1904. The rest of the Pianezzo cemetery was excavated in 1905 by Dr. A. Magni, of the Società Archeologica 
per l'Antica Diocesi Comense, and the painter E. Berta, member of the Museo of Lugano. This excavation was published in 1907 by Dr. A. Magni in the Rivista Archeologica Comense (RAC).

The Gran Consiglio of Ticino approved on 14th February 1909 the law about protection and conservation of historical monuments. The first Commissione Cantonale dei Monumenti Storici ed Artistici was appointed the 6th March 1909 by the Department of Education. The members were Emilio Motta, the poet and curator of the Museo of Lugano Dr. Francesco Chiesa and Edoardo Berta.

In spring 1909 some graves were discovered during works for the canalization of river Ticino at Gudo, in the plain of Magadino. The Department of Education was alerted and a priest, Don S. Bottani, was appointed to check for other graves. The Commission later appointed a drawing teacher from Bellinzona, A. Ortelli, to excavate the cemetery. He was first helped by Dr. Viollier of the Landesmuseum and later by monsignor G. Baserga of the Società Archeologica Comense, recovering over three-hundred graves. In 1911 Monsignor G. Baserga (1873-1924) was charged with publishing the cemetery in the Rivista Archeologica Comense. This publication is today largely outdated and lacks drawings or photographs of complete grave contents. The Gudo and the Pianezzo excavations, however, were the first to be carried out scientifically.

In 1914 R. Ulrich (1837-1924) published 'Die Gräberfelder in der Umgebung von Bellinzona-Kt. Tessin' (Ulrich 1914), containing details about the cemeteries of Claro, Castione, Castione-Bergàmo, Molinazzo, Cerinasca d'Arbedo and Giubiasco. In the case of Giubiasco, Ulrich described the graves 
from 1 to 540 , indicating those excavated by Corradi as scientifically reliable and those excavated without any supervision by Pini. He did not warn about methods of excavation or the possibility that graves $234-298$ might have come from Pianezzo. He also classified the cemetery following the chronology of the brooches only, even in association with much later material such as Roman pottery, without considering that the grave goods might have been mixed by Pini. His work remained one of the leading texts until 1971, when A. Crivelli published the revision of the Giubiasco cemetery (Crivelli 1971, 287ff.) showing that the grave groups excavated by Pini were totally unreliable.

The law of 1909 was revised in 1919 and introduced a new article about the appointment of an inspector of monuments. In 1936-1937 Dr. Christoph Simonett excavated on behalf of the Commission the Roman cemeteries of Solduno, Locarno-Muralto, Minusio and Stabio. He published the results of these excavations in 1941 (Simonett 1941). This book represents the first successful attempt to publish an excavation scientifically, with drawings, a detailed description of the items and considerations about the grave contents. In 1938 Aldo Crivelli (1907-1981) excavated and published the La Tène cemetery of Solduno (Crivelli 1938c, 49ff.) and founded the Rivista Storica Ticinese (RST). He was a secondary school teacher, who took up archaeology in the thirties working with Dr. E. Balli from Locarno.

Crivelli excavated and published many cemeteries, such as Cademario (Crivelli 1939/9, 212), Ceresol di Minusio (Crivelli 1942a, 608ff.) and Sementina (Crivelli 1942b, 640ff.). In 1943 he published the Atlante Preistorico e Storico della Svizzera Italiana, where he synthesized all existing archaeological data in a modern and scientific way. In 1944 the Canton 
founded the Ufficio dei Musei e degli Scavi. Crivelli was the first inspector, until 1959. Along with Crivelli worked Decio Silvestrini, appointed part time inspector and in charge of coin collections and Roman glass. One year after his death, in 1982, his 'Cronologia protostorica commerciale ticinese' was published in Studi in Onore di Ferrante Rittatore Vonwiller, part I. The second inspector of the Ufficio was Taddeo Carloni, in charge until 1967.

Prof. Dr. M. Primas published in 1970 her dissertation 'Die südschweizerischen Grabfunde der älteren Eisenzeit und ihre Chronologie'. She analysed finds from the Protovillanovian horizon to the introduction of the first La Tène brooches in Ticino and in the Mesocco valley (Canton Grigioni) and worked out the chronology of the first Iron Age. She proposed an evolution in four facies, Tessin A, B, C, D, according to the prevailing brooch types.

Dr. W. Stöckli published in 1975 his dissertation 'Chronologie der jüngeren Eisenzeit im Tessin', where he continued building the chronology of the second Iron Age (from Tessin D to La Tène D) working on the cemeteries of Giubiasco (excavated by Viollier in 1905), Pianezzo (excavated by Crivelli in 1948), Santa Maria (excavated by Schwarz in 1971), Sementina (excavated by Crivelli in 1941-53 and by Silvestrini in 1942).

An important contribution to the transition from the Iron Age to the Roman period in Ticino has been made by J. Graue with the publication 'Die Gräberfelder von Ornavasso' (1974).

In 1968 Pierangelo Donati (1937-1994) became head of the Ufficio Cantonale dei Monumenti Storici (UCMS), now the Ufficio dei Beni Culturali (UBC). In the last twenty years the Ufficio has recovered a large number of grave and 
settlement goods, especially dating from the Roman period. Except for the Roman cemeteries of Ascona (Donati 1987) and Locarno-Solduno (Donati 1988), and short notes about the excavations, however, nothing has yet been published. In particular, in 1983-4 the Ufficio dei Beni Culturali carried out an emergency excavation in the area of the Castel Grande at Bellinzona in order to recover important data concerning the Neolithic occupation of the hill. In the years 1982-92 the Ufficio also excavated a large area of the Roman settlement of Locarno-Muralto (Park Hotel). Unfortunately both excavations still await publication.

\section{Native background of Canton Ticino: Golasecca and La Tène}

In Ticino, as in Lombardy, the late Bronze Age can be divided into three phases according to the grave-goods. The earliest phase is attested in the cemetery of Locarno, whose grave-goods find their closest parallels in the Urnfield Culture north of the Alps. The two other phases are represented in the cemetery of Ascona and correspond to the Protovillanovan facies in central and northern Italy. The graves with brooches with lowered bow ('ad arco di violino') characterize the middle phase, whereas those with brooches with normal bow ('ad arco semplice') indicate the latest phase. In Sottoceneri the late Bronze Age is represented by the cemetery of Rovio, whose pottery finds its closest parallels at Canegrate (Milan).

Although there existed cultural links between northern and central Italy during the late Bronze Age, each area showed regional peculiarities. The area ranging from south of the Po to Mesolcina was characterized by another facies, called Protogolasecca (12th-10th centuries BC). During this facies 
different cultures appeared north of the Alps and were linked to central Europe rather than to Italy. In the meantime, however, bronze objects of southern manufacture found north of the Alps attest contacts between Lombardy and central Switzerland and the use of alpine passes across the central Alps.

With the facies Golasecca I (9th-7th centuries BC) appeared a first cultural diversification in northern Lombardy. The Golasecca Culture defines the cultural development of the areas around Verbano (Golasecca), Lago di Como (Ca' Morta) and Canton Ticino from the beginning of the Iron Age to the appearance of La Tène brooches in the graves (Peroni 1975, 193ff.).

No elements indicating the passage from the late Bronze Age to the Iron Age and the beginning of the Iron Age have been found in Ticino yet. These periods are represented in the Italian cemeteries of Ca' Morta (Lago di Como) and Ameno (Lago d'Orta), where the contacts with further regions were still evident in the use of brooches with large ribs ('a grandi coste').

The Golasecca Culture reached its apex in the facies Golasecca II-III (6th-5th centuries $\mathrm{BC}$ ). These facies are characterized by the large number of gravegoods, in particular metal ones such as brooches, needles, buckles, rings and blades. The regional diversification of the culture became more evident and constituted three groups: southern end of Verbano, southern end of Lago di Como, and Canton Ticino.

The earliest Iron Age graves found in Ticino date to Golasecca II and their grave-goods correspond to those from the latest graves of Ameno and Valtravaglia (Varese). Most of the graves found in Ticino, however, belonged to the end of Golasecca II. The contents of the earliest graves allow one to define two groups. In the first one, bronze and iron serpentine brooches are 
associated with iron knives and toilet objects. In the second group, bronze navicella- and leech-brooches are associated with bronze earrings, rings, oval and rectangular buckles and embossed disks. The two groups seem to represent male and female graves respectively, as analysis of bones in the graves from Dalpe, Ticino, has shown (Primas 1970, 128). Primas (1970, 47ff. ; 77) divided the facies Golasecca II and Golasecca III in Ticino into four groups : Tessin A (corresponding to Golasecca IIA), Tessin B (corresponding to Golasecca IIB), Tessin C (corresponding to Golasecca IIIA1), and Tessin D (corresponding to Golasecca IIIA2-3).

Tessin A is characterized by navicella- and serpentine brooches (with the bow circular in cross-section). The pottery is incised, decorated 'a stralucido' through burnishing, or is horizontally ribbed. Typical is the short, sharply carinated beaker with omphalos, short neck and wide everted rim. Graves belonging to this phase have been found in Sopraceneri at Arbedo-Cerinasca, Dalpe, Dalpe-Vidresco, Giubiasco, Minusio, Osco and Sant'Antonio.

Tessin B shows leech-brooches with long catch, serpentine brooches (with the bow rectangular in cross-section), bucket-shaped hangings and leaf-shaped buckles with middle rib. The incised decoration for pottery disappears. Graves have been found in Sopraceneri at Arbedo-Cerinasca, Castione, Giubiasco, Gorduno, Minusio and Sant'Antonio.

Tessin C is characterized by the presence of Certosa and dragon brooches. The pottery is often without decoration. Pottery decorated 'a stralucido' or ribbing, however, is still frequent. Bronze situlae appeared already in Tessin B, but occur now in larger number. This phase is represented in Sopraceneri at Arbedo (hoard), Arbedo-Cerinasca, Claro, Dalpe, Dalpe-Vidresco, Gudo, 
Minusio and Pianezzo, and appeared also in Sottoceneri at Cademario, Pazzallo, Porza and Pregassona.

Tessin D represents the transition from the Golasecca to the La Tène facies. In Ticino it appeared in graves from Sopraceneri at Arbedo-Carinasca, Arbedo-Molinazzo, Castione, Castione-Bergàmo, Dalpe, Giubiasco, Gudo and Solduno, and from Sottoceneri at Cademario, Novaggio and Pazzallo.

During the Golasecca facies cremation is the only rite in the regions to the north of Ticino, except for San Bernardino di Briona (Novara, Piemonte). In Sopraceneri cremation is attested especially for Tessin A and B. Inhumations, however, appeared in the same cemeteries and during the same periods and later outnumbered cremations. In Sottoceneri, on the contrary, the only rite was cremation, as occurred in the Como region.

Although the development of the Golasecca Culture in Ticino seems to have occurred later, the importance of the foreign elements appeared in the gravegoods. In Ticino imports were usually present as local imitations, whose prototypes moved across the Alps through the alpine passes. The graves of Ticino did not contain datable items such as Greeks imports. Therefore, the only datable items are metal objects which may be compared with those from dated complexes. Tessin A and B developed under eastern influence. The closest parallels for the metal items belonging to these phases are in the cemeteries of Este, Hallstatt and Slovenia. Tessin C and D, on the contrary, are strongly influenced by Etruscan metal forms. Grave-goods from Castaneda and Arbedo-Cerinasca made especially evident the presence of 'Schnabelkannen' of Etruscan manufacture. 
Primas' Tessin D corresponds roughly to La Tène $A$ to the north of the Alps (Stöckli 1975, 11). Between the graves containing La Tène brooches and those with dragon brooches of Tessin C there appeared south of the Alps some graves without La Tène brooches. The beginning of Tessin $D$ is characterized by the appearance of the biconical beaker. This form represents a short phase between the Tessin C beaker with low and rounded body and elongated neck and the Tessin $D$ beaker with high and rounded body and wall flaring towards the foot.

In Ticino, the first La Tène brooches belong to the phase La Tène B2 and were found in the cemetery of Solduno. The development from La Tène B2 to La Tène $D$ has been studied by Stöckli, who investigated the cemetery of Solduno analysing its horizontal stratigraphy.

The passage from Tessin D to La Tène B2 is not clearly identifiable in the cemeteries, because it appeared in some graves from Castaneda, Giubiasco, Minusio, Pazzallo and Pianezzo only (Stöckli 1975, 18ff.). At Münsingen-Rain (Hodson 1968), north of the Alps, phases La Tène B1 and B2 are recognizable by the brooches. For La Tène B1 were typical brooches with long bow and short, triangular catch, whereas for La Tène B2 were typical brooches with catch and decorated foot. The foot ended usually in a bulb or in a globe.

In Ticino the passage from La Tène B1 to B2 is difficult to identify because of the insufficient number of finds and the lack of complete horizontal stratigraphies. Leech-brooches with trumpet foot appeared for the first time in Tessin D. Their presence, however, continued until the end of La Tène B. It is therefore difficult to date a grave by presence or absence of these brooches. 
In the form of the foot, on the other hand, it is possible to recognize a particular feature of Ticino. Leech-brooches with trumpet foot are rare in the area of Como and did not occur at Ca' Morta. It is therefore noticeable, that whereas Tessin C brooches occurred often in northern Italy, Tessin D forms were very rare or did not occur at all (Stöckli 1975,103 ).

Large one-handled beakers (Stöckli's 'Ringhenkeltöpfe') appeared clearly in La Tène B1 graves from Giubiasco. This cemetery showed only one example dating from La Tène B2. The complete absence of these objects in the La Tène B2 graves of Solduno allows one to suppose that one-handled beakers, originating in Tessin D, probably just reached the beginning of La Tène B2.

The main feature of La Tène B2 are brooches characterized by a decorated foot, which is folded towards and joined to the bow. In the pottery a new form appeared in La Tène B2 and which also characterized La Tène C1: the jar with narrow bead rim, wide and high shoulder and conical body with flared wall (Stöckli's 'Topf mit geschweifter Wand').

The cemetery of Solduno showed the development from La Tène B 2 to La Tène $D$ and extended roughly on the axis north-west/south-east (Stöckli 1975, 24-5). La Tène B2 graves were situated in the north-western corner and contained early La Tène, leech-, scorpion- and Certosa brooches. In the pottery typical forms were the beaker with high and rounded body and flared foot, and the jar with flared wall. Both forms also characterized phase La Tène C1. Immediately to the south-east were La Tène $\mathrm{C} 1$ graves with early and middle La Tène brooches with elongated catch, scorpion-brooches and jars with conical body. Around this group were La Tène C1-C2 graves, usually with middle La Tène brooches with quadrangular bow. To the east lay La Tène C2 
graves with middle La Tène brooches with short catch. In this phase there appeared two new forms: the jar with everted rim, short vertical neck and thick body, and the 'vaso a trottola' without painted decoration. Directly to the east again followed La Tène C2-D graves with middle La Tène brooches with high bow. Finally, La Tène $D$ graves with late La Tène brooches, middle La Tène brooches with high bow, and long-spring brooches were situated around the earlier graves from the west to the south-east. In the pottery, the forms that appeared in La Tène C2 continued. The jar with thick body became lower and wider. The 'vaso a trottola' without painted decoration was substituted by the one with painted decoration, that originated during the previous phase. Except for this form, painted decoration did not occur during La Tène D, and also during La Tène $\mathrm{C}$ other forms with painted decoration were rare (Tizzoni 1981, 30). By the end of La Tène D appeared a new form: the jar with rim and foot of the same width and the body decorated by combing (Stöckli's 'Wellentonne').

The passage from La Tène B2 to $\mathrm{C} 1$ is well defined in Solduno because of the sudden appearance of middle La Tène brooches in large number. The passage from La Tène $C 2$ to $D$, however, is unclear because late La Tène brooches were in Solduno relatively rare.

To the west of the Iron Age cemetery of Solduno appeared some Roman graves dating from the second half of the 1st century AD. According to the position of the late La Tène graves, the cemetery should continue to the east. Therefore the horizontal stratigraphy of both, Iron Age and Roman cemetery, is interrupted. The end of La Tène D in Ticino corresponds to the end of La Tène D1 north of the Alps. Phase La Tène D2 did not occurr in Ticino. La Tène graves in Ticino were found in Sopraceneri at Arbedo-Cerinasca (LT 
B1), Arbedo-Molinazzo (LT B1 to LT C1), Castione (LT B1 to LT C1), Castione-Bergàmo (LT B1), Giubiasco (LT B1 to Roman times), Minusio (LT B1 and LT D), Pianezzo (LT B1 to LT B2), Solduno and Sementina (LT D). The cemetery of Giubiasco, in particular, was in use from Tessin A to Roman times. Unfortunately the cemetery was badly excavated at the beginning of this century and the grave-goods of different graves were mixed. Therefore, their associations cannot be considered. In Sottoceneri only two cemeteries contained La Tène graves: Pazzallo (two graves dating from LT B1) and Stabio (LT D).

The funerary rite in Sopraceneri from Tessin C to La Tène $D$ is inhumation. The graves consisted of stone-lined enclosures as occurred in the Roman period. In Sottoceneri, on the contrary, the use of cremations continued until and during the Roman period. The graves consisted of a box with stone slabs wall and cover. In Roman times flat tiles were often used instead of stone slabs. In both Sopra- and Sottoceneri the graves' position was sometimes marked by the presence of heaps of stones or stelae.

The absolute chronology of the different La Tène phases may be obtained through comparison with graves containing datable items (such as Greek imports) north of the Alps or in Italy (Stöckli 1975, 68-83). According to the grave-goods of Grave Este-Benvenuti 111, the graves at Rebbio and 'Tomba grande' at Bologna, Giardini-Margherita, the transition from Tessin C to Tessin D may be dated to the third quarter of the 5th century BC. In Ticino, most of the items from the bronze hoard at Arbedo date to Tessin C and no Tessin D objects were found. Among its latest items there were the handles of a stamnos and a stamnos-situla of Etruscan manufacture, dating from the first 
half to mid-5th century BC. Two serpentine brooches found in Grave 136 at Spina-Valle Pega bore some features, that occurred in the latest leechbrooches of Ticino dating from Tessin D. The grave from Spina may be dated to the beginning of the 4th century $\mathrm{BC}$ according to the associated Greek pottery.

The La Tène B1 period is characterized in art by the Waldalgesheim Style, which originated during the second half of the 4th century BC. In 283-2 BC, the Romans defeated the Celtic tribe of Sennones settled near Ancona. The latest graves of the Celtic cemeteries near Ancona dated to La Tène B1. Therefore, the end of La Tène B1 may correspond to the defeat of the Celts and the foundation of the colony Sena Gallica. There is less evidence for the absolute dating of the other periods. The grave found at Ceretolo (Casalecchio) contained very early La Tène $\mathrm{C}$ items and may be dated to the end of the 3rd century AD. Therefore, La Tène B2 may be dated to the 3rd century $A D$, between the end of La Tène $B 1$ and the beginning of La Tène $C$. For the next periods elements for an absolute chronology do not exist. It is possible, however, to trace the end of La Tène $D$ at Solduno by comparison with the two cemeteries from Ornavasso, San Bernardo and Persona. The presence in Ornavasso of a large number of coins among the grave-goods allowed Graue (1974) to trace an absolute chronology. The two cemeteries, however, were separate and the horizontal stratigraphy of San Bernardo does not continue in Persona. The latest coin of San Bernardo is a denarius dated to $76 \mathrm{BC}$. Most of the coins found in this cemetery date to Republican times (2nd and 1st centuries $\mathrm{BC}$ ), and no Imperial coins are known. The earliest coins of Persona are two denarii and a quinarius dating from 90 to $81 \mathrm{BC}$. 
Most of the coins from Persona date between $27 \mathrm{BC}$ and the time of Domitian. According to the coins, it seem that Persona was in use before the end of San Bernardo. Republican silver coins, however, were present in large numbers during the early Empire. The date of the graves seems therefore to depend more on the presence of other datable grave-goods than of the coins. In San Bernardo were found 95 'vasi a trottola'. In Solduno they appeared in La Tène $C 2$, reached their apex during La Tène $D$, but did not occur at the very end of the phase. Also La Tène swords, jars with conical neck and late La Tène brooches may be dated to La Tène D. To the latest graves of San Bernardo belonged three 'Wellentonnen', as occurred at Solduno. It is therefore possible to assume that the end of Solduno and San Bernardo occurred in the same years. No 'vasi a trottola' were found in Persona. On the contrary, among the grave-goods appeared Aco-beakers, Sarius Surus cups, Italian sigillata ware, glass vessels. Long-spiral brooches appeared in both San Bernardo and Persona. Whereas the former bore the hemispherical bow typical for La Tène, the bow of the brooches from Persona was rather ellipsoidal and corresponded to the examples from Minusio and Muralto. Late La Tène brooches did not occur in Persona, where 25 brooches similar to the Aucissa type were found. San Bernardo yielded 26 La Tène sword and one Roman gladius, Persona four gladii and no swords. In both cemeteries were found flagons: 11 in San Bernardo (earlier forms) and 61 in Persona (later forms). 'Wellentonnen' occurred in Solduno and San Bernardo as the latest form. In Persona, the two examples belonged to the earliest graves, situated in centre of the cemetery. Therefore, the cemetery of San Bernardo ran from La Tène $\mathrm{C} 2$ to the end of La Tène $\mathrm{D}$. Soon after its end began the cemetery 
of Persona, which continued to the end of the 1st century AD. The analysis of the coins in the cemeteries allowed Stöckli $(1975,89)$ to fix the end of San Bernardo and Solduno and, respectively, the beginning of Persona around 20 BC.

The absolute chronology from the late Bronze Age is summarized in the following figure (from Kossack 1997, 153, modified by the author) :

\begin{tabular}{|c|c|c|c|}
\hline Years BC & $\begin{array}{c}\text { Northern } \\
\text { Switzerland }\end{array}$ & Canton Ticino & Golasecca \\
\hline $1290-1220$ & Bronze Age D & Canegrate & Canegrate \\
\hline $1220-1150$ & $\mathrm{Ha} \mathrm{A1}$ & Asconal & \multirow{3}{*}{$\begin{array}{c}\text { Proto- } \\
\text { Golasecca I }\end{array}$} \\
\hline $1150-1080$ & $\mathrm{HaA2}$ & \multirow[b]{2}{*}{ Ascona II } & \\
\hline $1080-1020$ & $\mathrm{Ha} \mathrm{B1}$ & & \\
\hline $1020-950$ & \multirow[b]{2}{*}{$\mathrm{Ha} \mathrm{B2}$} & \multirow{4}{*}{ Ameno I } & Proto- \\
\hline $950-880$ & & & Golasecca II \\
\hline $880-810$ & \multirow[b]{2}{*}{$\mathrm{Ha} \mathrm{B3}$} & & \\
\hline $810-740$ & & & Golasecca IA \\
\hline $740-650$ & $\mathrm{HaC1}$ & \multirow[b]{2}{*}{ Ameno II } & Golasecca IB \\
\hline $650-600$ & $\mathrm{HaC2}$ & & Golasecca IC \\
\hline $600-580$ & Ha D1 & Tessin A & Golasecca IIA \\
\hline $580-520$ & $\mathrm{Ha} \mathrm{D2}$ & Tessin B & Golasecca IIB \\
\hline $520-480$ & $\mathrm{Ha} \mathrm{D3}$ & Tessin C & Golasecca IIIA1 \\
\hline $480-390$ & LTA & Tessin D & Golasecca IIIA2-3 \\
\hline
\end{tabular}




\begin{tabular}{|c|c|c|c|}
\hline $390-300$ & LT B1 & LT B1 & \multirow{2}{*}{ LT B } \\
\hline $300-250$ & LT B2 & LT B2 & \multirow{2}{*}{ LT C } \\
\hline $250-180$ & LT C1 & LT C1 & \multirow{2}{*}{ LT D } \\
\hline $180-110$ & LT C2 & LT C2 & LT D1 \\
\hline $110-50$ & LT D1 & LT D2 & \\
\hline $50-15$ & LT D2 & &
\end{tabular}

\section{Outline of later prehistory}

The 2 nd and 1st centuries BC correspond roughly to the second half of La Tène C1, La Tène C2 and La Tène D in Ticino (Stöckli 1975, 94).

The development of La Tène brooches occurred in the same way to the north and the south of the Alps from La Tène B1 onwards. Ticino, however, did not show all secondary forms as did the northern regions. Middle La Tène brooches appeared in Ticino suddenly and in large number at the beginning of La Tène $C$ and continued their evolution through La Tène $D$. Late La Tène brooches, on the contrary, seem to have occurred in Ticino later than north of the Alps and were never as common as middle La Tène brooches.

To highlight the transition from Iron Age to Roman pottery it is necessary to consider the development of La Tène forms at least during the two last centuries BC. The purposes of this analysis are to consider the genesis of Roman forms from La Tène ones and define the eventual introduction of new forms during the Roman period.

The pottery contained in La Tène graves can be grouped as follows (Stöckli 1975, 42ff.; 63): beakers, jars with flared wall ('Töpfe mit geschweifter Wand'), 
short jars with conical neck ('bauchige Töpfe mit kurzem Kegelhals'), cooking pots, 'Wellentonnen', 'vasi a trottola' and cups (fig. 2.5).

The beaker with short out-turned rim, high, rounded and prominent upper half of body and lower half flaring towards the foot originated during Tessin D. During La Tène B1 the wall ran from the rim to the narrow foot without break, but the passage between rounded upper half and flared lower half was marked by girth-grooves. La Tène B2 beakers maintained the general form of La Tène B1 ones. The upper half of the body, however, was not as high as before and was less prominent. The diameter of the foot increased slightly, giving as result a slightly pinched out foot. La Tène $\mathrm{C} 1$ beakers showed a more extended upper half and a shorter lower half, whose wall was more curved. The profile of the beaker became S-shaped and the diameter of the foot increased again. La Tène $\mathrm{C} 2$ beakers had wide and rounded upper half and short and curved lower half on very wide foot, or high and rounded upper half and conical-truncated lower half, separated by girth-grooves, and rather wide foot. The evolution of this form ended in La Tène C2. No La Tène D or Roman forms seem to correspond to this beaker.

The jar with flared wall appeared in La Tène B2 and continued until the beginning of La Tène $\mathrm{C} 2$. The earliest examples had out-turned or bead rim, high and wide shoulder, and conical body flaring to the pinched out foot. During La Tène $\mathrm{C} 1$ the shoulder lowered, the neck became higher and cylindrical or conical-truncated, and the wall showed a more convex profile.

The short jars with conical neck represent the continuation of the previous form. They appeared at the very end of La Tène $\mathrm{C} 1$ and continued until the end of La Tène D. They were, therefore, possible prototypes for Roman 
forms. The development from the jars with flared wall to those with conical neck appeared clearly in the angle between foot and wall. Whereas in the former this angle was obtuse, in the latter it became acute as consequence of the convex profile of the wall over the foot. As the jars with flared wall, La Tène $\mathrm{C}$ jars with conical neck still had a relatively slender body. La Tène C2 jars usually bore an out-turned and expanded rounded rim. Sharply profiled rims were rare. La Tène $D$ jars were usually wider than high. The maximal width of the vessel was situated in its upper half. The neck was always conical-truncated. The body could be globular or biconical, with high shoulder and carination. Between these two main variants there existed many subvariants. The rim was very short and out-turned, and had an angular profile, or was a bead rim. Typical for La Tène D was the foot, that stuck out only a little of the wall.

Coarse vessels considered to have been cooking pots often show traces of contact with the fire. This group includes handmade jars with incised decoration on the shoulder and wheelmade jars or bowls. The handmade jar had steep wall, wide and flat or slightly concave foot, high but not prominent shoulder and horizontal or slightly out-turned rim. The maximal width of the vessel was very high and, especially in earlier examples, it corresponded to the rim. Most of these jars date to La Tène C1. Examples also occurred in La Tène B2 and La Tène C2. The wheelmade vessels had thick bodies, wide and flat or slightly concave feet, and relatively wide rims. Therefore, they may be defined sometimes as jars and sometimes as bowls. They had out-turned rims, sometimes expanded. In later examples the rims became longer and thinner. This form appeared during La Tène $C_{1}$ and continued until the end of 
La Tène $D$. The vessels belonging to this phase had high shoulders and slightly flared walls. In La Tène C2 examples, the walls became more convex by the feet. A variant of this form was slightly slenderer and consisted of jars with egg-shaped bodies. La Tène $\mathrm{C} 1$ examples had slightly flared walls and almost vertical rims.

The small jars are very close in form to the latter variant. They have out-turned rims, flat or slightly concave feet and egg-shaped bodies. The maximal width of the vessels was set at mid-body or in its upper half. The thickness of the walls increased often near the feet. These jars date to the first half of La Tène D.

'Wellentonnen' are high jars with elongated, egg-shaped bodies. Ring feet, short conical necks and thick rims correspond to those of the latest jars with conical necks. The bodies were decorated with many girth-grooves and wavy lines traced with a comb. These vessels date to the last third of La Tène $D$ and represent therefore the latest La Tène form.

'Vasi a trottola' take their name from their characteristic spinning-top shape. Their main features are short foot-rings, short and narrow necks and very prominent rims. Their bodies are wider than high; the walls below the point of maximal width are always more curved than the upper parts. The transition between the upper and lower half may be rounded or correspond to a sharp carination. Their direct prototypes were high, handleless flasks with rounded bodies, foot-rings or disc-feet and out-turned, expanded rounded rims. These flasks were variants of other vessels, that appeared in Ticino during La Tène B1. Similar flasks, whose heights were lower than their widths, may be dated to La Tène B2, but because of their general form they cannot be considered 
as 'vasi a trottola'. The earliest 'vasi a trottola' date to La Tène C2. Their form was similar to the latest flasks. The body was more flattened and assumed an onion-like form. The out-turned triangular or rounded rim was closed over the wall and the foot-ring had a swelling at its lower end. During the second half of La Tène C2 appeared the first 'vasi a trottola' with painted decoration. In the meantime, the rim became higher, thicker and less prominent as a sort of bead rim, but triangular in section. It bore a short internal bevel. The lowest part of the wall, close to the foot-ring, was horizontal. During La Tène D this part appeared as concave or convex. Vessels of La Tène C2 were still relatively slender in comparison with their maximal width. During La Tène D they became quickly lower and wider. As a consequence, the angle between upper and lower half of the body became sharper. At the beginning of La Tène D, upper and lower half were almost symmetrical. In later examples, found associated with late La Tène brooches, the lower half was always bigger than the upper half. The rim of these vases had a very narrow opening, that began as a curve inside the rim. This feature characterized the latest examples. At Solduno, the distribution of the 'vasi a trottola' allowed Stöckli $(1975,50-52)$ to date them from La Tène C2 to La Tène D. The latest graves, however, situated at the south-eastern and western ends of the cemetery, did not contain 'vasi a trottola'. This element seems to mean, that this form did not last to the end of La Tène D. The distribution of the 'vasi a trottola' seems to follow the river Ticino. The maximal concentrations of these vessels appeared in Canton Ticino, Val d'Ossola, the region of Como and Lomellina. They occur less frequentely in the Po plain to the east of the rivers Serio and Adda. 
Cups usually appeared associated with a jar, a beaker or a 'vaso a trottola'. On the contrary, jars, beakers and 'vasi a trottola' never appeared together. The main groups of cups from Solduno are characterized by inturned rims, curved walls and foot-ring. These cups originated during La Tène $\mathrm{C} 1$, and also occurred in the variant with vertical, tapering rim. During La Tène $D$ the rim was sharply inturned. A general feature of the cups dating from this phase was that they became progressively flattened. Also the foot has chronological implications. Foot-rings, that developed S-shaped from the wall, were typical for La Tène C1 and C2. Profiled foot-rings appeared in La Tène C1 and C2, but became more frequent during La Tène $D$. As in the 'vasi a trottola', footrings dating from La Tène $D$ usually have a quadrangular or triangular swelling. La Tène cups ended during La Tène D. In Roman times, this form was replaced by sigillata and thin walled cups.

In Ticino, other late La Tène graves were found at Sementina (Crivelli 1942b, 640-3), Giubiasco (Stöckli 1975, pl. 1), Minusio (Crivelli 1942c, 716) and Stabio (Simonett 1941, 177-182). The cemetery of Sementina consisted of 19 graves. Most of the graves contained weapons such as knives and lances, associated with iron late La Tène brooches. A few graves had middle La Tène bronze brooches, associated with a spindle-whorl or a glass necklace. The 'vasi a trottola' of Sementina corresponded in rim and foot to the latest examples from Solduno. The jars with conical neck were associated with the comb decoration typical for 'Wellentonnen'. At Sementina appeared two forms that did not occur at Solduno. Grave 4 contained a jug and and iron brooch, now lost. According to the horizontal stratigraphy, the jug could date to La Tène D. Another new form was the jar from Grave 9 with rounded body, high 
and curved neck, out-turned rounded rim and foot-ring with swelling (Stöckli 1975, pl. 10, 9.1). Further parallels between the two cemeteries showed that Sementina is contemporary with the latest graves of Solduno. Giubiasco Grave 477 dates to late La Tène according to the painted 'vaso a trottola' and the cup. Giubiasco Grave 479 contained an iron late La Tène brooch, a cup and a jar. The foot-ring of this cup did not correspond to that of La Tène D cups from Solduno, but to earlier ones. The jar with high egg-shaped body, cylindrical neck, slightly out-turned rim and foot-ring with swelling represents a variant of the jar from Grave 9 at Sementina (Stöckli 1975, pl. 10, 9.1).

At Minusio in 1942, in property M. Pfeiffer behind the apse of Santa Maria delle Grazie, was found a grave with a late La Tène sword and a 'vaso a trottola' similar to the latest examples of Solduno.

Only two La Tène D graves are known from Sottoceneri. They were found in 1937 at Stabio, in property Realini. Each contained a 'vaso a trottola' with rim and foot typical for La Tène D. Although these vessels were very similar to those from the Sopraceneri, a slight difference occurred in the rim. At Solduno the rim has a sort of groove at its lower end, that results in a sharp angle between rim and neck. At Stabio, on the contrary, the transition from rim to neck does not show any break and the profile is S-shaped. Other vessels from Stabio, such as the jars with conical necks, correspond to those from Solduno. In both Sopra- and Sottoceneri the appearance of La Tène objects in the grave-goods did not correspond to changes in the funerary rite. In Sopraceneri the inhumation became the only rite, and in Sottoceneri the use of cremation continued as before (Stöckli 1975, 66). This continuation in use of cemeteries and funerary rites from Golasecca to La Tène indicated that although the 


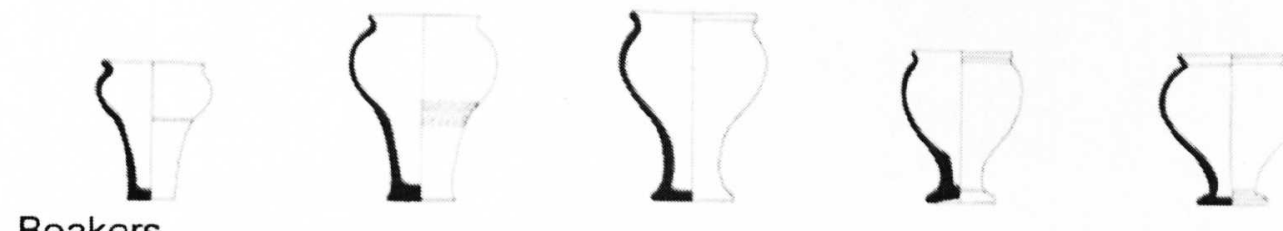

Beakers
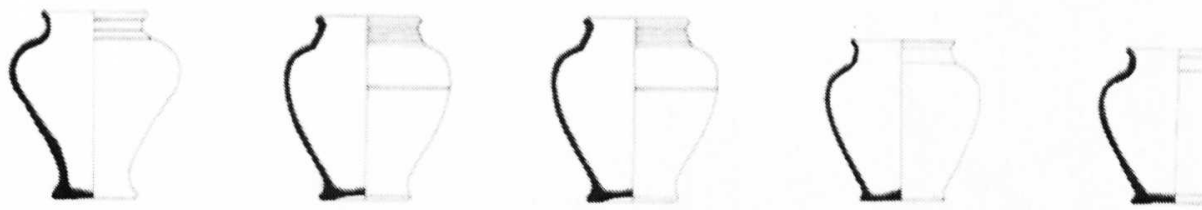

Jars with flared wall ('Töpfe mit geschweifter Wand')
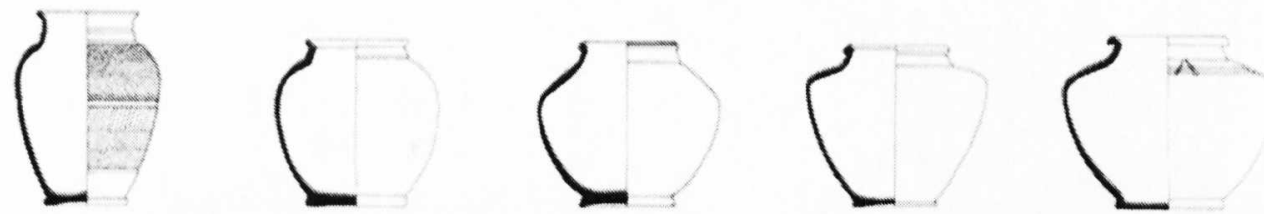

Short jars with conical neck ('Bauchige Töpfe mit kurzem Kegelhals')
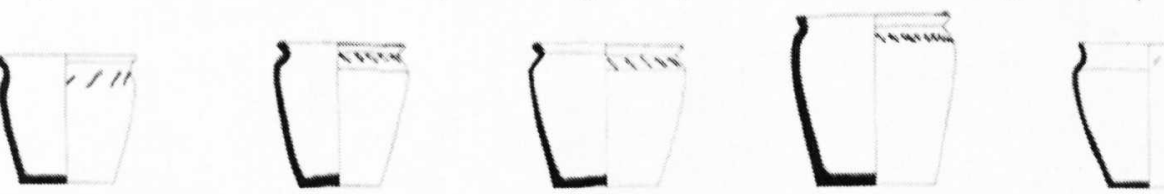

Cooking pots
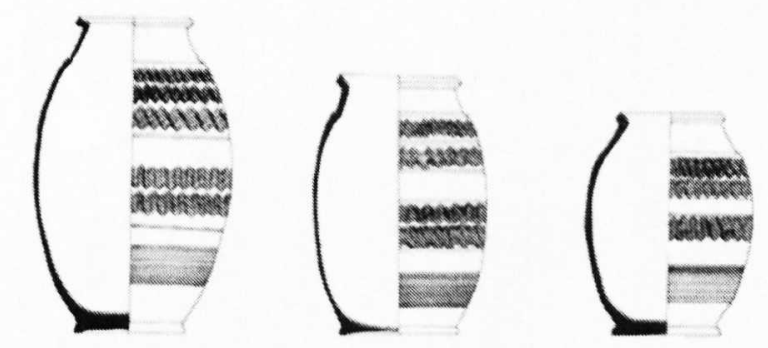

'Wellentonnen'
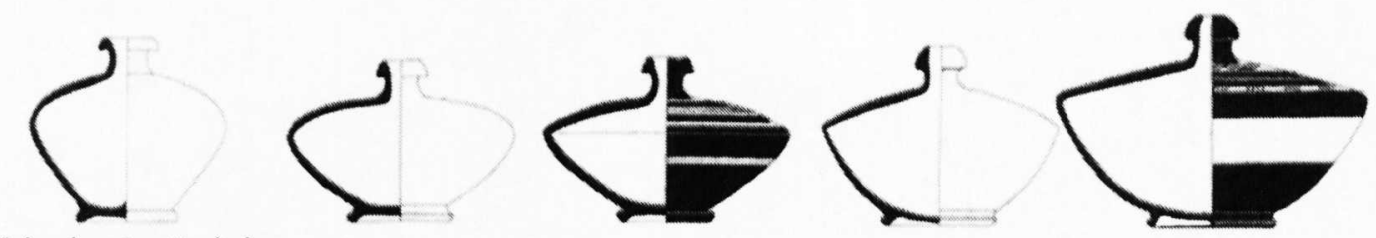

'Vasi a trottola'
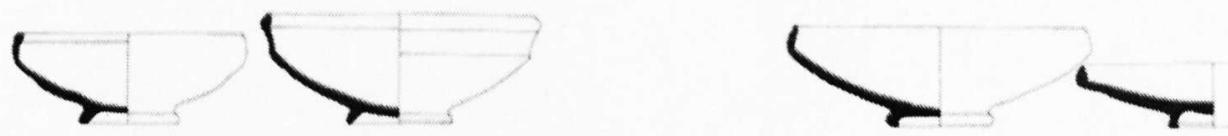

Cups

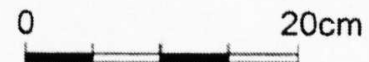

Fig 2.5. Outline of later Prehistory. Pottery from Canton Ticino (from Stöckli 1975). 
hypothesis of a Celtic immigration in Ticino exists, this phenomenon did not disturb the local cultural evolution. Jars with flared walls appeared during La Tène B2 and occurred only in La Tène C1. Soon afterwards they were modified, losing their typical features and assuming other proportions. Handleless flasks, that represent the prototypes for 'vasi a trottola', appeared in Ticino in limited number during La Tène B1 and B2. Bronze spouted jugs ('Röhrenkannen') of Celtic manufacture have been found in Ticino. Only two pottery examples, however, are known. The other forms seems to continue their evolution from Tessin D ones. On the contrary, La Tène brooches, buckles and swords appeared suddenly and in large number in the graves dating from the passage between Tessin D and La Tène B1-B2. On the other hand, many graves especially of women, contained only grave-goods of Tessin D tradition. Stöckli $(1975,103)$ hypothesized the immigration of a small Celtic group, of high social class, which influenced only some items, such as metal ones. The examples of Ancona and Bologna seem to prove this theory. According to historical sources, Celtic groups settled in both Ancona and Bologna. The vessels found among the grave-goods, however, did not indicate a break in the evolution of local pottery.

\section{The Romanization of Canton Ticino}

To understand the process of romanization in Ticino, it is necessary to summarize the development of the Roman occupation south of the Central Alps. The succession of events leading the Romans into the Po valley started in the 3rd century BC (Bandelli 1990, $251 \mathrm{ff}$; Sena Chiesa 1986, $325 \mathrm{ff}$; Crivelli 1964, 187ff.; Wielich 1970, 7-96). The first Roman expansion against the 
Sennones, a Celtic tribe settled along the Adriatic coast, began in 290 BC. The conflicts ended in 283/282 BC with the total defeat of the Sennones and the foundation of the Latin colony Sena Gallica/Senigallia. The next year also the Boii made peace with Rome (Livy, Ab urbe condita $V$ 35). In 268 BC was founded the Latin colony Ariminum/Rimini and Rome reached the river Rubicon. New conflicts rose in 232 BC from the promulgation of the Lex Flaminia, that sanctioned the apportionment of the ager gallicus south of the Po (Polybios, Rogatio de agro gallico et piceno viritim dividendo).

The second Roman movement occupied the period from 226 to $218 \mathrm{BC}$. The Gesates crossed the Po and joined Insubres and Boii, constituting an army and reaching Clusium/Chiusi. After the defeat of the Celtic army at Talamone, the Romans invaded the territory of the Boii (Polybios, Historiai II 25-31). Few years afterwards the Romans also invaded the territory of the Insubres (Polybios, Historiai II 34) as far as Milan, which was captured in 222 BC. Finally, the Insubres made peace with Rome. According to Polybios (Historiai II 35), this event had as a consequence the almost complete expulsion of the Celts from the Po valley, except for a few settlements very close to the Alps.

The Roman expansion in northern Italy was suddenly interrupted by the second Punic war. The Roman colonies of Mutina/Modena, Placentia/Piacenza and Cremona were founded in 218 BC as strong points against Hannibal's invasion (Polybios, Historiai III 40 1-5). Hannibal crossed the Alps through Mont-Cenis or a secondary pass in the same area (Meyer 1959, 227ff.; Meyer 1964, 99ff.) and conquered the Po valley as far as Modena thanks to the defection of Boii and Insubres (Polybios, Historiai III 40 6-8). Only the Roman colonies of Cremona and Piacenza resisted. The towns 
became quickly romanized with the foundation of Roman colonies, whereas the romanization of the areas outside the towns was generally difficult and took a long time.

After the end of the second Punic war and during the 2nd century BC the Romans reconquered the lost territory. They founded the colonies of Bononia/Bologna in $189 \mathrm{BC}$ and Aquileia in $181 \mathrm{BC}$ and occupied the territory of the Ligures in 155 BC. New conflicts with Insubres and Boii started in 198 BC and ended in 196 BC with the seizure of Como and twenty-eight small Gallic castles of the Oromboviri (Livy, Ab urbe condita XXVIII 38, 42; XXXIII 36; XXIX 5). After the opening of the Via Aemilia in $187 \mathrm{BC}$ and the Via Postumia in $148 \mathrm{BC}$ the Roman presence between the Po and the Alps increased in the most important centres of Celtic tradition, but significant archaeological evidence of a Roman tradition belongs to the 1st century BC (Arslan 1982, 179-269; Alföldi 1982, 309ff.; De Marinis 1984a, 22ff.). There is evidence of a delay in romanization in this area in comparison to the early apportionment of the territory of Cremona and the opening of the two routes linking the Po plain to Roman Italy. The colony of Eporedia/lvrea, in the valley occupied by the Gallic tribe of the Salassi, was founded in $100 \mathrm{BC}$ (Pliny, Naturalis Historia III 123). In 25 BC this tribe was definitively defeated. Augusta Praetoria Salassorum/Aosta and Augusta Taurinorum/Turin were founded. The Roman army conquered in $121 \mathrm{BC}$ the territory of the Allobroges, that constituted part of Gallia Narbonensis. In $115 \mathrm{BC}$ other tribes were defeated in Friuli and in $118 \mathrm{BC}$ in the area of Verona. The centres south of the Alps in the Po plain became Latin colonies in $89 \mathrm{BC}$ with the Lex Pompeia de civitate. In $49 \mathrm{BC}$ their inhabitants gained Roman citizenship and 
finally in $42 \mathrm{BC}$ the garrison troops left Gallia Cisalpina, which ceased being a Roman province and became part of Italy. The inhabitants of Como were registered in the tribe Oufentina, one of the thirty-five tribes among which were registered the Roman citizens and to which Milan also belonged (Luraschi 1980, 207ff.; Radcke 1964, 204ff.).

The final Roman expansion towards the Alps began under Augustus in 16/15 $\mathrm{BC}$ and ended in $7 / 6 \mathrm{BC}$ with the erection of the Tropaeum Alpium at Turbia/La Tourbie near Monaco. On the dedicatory inscription of the Tropaeum Alpium were listed all Alpine tribes which submitted to Rome at the end of this period. The inscription, now fragmentary, is mentioned by Pliny (Naturalis Historia III, 136). The inscription represents the first epigraphic evidence of Roman contacts with Canton Ticino. Among the tribes are mentioned the Lepontii. According to Pliny and other ancient authors, the Lepontii dwelled in the area around and north of Verbano, bordering on Central Alps to the west and the north, the region of the Adula to the east and the territory of Como to the south (Pliny, Naturalis Historia III 24, 133-5; Strabo, Geographia IV 6, 6-8; Ptolemy, Geographia III 1, 38; Caesar, De bello gallico IV, 10, 3). A first mention of a Leponticus, allied to the Carthaginians and killed during the second Punic war (Silius Italicus IV, 236), does not prove a real contact between Romans and Lepontii already at the end of the 3rd century $\mathrm{BC}$. On the other hand, it is not clear if the Roman conquest of the territory of the Lepontii was military or peaceful. There is no archaeological evidence of conflicts nor mention among the ancient authors. The regions of the romanized Como and Varese, included under Augustus in the XI Regio Italiae, seem to have allowed elements of Roman culture to be carried 
northwards, romanizing slowly but peacefully the neighbouring areas (Donati 1989, 295ff.; Gabba 1986, 23-5). The names of the other tribes on the Tropaeum Alpium also allow one to understand the aims and the direction of the Roman expansion. Except for the Lepontii, the other tribes are not situated close to Central Alps, but on the periphery. Therefore, the romanization of Canton Ticino seems to be the result of an osmosis process due to the vicinity of the completely romanized Po plain.

The high density of cemeteries and settlements at the northern end of Verbano with Ascona, Losone, Locarno-Solduno, Locarno-Muralto, Minusio and Tenero allows one to understand the importance of the route, the proximity to Vicus Sebuinus/Angera and the link to the municipium of Milan. Sottoceneri, on the contrary, bears many isolated finds and only three cemeteries at Stabio, Besazio and Melano.

The differences between Sopra- and Sottoceneri appear clearly in the cemeteries.

In northern Italy cremation is the only rite from the Bronze Age to the end of the Iron Age. During La Tène D, both inhumations and cremations appeared in the cemeteries of Transpadana. At Remedello (Brescia), Piadena (Cremona), Povegliano (Verona) and Bigarello (Mantova) the inhumations were reserved for women and children, whereas the cremations were for men (Tizzoni 1981, 32). This practice corresponds roughly to the Roman one. In fact, a general feature of Roman funerary rites in Italy until the end of the 1st century $A D$ is cremation for adults, whereas inhumation was used only for children and adolescents (Plinius, Naturalis Historia VII, 72; 187). From Hadrianic times inhumations progressively outnumbered cremations. In the 
Roman cemeteries of Como (Anonimous 1962, 70) and Mariano Comense (Piovan 1980, 29-48) the cremation is the sole rite even during the 1st century AD.

The same features occur in Sottoceneri. At Rovio (late Bronze Age), Pregassona (Iron Age, Primas' Tessin C), Cademario (Iron Age, Primas' Tessin D), Pazzallo (La Tène B) and Stabio-Realini (La Tène D) all graves are cremations. The Roman cemeteries of Besazio and Melano consist almost exclusively of cremations. At Stabio-Vignetto the cremations seem to be earlier than inhumations, and to date, according to their grave goods, to the 1st and 2 nd centuries $A D$.

In Sopraceneri cremation is the only rite during the late Bronze Age (AsconaS.Jorio). This rite characterized the Iron Age cemeteries of Golasecca, Castelletto Ticino and Ameno (Lago d'Orta), whereas in the cemetery of San Bernardino di Briona (Lago D'Orta) some graves allow one to suppose the use of both rites. The Iron Age cemeteries of the Sopraceneri, however, yield inhumations only from Primas' Tessin C to La Tène D (Stöckli 1975, 103; Primas 1970,83$)$. The sole exception is Grave 154 from the cemetery of Gudo (Donati 1972-73, 290-92, fig. 4). The rite of inhumation occurs also in the La Tène and La Tène-early Roman cemeteries of San Bernardo and Persona at Ornavasso, Val d'Ossola (Graue 1974, 9-10). The cemetery of Persona, however, has two cremations among its latest graves. In the Roman cemeteries of Sopraceneri inhumations clearly outnumber cremations. In particular, cremations did not appear or appear in extremely limited number in cemeteries far from the lake and from the direct contact with the Roman culture, as at Losone-Arcegno, Losone-Papögna and Moghegno. As in Stabio- 
Vignetto, also in the cemeteries of Ascona, Locarno-Solduno, Locarno-Muralto and Minusio cremations seem to stop after the end of the 2 nd century AD.

The Roman presence or influence appears clearly in the grave goods of the cemeteries.

In Sopraceneri, the cemeteries situated near the lake, such as Minusio, Muralto, Locarno and Ascona, usually had richer graves than those farther away from the lake. Generally, the inhumations outnumber the cremations, which seem to be later (Simonett 1941, 6; 25). In particular, the graves were rich in fine pottery such as Italian sigillata and thin walled ware, glass, bronze and jewellery. Also Imperial glazed ware, although not frequent, is attested. At Losone, not close to the lake, the graves often contained coin hoards. The presence of black slip ware is attested only in Locarnese. Its rarity in funerary contexts, however, proves that the earliest graves with Roman goods belong to the 1st century AD. The coins found in Locarnese range from the end of Republican times to the end of the 2 nd century $A D$. Coins dating from the 3 rd and the 4th centuries AD occur more isolatedly in cemeteries near the lake but especially in those higher in the valley. Long-spiral brooches, belonging to the period between the end of the 1st century $B C$ and the beginning of the 1 st century AD, appeared mostly in Roman contexts. Aucissa brooches and their smaller variants, dating from Augustan times to mid-1st century AD occurred exclusively in Sopraceneri.

In Sottoceneri, at Stabio and Melano, glass was rare and sigillata ware occurred only in cremations. Cremations seem to be earlier than inhumations and are usually richer in objects. The coins range from the 2 nd to the 4 th century $A D$, although coins dating from the $3 r d$ and 4 th centuries $A D$ clearly 
outnumber earlier coins, and no black slip pottery has been found. Whereas late Roman glazed pottery is rare in Locarnese, it occurs more frequently at Stabio.

According to the grave goods, it seems that the romanization of Sopraceneri occurred earlier and in a more massive way than in Sottoceneri. This fact is probably explained by the importance of Verbano as trade route. On the other hand, the rite of cremation was never very common in the cemeteries of Locarnese. It appeared late in the 1st century $A D$ in the cemeteries close to the lake and disappeared soon after the end of the 2nd century AD. Inhumation is the only rite in Sopraceneri from the Iron Age onwards and even the contacts with the Roman culture, that according to the grave goods may have been strong, do not seem to have changed the traditional funerary rite. In Sopraceneri the graves were stone-lined as in the Iron Age, but were usually covered by stone slabs and not stones. Heaps of stones or stelae to indicate the graves' position are not attested for the Roman period. Graves 4 , 5, 31, 32, 33 from Minusio-Cadra showed a completely new type in Ticino: the chambered grave. In Roman cemeteries iron nails often appeared as the remains of wooden coffins. Such nails did not appear in the La Tène cemeteries of Ticino. In Sottoceneri, as in northern Italy, the rite of cremation was the sole one from the Bronze Age to the Roman period. The earlier Roman graves at Stabio were cremations. The Roman presence among the grave-goods from this cemetery, however, seem to be slightly later in comparison to the cemeteries of Locarnese because of the lack of black slip ware and of coins dating from late Republican and early Imperial times, and the association of long-spiral brooches only with pre-Roman items. Therefore, 
it is possible to assume that the romanization of Sottoceneri occurred as a result of the proximity of Como, but not as strongly and massively as in the Sopraceneri.

The graves at Muralto and Minusio, excavated in 1936 by Ch. Simonett, are Roman. The cemeteries Muralto-Passalli and Muralto-Liverpool sotto were close to Via San Gottardo, the latter extending along this road. Passalli showed the maximal concentration of graves along Via San Gottardo, whereas the graves thinned to the north of the road. It seems therefore, that the graves were distributed along an ancient road, whose route corresponded roughly to that of Via San Gottardo. The siting of graves along a road is typically Roman.

The period between the end of the La Tène cemetery of Solduno and the earliest Roman graves at Minusio and Muralto is represented by the graves at Solduno-Pedrotta, Minusio-Bonfanti and Minusio-Scascighini.

The earliest group is Minusio-Scascighini. Four or five graves were discovered in 1945 during the construction of a house in property Scascighini, in the neighbourhood of the church of Santa Maria delle Grazie. The grave-goods found their closest parallels in the cemetery of Ornavasso-Persona. There occurred a 'Wellentonne', a serpentine armband and a beaker with curved rim. The presence of black slip ware and a sigillata fragment is important for the chronology.

The two graves of Solduno were in property Pedrotta, north of the La Tène cemetery, but without any relationship to it. The earliest Grave 1 contained black slip pottery, sigillata ware with a rectangular mark dating from early Augustan times, a beaker with curved rim, a flagon and some iron items. The 
later Grave 2 yielded fragments of two Aco-beakers, sigillata sherds with a rectangular mark and a knife.

The grave-goods from Minusio, property Bonfanti, consisted of two sigillata cups with rectangular marks, an Aco-beaker by Creatus T. Rubri and an axe. This grave and grave 2 from Solduno-Pedrotta were almost contemporary and belonged to the latest graves. Aco-beakers were common at Oberaden (11-9 $\mathrm{BC})$, whereas they were very rare at Haltern and did not appear at Oberhausen and Vindonissa.

Grave 1 from Solduno-Pedrotta and the grave group from Minusio-Scascighini contained beakers with curved rims. This form had its prototypes at Ornavasso-San Bernardo and in the filling for the construction of 'Casa di Livia' in Rome. According to finds north of the Alps, the terminus ante quem for the production of beakers with curved rims is the beginning of Oberaden (11 BC) or of Dagstetten (15 BC). These beakers did not appear in later military camps. Therefore, grave 1 from Solduno-Pedrotta and the graves from Minusio-Scascighini seem to be earlier than Oberaden, but later than the end of the La Tène cemetery of Solduno.

Roman inscriptions from both Locarnese and Mendrisiotto attested the presence of people belonging to the tribe Oufentina, to which were registered also Como and Milan. There is little evidence of the origins and the professions of the inhabitants of Ticino. Some inscriptions and graffitos on fine and coarse pottery attest the presence of people bearing Roman and Gallic names. A few funerary inscriptions found at Locarno, Riva San Vitale and Ligornetto mention the public office of quatuovir, connected to Como. The quatuovir had the job of administering justice and looking after public buildings 
and roads. More relevant are the mentions of sevir from Stabio and Gravesano. The sevir was a low-class authority, whose office was occupied in Imperial times by plebeians or freedmen. He had the job of keeping order in the town or the village. For the moment, the offices of quatuovir and sevir are the only professions attested in epigraphic documents. 


\section{ChAPTER 3}

\section{Cemeteries and Settlements}

\subsection{INTRODUCTION AND METHODOLOGY OF DATING}

Chapter 3 deals with the sites within the study area (figs. 3.1 and 3.2), as the essential first stage in determining a chronology.

The Locarno region pottery comes mainly from cemeteries. The Locarno area cemeteries, in fact, have yielded the most substantial body of data and greatest number of instances of associations, etc. Of 535 graves, 396 contained datable material or a dating could be suggested according to their vertical stratigraphy. There has been relatively little systematic excavation at the settlement sites, and whatever stratigraphical information they may have contained is either unpublished or lost. Moreover, the cemeteries usually yield complete pots or pot profiles, enabling a more satisfactory study of forms. Other cemeteries in Ticino have not been considered in this study either because of the lack of information or because situated in other areas and subject to different geographical and cultural conditions (e.g. Madrano in the Leventina valley, and Stabio or Melano in Sottoceneri).

Each item, even if already published, has been checked, drawn and described by the author. The identifications, and associations of accompanying datable material have also been checked. Usually, recent publications (e.g. Ascona and Solduno) yielded reliable drawings and dates. 
The sites are described with details summarizing location, size, type and chronology of the cemetery, and history of archaeological research, in form of a catalogue of cemeteries and graves and of settlements.

The thin walled and coarse pottery from each grave is listed in Appendix IV, along with all other associated datable grave-goods. The analysis and discussion of the associations in the graves and the suggestion of an internal chronology, are considered as the basis for the present study in order to provide a reference for Canton Ticino. Thin walled and coarse vessels are further divided into open and closed forms and listed with their catalogue numbers. Full descriptions of each item are contained in the Catalogue (Appendix 1). Other non-datable grave-goods, such as iron objects, are omitted.

The most valuable datable grave-goods include Campanian, Italian sigillata and glass ware, glazed pottery, lamps, bronze vessels, brooches and coins. These materials are only listed and used for their dating potential, without considering further details such as decoration or origin, which is considered beyond the scope of the present work. In the same way the associations of material in graves and their disposition are considered only to highlight their dating potential or eventual problems related to intrusion or residuality, but not in connection with funerary practices. Details of datable materials and the particular disposition of the items in the graves may be considered in association with elements issued from the analysis of coarse and thin walled pottery, in Chapter 4. On the basis of the datable material, the present writer has reviewed the date of the contexts given in previous publication. The dates given in Chapter 3 are those preferred by the author. 
Datable grave-goods, however, cannot provide an absolute dating for their deposition or context. In fact, it is assumed that the date of manufacture of datable grave-goods does not necessarily correspond to the date of the archaeological context in which they have been found. There also exists the problem of life-span of these materials and, further, the question of their postdepositional history, in particular for coins (Orton 1993, 185 ; Donati 1983b, 343). Assuming that the context is uncontaminated, however, it cannot have been earlier in date than its latest grave-goods. Therefore, the latest datable grave-goods may be used to define a terminus post quem for the grave and to evaluate a possible dating of the whole group. This terminus may be further postponed according to the stratigraphy. Rarely, the stratigraphy also provides a terminus ante quem for the grave.

Sigillata and Campanian wares are dated according to the recently published Conspectus Formarum Terrae Sigillatae Italico Modo Confectae (Ettlinger et al. 1990). There have also been considered, when necessary, other works such as Oswald \& Price (1920), Dragendorff (1895), Goudineau (1968). Glass is dated according to Ising's Roman Glass from Dated Finds (1957), even if this work may need some updating. In a more recent publication on Roman glass from Ticino, the contexts containing glass are dated considering, among other grave-goods, the thin walled pottery (Biaggio Simona 1991, 261 and note 22). Since in this thesis thin walled pottery is not considered as primarily datable material, it has been preferred not to consider this work for the initial dating of the contexts. The reference for glazed pottery is Maccabruni's Ceramica invetriata nelle necropoli del Ticino (1981). Lamps, although rare in Ticino, are dated according to Leibundgut's Die römischen Lampen der 
Schweiz (1977) and Loeschcke's Lampen aus Vindonissa (1919). References for bronze vessels are Eggers (1951), Den Boesterd (1956), Massari-Castoldi (1985). Brooches are dated according to Ettlinger's Die römischen Fibeln in der Schweiz (1973). The coins have been identified and dated by Nevio Quadri of the Ufficio dei Beni Culturali, Bellinzona. Most of the coins were rather worn, indicating a long circulation before their deposition in the graves. The proposed dates of the graves are expressed in years rather than less specific terms (such as Trajanic, Hadrianic, etc.) to make the suggested date ranges plainer. If such terms are used by other scholars, however, they are indicated in the discussion. Among the cemeteries, those of Ascona, Solduno and few graves from Losone-Arcegno have been published. In these cases, after each grave are given the date suggested in the literature followed by the date proposed by the present writer. Two other cemeteries, at Minusio and Muralto, have also been published, but without suggesting dates for the graves.

The evidence derived from each datable object has been used to propose dates for the graves. Strictly speaking, the date of the latest item in a grave group provides nothing more than a terminus post quem, and the date of deposition can be at any time - even centuries - thereafter. In practice, however, it may be sensible to assume, albeit arbitrarily, a shorter period for deposition, which is more likely to accord with reality. How long such a period should be is an entirely subjective matter, and each scholar will have his own opinion. 
The criteria I have adopted are as follows:

- Where a coin constitutes an acceptable terminus post quem for the grave, the suggested date-range of deposition is taken to be within fifty years of the date of minting. It is assumed that the probability of the coin's deposition decreases gradually within this period. There needs to be considered the possibility of a wide chronological gap between minting and deposition, but this can be checked by looking at the association of the coin with other datable grave-goods. The presence in a grave of many coins issued within a circumscribed period (e.g. Ascona, Grave 2; Losone-Arcegno, Grave 20, etc.), perhaps allows one to suggest a date of deposition shortly after the latest coin, helping to overcome the problem of life-span.

- For other datable grave-goods, whose date of manufacture is not so precise and whose date-ranges may be considerably wider, the suggested date for the grave will be an evaluation of the latest material with the other associated items of earlier date. A substantial amount of earlier material might suggest that the deposition date lies earlier with the date-range of the latest item (Example 1). If, however, the grave-goods seem to date mainly to the later part of the range of the latest item, the deposition date could therefore lie towards the end of that date-range or even later. The suggested dates of the graves may need re-consideration in light of the presence of coarse or thin walled vessels, even if these materials cannot be considered datable items (Example 2). 
Example 1 Each horizontal line represents the date range of an artifact Minusio-Cadra, Grave 28, c. AD 50-100

0 $50 \quad 100$ 150

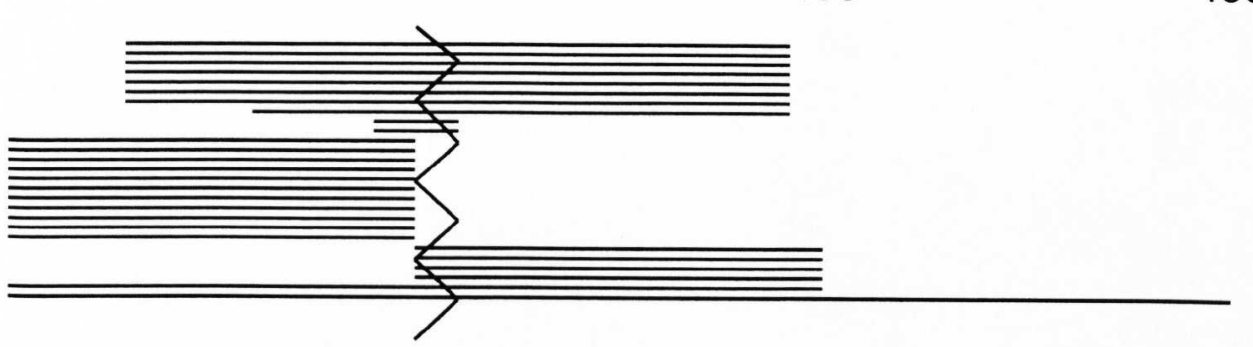

Suggested deposition date

Example 2 Each horizontal line represents the date range of an artifact Minusio-Cadra, Grave 33, c. AD 70-120

0 50

100

150

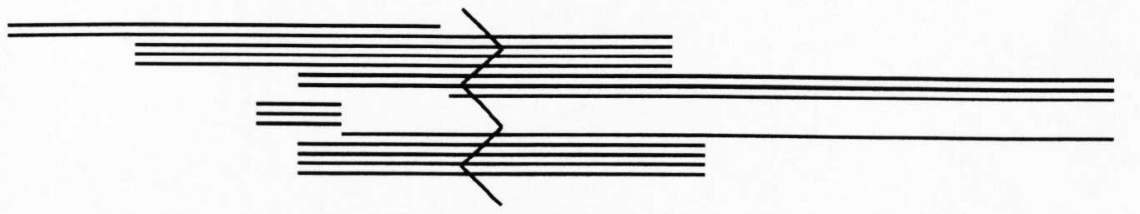

Suggested deposition date 


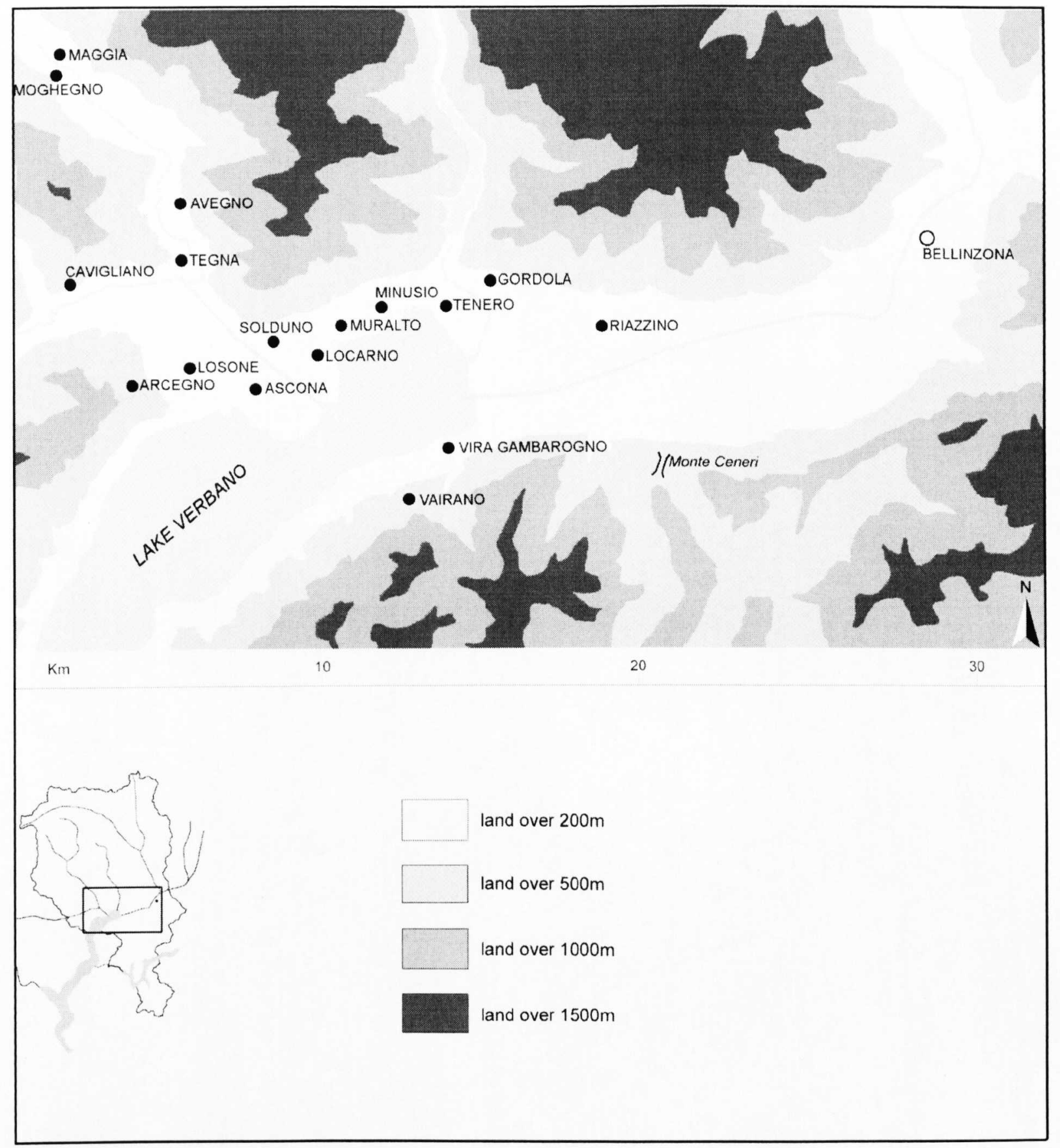

Fig. 3.1. The study area. Location map, showing the principal cemeteries of the Roman period. 


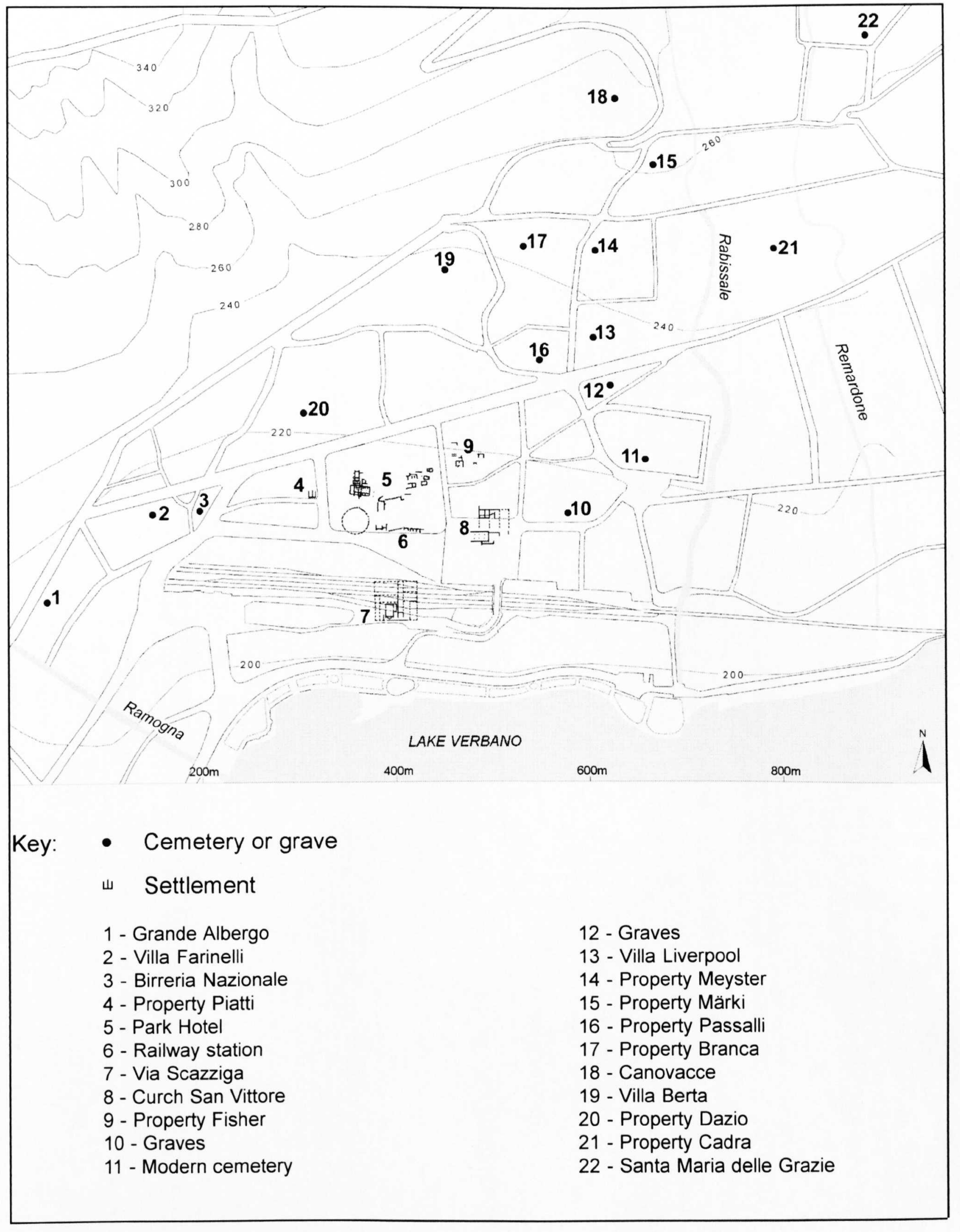

Fig. 3.2. Roman finds at Muralto and Minusio. Location map (from Donati 1983a, 121, and Drack \& Fellmann 1988, 448; modified by the author). 


\subsection{THE SITES}

\section{Ascona}

The Roman cemetery of Ascona, AK 703000/113000, lay south of the river Maggia. It occupied the area of the castle San Materno, partly below the modern cemetery, at $210 \mathrm{~m}$ asl. This area constitutes today the northern end of Ascona, bordering to the north the territory of Losone. It is about one kilometre from the lake shore, but is, however, out of sight of the lake. The area is also known for its prehistoric finds. At Balladrüm were discovered remains of prehistoric structures and pottery, dated to the Iron Age (Crivelli $1945,1043-44)$. Directly to the south of Castle San Materno, to the east of the Roman cemetery, was a Late Bronze Age cemetery (Crivelli 1953-54, 49-66). Excavations executed by W. Meyer Hoffmann in 1969 in Castle San Michele, on the lake shore, showed a stratigraphy from the late Neolithic onwards (Archive of the Ufficio dei Beni Culturali; Donati 1990, 135-6).

\section{Circumstances of discovery}

The presence of 'ancient graves' in the area was already noted at the beginning of this century during works for the new cemetery (Crivelli 1953-54, 49-66). In 1953 Rupert Spillmann (later Dr. Med. Spillmann), at that time thirteen years old but already interested in antiquities, was invited by the owners of castle San Materno for a holiday at Ascona. To the castle belonged a wide terrace situated on the other side of the via Losone, at $230 \mathrm{~m}$ asl, used as grazing land. South of the terrace, on a slope, lies the modern cemetery of Ascona. 
The young Spillmann started digging on the terrace and discovered a Roman grave. Crivelli, head of the Ispettorato degli Scavi e dei Musei, was told about the find. The enlargement of the modern cemetery, started in December 1953, obliged Crivelli to undertake an emergency excavation, which made it impossible for him to continue the investigation of the terrace. During this emergency excavation Crivelli discovered about 20 cremations dated to the late Bronze Age and five Roman graves, part of the Roman cemetery. In the next years both Spillmann and Crivelli continued the excavation on the terrace and discovered 23, and 10 graves respectively. In 1954, Crivelli also investigated Castle San Materno's park and discovered walls, that could belong to a Roman settlement, and a considerable quantity of Lavez-rock (Crivelli 1954, 110).

\section{The graves}

The cemetery of Ascona contained 38 graves.

Five graves, discovered by Crivelli, lay at the foot of the slope, along the via Losone, at c. $210 \mathrm{~m}$ asl. The group comprised one cremation and four inhumations. Only one inhumation was accompanied by grave-goods, which are now lost. It has not been possible to find any detailed description or plan of the graves, except that they were orientated north-south.

Two graves (S22 and 3) of the other 33 excavated on the terrace are clearly identified as cremations. The interpretation of grave $\$ 20$ is difficult, because it is described as a cremation but drawn as an inhumation.

The remaining 30 graves consist of dry-stone enclosures covered by stone slabs. The use of flat tiles is not attested. Four graves are orientated north- 
south, whereas the others east-west. The frequent presence of iron nails in the corners of the graves proves the use of wooden coffins.

The limited number of cremations in comparison with the inhumations makes difficult to consider analogies or differences in their content. The only difference seems to consist of the poor preservation of the grave-goods from cremations.

\section{Publication of the cemetery}

The cemetery was published in 1987 (Donati 1987). The items are kept in the Ufficio dei Beni Culturali at Bellinzona and in the National Museum in Zürich.

\section{List of graves}

The numbering of the graves shows a distinction in two groups: graves excavated by Spillmann from 1954 to 1961 bear the capital 'S' before the number; graves excavated by Crivelli from 1953 to 1956 bear simply the progressive number.

$\begin{array}{lll}\text { Grave S1 } & \text { inhumation } & \text { c. AD 70-120 } \\ \text { Grave S2 } & \text { inhumation } & \text { c. AD 80-100 } \\ \text { Grave S3 } & \text { inhumation } & \text { c. AD 70-100 } \\ \text { Grave S4 } & \text { inhumation } & \text { c. AD 70-120 } \\ \text { Grave S5 } & \text { inhumation } & \text { c. AD 80-130 } \\ \text { Grave S6 } & \text { inhumation } & \text { c. AD 70-120 } \\ \text { Grave S7 } & \text { inhumation } & ---; \text { no datable items } \\ \text { Grave S8 } & \text { inhumation } & \text { c. AD 50-100 } \\ \text { Grave S9 } & \text { inhumation } & ---; \text { no grave-goods }\end{array}$


Grave S10 inhumation $\quad--$; no datable items

Vertical stratigraphy : earlier than grave S 11

(c. AD 96-110)

Grave 11 inhumation

c. $A D 96-110$

Grave $\mathrm{S} 12$ inhumation

c. $A D 100-120$

Grave $\mathrm{S} 13$ inhumation

c. $A D 100-150$

Grave S14 inhumation

c. $A D 114-50$

Grave S15 inhumation

C. $A D 200-50$

Grave S16 inhumation

c. $A D$ 30-70

Grave S17 inhumation

C. $A D 138-60$

Grave S18 inhumation

c. $A D 50-100$

Grave S19

not investigated

Grave S20 rite not clearly --- ; no datable items

definable

Grave S21 inhumation

c. $A D 98 / 99-150$

Grave S22 cremation

c. $A D 50-100$

Grave S23 inhumation

C. $A D 80-130$

Grave 1

inhumation

C. $A D 80-130$

Grave 2

inhumation

c. $A D 100-150$

Grave 3

cremation

c. $A D 70-120 / 30$

Grave 4

inhumation

-- ; no datable items

Grave 5 inhumation

c. $A D 40-100$

Grave 6

inhumation

-.- ; no datable items

Grave 7

inhumation

c. $A D 70-120 / 30$

Grave 8

inhumation

c. $A D 81-130$ 


$\begin{array}{lll}\text { Grave } 9 & \text { inhumation } & \text { c. AD 112-50 } \\ \text { Grave } 10 & \text { inhumation } & \text { c. AD 103-50 }\end{array}$

\section{Dating of the cemetery}

According to the datable grave-goods and assuming a life-expectancy of c. 50 years, the graves of the cemetery of Ascona belong to the period C. AD 40250. However, prudence is necessary in considering life-expectancy of gravegoods as a fixed period. Most of datable materials in Graves S14 and S17, for example, are 30 to 40 years earlier than the latest coin, and in Grave S15 the chronological gap between the three coins amounts to over hundred years. On the other hand, materials occurring within a defined period may have been deposited in the grave soon after their manufacture. In this case, the date of the grave is necessarily earlier and no life-expectancy of these grave-goods needs to be considered in dating the grave. Therefore the proposed dating of the graves need to be re-considered in light of new data issued from the presence of coarse or thin walled pottery, even if these materials are not closely datable.

The proposed dates of graves according to datable grave-goods do often correspond to the dates proposed in the literature (Donati 1987). These graves have been studied and published more than 35 years after their discovery and not by the same person who excavated them, and it is emphasized that graphic and photographic documentation was sometimes incomplete. In the literature, however, is neither given any information about reasons of dating nor mentioned the problem of eventual intrusive materials in the graves. There are only highlighted the poor condition of the coins in the 
graves and the fact that, therefore, they may have circulated for a certain period before deposition (Donati 1987, 24). This hypothesis might suggest longer life-expectancy for the coins and therefore add new evidence for dating the graves. It should be remembered, however, that the high acidity of the soil in Canton Ticino results in the poor preservation of coins from graves.

\section{Avegno}

Avegno, AK 700800/118100, is situated on the left bank of the river Maggia, at the foot of the mountain, at $290-300 \mathrm{~m}$ asl. The village lies half way between Locarno and Moghegno/Maggia, about 6.5 kilometres from the lakeshore at Ascona.

\section{Circumstances of discovery}

A grave was found in November 1935, in the area west of the cantonal road and east of the river, AK 700500/118000 (Crivelli 1938a, 21; Crivelli 1943, 73). Two items, a thin walled cup and a flagon, were recovered, and are now at Bellinzona.

Grave (1) rite not no datable items definable 


\section{Cavigliano}

The Roman cemetery of Cavigliano, AK 698900/115600, is named after the independent municipality. Cavigliano belongs with Verscio and Tegna to the area called 'Terre di Pedemonte'. It lies on the left side of the river Melezza on a wide terrace at $300 \mathrm{~m}$ asl and is about eight kilometres north-west of Locarno. The river Melezza flows from the artificial lake by Palagnedra and joins the Maggia to the south of Ponte Brolla.

The Terre di Pedemonte continue to the west as Centovalli, leading to Brig and Canton Wallis, crossing the Alps through the pass of Simplon.

\section{Circumstances of discovery}

Emilio Balli was the first to mention Roman graves at Cavigliano, in 1878. Five graves were found in $1882-83$ on the property of G. Galgiani (map no. 195), situated to the north of the path linking Cavigliano and Verscio, and excavated by Balli (Motta 1884a, 255). In 1888, a grave was discovered on the property of P. Selna (map no. 215), south of the path and not far away from Galgiani's property (Motta 1888, 275). The grave contained some pottery and coins dating from the 2nd century AD (Faustina I, Trajan, Marcus Aurelius, Antoninus Pius). In 1923, during work for a vineyard on the property of $F$. Monotti (map no. 207), to the north of the railway station, appeared four stonelined graves, covered by stone slabs. A few months later, in 1924, in the same meadow three more graves were discovered. Two were empty, but one contained a coin dated to the 3rd century AD and some pottery (Magni 1925, 27-8). In 1944, eight graves were discovered on the property of F. Monotti (map no. 209, to the south of map. no. 207) and excavated by Silvestrini and 
Crivelli (Crivelli 1946b, 1219). All graves were stone-lined and covered by stone slabs. A jar was found in October 1948, while digging for a well, in the courtyard of the mayor's house. In 1957, Crivelli investigated four graves found on the property of A. Cavalli (map no. 208, to the west of map no. 209) during the construction of a house (Crivelli 1959, 145; 147). In 1959 on the property of A. Monotti to the east of the station (map no. 214) was discovered an inhumation grave, marked by an uninscribed stele. In September 1989 in the property of the family Galgiani Cavalli was found a coin of Elagabalus' wife Julia Cornelia Paula. Since the family owns many meadows at Cavigliano, it is difficult to position the discovery correctly (Donati 1990, 148).

\section{The graves}

All 27 burials were inhumations and consisted of stone-lined graves covered by stone slabs. Only sketch-plans exist of the graves excavated in 1944, 1957 and 1959. All were orientated east-west. The graves found in 1923-24, 1944 and 1957 in the meadows 207, 208 and 209 constitute a small cemetery. The other finds were distributed along the path which links Cavigliano to Verscio. They seem to suggest the Roman practice of siting graves along roads. Graves 1944.1 and 1957.1 were empty. All other graves contained Italian sigillata, glass and coins. Some of the items found at Cavigliano are lost. Those from the excavations 1944 and 1957 are kept in the Museo Civico at Locarno.

\section{Publication of the cemetery}


The graves found at Cavigliano have not been published, except for the notice of their discovery (Bertolone 1939, 291-2). The graves discovered in 1944 and 1957 were partly studied by Matteo Buzzi from Locarno in 1992, but have not been published.

\section{List of graves}

The items from the old excavations between 1878 and 1924 are today lost and only partly listed in the reports of their discovery. These reports, however, are not sufficiently detailed and cannot be used as reference for further studies on the pottery.

\section{Cavigliano, Property Monotti (1944)}

$\begin{array}{lll}\text { Grave } 1 & \text { inhumation } & --- \text {; no grave-goods } \\ \text { Grave } 2 & \text { inhumation } & \text { c. AD } 98-120 \\ \text { Grave } 3 & \text { inhumation } & \text { c. AD 50-100 } \\ \text { Grave } 4 & \text { inhumation } & --- \text {; no datable items } \\ \text { Grave } 5 & \text { inhumation } & \text { c. AD } 79-100 \\ \text { Grave } 6 & \text { inhumation } & \text { c. AD 50-100 } \\ \text { Grave } 7 & \text { inhumation } & \text { c. AD 50-100 } \\ \text { Grave } 8 & \text { inhumation } & \text { c. AD 50-100 }\end{array}$

\section{Cavigliano, Property Cavalli (1957)}

$\begin{array}{lll}\text { Grave } 1 & \text { inhumation } & --- \text {; no grave-goods } \\ \text { Grave } 2 & \text { inhumation } & \text { c. AD 176-200 } \\ \text { Grave } 3 & \text { inhumation } & \text { c. AD 174-200 }\end{array}$


Grave 4 inhumation c. AD 186-210

\section{Dating of the cemetery}

According to the datable grave-goods and assuming a life-expectancy of c. 50 years, the graves of the cemetery of Cavigliano belong to the period c. AD 50210. The datable grave-goods only give a terminus post quem for the graves, which may be later. This dating of the cemetery seems to coincide with that resulting from the items found at the end of the 19th and the beginning of the 20th centuries.

\section{Gambarogno}

Gambarogno is the region situated at the northern end of Verbano, on its southern shore, and faces Locarnese. It extends from Magadino, where river Ticino flows into Verbano, to the Italian boundary at Dirinella. Whereas the Locarno region consists of wide and low terraces situated at $200-230 \mathrm{~m}$ asl at the foot of the hills, the Gambarogno area is much steeper. A narrow band of flatter ground at $200-210 \mathrm{~m}$ asl follows the lake edge and is occupied by medieval and modern villages. Another row of villages lies at the higher altitude of $300-350 \mathrm{~m}$ asl. Because of its morphology, Gambarogno is not densely populated. The region is dominated by Monte Gambarogno (1735m asl) and, farther to the south, by Monte Tamaro (1962m asl). To the south of Monte Tamaro lies the valley of river Vedeggio, that flows from Monte Ceneri to Agno, where it joins the western arm of lake Ceresio. No important rivers flow into the Verbano in Gambarogno. 


\section{Vira Gambarogno}

Vira Gambarogno, AK $708300 / 111200$, lies on the shore of Verbano at $200 \mathrm{~m}$ asl and is 1.2 kilometres from Magadino, at the very end of the lake. The distance from Vira to Locarno and Muralto as the crow flies is about 4.2 kilometres.

\section{Circumstances of discovery}

A grave was discovered in 1972 during the building of a house on property Saxer (Donati 1981, 25). Property Saxer was at Corognola, $350 \mathrm{~m}$ to the south-east of Vira, at $250 \mathrm{~m}$ asl. According to information from the archive of the Ufficio dei Beni Culturali, Bellinzona, the grave was partly destroyed and only some grave-goods were recovered. The grave was probably a stone-lined inhumation with cover of stone slabs. It contained iron shears and coarse vessels.

Grave (1) inhumation ? --- ; no datable items

\section{San Nazzaro}

San Nazzaro, AK 705200/109900, lies, like Vira, on the shore of Verbano, at $198 \mathrm{~m}$ asl. It is situated 3.4 kilometres south-west of Vira and 3.8 kilometres from Ascona, on the opposite shore.

Circumstances of discovery 
Some graves were discovered at the beginning of the 20th century, during the construction of the road that links San Nazzaro to Magadino. Prof. Dr. Hans Bögli, University of Basel, was told about the discovery and tried to organize an investigation. Unfortunately, cantonal authority and building contractors considered the construction of the road more important and urgent and the graves were destroyed (information P. Schultess).

\section{Vairano}

Vairano, AK 706050/109900, lies on a wide terrace over San Nazzaro, at $392 \mathrm{~m}$ asl.

\section{Circumstances of discovery}

In 1958, during agricultural work at property Schulthess, were found several cremations in stone-slab cists. The grave-goods were only partly recovered, distributed among private people or lost. Today only two jars, two bowls and one flagon are available for study (information P. Schulthess).

\section{Gordola}

The village of Gordola, AK $710000 / 115400$, lies to the east of the river Verzasca, opposite Tenero and about 1.5 kilometres from the modern northern end of Verbano. In earlier times, when the delta of river Verzasca was not as prominent as today, the lake extended farther north. A document dated to 1388 gives evidence of the purchase and delivery of goods, that occurred on the lakeshore at Gordola (Motta 1915a, 11). The modern 
settlement extends today to the south of the railway line. On the hills it reaches $400 \mathrm{~m}$ asl .

Gordemo, AK 709000/116100, is an outlying division of Gorduno and is about $800 \mathrm{~m}$ to the north, at $400-420 \mathrm{~m}$ asl.

\section{Circumstances of discovery}

The graves were found in the area south of the railway station, AK $710000 / 115000$, at $205 \mathrm{~m}$ asl. In 1881 were found c. fifty graves, identified as Roman (Motta 1881, 40). Five or six inhumations were destroyed in the Spring of 1954, during the construction of the house of S. Macciantelli (parcel 194). There were recovered only three flagons, some sherds of jars and of a sigillata dish with the mark L.M.VIR. in planta pedis (Crivelli 1954, 110). In April 1954, Crivelli opened a trench between parcels 194 and 193, and recovered another grave. It consisted of an inhumation with stone slab walls and cover and was orientated east-west. It contained a jar, an iron nail and an iron ring.

An inhumation was partly destroyed in 1969, during work on property Scheggia (parcel 193, bordering to the north parcel 194). The grave-goods were recovered and catalogued by the Ufficio dei Beni Culturali in 1979. In the same year the Ufficio also recovered some grave-goods from another grave, partly destroyed during canalization work. It consisted of a stone-lined inhumation and lay about $40 \mathrm{~m}$ east of property Macciantelli. All grave-goods are kept in the Ufficio dei Beni Culturali, Bellinzona.

In 1959 were discovered at Gordemo some empty graves. Further details about position and structure of the graves are unknown. In 1978, at property 
Papparelli (parcel no. 1140) at Gordemo was found a stone-lined inhumation. The grave, as those found in 1959, was empty (Archive of the Ufficio dei Beni Culturali, Bellinzona).

The graves

All of the graves were inhumations. Further details about their structures are not available.

Property Macciantelli (parcel 194; 1954)

Group of five inhumation second half of the 1st century AD or six graves

Crivelli's excavation, 1954 (between parcels 194 and 193)

Grave 1 inhumation --- ; no datable items

Property Scheggia (parcel 193; 1969)

Grave 1 inhumation c. AD 30-70

Recovery 1979

Grave 1 inhumation $\quad$ c. AD 30-70

Publication of the cemetery

Except for short reports on the discovery (Crivelli 1954, 110; Donati 1981, 15), the graves have not yet been published. 


\section{Dating of the cemetery}

The eight or nine graves were close enough together to allow one to suppose that they belonged to a cemetery. The limited number of graves, however, cannot give a wide spectrum of dating. The datable grave-goods range from the first to the second half of the 1 st century $A D$.

\section{Locarno}

Locarno, AK 705000/114000, is the chief town of district Locarnese. Its lies north of river Maggia, between Solduno and Muralto, once independent towns and now parts of Locarno. The centre extends from the foot of the hills at $210 \mathrm{~m}$ asl, to shore of the lake at $197 \mathrm{~m}$ asl, although today the town occupies a large area of the northern half of the Maggia's delta.

The first traces of Roman presence at Locarno and in its region date to the beginning of the 1st century $A D$. According to a Roman inscription and the report of Gregory of Tour (6th century AD), Locarno belonged, like the regions of Lugano and Bellinzona, to the municipium of Milan (Wielich 1970, 55-8). The importance of Locarno appears clearly from the distribution of fortifications during the Middle Ages: at the northern end of Verbano the town developed as trading centre and belonged to the signalling system that linked the castrum at Bellinzona with the other defensive centres along the lake (Frigerio \& Pisoni 1979,127$)$. From the 10th century AD onwards the archbishop of Milan owned many castles, controlling the lake route and access to northern Italy through Val d'Ossola and Simplon or Valle Maggia, 
Leventina and Mesolcina. From the end of the 12th century to mid-14th century $A D$, Locarno belonged to Como. The following century was characterized by the presence of the Visconti from Milan as rulers until shortly after 1439, when Filippo Maria Visconti gave the Locarnese to Earl Franchino, of the house Rusca. At the end of the 15th century Locarno, Lugano and Bellinzona were occupied by troops of the Swiss Confederates. Finally, in 1516, the Eleventh Article of the Peace of Freiburg ratified the conveyance of Lugano, Locarno and the surrounding territory to the Swiss Cantons (Wielich 1970, 352).

\section{Circumstances of discovery}

Between 1890 and 1920 many Roman graves were discovered in properties situated along Via Valle Maggia, Via Torretta, Via della Motta and the the areas 'Contrada Borghese' and 'In Selva' (Bertolone 1939, 305-7; Crivelli 1943, 73). The grave-goods were lost or became private property.

A grave was found during work to broaden Via Cappuccini in 1910, containing a flagon and a bronze needle for fishing nets (Magni 1912b, 139). One or more graves were discovered in 1946 in Via Cappuccini, during the construction of the Library of the Franciscan Friars near the Palazzo Morettini. Crivelli listed 62 grave-goods as belonging to a single grave (Crivelli 1946b, 1221), but they may have belonged to more than one grave and have been grouped by the building workers. Some of the grave-goods are kept in Museo Civico, Locarno; the others are lost.

In the property Vandoni (parcel no. 1068), by Sant'Antonio's church, several graves were destroyed in 1949 (Donati 1980, 286). Some grave-goods were 
lost as well as all associations. The remaining grave-goods are kept in the Ufficio dei Beni Culturali, Bellinzona.

\section{The graves}

No information about orientation, type or structure of the graves is available.

\section{Locarno-Muralto}

Muralto (AK 114500/705500), once a village between Locarno and Minusio, belongs today to Locarno. Like Minusio, it is situated on wide terraces at 200$300 \mathrm{~m}$ asl and extends from the lake to the foot of the hills. Above Muralto, at $450 \mathrm{~m}$ asl, is situated the municipality of Orselina. Until 1881 both belonged to the same municipality, but in 1881 , Muralto parted from Orselina. The lower part of Orselina, whose territory reached the lake, was named Muralto. Orselina was limited to the upper part of the village, situated on the hill. Some grave-goods, now in the Historisches Museum, Bern, bear the provenance 'Orselina' but actually come from Muralto.

\section{Circumstances of discovery}

The territory of Muralto is today one the the richest in archaeological finds of Canton Ticino. The earliest known discoveries date to the beginning of the 19th century. Unfortunately, there do not exist detailed reports about these discoveries, nor about most of those of this century. Moreover, the exact position of some of them cannot be identified.

The first discoveries date to 1808 , when some graves were found during the construction of the 'cantonal road' by the river Rabissale. The type of graves is 
unknown, but they are described as 'rich in grave-goods' (Nessi 1854, 17). It is not possible to identify the 'cantonal road', although it could be the Via San Gottardo, the Via Bacilieri or the Via Nessi.

Many graves were discovered during the construction of the railway station at the end of the 19th century, although their exact position is unknown. They contained many grave-goods. Walls were also discovered, two metres in width, partly preserved under the ground in front of Collegiata San Vittore, and probably parts of a Roman villa (Archive of the Ufficio dei Beni Culturali ; Drack \& Fellmann 1988, 447ff.). In the Collegiata San Vittore were also found a Roman funerary inscription and a votive ara for Minerva, both re-used as building stones (Bertolone 1939, 311-12). The archaeological investigation of the Collegiata, carried out in 1977-80 and 1985 by the Ufficio dei Beni Culturali, showed the remains of an early Christian basilica with some graves, built on a Roman structure (Donati 1981, 22). North of the railway station, on property Piatti on the crossing between Via Scazziga, Via Francesca and Via Sempione, Crivelli excavated in 1935 foundations of buildings, dry-stone walls, tiles, pottery and stone floors. Only a preliminary report of this excavation was published (Crivelli 1949, 34-35; Crivelli 1953, 190-93), although some plan sketches exist. During work to broaden Via Stazione some Roman objects appeared; they were sent to the Museo Civico, Locarno (Bertolone 1939, 309), but are now lost. South of the railway station, in Via Scazziga, Crivelli excavated in 1947 part of a Roman house. He discovered baths with frigidarium, tepidarium and caldarium, from the latter came some pottery, window glass and a coin of Magnentius dated AD 350 (Crivelli 1949, 34-5; Crivelli 1953, 190-93; Crivelli 1959, 103). Crivelli wrote a preliminary report 
only, and details of excavation and statigraphy are unknown. The rest of the house lies under the railway station or was destroyed by its construction. Undefined finds came from Via dei Pescatori, by the eastern end of the railway station (Bertolone 1939,313 ). North of the railway station, in the area between Via Collegiata and Via Sempione, called Park Hotel and once occupied by the church of Santo Stefano (destroyed in 1911), were excavated in 1982-85 buildings and the remains of the Via Francesca, once part of the public area of the Roman settlement (Donati 1983a, 120-36). In particular there was excavated a building with many spaces for different shops and workshops (bronze, glass) ('Werkhalle') and a bath to the west, parts of buildings to the east and the south-east and a circular structure to the southwest. Later, on the eastern group of buildings, were built an early medieval church and its cemetery.

In c. 1870 , a grave was discovered under the building Birreria Nazionale, south of Via Sempione and west of Via G.B. Pioda, c. 8 metres below ground level. The grave contained a two-handled bronze bowl with moulded decoration and silver inlay and a bronze jug with a richly decorated handle. Both items are in the Salone Dorato of Museo Poldi Pezzoli, Milan (Ponti 1914, 36). In the same area, during the construction of the Cinema Pax, appeared other graves (Archive of Società del Museo di Locarno). In 1936, close to the Birreria Nazionale, were found two or three graves in the garden of Villa Buetti, situated along the river Gutta. The graves, consisting of stonelined enclosures with stone covers, were not excavated, and still lie in the ground (Crivelli 1938a, 21). 
In 1872-73, during the construction of the Grande Albergo, were found about 40 stone-lined graves c. 6-7 metres below ground level. Excavated by E. Balli, the graves contained rich grave-goods such as bronze items and glass. A small part of the grave-goods are kept in the Museo Civico, Locarno. The other items were scattered among private people or sold to the National Museum at Zürich at the beginning of this century (Gazzetta Ticinese, 9th April 1873, n. 83; Motta 1884b, 36; Baserga 1916, 68-9).

Towards the end of the 19th century on property Farinelli, along Via G. B. Pioda and east of the modern funicular station, was found a stone-lined grave with pottery, glass and bronze vessels (Pometta 1933, 4, 105-6). North of the same road, on property Gamba, during the construction of shops, appeared many stone-lined graves with pottery and coins. The items were lost (Bertolone 1939, 309).

The area between Via Gottardo and Via Bacilieri, which borders the river Rabissale to the east, was occupied by properties Meyster (close to Via Bacilieri) and Villa Liverpool (close to Via San Gottardo). The items from property Meyster were discovered during the construction of a greenhouse. Circumstances of discovery and context are unknown. The items carry catalogue numbers with indication of the year 1940. Villa Liverpool was first excavated by Simonett in 1936 ; here he discovered 66 graves. Other graves, whose grave-goods are today lost, appeared during work on Via Gottardo in the same area (Bertolone 1939, 314-15). In 1964, Crivelli recovered many grave-goods from the west corner of the park of Villa Liverpool between Via San Gottardo and Via San Carlo. The graves were destroyed during the construction of two buildings and the grave-goods today bear insufficient 
evidence of their context. Some items, however, seem to belong to cremations, whereas the majority came from inhumations. An emergency excavation was carried by the Ufficio dei Beni Culturali in 1984 on property Tommasi (parcel no. 226) south of Via San Gottardo, north of Via Francesca and east of the Via Ballerini. Five more graves were excavated. In area Dazio, north of Via San Gottardo and west of Via D'Alberti, Simonett recovered in 1936 grave-goods probably from cremations (Simonett 1941, 39). On property Villa Berta, south of the crossing between Via del Sole and Via Sciaroni, Simonett discovered in the same year walls and empty graves (Archive of the Ufficio dei Beni Culturali, Bellinzona).

Some grave-goods, now in the Historisches Museum, Bern, bear the provenance 'Orselina'. They were discovered in 1867 during the construction of Villa Liverpool (Tschumi 1927, 114) and sold to the Museum in 1874, when the area lay in the territory of Orselina. In 1936, Simonett also investigated properties Passalli and Branca, west of properties Meister and Villa Liverpool, and property Märki, north of property Meister. Here were discovered 53 graves (Passalli: 39 graves; Branca: 4 graves; Märki: 10 graves). The grave-goods recovered by Simonett in 1936 were brought to the Museo Civico, Locarno. They were then scattered at Lugano, Locarno and Bellinzona. Today, the grave-goods are kept at Locarno and Bellinzona. Some of them, however, were lost during the many movings and a group bears catalogue numbers, which cannot be identified in Simonett's publication. Simonett also recovered some items on property Fischer, north-east of the crossing between Via Santo Stefano and Via Municipio, where he discovered part of a building. Further details about the finds are unknown (Simonett 1941, 23; Baserga 1936, 41). In 
1895 were found many graves on property Maggetti, situated in the area called Canovacce, between Via Orselina, Vicolo dei Colli and Via Attilio Balli (Bertolone 1939, 315).

In 1945, twenty-one grave-goods discovered in property Fivian were recovered by Crivelli (Crivelli 1946b, 1221); some of them are today in the Museo Civico, Locarno. The property Fivian cannot be precisely localized.

In 1947, during the construction of a garage on property Biffoni, north of the railway station and south of Via Sempione, were discovered three cremations. Two graves were destroyed and only few grave-goods were recovered (Crivelli $1949,34)$. In 1984, during the construction of a multistorey car park by Piazza Stazione, Donati discovered remains of other buildings.

Bertolone $(1939,307-19)$ lists other areas or properties, where Roman graves were found, usually as consequence of building activities. In 1898, during the construction of the Chiesa Evangelica, and in 1906, during the construction of Casa Wellauer and Pensione Helvetia, were found several graves. In Via del Sole, during work in front of the Hôtel Pension Quisiana; were discovered a number of inhumations. During the construction of the new nursery school, east of San Vittore church, was found a stone-lined grave with some bones. The grave was similar to those excavated by the Grande Albergo. On a stone slab there was the inscription : P.F.S . E. (Magni 1902, 115). During work for the new cemetery, by the river Rabissale, was found a stone-lined grave. On a stone slab there was the inscripion: VIC REC F. (Motta 1884a, 292; Motta 1885, 135). During work to broaden Via Ballerini, by Villa Leoni, was found a stone-lined grave. The grave was empty. 


\section{The cemeteries}

Unfortunately, for all the great number of Roman graves found at Muralto, there exist detailed descriptions of grave-goods and structures only of the graves found on properties Passalli, Villa Liverpool sopra and sotto, Branca, Märki and Tommasi. The inhumations clearly outnumbered the cremations, as usually occurred in Roman cemeteries of Sopraceneri. This feature may be seen as a persistence of the Iron Age funerary habit typical for Sopraceneri, whereas Sottoceneri showed until rather late Roman times cremations only. The graves at Muralto represented few types of funerary structures. Both cremations and inhumations may occur as simple pits. Whereas this feature appeared in other cemeteries for cremations, it did not occur for inhumations. The second variant for cremations and inhumations is the dry-stone enclosure. Muralto does not seem to have the coffin-shaped grave with walls of stone-slabs as at Losone and Solduno, except for the five inhumations on property Tommasi. These graves, however, consisted of chambered graves with dressed stone slabs or walls and flat tiles; they date to the 4th century $A D$, whereas the other graves date to the 1 st century $A D$ and the first half of the 2 nd century $A D$. Another unusual structure, among the earlier graves, is Grave 33 on property Villa Liverpool sotto, which consisted of a chambered grave with dressed walls and an adjoining chamber for the grave-goods. This grave is closely paralleled at Minusio-Cadra.

The contents of cremations seem not to differ from those of inhumations in the number and type of grave-goods. They consisted of Italian sigillata, coarse and thin walled pottery, coins, and bronze and iron items. Glass, however, did not occur often in cremations, but was common in inhumations. In particular, 
many balsamaria occurred frequently in each grave. The scarcity or absence of glass in the cremations could result from the usual poor preservation of the grave-goods.

Except for the grave group on property Tommasi, all other graves have a terminus post quem in the 1st century $A D$ or in the first half of the 2nd century AD. The horizontal stratigraphy of these graves, however, does not indicate the development of the cemeteries. This matter needs to be considered again after closer study of the remains in the neighbouring territories of Locarno and Minusio.

\section{Topography of settlement and cemeteries}

Muralto has the only remains so far found of a Roman settlement in Sopraceneri. Some remains were also identified by Crivelli at Tegna (Terre di Pedemonte, lower Valle Maggia), but further information is not available. A clear view of the Locarnese in Roman times still needs closer investigation. There are too many areas which have been only partly or badly excavated, and it is therefore impossible to trace the boundaries of settlements and cemeteries.

The distribution map of Roman remains at Muralto, however, shows clearly that the settlement was close to the lake, whereas the cemeteries were situated behind the settlement, at the foot of the hills. The buildings that belonged to the public area of the vicus were crossed by part of the Via Francesca, which continues today to the north-east and joins Via San Gottardo by the river Rabissale. South of the buildings were discovered the remains of houses. Another interesting element seems to be the distribution of 
the cemeteries along the roads and not far away from the settlement, as was the Roman custom.

\section{Publication of cemeteries and settlement}

The cemeteries on properties Villa Liverpool, Passalli, Branca and Märki, investigated in 1936 by Simonett, were studied and published in 1941 (Simonett 1941). There exist only short preliminary reports about the discoveries of parts of the Roman settlement in 1947 in Via Scazziga (Crivelli 1953) and in 1982-1992 in the area Park Hôtel (Donati 1983a). The information about all other discoveries is limited to simple notes or rough lists of grave-goods. Furthermore, no study of the distribution of settlement and cemeteries in the area and their implications has yet been published.

\section{List of graves}

Here is given a list of the graves, whose grave-goods still bear the original associations. Simonett $(1941,59 ; 69)$ divided the graves investigated on property Villa Liverpool in two groups: Villa Liverpool sopra and Villa Liverpool sotto. The first group consists of 15 graves found north of the building Villa Liverpool. To the second group belong 51 graves situated south of the building, along Via San Gottardo and Via San Carlo.

The grave-goods without any association are only listed and grouped according to type or class. 


\section{Muralto, property Passalli (1936)}

The 39 graves consisted of 15 cremations and 24 inhumations. Cremations and inhumations were both simple pits or stone-lined. Twelve inhumation were orientated north-south; five were orientated east-west.

\begin{tabular}{|c|c|c|}
\hline Grave 1 & inhumation & c. $A D 70-120$ \\
\hline Grave 2 & inhumation & -- ; no datable items \\
\hline Grave 3 & inhumation & c. AD 50-100 \\
\hline Grave 4 & inhumation & c. $A D$ 15-65 \\
\hline Grave 5 & inhumation & c. $A D 10-60$ \\
\hline Grave 6 & inhumation & c. AD 10-60 \\
\hline Grave 7 & inhumation & -- \\
\hline Grave 8 & inhumation & -- ; no grave-goods \\
\hline Grave 9 & inhumation & c. AD 50-100 \\
\hline Grave 10 & inhumation & c. AD 50-100 \\
\hline Grave 11 & inhumation & -- ; no grave-goods \\
\hline Grave 12 & cremation & c. AD 50-100 \\
\hline Grave 13 & cremation & -- \\
\hline Grave 14 & inhumation & c. AD $20-70$ \\
\hline Grave 15 & cremation & c. $A D 0-50$ \\
\hline Grave 16 & cremation & c. $A D 70-120$ \\
\hline Grave 17 & cremation & -- ; no datable items \\
\hline Grave 18 & cremation & -- ; no datable items \\
\hline Grave 19 & cremation & -- ; no grave-goods \\
\hline Grave 20 & inhumation & - ; no datable items \\
\hline Grave 21 & inhumation & - \\
\hline
\end{tabular}




$\begin{array}{lll}\text { Grave 22 } & \text { inhumation } & \text { c. AD 20-70 } \\ \text { Grave 23 } & \text { inhumation } & - \text {; no datable items } \\ \text { Grave 24 } & \text { cremation } & \text { c. AD 14-60/70 } \\ \text { Grave 25 } & \text { inhumation } & \text { c. AD 70-120 } \\ \text { Grave 26 } & \text { inhumation } & \text { c. AD 70-120 } \\ \text { Grave 27 } & \text { cremation } & - \text { - } \\ \text { Grave 28 } & \text { inhumation } & \text { c. AD 100-150 } \\ \text { Grave 29 } & \text { inhumation } & \text { c. AD 50-100 } \\ \text { Grave 30 } & \text { inhumation } & \text { c. AD 70-120 } \\ \text { Grave 31 } & \text { inhumation } & - \text { - ; no datable items } \\ \text { Grave 32 } & \text { cremation } & - \text {; no grave-goods } \\ \text { Grave 33 } & \text { inhumation } & \text { c. AD } 80-130 \\ \text { Grave 34 } & \text { cremation } & - \text {; no datable items } \\ \text { Grave 35 } & \text { cremation } & -- \text {; no grave-goods } \\ \text { Grave 36 } & \text { cremation } & - \text {; no datable items } \\ \text { Grave 37 } & \text { inhumation } & \text { c. AD 70-120 } \\ \text { Grave 38 } & \text { inhumation } & - \text {; no datable items } \\ \text { Grave 39 } & \text { cremation } & \text { c. AD 70-120 }\end{array}$

Muralto, property Villa Liverpool sopra (1936)

The 15 graves consisted of three cremations and 12 inhumations. The cremations were simple pits; the inhumations were stone-lined or simple pits. Two inhumations were orientated north-south and five were orientated eastwest. 


$\begin{array}{lll}\text { Grave } 1 & \text { cremation } & \text { c. AD 50-100 } \\ \text { Grave } 2 & \text { cremation } & -- \\ \text { Grave } 3 & \text { inhumation } & \text { C. AD 70-120 } \\ \text { Grave 4 } & \text { inhumation } & \text { c. AD 20-50 } \\ \text { Grave 5 } & \text { inhumation } & \text { c. AD 70-120 } \\ \text { Grave 6 } & \text { inhumation } & \text { c. AD 70-120 } \\ \text { Grave 7 } & \text { inhumation } & \text { c. AD 70-120 } \\ \text { Grave 8 } & \text { inhumation } & \text { c. AD 79-100 } \\ \text { Grave 9 } & \text { inhumation } & \text {-- ; no grave-goods } \\ \text { Grave 10 } & \text { inhumation } & \text { c. AD 37-80 } \\ \text { Grave 11 } & \text { inhumation } & \text { c. AD 20-70 } \\ \text { Grave 12 } & \text { inhumation } & \text { c. AD 80-100 } \\ \text { Grave 13 } & \text { inhumation } & \text {-- ; no datable items } \\ \text { Grave 14 } & \text { inhumation } & \text { c. AD 100-130 } \\ \text { Grave 15 } & \text { cremation } & \text { - ; no datable items }\end{array}$

\section{Muralto, property Villa Liverpool sotto (1936)}

The 51 graves consisted of 10 cremations and 41 inhumations. All cremations were simple pits; the inhumations were stone-lined or simple pits. Nine inhumations were orientated north-south and 30 were orientated east-west. Grave 33 was a chambered grave with stone dressed walls and adjoining chamber.

Grave 1 cremation -

$\begin{array}{lll}\text { Grave } 2 & \text { inhumation } & \text { c. AD 70-120 } \\ \text { Grave } 3 & \text { inhumation } & \text { c. AD 100-150 }\end{array}$




\begin{tabular}{|c|c|c|}
\hline Grave 4 & inhumation & c. $A D 60-100$ \\
\hline Grave 5 & inhumation & c. $A D 22 / 3-70$ \\
\hline Grave 6 & inhumation & c. $A D 70-120$ \\
\hline Grave 7 & inhumation & c. $A D 70-120$ \\
\hline Grave 8 & inhumation & c. $A D 70-120$ \\
\hline Grave 9 & inhumation & c. AD 34-70 \\
\hline Grave 10 & inhumation & c. $A D 30-80$ \\
\hline Grave 11 & inhumation & c. AD $20-70$ \\
\hline Grave 12 & inhumation & c. $A D 30-60$ \\
\hline Grave 13 & inhumation & c. $A D 14 / 5-30$ \\
\hline Grave 14 & inhumation & c. $A D 41-80$ \\
\hline Grave 15 & inhumation & c. $A D 70-120$ \\
\hline Grave 16 & inhumation & c. $A D 70-120$ \\
\hline Grave 17 & inhumation & c. $A D 70-120$ \\
\hline Grave 18 & cremation & c. $A D 80-130$ \\
\hline Grave 19 & inhumation & c. $A D 70-120 / 30$ \\
\hline Grave 20 & inhumation & c. AD $50-100$ \\
\hline Grave 21 & inhumation & c. $A D$ 125/6-150 \\
\hline Grave 22 & cremation & — ; no grave-goods \\
\hline Grave 23 & inhumation & c. $A D 70-120$ \\
\hline Grave 24 & inhumation & c. $A D 50-100$ \\
\hline Grave 25 & inhumation & c. $A D$ 37/8-70 \\
\hline Grave 26 & inhumation & c. $A D 50-80$ \\
\hline Grave 27 & inhumation & c. AD $98-150$ \\
\hline Grave 28 & cremation & - \\
\hline
\end{tabular}




$\begin{array}{lll}\text { Grave } 29 & \text { cremation } & - \\ \text { Grave } 30 & \text { inhumation } & - \text {; no datable items } \\ \text { Grave } 31 & \text { cremation } & -- \\ \text { Grave } 32 & \text { inhumation } & \text { c. AD 41-80 } \\ \text { Grave 33 } & \text { inhumation } & \text { c. AD } 36 / 7-70 \\ \text { Grave 34 } & \text { inhumation } & \text { c. AD } 81-130 \\ \text { Grave 35 } & \text { inhumation } & \text { c. AD 50-100 } \\ \text { Grave 36 } & \text { cremation } & - \text {; no datable items } \\ \text { Grave 37 } & \text { inhumation } & \text { c. AD 37/8-70 } \\ \text { Grave 38 } & \text { inhumation } & \text { c. AD 40-70 } \\ \text { Grave 39 } & \text { inhumation } & \text { c. AD 41-90 } \\ \text { Grave 40 } & \text { inhumation } & \text { c. AD 70-120 } \\ \text { Grave 41 } & \text { inhumation } & \text { c. AD 22/3-70/80 } \\ \text { Grave 42 } & \text { inhumation } & \text { c. AD 161-200 } \\ \text { Grave 43 } & \text { inhumation } & \text { c. AD 40-70 } \\ \text { Grave 44 } & \text { inhumation } & \text { c. AD 41-80 } \\ \text { Grave 45 } & \text { cremation } & - \text { - ; no grave-goods } \\ \text { Grave 46 } & \text { inhumation } & \text { c. AD 22/3-70/80 } \\ \text { Grave 47 } & \text { inhumation } & - \text {; no datable items } \\ \text { Grave 48 } & \text { inhumation } & \text { c. AD 40-80 } \\ \text { Grave 49 } 50 & \text { inhumation } & \text { c. AD 23-60/70 } \\ \text { cremation } & -- \\ \text { cremation } & - \text { - } \text { no datable items }\end{array}$




\section{Muralto, property Villa Liverpool and Via San Carlo (1964)}

Crivelli, who recovered the grave-goods, divided the items into 31 bags associated with cards listing the contents. Therefore, it is possible to suppose that each bag corresponded to a grave. In this case, the 31 graves consisted of four cremations and 27 inhumations. The circumstances of discovery of the graves, the removal of items from Locarno to Bellinzona and to different places at Bellinzona, and a certain inconsistency in the information on the cards, however, suggests that some grave-goods may have been mixed or lost. Therefore, these grave-goods will not be considered in the associations proposed by Crivelli.

The datable grave-goods suggest a date of these graves between the 1st century $A D$ and the first half of the 2 nd century $A D$. They consisted of Italian sigillata (Conspectus Forms $3,4,8,18,20-22,27,29,34,36,39,47,49$ ) and glass (Isings Forms 6, 8, 10, 28, 42).

\section{Muralto, property Tommasi (1984)}

The five graves were east-west orientated inhumations. Four had walls of stone slabs and flat tiles and stone covers; Grave 5 was a chambered one with stone dressed walls. Grave 2 bore an adjoining chamber with stone dressed walls.

$\begin{array}{lll}\text { Grave } 1 & \text { inhumation } & \text { c. AD } 330-80 \\ \text { Grave } 2 & \text { inhumation } & \text { c. AD } 330-80 \\ \text { Grave } 3 & \text { inhumation } & \text { c. AD } 351-80 \\ \text { Grave } 4 & \text { inhumation } & \text { c. AD } 321-70 \\ \text { Grave } 5 & \text { inhumation } & \text { c. AD } 350-80\end{array}$




\section{Muralto, property Branca (1936)}

The four graves consisted of one cremation and three inhumations. The structure of the graves is similar to that of the graves found in other areas. All inhumations were orientated east-west.
Grave 1
inhumation
c. $A D 41-80$
Grave 2
inhumation
c. $A D$ 20-70
Grave 3
cremation
- ; no datable items

Grave 4

inhumation

\section{Muralto, property Meyster}

The associated datable grave-goods like sigillata and glass may be dated to the 1st century $A D$ and the first half of the 2 nd century $A D$.

\section{Muralto, property Märki (1936)}

The 10 graves consisted of five cremations and five inhumations. Both cremations and inhumations were simple pits or were stone-lined. Two inhumations were orientated north-south and three were orientated east-west.
Grave 1
cremation
C. $A D 70-120$
Grave 2
cremation
c. $A D 50-80$

Grave 3

cremation

Grave 4

cremation

Grave 5

inhumation

Grave 6

inhumation

c. $A D 101 / 2-140$

Grave 7

inhumation

-- ; no grave-goods

Grave 8

inhumation

- ; no grave-goods 

Grave 9
inhumation
c. $A D 70-120 / 30$
Grave 10
cremation
-- ; no datable items

Muralto, property Maggetti/Canovacce (1895)

Cemetery. Contexts unknown.

Muralto, once Orselina (Bern, Historisches Museum)

Cemetery. Contexts unknown.

Muralto, Dazio (Simonett, 1936)

Simonett recovered two bowls, probably from destroyed cremations.

Muralto, property Farinelli (end 19th century)

Cemetery. Contexts unknown.

Muralto, Grande Albergo (1873-74)

Cemetery. Contexts unknown.

The associated datable grave-goods like sigillata and glass may be dated to the 1 st century $A D$ and the first half of the $2 n d$ century $A D$. 


\section{The settlement}

\section{Muralto, Via Scazziga (1947)}

The remains of a Roman villa partly under the railway station of Muralto were excavated by Aldo Crivelli in 1947. He explored the area in Via Vittore Scazziga, south of the station, and discovered part of the baths of a villa with calidarium, tepidarium and frigidarium (c. $15 \times 13 \mathrm{~m}$ ). Crivelli reported the discovery of some pottery ('cocciame interessante'), a coin of Magnentius, fragments of window pane and of glass vessels in the calidarium (Crivelli $1949,34-5$; Crivelli 1953, 190-93). He dated the structure to the end of the 1st century AD. The presence of a coin of Magnentius, however, allows one to suppose that the house may have been in use in later times. Unfortunately, further details of excavation and stratigraphy do not exist. In the 1980s, the Ufficio dei Beni Culturali brought to light other parts of walls, probably belonging to the same villa, from under Via Collegiata situated north of Via Vittore Scazziga and south of the area of Park Hotel.

\section{Muralto, Park Hotel (1982-85)}

The area between Via Collegiata and Via Sempione, once occupied by the Park Hotel, was excavated in 1982-85. The excavations of 1982 and 1982/83 brought to light a group of buildings and a bath. Donati (1983a, 120-36 ; Drack \& Fellmann 1988, 449-50) identified ten phases of development, ranging from the last decades of the 1 st century $B C$ to the 17 th century $A D$. To the first phase, dated c. $20 \mathrm{BC}-\mathrm{AD} 10$, belong four rectangular buildings (c. $3.5 \times 2.2 \mathrm{~m}$ and $5.2 \times 3.7 \mathrm{~m}$ ) and a drain. The successive phases see the expansion of the buildings towards the south and north-west, the reorganization of the network 
of drains and the presence of new roads including a pavement. Afterwards, to the west the ancient buildings were destroyed and the ground levelled. The northern half of this area was occupied by houses, whereas other structures were built in the southern half. Among them was a public building with internal subdivisions. At the end of the 2 nd century $A D$, these buildings were destroyed and instead was built a two-nave structure (c. $35 \times 18 \mathrm{~m}$ ) with internal subdivisions, containing different shops and workshops for glass, bronze, etc. North of this craft centre were built baths, with three rooms (c. $14 \times 6 \mathrm{~m}$ ) : a changing room (apodyterium) with two benches along the walls, a frigidarium in the apse and a caldarium with hypocaust. On the eastern side of the site was built a temple (fanum); houses lay to the north-east and bigger houses to the south. All structures, the craft centre and the baths seem to have been in use until the beginning of the 5th century AD. During the 5th-6th century AD the area was occupied by a cemetery; in the 6th-7th centuries was built the church of Santo Stefano, destroyed in 1911.

The excavations of 1984 and 1985 investigated the area to the south of that excavated in 1982 and 1982/83. Foundations of houses and other buildings, and a circular structure were discovered. This structure occupied the western end of the investigated area. It measured c. $200 \mathrm{~m}$ in diameter and shows to the north an opening (c. $1.50 \mathrm{~m}$ ) with stairs ; a suggested function is that of an arena (Drack \& Fellmann 1988, 450).

During the excavations different artefacts came to light: coins, tools, jewellery, glass and pottery (Donati 1983, 128-9). From the excavated area, however, no complete vessel was found, but many fragments of vessels (among them that of a millefiori cup) and of frit, indicating the possible presence of kilns. 
According to the reports, all classes of pottery were represented : Campanian ware (with few fragments), Italian sigillata, thin walled pottery and coarse ware. Amphorae also occurred, unknown in the funerary contexts. Except for a small number of vessels, in particular Campanian and sigillata wares, immediately studied because of their dating evidence, the thin walled and coarse pottery are still not accessible for study.

\section{Locarno-Solduno}

Solduno, AK 703500/114200, lies on the left side of the river Maggia on a wide terrace at $220-225 \mathrm{~m}$ asl. A hundred years ago Solduno was an independent municipality; today it belongs to the town of Locarno.

The Roman cemetery of Solduno lies at the foot of the mountain, between the modern cemetery of Locarno to the east and the cemetery of Solduno to the west. The main group of Roman graves lay north of Via Vallemaggia, whereas some Roman graves and an Iron Age cemetery were situated south of the road. Like the modern settlement, both cemeteries were situated on a terrace at c. $225 \mathrm{~m}$ asl, sheltered from the floods of the Maggia and variations of lake level. At the same height asl were situated the other cemeteries to the east of river Maggia: Locarno-Muralto and Minusio. South of the Iron Age and Roman cemeteries, in Via San Jorio, was a Late Bronze Age cemetery. Although links to the Bronze Age and the Iron Age cemeteries have not been found yet, the horizontal stratigraphy of the cemeteries of Solduno seems to go northwards. The Bronze Age cemetery lay to the south, at $200 \mathrm{~m}$ asl. About $800 \mathrm{~m}$ to the north was the Iron Age cemetery at $210-220 m$ asl. Directly north of the Iron 
Age graves, and sometimes mixed with them, were the Roman graves, reaching to the foot of the hills.

\section{Circumstances of discovery}

The position of the cemetery allows one to suppose that some graves were destroyed during the works for the two modern cemeteries. Investigation of the cemetery and the study of its finds started in 1936. The economic crisis of the thirties caused an increase in unemployment. To reduce the unemployment rate in Switzerland, groups of volunteers were organized to carry out archaeological research. These groups excavated in LocarnoSolduno, Locarno-Muralto, Minusio and Stabio in 1936 and 1937 under the supervision of Christoph Simonett (Simonett 1941).

Simonett discovered in Via al Passetto seven graves dated to the Iron Age (Graves A1-A7; Simonett 1941, 37-9). The investigation was carried on by Crivelli in 1938 in the same area (Graves B1-B15; Crivelli 1938c, 49-53), who excavated 15 La Tène and four Roman graves. In the same and the following years other properties were investigated by Crivelli. In 1938 were found 55 graves in the property Ardito (Graves C1-C55), to the east of Via al Passetto. Twenty more graves were excavated north of the main road linking Solduno to Locarno, in the properties Balli (Graves Ba1-Ba11), Bonetti (Graves Bo1-Bo5) and Pedrotta (Graves Pe1-Pe4) (Silvestrini 1942, 582). In 1939 in the property Ardito were discovered another 57 graves (Graves D1-D57). The investigation of the neighbouring property Botta in 1946 and 1946 yielded 32 graves (E1E17 and F1-F15). In 1948 and 1949 another seven graves were found in the property Isolino SA (Graves $\mathrm{G} 1-\mathrm{G} 2$ and $\mathrm{H} 1-\mathrm{H} 5$ ), east of the former group. In 
the properties Buffi (1950; Graves 11-12), Boccadoro (1952; Graves J1-J31), Ceschi (1953; Graves K1-K8) and Bui (1955; Graves L1-L16), close to Via al Passetto, were excavated 67 graves between 1950 and 1955.

From 1956 to 1958 , twenty-two more graves were discovered during works for the enlargement of the modern cemetery of Solduno (1956: Graves 56.1-56.2; 1957: Graves 57.1-57.10; 1958: Graves 58.11-58.20).

Donati excavated seven graves in 1976 in the area of church San Carlo at Locarno (Graves 76.1-76.7). Another grave was discovered in the area of the modern cemetery of Solduno in 1980 (Grave 80.1; Donati 1963, 63-74).

\section{The graves}

The cemetery of Solduno consisted in all of 280 graves; 59 of them were Roman, the other $\mathbf{2 2 9}$ dated to the Iron Age.

Of the Roman graves, fifty were inhumations. The main group consisted of unmortared stone-lined graves by stone slabs. The few exceptions were two coffins made of large stone slabs (Graves 76.1 and 76.6), a coffin made of flat tiles with flat roof of flat and bent tiles (Grave 76.2) and a coffin of flat tiles with sloping roof of flat and bent tiles ('alla cappuccina', Grave 76.4). To the latter belonged a separate store annex for the objects. The inhumations were usually orientated on an east-west axis; only few examples were orientated north-south.

The main group of cremations was situated to the east of the modern cemetery of Solduno. Seven cremations were simply in earth (Graves Bo 2, C $3,57.1,57.2,57.3,57.4,57.5)$. Graves 57.6 and 76.3 consisted of a box of 
stone slabs and, respectively, of flat tiles. In the group of graves excavated in 1957, the cremation 57.5 overlay the inhumations 57.7 and 57.8 .

Both cremations and some inhumations were accompanied by a small amount of glass, Italian sigillata and coarse pottery. Therefore, it seems to be impossible to distinguish them according to their content. The inhumations excavated in 1958 , however, usually bore rich grave-goods of sigillata, glass, coins, iron and bronze items.

\section{Publication of the cemetery}

The Roman cemetery was published first in 1979 and reprinted in 1988 (Donati 1988). The finds are now in the Ufficio dei Beni Culturali, Bellinzona.

\section{List of graves}

The numbering of graves is progressive according to the excavated areas. A capital letter or a group of letters before the catalogue number indicated the property and the year of discovery. The numbering of Roman graves within each area is not always in succession because some excavated graves are dated to the Iron Age. 
The following table gives the concordance of graves' code, property, year of discovery and chronology of graves.

\section{Code}

A

B

$\mathrm{Ba}$

Bo

$\mathrm{Pe}$

C

D

E

$\mathrm{F}$

G

H

\section{1}

$J$

K

L

56.

57.

58.

Property
via al Passetto
via al Passetto

Balli

Bonetti

Pedrotta

Ardito

Ardito

Botta

Botta

Isolino S. A.

Isolini S. A.

Buffi

Boccadoro

Ceschi

Bui

cemetery of Solduno 1956

cemetery of Solduno 1957

cemetery of Solduno 1958

\section{Chronology}

Iron Age

Iron Agel

Roman

Roman

Iron Agel

Roman

Roman

Iron Age/

Roman

Iron Age

Iron Age

Iron Age

Iron Age

Iron Age

Iron Age

Iron Age/

Roman

Iron Age/

Roman

Iron Age

Roman

Roman

Roman 
76.

cemetery of Locarno 1976

Roman

80.

cemetery of Solduno 1980

Roman

Solduno, via al Passetto (1938)

$\begin{array}{lll}\text { Grave B1 } & \text { inhumation } & \text { c. AD 70-120 } \\ \text { Grave B2 } & \text { inhumation } & \text { c. AD 50-100 } \\ \text { Grave B3 } & \text { inhumation } & \text { c. AD 50-100 } \\ \text { Grave B10 } & \text { inhumation } & \text { c. AD 40-90 }\end{array}$

Solduno, property Balli (1938)

Grave Ba1 inhumation --- ; no datable items

Grave $\mathrm{Ba} 2$ inhumation c. AD 50-100

Grave $\mathrm{Ba} 3$ inhumation c. AD 40-60

Grave Ba4 inhumation c. AD 50-100

Grave Ba5 inhumation --- ; no datable items

Grave Ba6 inhumation c. AD 41-80

Grave Ba7 inhumation ---

Grave Ba8 inhumation c. AD $30-80$

Grave Ba9 inhumation c. AD 30-70

Grave Ba10 inhumation -- ; no grave-goods

Grave Ba11 inhumation ---

Solduno, property Bonetti (1938)

Grave Bo1 inhumation --- ; no datable items

Grave Bo2 cremation --- ; no datable items 
Solduno, property Ardito (1938)

$\begin{array}{lll}\text { Grave C3 } & \text { cremation } & \text { c. AD 70/80-120/30 } \\ \text { Grave C26 } & \text { inhumation } & \text { c. AD 69-120 } \\ \text { Grave C28 } & \text { inhumation } & \text { c. AD 69-120 }\end{array}$

Solduno, property Pedrotta (1938)

Grave Pe1 inhumation C. AD 0-30

Grave $\mathrm{Pe} 2$ inhumation $\quad$ c. $\mathrm{AD}$ 0-30

Grave Pe3 inhumation --- ; no datable items

Grave Pe4 inhumation _.- ; no datable items

Solduno, property Boccadoro (1952)

Grave J25 inhumation c. AD 70-120

Solduno, property Ceschi (1953)

$\begin{array}{lll}\text { Grave K1 } & \text { inhumation } & --- \text {; no grave-goods } \\ \text { Grave K2 } & \text { inhumation } & \text { C. AD 20-70 } \\ \text { Grave K3 } & \text { inhumation } & \text { c. AD 70-120 } \\ \text { Grave K6 } & \text { inhumation } & \text { c. AD 70-120 }\end{array}$

Solduno, Modern cemetery (1956)

Grave 56.1 inhumation c. AD 50-100

Grave 56.2 inhumation c. AD 50-100 


\section{Solduno, Modern cemetery (1957)}

Grave $57.1 \quad$ cremation --- ; no datable items

Grave 57.2 cremation -- ; no datable items

Grave $\mathbf{5 7 . 3}$ cremation --

Grave $57.4 \quad$ cremation $\quad--$

Grave $\mathbf{5 7 . 5}$ cremation ---

Grave 57.6 cremation --- ; no datable items

Grave 57.7 inhumation _--

Grave 57.8 inhumation --- ; no datable items

Grave 57.9 inhumation $\quad$ c. AD 179-230

Grave 57.10 inhumation c. AD 70-120

Solduno, Modern cemetery (1958)

Grave 58.11 inhumation c. AD 50-100

Grave 58.12 inhumation c. AD 70-120

Grave 58.13 inhumation c. AD 70-120

Grave 58.14 inhumation _-.

Graves 58.15 inhumation ---

Grave 58.16 inhumation c. AD 70-120

Grave 58.17 inhumation c. AD 77/78-100

Grave 58.18 inhumation c. AD 81-130

Grave 58.19 inhumation c. AD 69-120

Grave 58.20 inhumation c. AD 70-120 


\section{Solduno, Modern cemetery (1976)}

Grave 76.1 inhumation

Grave 76.2 inhumation c. AD 200-250

Grave 76.3 cremation c. AD 200-250

Grave 76.4 inhumation $\quad$ c. AD 117-50

Grave 76.5 inhumation _--; no datable items

Grave 76.6 inhumation ---

Grave 76.7 inhumation --- ; no datable items

Solduno, Modern cemetery (1980)

Grave $80.1 \quad$ inhumation _..- ; no datable items

\section{Dating of the cemetery}

The dated finds from the Roman graves of Solduno run from the beginning of the 1 st century AD to the first half of the 3rd century AD. The main part of the Roman cemetery is situated north of the cantonal road, linking Solduno to Locarno. The area south of the road is occupied predominantly by the La Tène cemetery, which seems to run chronologically from west to east (Donati 1988, plan). The few Roman graves in this area are situated in Via al Passetto (Graves B 1-3; B 10) and in the properties Ardito (Graves C 3; C 26; C 28), Boccadoro (Grave J 25) and Ceschi (Graves K 1-3; K 6). They lay south of the La Tène $B_{2}$ graves and east of the graves dated to the end of the 1st century BC. Their suggested dates belong within the period C. AD 70-120.

To the north of the cantonal road, the Roman graves in the properties Balli (Graves Ba 1-11), Bonetti (Graves Bo 1-2) and Pedrotta (Graves Pe 1-4) are 
situated to the west of the graves dated to the end of the 1st century BC. Their suggested dates belong within the 1st century $A D$, from the first quarter (graves in property Pedrotta) to the second half (graves in the properties Balli and Bonetti).

All graves excavated in $1956 / 57 / 58$ and 1980 near the modern cemetery of Solduno are Roman. Their suggested dates range from Flavian times to the first quarter of the 2 nd century $A D$. According to the dated items, the main group including the graves with rich grave-goods belongs to the second half of the 1st century $A D$.

The graves excavated in 1976 near the church of San Carlo at Locarno seem to date from the 2 nd and the 3 rd centuries $A D$. The content of late forms of glass and of glazed pottery, the particular structure of the graves and the position to the east of the area allow one to assume a much later date in comparison to the rest of the cemetery. As for Ascona, it is possible to take a longer view of the chronology than that of Donati (1988).

\section{Losone}

Losone, AK 702000/113500, lies on the west side of river Maggia at 210$220 \mathrm{~m}$ asl. Its territory borders today Ascona to the south and reaches the river Melezza to the north. Losone faces Solduno, situated on the opposite side of river Maggia. 


\section{Losone-Arcegno}

Arcegno, AK $700900 / 113050$, is an outlying division of the municipality of Losone, about one kilometre distant. It lies west of Losone, on a wide slope at $387 \mathrm{~m}$ asl and is surrounded by hills. To the south of Arcegno, 0.5 kilometre away, is situated Balladrüm at $483 \mathrm{~m}$ asl, with prehistoric remains (Iron Age). The Roman cemetery lay at $380 \mathrm{~m}$ asl, on the terrace to the south of the church, and occupied an area of about six hundred square metres. Arcegno is about 1.5 kilometres from the lake and 4.5 kilometres from Locarno.

\section{Circumstances of discovery}

In 1930s, works for the modern road linking Arcegno to Losone destroyed some Roman graves. Their grave-goods were lost or became private property (Crivelli 1943, 75), but their presence was reported in the newspaper Avanguardia (1934/35). Some Roman pottery appeared again in 1970 during building works. The Ufficio dei Beni Culturali was informed and in the same year investigated eighty-seven graves. Another ten graves were excavated in 1972 , reaching the boundary of the Roman cemetery.

\section{The graves}

All 97 were inhumations and consisted of unmortered stone-lines graves or stone slabs set vertically covered by stone covers. They are distributed irregularly in the area and earlier graves are frequently cut by later ones. Most of the graves are orientated east-west. One group, however, was orientated north-south. 


\section{Publication of the cemetery}

The cemetery was partly studied by the late P. Donati, who compiled a simple catalogue of finds (unpublished). Catalogue and description of the graves excavated in 1972 (Graves $3,5,88,91,93,94,96,97$ ) were published by $P$. Donati (Donati 1974, 63-84). The items are now in the Ufficio dei Beni Culturali, Bellinzona.

\section{List of graves}

Grave 1 inhumation --- ; no datable items

Grave 2 inhumation c. AD 70-100

Grave 3 inhumation c. AD 70-120

Grave 4 inhumation c. AD 154-80

Grave 5 inhumation $\quad$ c. AD 231-50

Grave 6 inhumation c. AD 0-50

Grave $7 \quad$ inhumation $\quad-$; no datable items

Grave 8 inhumation c. AD 194-210

Grave 9 inhumation c. AD 161-80

Grave $10 \quad$ inhumation --- ; no grave-goods

Vertical stratigraphy : later than grave 9

(c. AD 161-80)

Grave 11 inhumation _-- ; no grave-goods

Grave 12 inhumation c. AD 180-200

Grave 13 inhumation --- ; no grave-goods

Grave 14 inhumation c. AD 161-90

Grave 15 inhumation c. AD 98-140 


\begin{tabular}{|c|c|c|}
\hline Grave 16 & inhumation & c. $A D 119-40$ \\
\hline Grave 17 & inhumation & c. AD $50-100$ \\
\hline Grave 18 & inhumation & c. AD $86-110$ \\
\hline Grave 19 & inhumation & c. AD $85-100$ \\
\hline Grave 20 & inhumation & c. AD $235-50$ \\
\hline Grave 21 & inhumation & c. AD $40-70$ \\
\hline Grave 22 & inhumation & --- ; no datable items \\
\hline Grave 23 & inhumation & c. $A D 80 / 81-130$ \\
\hline Grave 24 & inhumation & c. AD $210-30$ \\
\hline Grave 25 & inhumation & -- ; no datable items \\
\hline Grave 26 & inhumation & c. AD $80 / 81-100$ \\
\hline Grave 27 & inhumation & c. $A D 244-60$ \\
\hline Grave 28 & inhumation & c. AD 235-50 \\
\hline Grave 29 & inhumation & c. $A D$ 50-100 \\
\hline Grave 30 & inhumation & c. $A D 80 / 81-100$ \\
\hline Grave 31 & inhumation & c. AD $229-50$ \\
\hline Grave 32 & inhumation & c. AD $180-230$ \\
\hline Grave 33 & inhumation & c. AD 167-90 \\
\hline Grave 34 & inhumation & c. AD 86-110 \\
\hline Grave 35 & inhumation & --- ; no datable items \\
\hline Grave 36 & inhumation & --- ; no datable items \\
\hline Grave 37 & inhumation & -- ; no datable items \\
\hline
\end{tabular}

Vertical stratigraphy : later than grave 38 (c. AD 0-50)

Grave 38 inhumation c. AD 40-60 
$\begin{array}{lll}\text { Grave } 39 & \text { inhumation } & \text { c. AD 180-230 } \\ \text { Grave 40 } & \text { inhumation } & --- \text {; no datable items }\end{array}$

Vertical stratigraphy : later than grave 39

(c. AD 180-230), grave 41 (c. AD 375-400)

(d. and grave 44 (no grave-goods)

Grave 41 inhumation

c. $A D 375-400$

Grave 42

inhumation

-- ; no datable items

Vertical stratigraphy : later than grave 43

(no grave-goods)

Grave 43

inhumation

--- ; no grave-goods

Vertical stratigraphy : earlier than grave 42 (no grave-goods)

Grave $44 \quad$ inhumation --- ; no datable items

Vertical stratigraphy : earlier than grave 40 (no datable items)

Grave 45 inhumation --- ; no grave-goods

Grave 46 inhumation c. AD 80/81-130

Grave 47 inhumation c. AD 141-60

Grave 48 inhumation c. AD 244-60

Grave 49 inhumation c. AD 179-200

Grave 50 inhumation c. AD 244-60

Grave $51 \quad$ inhumation $\quad-.-$; no datable items

Vertical stratigraphy : later than grave 55

(c. AD 235-50) and possibly contemporary to grave 52 (no datable items)

Grave 52 inhumation --- ; no datable items

Vertical stratigraphy : later than grave 57

(c. AD 235-50) and possibly contemporary to grave 51 (no datable items) 


\begin{tabular}{|c|c|c|}
\hline Grave 53 & inhumation & c. AD 193-210 \\
\hline \multirow[t]{3}{*}{ Grave 54} & inhumation & --- ; no grave-goods \\
\hline & & Vertical stratigraphy : \\
\hline & & (c. AD 243-60) \\
\hline Grave 55 & inhumation & c. AD $235-50$ \\
\hline Grave 56 & inhumation & -.- ; no grave-goods \\
\hline Grave 57 & inhumation & c. $A D 235-50$ \\
\hline Grave 58 & inhumation & c. $A D 231-50$ \\
\hline Grave 59 & inhumation & c. AD $222-50$ \\
\hline Grave 60 & inhumation & c. $A D 383-400$ \\
\hline Grave 61 & inhumation & c. $A D 243-60$ \\
\hline Grave 62 & inhumation & c. AD $183-230$ \\
\hline Grave 63 & inhumation & c. $A D 244-60$ \\
\hline Grave 64 & inhumation & -- ; no datable items \\
\hline Grave 65 & inhumation & -- ; no grave-goods \\
\hline
\end{tabular}

Vertical stratigraphy : later than grave 66

(c. AD 244-290)

Grave 66 inhumation

c. $A D 244-90$

Grave 67 inhumation

c. AD 222-70

Grave 68 inhumation

--- ; no datable items

Grave 69 inhumation

--- ; no datable items

Vertical stratigraphy : earlier than grave 70 (no grave-goods)

Grave $70 \quad$ inhumation --- ; no datable items

Vertical stratigraphy : later than grave 69 (no grave-goods) and grave 71 (c. 168/69-200)

Grave 71 inhumation c. AD 168/69-200 


\begin{tabular}{|c|c|c|}
\hline Grave 72 & inhumation & -- ; no grave-goods \\
\hline \multirow[t]{2}{*}{ Grave 73} & inhumation & --- ; no grave-goods \\
\hline & & $\begin{array}{l}\text { Vertical stratigraphy : later than grave } 74 \\
\text { (c. AD 253-70) }\end{array}$ \\
\hline Grave 74 & inhumation & c. AD 253-70 \\
\hline Grave 75 & inhumation & c. $A D 383-400$ \\
\hline Grave 76 & inhumation & c. AD $163-80$ \\
\hline Grave 77 & inhumation & --- ; no grave-goods \\
\hline
\end{tabular}

Vertical stratigraphy : later than grave 81 (c. AD 193-220) and contemporary to grave 78 (no grave-goods)

Grave $78 \quad$ inhumation -- ; no grave-goods

Vertical stratigraphy : later than grave 79 (c. AD 236-50) and contemporary to grave 77 (no grave-goods)

$\begin{array}{lll}\text { Grave } 79 & \text { inhumation } & \text { c. AD 236-50 } \\ \text { Grave } 80 & \text { inhumation } & \text { c. AD } 306-50 \\ \text { Grave } 81 & \text { inhumation } & \text { C. AD } 193-220 \\ \text { Grave } 82 & \text { inhumation } & \text { c. AD } 236-50 \\ \text { Grave } 83 & \text { inhumation } & \text { c. AD } 306-50 \\ \text { Grave } 84 & \text { inhumation } & --. \text {; no datable items } \\ \text { Grave } 85 & \text { inhumation } & \text { c. AD } 351-70 \\ \text { Grave } 86 & \text { inhumation } & \text { c. AD } 361-80 \\ \text { Grave } 87 & \text { inhumation } & \text {-.- ; no datable items } \\ \text { Grave } 88 & \text { inhumation } & \text { c. AD } 25-75\end{array}$


Grave 89

inhumation

-- ; no grave-goods

Vertical stratigraphy : earlier than grave 90

(c. AD 98-140)

$\begin{array}{lll}\text { Grave } 90 & \text { inhumation } & \text { c. AD 98-140 } \\ \text { Grave } 91 & \text { inhumation } & \text { c. AD 25-75 } \\ \text { Grave } 92 & \text { inhumation } & \text { c. AD 70-120 } \\ \text { Grave } 93 & \text { inhumation } & \text { c. AD 173-200 } \\ \text { Grave } 94 & \text { inhumation } & \text { c. AD 79-130 } \\ \text { Grave } 95 & \text { inhumation } & --. \text {; no grave-goods } \\ \text { Grave } 96 & \text { inhumation } & \text { c. AD 161/62-200 } \\ \text { Grave } 97 & \text { inhumation } & \text { c. AD 50-100 }\end{array}$

\section{Dating of the cemetery}

The datable finds from the cemetery of Arcegno run from the beginning of the 1 st century $A D$ to the end of the 4 th century $A D$. The graves dated to the 1 st century $A D$ according to their contents were situated in the eastern half of the cemetery. In particular, graves dated to the beginning or the first half of the 1st century $A D$ occupied the south-eastern corner.

Graves dated to the 2 nd century AD were in the centre of the cemetery, on a north-west/south-east axis. North of this axis were found graves dating in the 3rd century $A D$, in particular in the first half of the century. The northern corner of the area was occupied by graves dated to the second half of the 3rd and to the 4th centuries AD. North of these graves is situated the church.

Therefore, the chronological development of the cemetery seems to run from south-west to north-east. 
The jar 139.70 .787 in Grave 60 finds its closest parallels in similar vessels found in the Late La Tène cemetery San Bernardo at Ornavasso (Graue 1974, pl. $35 \mathrm{nn} .5-6)$, whereas the terminus post quem of Arcegno Grave 60 in the first half of the 4th century $A D$ is suggested by the presence of a coin of Maximus (AD 338).

One problem of dating the graves is the presence of coin hoards, where some coins are substantially later than the rest. The use of accumulated coins in a hoard allow one to suppose that the latest coins constitute a terminus post quem much earlier than the real date of the grave. On the other hand, some graves have been cut by later ones, whose terminus post quem according to the coins corresponds to the terminus ante quem (according to the position) of the graves cut (e.g. Grave 57 with terminus post quem: after AD 235 and terminus ante quem: before grave 52 (terminus post quem: after AD 235)). There is no evidence that any grave was re-used. This evidence allows one to suppose that at the time of the construction of a grave cutting an earlier one, the memory of the latter had been lost. Therefore, some graves are probably much later than their terminus post quem, and some may even be 5th century $A D$.

\section{Losone-Papögna}

Papögna is a small area of the village Losone and is situated at $240 \mathrm{~m}$ asl between the Saleggi and the church of San Giorgio, AK 702100/113900. It lies north-east of Arcegno, about two kilometres distant. 


\section{Circumstances of discovery}

In 1934, the construction of a path and while ploughing, sherds of pottery were found and identified as Roman by Ugo Zaccheo, member of the Società del Museo di Locarno. He reported his discovery to Crivelli, and together they started the investigation of the cemetery in the same year. The information about this excavation is extremely poor.

On plan of the cemetery, signed 'Aldo Crivelli, Muralto 1935', the number of graves is sixty. The graves were situated on properties marked on the plan with the numbers $182,183,351$ and 352 . They seem to have been mainly orientated east-west, with two exceptions orientated north-south (Graves 25 and 27). In the newspaper Avanguardia, between October 1934 and January 1935, were published descriptions of the first forty seven graves excavated. A short note about the cemetery appeared also in Jahrbuch der Schweizerischen Gesellschaft für Ur- und Frühgeschichte 26, 1934, 57-8. There is no trace of further information about the last thirteen graves.

Two more graves were excavated in 1954 by Crivelli along the path. Their structure and content have been described in detail by the finder (Crivelli $1954,110-11)$

\section{The graves}

The contents of the first forty-seven graves were listed in the newspaper Avanguardia, but not recorded with a number. Moreover, their descriptions are vague and do not allow one to identify the items. The objects were later catalogued, but associations are now unknown. Only in few cases, are items accompanied by paper labels, written by Crivelli, with a grave number. These 
labels, however, do not provide enough evidence for the reconstruction of grave groups or the horizontal stratigraphy of the cemetery. Some burials are described as inhumations in stone-lined graves covered by stone slabs. There is no evidence for cremations, and the presence of nails in each grave allows one to suppose the use of wooden coffins.

The items listed belong generally to the following categories: Italian sigillata and thin walled ware, coarse pottery, glass, coins, iron nails and tools.

\section{Publication of the cemetery}

The cemetery has been partly studied by R. Fontana in 1985/86 (Fontana 1985/86). Further studies for the publication of the cemetery for a publication were started in 1987 by Fontana but have not yet appeared in print.

\section{List of graves}

Here are listed dated items and coarse/thin walled pottery from the two graves excavated in 1954, whose contents are known.

\section{Graves excavated in 1954}

Grave 1 inhumation $\quad--$; no datable items

Grave 2 inhumation c. AD 182-200

\section{Graves excavated in 1934}

The lack of associations among the items excavated in 1934 does not allow one to reconstruct the grave contents. 


\section{Dating of the cemetery}

The cemetery yielded 116 coins from twenty-two graves. The dates of the coin range from Augustus to Probus. Most of the graves contained one or two coins ; nine graves contained from three to thirteen coins ; Grave 24 contained 31 coins, ranging from Trajan ( $A D$ 98-117) to Probus ( $A D$ 282). The frequency of coin hoards has been already noted in the cemetery at Losone-Arcegno. This feature seems to be typical for the cemeteries of Losone, but does not appear either in the cemetery of Ascona or in those situated to the north of river Maggia.

Graves dated to the 1 st and 2 nd centuries $A D$ usually contain sigillata, glass and small numbers of coins (1-4) among their contents. The quantities of sigillata and glass is always small. By contrast, cemeteries closer to the lake such as Locarno-Muralto and Minusio (Simonett 1941) contain more Italian sigillata and glass.

Later graves have more brooches and larger numbers of coins. About the half of the thirty-three graves dated to the 3rd century $A D$ contained more than ten coins. The main group of them has twenty to seventy coins. In some of these graves, wood fragments were found associated to small coin hoards. In some cases, groups of coins date over a period of up to two centuries. The group of graves dated to the 4th century AD contain, like the earliest graves, fewer coins, from two to thirteen.

Almost all graves, except for those without any item, contained one or two iron tools, in particular knives, sickles, billhooks and axes, together with hobnails. 
A Republican coin, dated to the 3rd century BC shows, as coin hoards themselves do, the use of placing in graves coins much earlier than the grave itself.

The lack of complete grave contents does not allow one to define a date of the grave according to the datable elements. There were sigillata vessels, of Conspectus types $21,26 / 27,29,33,37,39,43$ and $46 / 49$, ranging from the first half of the 1 st century AD to the first half of the 2 nd century AD. Seventy examples of glass of Isings types $10,11,14,17,21,28,32,35,41,42,50$, $51,52,61,68,79,82$ and 87 , have the same date-range as the sigillata.

\section{Maggia}

The village (AK 697900/122400) is named after the river Maggia. It lies at the foot of the mountain, on the left bank of the river, south of the torrent Rii. Maggia is about 13 kilometres from Locarno and one kilometre north of Moghegno.

\section{Circumstances of discovery}

Grave-goods appeared in 1906, during the construction of the railway line. They consisted of some bowls or jars, a thin walled beaker with dotted decoration, an iron knife and a copper alloy coin (Magni 1906, 190). The objects were brought to the Museo Civico, Locarno. 


\section{Thin walled and coarse pottery}

In the Museo Civico, Locarno, are three objects with 'Maggia' indicated as provenance and further information about private collections (1936.1271: Collection Balli ; 1936.1272 and 1936.1273: Collection Pozzi). Cup 1936.1273a, with indication 'Maggia, collezione Pozzi', is kept by the Ufficio dei Beni Culturali, Bellinzona.

\section{Minusio}

Minusio, AK 706500/115000, is an independent municipality, situated at the northern end of Verbano, at $200 \mathrm{~m}$ asl. Its territory extends on the wide terraces from the lake to $300 \mathrm{~m}$ asl and borders Muralto to the west, from which is separated by the river Rabissale. Today Locarno, Muralto and Minusio form a single densely populated area. This situation probably corresponds, although with different proportions, to that in the past.

To the south of the Roman finds, in Via Ceresol about 200m from the lake, was an Iron Age cemetery. The situation of early graves south of later (Roman) ones is similar to that at Solduno and Tenero.

\section{Circumstances of discovery}

Emilio Balli was the first to mention the discovery of some graves in the neighbourhood of the church Santa Maria delle Grazie (Motta 1881, 264). In 1888, other graves were found in property Bignozzi, by the river Rabissale, and in property Regalli, by Santa Maria delle Grazie (Bertolone 1939, 319- 
320 ; Motta 1884a, 292). The grave-goods were brought to the Museo Civico, Locarno, and registered under the year 1931.

In 1936, Ch. Simonett (Simonett 1941, 125-176) investigated 33 graves in property Cadra, along Via San Gottardo and to the east of the river Rabissale. In the same property, during the construction of a road in 1931 and 1933 , were found two other graves.

In 1939 a grave was found in property Mondada, south of Via Architetto Frizzi and east of Via Borgaccio. There exist only sketches of three vessel found in the grave and some notes by Crivelli (Crivelli 1940a, 355).

In 1945 a grave was excavated in property Bonfanti (Silvestrini 1946, 1223) and four or five appeared during building work on property Scascighini, to the north of the church of Santa Maria delle Grazie, (Crivelli 1946, 1222). Two inhumations were destroyed in 1947, during the construction of a house on property Marazzi. Only a flagon, a jar and an iron knife were recovered (Crivelli 1949, 34-35). Other graves were found along the continuation of the actual Via Francesca (Bertolone 1939, 321; Crivelli 1943, 74). Their exact position is today unknown. Some grave-goods, now in the Museo Civico, Locarno, bear the following indications: property Pfeiffer/1942, Frizzi/1944, Cadogno/1935. No further details about this finds are known. Property Pfeiffer has not been identified. Frizzi and Cadogno are two areas of Minusio, where the graves were probably discovered.

Finally, a Roman dedicatory inscription was re-used as building stone in a wall of the church of San Quirico, situated close to the lake in the area called Rivapiana (Giussani 1927, 157-158). 


\section{The graves}

The graves found in property Scascighini were stone-lined and covered with stone slabs. According to Crivelli's notes, they were excavated in the virgin soil, as occurred in Moghegno. The 33 graves excavated by Simonett in property Cadra were 13 cremations and 20 inhumations. The cremations usually consisted of simple pits. Only four graves were stone-slabs cists. Most inhumations were orientated north-south and were stone-lined. Grave 19 was a rectangular stone-slabs cist. Graves 4,5 and 31 were 'L'-shaped chambered graves with stone dressed walls and adjoining chamber. In Grave 31 the grave-goods were placed on four stone shelves projecting from the wall of the grave. Grave 33 consisted of a dry-stone, rectangular grave and was bipartite, with the grave-goods placed in the western half.

The grave-goods with the cremations were generally poorer than those of the inhumations and consisted of few sigillata vessels, glass, coins, iron and bronze items, and some thin walled and coarse pottery. Among the inhumations, the chambered graves were particularly rich in quantity and quality of grave-goods. They contained many glass vessels, Italian sigillata, bronze vessels, jewellery such as gold rings and earrings, silver coins and brooches, iron objects and some thin walled and coarse pottery. The content of the other inhumations is sometimes as rich as that of the chambered graves and sometimes similar to that of the cremations, although in better condition. The geographical position of the graves or cemeteries far from the lake corresponds to that of Muralto and Locarno. The area close to the lake may have been occupied by the Roman settlement, as is demonstrated at Muralto. 


\section{Publication of the cemeteries}

The graves excavated in 1936 by Simonett on property Cadra were published in 1941 (Simonett 1941, 125-76). The graves found in 1945 on property Scascighini were studied by Stöckli $(1975,90-4)$. Information about the other graves is limited to the report of their discovery and a description of their grave-goods.

\section{List of graves}

Property Frizzi (parcel no. 854; 1939)

There exist only sketches of two vessel found in the grave (a flagon and fragments of an open form) and some notes by Crivelli. He described the grave as 'without protection'.

Grave 1 rite unknown --, no datable items

Property Scascighini (parcel no. 106; 1945)

Grave 1 inhumation --- ; no datable items

Grave 2 inhumation c. AD 20-70

Grave 3 inhumation c. AD 0-30

Grave 4 inhumation c. AD 10-50

Grave 5 inhumation c. AD 0-30

\section{Property Bonfanti (1945)}
Grave 1
rite unknown
c. $A D 10-50$ 


\section{Property Mondada (parcel no. 1344; 1946)}

There exist only sketches of three vessel found in the grave (two jars and a two-handled bowls) and some notes by Crivelli. He described the grave as 'rather oval with stones'.

Grave $1 \quad$ cremation (?) --- ; no datable items

\section{Property Cadra (1936)}

$\begin{array}{lll}\text { Grave } 1 & \text { inhumation } & \text { c. AD 180-230 } \\ \text { Grave } 2 & \text { cremation } & \text { c. AD 40-90 } \\ \text { Grave } 3 & \text { cremation } & --- \\ \text { Grave } 4 & \text { inhumation } & \text { c. AD 0-30 } \\ \text { Grave } 5 & \text { inhumation } & \text { c. AD 0-30 } \\ \text { Grave } 6 & \text { inhumation } & \text { c. AD 40-90 } \\ \text { Grave } 7 & \text { cremation } & \text { c. AD 70-120 } \\ \text { Grave } 8 & \text { cremation } & \text { c. AD 50-80 } \\ \text { Grave } 9 & \text { inhumation } & \text { c. AD 40-90 } \\ \text { Grave 10 } & \text { inhumation } & \text { c. AD 10-30 (?) } \\ \text { Grave 11 } & \text { inhumation } & \text { c. AD 77/8-100 } \\ \text { Grave 12 } & \text { inhumation } & \text { c. AD 73-100 } \\ \text { Grave 13 } & \text { cremation } & \text { c. AD 20-70 } \\ \text { Grave 14 } & \text { inhumation } & \text { c. AD 70-120; }\end{array}$

Vertical stratigraphy : later than grave 8 (c. AD 50-80) and grave 13 (c. 20-70)

Grave 15 inhumation c. AD 60-110

Grave 16 inhumation C. AD 15-50 


\begin{tabular}{|c|c|c|}
\hline Grave 17 & cremation & --- ; no grave-goods \\
\hline Grave 18 & cremation & 1st century $A D$ \\
\hline Grave 19 & inhumation & c. $A D 70-120$ \\
\hline Grave 20 & cremation & c. $A D 81-130$ \\
\hline Grave 21 & cremation & --- ; no datable items \\
\hline Grave 22 & cremation & c. $A D 80-130$ \\
\hline Grave 23 & inhumation & c. AD $50-100$ \\
\hline Grave 24 & inhumation & first half of the 1 st century $A D$ \\
\hline Grave 25: & inhumation & --; no datable items \\
\hline Grave 26 & inhumation & c. $A D$ 161-210 \\
\hline Grave 27 & cremation & --- ; no datable items \\
\hline Grave 28 & inhumation & c. AD 50-100 \\
\hline Grave 29 & cremation & c. AD 50-100 \\
\hline Grave 30 & cremation & -- ; no grave-goods \\
\hline Grave 31 & inhumation & c. AD 54-100 \\
\hline Grave 32 & inhumation & c. $A D$ 69-100 \\
\hline Grave 33 & inhumation & c. $A D 70-120$ \\
\hline
\end{tabular}

Dating of the cemeteries

The distribution of graves or grave-groups over a wide area allows one to suppose that they may not have belonged to the same cemetery. However, all graves lay apart from the Iron Age cemetery, which is situated south of the Roman graves, in the area called Ceresol.

The graves found on properties Scascighini and Bonfanti date to Augustan times. They seem, therefore, to be the oldest in the cemetery. 
The date of the graves found on property Cadra, south of the former group, ranges from Augustan times to the end of the 2 nd century $A D$ and the very beginning of the 3rd century $A D$.

\section{Moghegno}

Moghegno, AK 697800/121800, is a village of the middle-to-lower Valle Maggia, about 10.5 kilometres from Locarno. The actual settlement lies at $320 \mathrm{~m}$ asl, at the foot of the mountain, on the wide right bank of the river Maggia facing Maggia village.

The Roman cemetery is situated south of the modern village and was cut by a small road, that runs along the mountain and links Moghegno and Aurigeno.

\section{Circumstances of discovery}

Six inhumations were discovered on property Leoni in 1936, during work for the road between Aurigeno and Moghegno (Crivelli 1938b, 46). Other graves appeared in 1994 in the property Tomamichel-Vicedomini (parcel 57), east of the road, during the construction of a house. Fortunately, the Ufficio dei Beni Culturali, was informed and organized the investigation.

\section{The graves}

Grave-goods and further information about six inhumations excavated in 1936 are today lost.

In 1994-95 were discovered 40 graves. They consisted of inhumations, were stone-lined and covered by stone slabs. The presence of small stone slabs on 
the graves' bottom to support a wooden plank for the body is attested in 14 graves $(1,2-4,8,11,13,22,24-25,31,34,35,36)$. Some graves contained iron nails, situated in the four corners, indicating the remains of wooden coffins. Thirty-one graves were orientated north-south and seven were orientated east-west. No graves were cut by later ones.

The grave-goods consisted of thin walled and coarse pottery, Italian sigillata, glass vessels and bronzes, iron tools and shoes. In particular, almost every grave contained a coarse jar. About the half of the graves also contained from one to seven coins. Because of the high acidity rate of the soil, typical of Ticino, no grave contained human remains. The particular consistency of the soil at Moghegno (sand rich in mica, quartz and other minerals) could allow one to gain further information such as the position of the body. Unfortunately, the excavators limited the investigation of each grave to drawing of the plan and recovery of the grave-goods.

The forty graves formed a compact unit. Graves $1,26,17,10$ and 9 seem to represent the outer limit of the cemetery : all of the graves lay to the west of this line. A Grave 39 was identified, but it disappeared under the road, where in 1936 were found six other graves. Therefore, the cemetery seems to continue westwards, towards the foot of the mountain.

\section{Dating of the cemetery}

The datable items from the cemetery of Moghegno run from the first half of the 1 st to the end of the 2 nd century AD. According to their datable grave-goods, the latest graves $(1,10,17)$ were east of the main group and date $c . A D$ 
$160 / 80-200 / 210$. The horizontal stratigraphy of the other graves does not allow one to gain further information about the development of the cemetery.

\section{Publication of the cemetery}

The cemetery was published as a catalogue of grave-goods in 1995 (Biaggio Simona 1995). The items are kept in the Ufficio dei Beni Culturali at Bellinzona and at Cevio, in the Museo di Valmaggia.

\section{List of graves}

\begin{tabular}{|c|c|c|}
\hline Grave 1 & inhumation & c. $A D 161-200$ \\
\hline Grave 2 & inhumation & -- ; no datable items \\
\hline Grave 3 & inhumation & c. AD 117-50 \\
\hline Grave 4 & inhumation & c. AD $149-200$ \\
\hline Grave 5 & inhumation & c. AD $80 / 1-100$ \\
\hline $6 / 1$ and $6 / 2$ & - & -- ; no datable items \\
\hline Grave 7 & inhumation & c. $A D 40-90$ \\
\hline Grave 8 & inhumation & c. AD $85 / 6-100$ \\
\hline Grave 9 & inhumation & c. $A D 20-70$ \\
\hline Grave 10 & inhumation & c. $A D 180-200$ \\
\hline Grave 11 & inhumation & c. AD 85/6-120 \\
\hline Grave 12 & inhumation & c. AD $81-120$ \\
\hline Grave 13 & inhumation & c. AD $20-70$ \\
\hline Grave 14 & inhumation & c. $A D 20-70$ \\
\hline Grave 15 & inhumation & c. $A D 71-120$ \\
\hline Grave 16 & inhumation & --- ; no datable items \\
\hline
\end{tabular}




\begin{tabular}{|c|c|c|}
\hline Grave 17 & inhumation & c. $A D 175-200$ \\
\hline Grave 18 & inhumation & c. AD 95/6-130 \\
\hline Grave 19 & inhumation & c. AD $157 / 8-200$ \\
\hline Grave 20 & inhumation & c. $A D 30-80$ \\
\hline Grave 21 & inhumation & C. AD $160-210$ \\
\hline Grave 22 & inhumation & c. AD $138-50$ \\
\hline Grave 23 & inhumation & c. $A D 117-150$ \\
\hline Grave 24 & inhumation & c. AD 50-100 \\
\hline Grave 25 & inhumation & c. AD $81-100$ \\
\hline Grave 26 & inhumation & --- ; no datable items \\
\hline Grave 27 & inhumation & C. AD $81-130$ \\
\hline Grave 28 & inhumation & --- ; no datable items \\
\hline Grave 29 & inhumation & c. AD $70-120$ \\
\hline Grave 30 & inhumation & c. $A D 98-130$ \\
\hline Grave 31 & inhumation & c. $A D 80-130$ \\
\hline Grave 32 & inhumation & c. AD $50-100$ \\
\hline Grave 33 & inhumation & c. AD $90 / 91-140$ \\
\hline Grave 34 & inhumation & c. $A D 71-120$ \\
\hline Grave 35 & inhumation & c. $A D 30-80$ \\
\hline Grave 36 & inhumation & c. $A D 34-80$ \\
\hline Grave 37 & inhumation & c. $A D 30-80$ \\
\hline Grave 38 & inhumation & c. $A D 40-90$ \\
\hline Grave 39 & --- & not excavated \\
\hline Grave 40 & inhumation & c. $A D 117-50$ \\
\hline
\end{tabular}




\section{Riazzino}

The independent municipality is named after the river Riazzino, which flows into the river Ticino. Riazzino, AK 712900/114900, lies on the northern river side of the plain of Ticino, at the foot of the hills, at $200-205 \mathrm{~m}$ asl. The small village is about four kilometres from Tenero and the northern end of Verbano.

\section{Circumstances of discovery}

In 1938, during the containment of the river Riazzino, some inhumations were destroyed. The graves lay north of the cantonal road and east of the river, about 50 metres from the containment wall. Only in the following year was Crivelli told about the discovery. He recovered few grave-goods, but associations are unknown. The objects are kept in the Civico Museo, Locarno.

\section{The graves}

Crivelli identified the structure of the destroyed graves. They consisted of stone-lined enclosures with stone covers and occupied an area of c. $10 \times 15 \mathrm{~m}$. Orientation and number of graves are unknown.

\section{Publication of the cemetery}

The graves found at Riazzino have not been published, except for the notice of their discovery (Crivelli 1939b, 262-3). 


\section{List of grave-goods}

The lack of associations among the grave-goods excavated in 1938 does not allow one to reconstruct the grave contents.

\section{Tegna}

Tegna, AK $700900 / 115900$, is the first village situated in the 'Terre di Pedemonte'. It lies at the foot of the hills, on the wide terrace on the northern side of the river Melezza, at $254 \mathrm{~m}$ asl. It is about 0.5 kilometres from the elbow inlet of river Maggia by Ponte Brolla, and five kilometres from Locarno.

\section{Circumstances of discovery}

In May 1940, during the construction of the house of E. Margaroli by the level crossing of the Centovalli railway, were found three inhumations (Crivelli 1943, 75). The graves consisted of stone slabs enclosures and covers. Grave 1 and 2 were destroyed, whereas Grave 3 was carefully excavated by Crivelli. Grave 1 was orientated east-west. Crivelli recovered only a bowl and some nails, now lost. Fortunately Crivelli published dimensions (height $13 \mathrm{~cm}$; rim $18 \mathrm{~cm}$; foot $9 \mathrm{~cm}$ ) and a sketch drawing of the bowl (Crivelli 1940b, 382). Grave 2 was orientated north-east/south-west. The only grave-good was a sigillata dish. According to Crivelli's sketch drawing, it can be identified as similar to Dragendorff Form 37/32. Grave 3 was smaller than Graves 1 and 2 and orientated north-south. It contained a nail.

The area called 'Castello', AK $701100 / 116200$, on a plateau at $529 \mathrm{~m}$ als north of the village, was partly investigated by Crivelli and the architect Gerster in 
1941-42. They discovered some wide walls, a quadrangular structure with a cistern interpreted by Crivelli as a Roman house, hut floors, and Roman and prehistoric pottery (Crivelli 1943,$75 ; 82-4$ ). Unfortunately, Crivelli did not publish an excavation report, and there only exists some sketch-plans and notes. The pottery included Iron Age wares. Some of the latter and all of the Roman is now in the Ufficio dei Beni Culturali, Bellinzona. The Roman ware consists mainly of coarse pottery, but there are also many burnt fragments of sigillata vessels.

The geographical position of these remains is of strategical relevance and allows one to imagine a (fortified) settlement, from which it was possible to control both the access to Terre di Pedemonte and Centovalli, and the passage along the river Maggia from Locarnese and Verbano to Valle Maggia and the route to the Alps.

\section{Tenero}

Tenero, AK 709000/115500, lies at the northern end of Verbano, on the west side of river Verzasca, at the foot of the hills and of Val Verzasca. It is about five kilometres from Locarno and faces Gordola, situated on the east side of river Verzasca. The centre of Tenero is about $700 \mathrm{~m}$ from the lakeside. The presence of a Roman cemetery in the area of 'Mappo', 350m from the lake, indicates that the actual lakeshore in this position corresponds roughly to that of the past.

Contra, AK 708100/116000, is an outlying division of Tenero and is about 1.2 kilometres north, at $450 \mathrm{~m}$ asl. 


\section{Circumstances of discovery}

In the winter of $1880-81$, Emilio Balli excavated 91 graves in the property Carlo Roggero, situated between the cantonal road and the railways line in the area called 'Mappo', AK 708600/115150, 350m from the lakeshore (Motta 1880, 295; Motta 1881, 39-40; Motta 1882, 287). He also described graves and grave-goods in a catalogue, which he intended to publish together with $F$. Ponti and the Tipografia Intrese (Intra, Italy). Because of financial problems, the catalogue was never published. Part of these documents were used by $D$. Silvestrini for an outline publication of the cemetery (Silvestrini 1940, 322331). Silvestrini, however, was not allowed to consult E. Balli's manuscript, but only to use some plates with figures and an 'inventory of the cemetery of Tenero'. He also pointed out the difficulty of identifying the grave-goods from Balli's descriptions. In his article, Silvestrini did not publish catalogue numbers of the objects. Therefore, it is today almost impossible to identify the gravegoods, some of which are kept in the Civico Museo, Locarno, and some of which are the private property of family Balli. The latter are unfortunately not available for study.

In 1887, Balli excavated other graves by the railway station, in the same area between the railways line and the cantonal road. The grave-goods became property of the family Balli (Bertolone 1939, 323). In 1896 were discovered three empty inhumations on property Perini (Motta 1896, 50), whose exact position is unknown. In 1948, Crivelli recovered many fragments of pottery discovered on property Scolari during work by the owner (Archive of the Ufficio dei Beni Culturali, Bellinzona). Property Scolari lay close to the cemetery investigated by Balli. The items seem to have been brought to Locarno, but 
are today lost. There only exist some sketch drawings by Crivelli. In 1957, pottery was collected from the surface and brought to Bellinzona. In 1970, during an emergency excavation by Tenero's post office, the Ufficio dei Beni Culturali recovered 23 graves. They lay east of the modern cemetery, and north-east of the cemetery excavated by Balli. Thirteen of these graves contained grave-goods dating from the Iron Age; four dated to Roman times. To the east of this cemetery were discovered Late Bronze Age burials. Other Roman graves were found in 1932, 1933 and 1940-1941, but their exact position is not identifiable.

At Contra, in 1877 and 1878 were discovered many graves and over 200 grave-goods in the properties Cajocca and Canevascini. These properties laid by the church, to the west of the centre of Contra. The grave-goods were scattered among private people (Motta 1879, 248). In 1910, some objects and coins were recovered in property Giudici, also by the church (Balli's manuscript, 1935).

\section{Publication of the cemeteries}

The graves excavated by Balli in $1880-81$ were published by Silvestrini in 1940. The grave-goods recovered in 1957 and 1970 are kept in Bellinzona (Ufficio dei Beni Culturali) and are unpublished. The other finds at Tenero and Contra were scattered among private people or lost. They also are unpublished. 


\section{The graves}

All graves consisted of inhumations, except for both graves number 3 of Balli's and Ufficio dei Beni Culturali's excavations.

According to Balli's descriptions, the graves excavated in $1880-81$ seem to contain more grave-goods than the graves excavated in 1970, which did not contain any sigillata or glass ware. Therefore, it could be supposed that they must be later, dating to a time when few or no grave-goods were put in the graves. On the other hand, these graves were surrounded by Iron Age graves and partly cut them. Moreover, Grave 4 contained two asses of Hadrian.

\section{The cemeteries}

Balli investigated a wide area between the cantonal road to the north and the small Via Francesca to the south, on the property Roggeri and partly on the neighbouring properties Bacilieri, south of Via Francesca, and Leoni, east of property Bacilieri. The graves occupied this area densely, but stopped along its western and eastern side, indicating the limits of the cemetery. The graves excavated in 1970 lay north-east of Balli's group, about $350 \mathrm{~m}$ away. Other grave-goods, recovered by Crivelli in 1948, came from the same area as Balli's group. They may, therefore, represent the continuation of the cemetery to the north or east. It is still impossible to be sure whether the graves excavated in 1880-81 and in 1970 belonged to the same cemetery. Moreover, Solduno and Minusio showed Bronze Age graves close to the lake and Roman graves towards the foot of the hills. At Tenero the contrary happened. One reason may be seen in the different position of the end of Verbano. The 
presence of river Verzasca, carrying down many cubic metres of sand and rocks every year, may have moved the lakeshore southwards.

The graves found at Contra were 1.2 kilometres north-west of those at Tenero. It seems therefore likely that they belonged to another cemetery.

\section{List of graves}

\section{Balli's excavation $1880-81$}

Balli's inventory lists 91 inhumations. On Balli's sketch-plan of the cemetery, published by Silvestrini, Grave 3 is drawn as a cremation and among its grave-goods is listed some charcoal. Most graves were orientated east-west or north-east/south-west. Graves $32,57,58$ and 73 to 82 were orientated north-south. Silvestrini $(1940,323)$ mentions some difficulties in identifying the grave-goods from Balli's descriptions. Fortunately, these descriptions refer to plates with some photographs and Balli gave the dimensions of the gravegoods. In the following list is given reference for the grave-goods illustrated by Silvestrini.

$\begin{array}{lll}\text { Grave } 1 & \text { inhumation } & \text { c. AD 30-80 } \\ \text { Grave } 2 & \text { inhumation } & \text { c. AD 22/3-70 } \\ \text { Grave } 3 & \text { cremation } & --- \text {; no datable items } \\ \text { Grave } 4 & \text { inhumation } & --- \\ \text { Grave } 5 & \text { inhumation } & \text { c. AD } 30-80 \\ \text { Grave 6 } & \text { inhumation } & \text { c. AD } 30-80 \\ \text { Grave } 7 & \text { inhumation } & \text { c. AD 40-90 } \\ \text { Graves } 8 / 9 & \text { inhumation } & \text { c. AD 50-100 } \\ \text { Grave 10 } & \text { inhumation } & \text { c. AD 40-80 }\end{array}$




\begin{tabular}{|c|c|c|}
\hline Grave 11 & inhumation & c. $A D 10-50$ \\
\hline Grave 12 & inhumation & c. $A D 40-80$ \\
\hline Grave 13 & inhumation & -- ; no datable items \\
\hline Grave 14 & inhumation & c. $A D 30-70$ \\
\hline Grave 15 & inhumation & -- ; no datable items \\
\hline Grave 16 & inhumation & c. $A D 50-100$ \\
\hline Grave 17 & inhumation & c. $A D 50-100$ \\
\hline Grave 18 & inhumation & c. AD 50-100 \\
\hline Grave 19 & inhumation & c. AD $92-150$ \\
\hline Grave 20 & inhumation & c. $A D 50-100$ \\
\hline Grave 21 & inhumation & --; no datable items \\
\hline Grave 22 & inhumation & c. AD 15-65 \\
\hline Grave 23 & inhumation & c. AD $40-90$ \\
\hline Grave 24 & inhumation & --; no datable items \\
\hline Grave 25 & inhumation & -- \\
\hline Grave 26 & inhumation & c. $A D 50-100$ \\
\hline Grave 27 & inhumation & --- ; no datable items \\
\hline Grave 28 & inhumation & c. AD 14-65 \\
\hline Grave 29 & inhumation & -- ; no datable items \\
\hline Grave 30 & inhumation & -- \\
\hline Grave 31 & inhumation & -- \\
\hline Grave 32 & inhumation & c. AD $30-80$ \\
\hline Grave 33 & inhumation & c. $A D 50-120$ \\
\hline Grave 34 & inhumation & c. AD $40-90$ \\
\hline Grave 35 & inhumation & c. AD 50-100 \\
\hline
\end{tabular}




\begin{tabular}{|c|c|c|}
\hline Grave 36 & inhumation & c. AD 50-100 \\
\hline Grave 37 & inhumation & c. $A D 50-100$ \\
\hline Grave 38 & inhumation & c. AD $179-230$ \\
\hline Grave 39 & inhumation & c. AD $70-130$ \\
\hline Grave 40 & inhumation & c. AD $70-120$ \\
\hline Grave 41 & inhumation & c. $A D 70-120$ \\
\hline Grave 42 & inhumation & c. AD $69-130$ \\
\hline Grave 43 & inhumation & c. $A D 81-130$ \\
\hline Grave 44 & inhumation & -- \\
\hline Grave 45 & inhumation & c. $A D 77-130$ \\
\hline Grave 46 & inhumation & c. $A D 30-80$ \\
\hline Grave 47 & inhumation & c. $A D 75-125$ \\
\hline Grave 48 & inhumation & c. $A D 130-80$ \\
\hline Grave 49 & inhumation & c. AD $50-100$ \\
\hline Grave 50 & inhumation & --- ; no datable items \\
\hline Grave 51 & inhumation & -- \\
\hline Grave 52 & inhumation & -- \\
\hline Grave 53 & inhumation & -- \\
\hline Grave 54 & inhumation & --- ; no datable items \\
\hline Grave 55 & inhumation & -- ; no datable items \\
\hline Grave 56 & inhumation & --- ; no datable items \\
\hline Grave 57 & inhumation & c. $A D 71-120$ \\
\hline Grave 58 & inhumation & c. $A D 70-120$ \\
\hline Grave 59 & inhumation & --- ; no datable items \\
\hline Grave 60 & inhumation & c. $A D 138-90$ \\
\hline
\end{tabular}




\begin{tabular}{|c|c|c|}
\hline Grave 61 & inhumation & c. $A D 117-70$ \\
\hline Grave 62 & inhumation & c. AD $50-100$ \\
\hline Grave 63 & inhumation & c. $A D 99-150$ \\
\hline Grave 64 & inhumation & c. $A D 86-120$ \\
\hline Grave 65 & inhumation & -- \\
\hline Grave 66 & inhumation & c. $A D 70-120$ \\
\hline Grave 67 & inhumation & c. $A D 50-100$ \\
\hline Grave 68 & inhumation & c. $A D 71-120$ \\
\hline Grave 69 & inhumation & c. $A D 50-100$ \\
\hline Grave 70 & inhumation & c. $A D 71-120$ \\
\hline Grave 71 & inhumation & c. $A D 50-100$ \\
\hline Grave 72 & inhumation & -- \\
\hline Grave 73 & inhumation & c. $A D 50-100$ \\
\hline Grave 74 & inhumation & -- \\
\hline Grave 75 & inhumation & -- \\
\hline Grave 76 & inhumation & -- \\
\hline Grave 77 & inhumation & $---;$ no datable items \\
\hline Grave 78 & inhumation & -- \\
\hline Grave 79 & inhumation & -- \\
\hline Grave 80 & inhumation & -- \\
\hline Grave 81 & inhumation & -- ; no datable items \\
\hline Grave 82 & inhumation & c. $A D 138-190$ \\
\hline Grave 83 & inhumation & c. $A D 31-80$ \\
\hline Grave 84 & inhumation & c. $A D 117-50$ \\
\hline Grave 85 & inhumation & c. $A D 50-100$ \\
\hline
\end{tabular}




$\begin{array}{lll}\text { Grave } 86 & \text { inhumation } & \text { c. AD 68-100 } \\ \text { Grave } 87 & \text { inhumation } & \text { c. AD 40-90 } \\ \text { Grave } 88 & \text { inhumation } & \text { c. AD 71-130 } \\ \text { Grave } 89 & \text { inhumation } & \text {--- } \\ \text { Grave } 90 & \text { inhumation } & \text { c. AD 71-130 } \\ \text { Grave } 91 & \text { inhumation } & \text {-.- }\end{array}$

\section{Excavation near the Post Office (1970)}

Here were discovered 23 graves. Except for Grave 3 and Grave 18, respectively a cremation and a heap of stones, all were orientated east-west. The thirteen Iron Age graves were stone-lined inhumations. The five Roman graves consisted of one cremation (Grave 3 ) and four stone-lined inhumations (Graves 4, 7, 14, 19). Grave 3 cut the Iron Age Grave 15. Grave 14 laid embedded between Graves 5 and 17 . Graves 7 and 14 were covered by stone slabs, whereas graves 4 and 19 were covered by stone slabs, tiles and flat tiles. Graves 1, 2, 5 and 17 were inhumations, but they did not contain any grave-goods. Grave 17 cut the Iron Age Grave 6. Grave 18 consisted of a heap of stones. The lack of grave-goods did not allow one to understand if it was a cremation and its date.

$\begin{array}{lll}\text { Grave } 3 & \text { cremation } & \text {--- ; no datable items } \\ \text { Grave 4 } & \text { inhumation } & \text { c. AD 139-90 } \\ \text { Grave 7 } & \text { inhumation } & \text {---; no datable items } \\ \text { Grave 14 } & \text { inhumation } & \text {-.- ; no datable items } \\ \text { Grave 19 } & \text { inhumation } & \text {--- ; no datable items }\end{array}$




\subsection{VERTICAL STRATIGRAPHY}

Five cemeteries within the study area show examples of superimposed graves and therefore of vertical stratigraphy: Ascona (Graves S10-S11 and S15-S16), Losone-Arcegno (Graves 3-93, 9-10, 16-23, 28-29, 33-46, 37-38-39, 38-39$40,39-40-41-44,40-41,42-43,48-49,50-76,51-55,52-57,54-61,65-66,70-$ 71, 73-74, 77-81, 78-79, 83-86 and 89-90), Minusio-property Cadra (Graves 13-14), Muralto-property Villa Liverpool sopra (Graves 4-5), and SoldunoModern cemetery (Graves 57.5-57.7-57.8 and 58.14-58.15).

These five cemeteries contained 56 intersecting graves, comprising 28 groups. Only in 11 cases, however, did each grave in the group contain datable material, enabling chronological consideration to be based on stratigraphy. At Losone-Arcegno, most of the later graves in such groupings were orientated on a north-south axis, rather than the east-west axis characteristic of the rest of the cemetery.

\section{Cemetery Earlier graves Later graves}

Ascona $\quad S 15, \mathrm{c} . \mathrm{AD} 30-70 \quad S 16, \mathrm{C} . \mathrm{AD} 200-50 \quad 170-180$ years $\quad 175$ years

\section{Losone-}

Arcegno

$\begin{array}{llll}\text { 3, c. AD } 70-120 & 93, \text { c. AD 173-200 } & 80-103 \text { years } & 91.5 \text { years } \\ \text { 23, c. AD } 80 / 81-100 & 16, \text { c. AD } 119-40 & 39-40 \text { years } & 39.5 \text { years } \\ 29, \text { c. AD } 50-100 & 28, \text { c. AD } 235-50 & 150-185 \text { years } & 167.5 \text { years } \\ 46, \text { c. AD } 80 / 81-130 & 33, \text { c. AD } 167-90 & 60-87 \text { years } & 73.5 \text { years } \\ \text { 38, c. AD } 40-60 & 39, \text { c. AD } 180-230 & 140-170 \text { years } & 155 \text { years } \\ \text { 49, c. AD } 179-200 & 48, \text { c. AD } 244-60 & 60-65 \text { years } & 62.5 \text { years } \\ \text { 76, c. AD } 163-80 & 50, \text { c. AD } 244-60 & 80-81 \text { years } & 80.5 \text { years }\end{array}$




$$
83, \text { c. AD } 306-350 \quad 86, \text { c. AD } 361-80 \quad 30-55 \text { years } \quad 42.5 \text { years }
$$

Minusio,
Cadra
13, c. AD $20-70$
14 , c. $A D 70-120$
50 years
50 years

Muralto,
Liv. sopra 4, c. AD 20-50
5, c. AD 70-120
50-70 years
60 years

The average gaps between earlier and later graves range from 39.5 up to 175 years.

A closer examination of the elements determining the dates of the graves, however, highlights different degrees of reliability. The proposed dates at Losone-Arcegno of graves 50-76, 33-46, 48-49 are based on the presence of coins issued within a defined period and providing therefore a probable terminus post quem. The gaps for these graves range from 62.5 to 80.5 years. Other two groups, those from Minusio and Muralto, show gaps of 50 and 60 years and another group of Losone a gap of 91.5 years. It is therefore possible to suppose an interval of c. $60-80$ years between the earlier and the later deposition and to consider this period the average time necessary to forget the presence of earlier graves. The other groups of superimposed graves indicate time gaps of c. 40 years or of c. $155-175$ years. In all these cases, however, one of the graves of the group (the earlier or the later one) did not contain enough datable elements to provide a high degree of reliability in dating. It may therefore be necessary to postpone a date, increasing or reducing the gap. Since the suggested interval of $60-80$ years is a hypothesis and at present cannot be demonstrated because of the limited number of examples, all dates proposed in the different sections of Chapter 3 are not modified. 


\subsection{DATE-RANGES OF COINS IN GRAVES OF THE LOCARNO REGION}

Out of six hundred graves in the Locarno region, 183 contain small numbers of coins among their grave-goods. There exists the problem of determining whether the coins are grave-goods or intrusive. In some graves, coins are contained in pots (e.g. Moghegno, Grave 40) or occur as hoards (e.g. LosoneArcegno, Grave 48), and are therefore certainly grave-goods. Elsewhere, early records usually assume that the coins were grave-goods, but do not give specific evidence that they were not intrusive.

The cemeteries of Ascona, Solduno, Muralto and Minusio were ca. 500-900m from the lake in Roman times. Their graves contained one to three coins. A few graves contained four or five coins: Graves $S 11$ and 9 at Ascona; Graves 4 and 12 at Minusio-Cadra, Grave 33 at Muralto-Villa Liverpool sotto. The graves without coins, however, nearly outnumber those with coins. The richest graves contained more Italian sigillata and glass vessels, than coins. In graves with a single coin, the coin is usually contemporary with the other datable grave-goods. The same usually occurs in graves with more coins: the latest coin, taken as the terminus post quem for the grave, is also consistent with the apparent date of the other grave-goods. The few exceptions are Graves 4 and 5 at Minusio-Cadra, dated to $C$. AD 0-30 on the grounds of other datable grave-goods, but which have Republican or early Imperial coins. A similar pattern occurred in the cemetery of Moghegno, situated in the Valle Maggia ca. 10.5 kilometres from the lake. The graves usually contained one or two coins; only Grave 23 contained seven coins. 
By contrast, the cemetery of Losone-Arcegno, situated ca. 1.5 kilometres from the lake and nearly opposite to Solduno, is the only one rich in coins. Eighteen of the ninety-seven graves contained ten or more coins ; another nineteen graves contained five or more coins.

The graves in the study area with five coins or more are grouped in the following table; the average interval in years is calculated considering middle dates of earliest and latest coins :

Average

Grave No. of

Cemetery no. coins Earliest coin Latest coin in years

Ascona

S11

5

Vespasian,

Nerva,

c. 23 AD 69-79

AD 96-98

9

5 Titus, AD 79-81

Trajan,

c. 28 interval

Minusio

4

5

C. N. Balbo, AD 98-117

- Cadra

5

3
$79 \mathrm{BC}$

Augustus,

c. 73

5

L. Piso Frugi, $90 \mathrm{BC}$

Augustus,

c. 75

12

4 Nero, AD 54-68

Domitian,

AD 73-79

c. 15

Moghegno

23

7 Vesp./Titus, AD 69-81

Hadrian,

c. 48

\section{Muralto}

- Liv. sotto 33

4 Cn. E. Caii,

Tiberius,

$97 \mathrm{BC}$

AD 36-37

c. 134

- Tommasi 3

3 Constantius I, Constans II, AD 321-23 AD 351-61

c. 34 
5

$\begin{array}{ll}\text { Constantinus } & \text { Magnentius, } \\ \text { II, } & A D 350-53\end{array}$

c. 2

AD 350

Losone

- Arcegno

\begin{tabular}{|c|c|c|c|c|}
\hline 5 & 11 & $\begin{array}{l}\text { Hadrian, } \\
\text { AD 117-38 }\end{array}$ & $\begin{array}{l}\text { Alex. Severus, } \\
\text { AD 231-35 }\end{array}$ & c. 106 \\
\hline 14 & 5 & $\begin{array}{l}\text { Hadrian, } \\
\text { AD 117-38 }\end{array}$ & $\begin{array}{l}\text { M. Aurelius, } \\
\text { N. AD 161-80 }\end{array}$ & c. 43 \\
\hline 20 & 10 & $\begin{array}{l}\text { Hadrian, } \\
\text { AD 117-38 }\end{array}$ & $\begin{array}{l}\text { Maximinus I, } \\
\text { AD 235-36 }\end{array}$ & c. 108 \\
\hline 27 & 17 & $\begin{array}{l}\text { Hadrian, } \\
\text { AD 117-38 }\end{array}$ & $\begin{array}{l}\text { Philippus I, } \\
\text { AD 244-49 }\end{array}$ & c. 120 \\
\hline 28 & 8 & $\begin{array}{l}\text { Domitian, } \\
\text { AD 81-96 }\end{array}$ & $\begin{array}{l}\text { Alex. Severus, } \\
\text { after AD } 235\end{array}$ & c. 147 \\
\hline 31 & 11 & $\begin{array}{l}\text { Trajan, } \\
\text { AD 98-117 }\end{array}$ & $\begin{array}{l}\text { Sept. } \\
\text { Severus, } \\
\text { AD } 229\end{array}$ & c. 122 \\
\hline 33 & 6 & $\begin{array}{l}\text { Titus, } \\
\text { AD 79-81 }\end{array}$ & $\begin{array}{l}\text { M. Aurelius, } \\
\text { N. AD 161-80 }\end{array}$ & c. 91 \\
\hline 48 & 34 & $\begin{array}{l}\text { Trajan, } \\
\text { AD 98-117 }\end{array}$ & $\begin{array}{l}\text { Philippus I, } \\
\text { AD 244-49 }\end{array}$ & c. 139 \\
\hline 49 & 8 & $\begin{array}{l}\text { Domitian, } \\
\text { AD 81-96 }\end{array}$ & $\begin{array}{l}\text { M. Aurelius, } \\
\text { AD 161-80 }\end{array}$ & c. 82 \\
\hline 50 & 6 & $\begin{array}{l}\text { Ant.Pius, } \\
\text { AD } 139\end{array}$ & $\begin{array}{l}\text { Philippus I, } \\
\text { AD 244-49 }\end{array}$ & C. 108 \\
\hline 53 & 12 & $\begin{array}{l}\text { Trajan, } \\
\text { AD 98-117 }\end{array}$ & $\begin{array}{l}\text { Iulia Domna, } \\
\text { AD 193-96 }\end{array}$ & c. 87 \\
\hline 55 & 17 & $\begin{array}{l}\text { Domitian, } \\
\text { AD 81-96 }\end{array}$ & $\begin{array}{l}\text { Alex. Severus, } \\
\text { after AD } 235\end{array}$ & c. 147 \\
\hline 57 & 14 & $\begin{array}{l}\text { Ant. Pius, } \\
\text { after AD } 141\end{array}$ & $\begin{array}{l}\text { Alex. Severus, } \\
\text { after AD } 235\end{array}$ & c. 94 \\
\hline 58 & 12 & $\begin{array}{l}\text { Trajan, } \\
\text { AD 98-117 }\end{array}$ & $\begin{array}{l}\text { Alex. Severus, } \\
\text { AD 231-35 }\end{array}$ & C. 126 \\
\hline
\end{tabular}


59

30 Vespasian, AD 69-79

Alex. Severus,

c. 155 AD 222-35

Losone

- Arcegno

\begin{tabular}{|c|c|c|c|c|}
\hline 60 & 61 & $\begin{array}{l}\text { Domitian, } \\
\text { AD 81-96 }\end{array}$ & $\begin{array}{l}\text { Maximus I, } \\
A D \text { 383-88 }\end{array}$ & c. 301 \\
\hline 61 & 69 & $\begin{array}{l}\text { Trajan, } \\
\text { AD 98-117 }\end{array}$ & $\begin{array}{l}\text { Gordianus III, } \\
\text { AD 243-44 }\end{array}$ & c. 136 \\
\hline 63 & 20 & $\begin{array}{l}\text { Hadrian, } \\
\text { AD 117-38 }\end{array}$ & $\begin{array}{l}\text { Philippus I, } \\
\text { AD 244-49 }\end{array}$ & c. 119 \\
\hline 66 & 7 & $\begin{array}{l}\text { Trajan, } \\
\text { AD 98-117 }\end{array}$ & $\begin{array}{l}\text { Ot. Severa, } \\
\text { AD 244-49 }\end{array}$ & c. 139 \\
\hline 74 & 36 & $\begin{array}{l}\text { Trajan, } \\
\text { AD 98-117 }\end{array}$ & $\begin{array}{l}\text { Gallienus, } \\
\text { AD 253-58 }\end{array}$ & C. 153 \\
\hline 75 & 17 & $\begin{array}{l}\text { Titus, } \\
\text { AD 79-81 }\end{array}$ & $\begin{array}{l}\text { Maximus I, } \\
\text { AD 383-88 }\end{array}$ & c. 306 \\
\hline 79 & 5 & $\begin{array}{l}\text { Hadrian, } \\
\text { AD 117-38 }\end{array}$ & $\begin{array}{l}\text { Maximinus I, } \\
\text { AD 236-38 }\end{array}$ & c. 110 \\
\hline 81 & 14 & $\begin{array}{l}\text { Vespasian, } \\
\text { AD 69-79 }\end{array}$ & $\begin{array}{l}\text { Sept. } \\
\text { Severus, } \\
\text { AD 193-211 }\end{array}$ & C. 128 \\
\hline 82 & 34 & $\begin{array}{l}\text { Trajan, } \\
\text { AD 98-117 }\end{array}$ & $\begin{array}{l}\text { Maximinus I, } \\
\text { AD 236-38 }\end{array}$ & c. 130 \\
\hline 85 & 5 & $\begin{array}{l}\text { Constantius II, } \\
\text { AD 322-61 }\end{array}$ & $\begin{array}{l}\text { Decentius, } \\
\text { AD 351-53 }\end{array}$ & c. 11 \\
\hline 86 & 6 & $\begin{array}{l}\text { Constantinus I, } \\
\text { AD 306-7 }\end{array}$ & $\begin{array}{l}\text { Constantinop., } \\
\text { AD } 306-61\end{array}$ & C. 12 \\
\hline 93 & 7 & $\begin{array}{l}\text { Domitian, } \\
\text { AD 81-96 }\end{array}$ & $\begin{array}{l}\text { Lucilla, } \\
\text { AD 164-82 }\end{array}$ & c. 99 \\
\hline
\end{tabular}

The average intervals between the earliest and the latest coin of the graves range from c. 2 to c. 306 years. Most of the values, however, belong to the interval within 74 and 155 years (25 graves of 36). Except for two graves from Minusio-Cadra, whose coins date to Republican or early Imperial times but do 
not constitute a terminus post quem, and the only grave from Muralto-Villa Liverpool sotto, all graves belong to the cemetery of Losone-Arcegno. Two graves from Losone-Arcegno show larger intervals: 301 years (Grave 60) and 306 years (Grave 75 ). The dates of both graves depend on the presence of a coin of Maximus I, dated AD 383-388 and considered as terminus post quem. Most of the coins in Grave 60 belong within C. AD 80-256/7, in Grave 75 within C. $A D$ 80-190, and a further coin dates to $A D$ 236-8. The chronological gaps between AD 256-7 and AD 383-8 (Grave 60) and between AD 236-8 and AD 383-8 (Grave 75) amount to over one-hundred years. Since in the excavation report there is no mention about the possibility of being intrusive, these coins could indicate a long interval between the formation of the hoards and their deposition in a grave.

Nine graves show intervals within 50 years, mostly within 15 and 48 years (six graves out of nine). Only three belong to the cemetery of Losone-Arcegno, one to the cemetery of Moghegno, whereas the other come from the cemeteries of Ascona, Minusio and Muralto close to the lake.

Except for the graves with coins dating from Republican times (Graves 4 and 5 at Minusio-Cadra; Grave 33 at Muralto-Villa Liverpool sotto) and the two graves from Losone-Arcegno with a large interval between the last coin the the others (Graves 60 and 75), all other graves contained coins issued in consecutive periods. The dates, in particular at Losone-Arcegno, usually range from $A D$ 81/96-117/38 (Domitian/ Hadrian) to $A D$ 230/35-236-38/244-49 (Alexander Severus/ Maximinus I/ Philippus I). 


\section{Intervals}

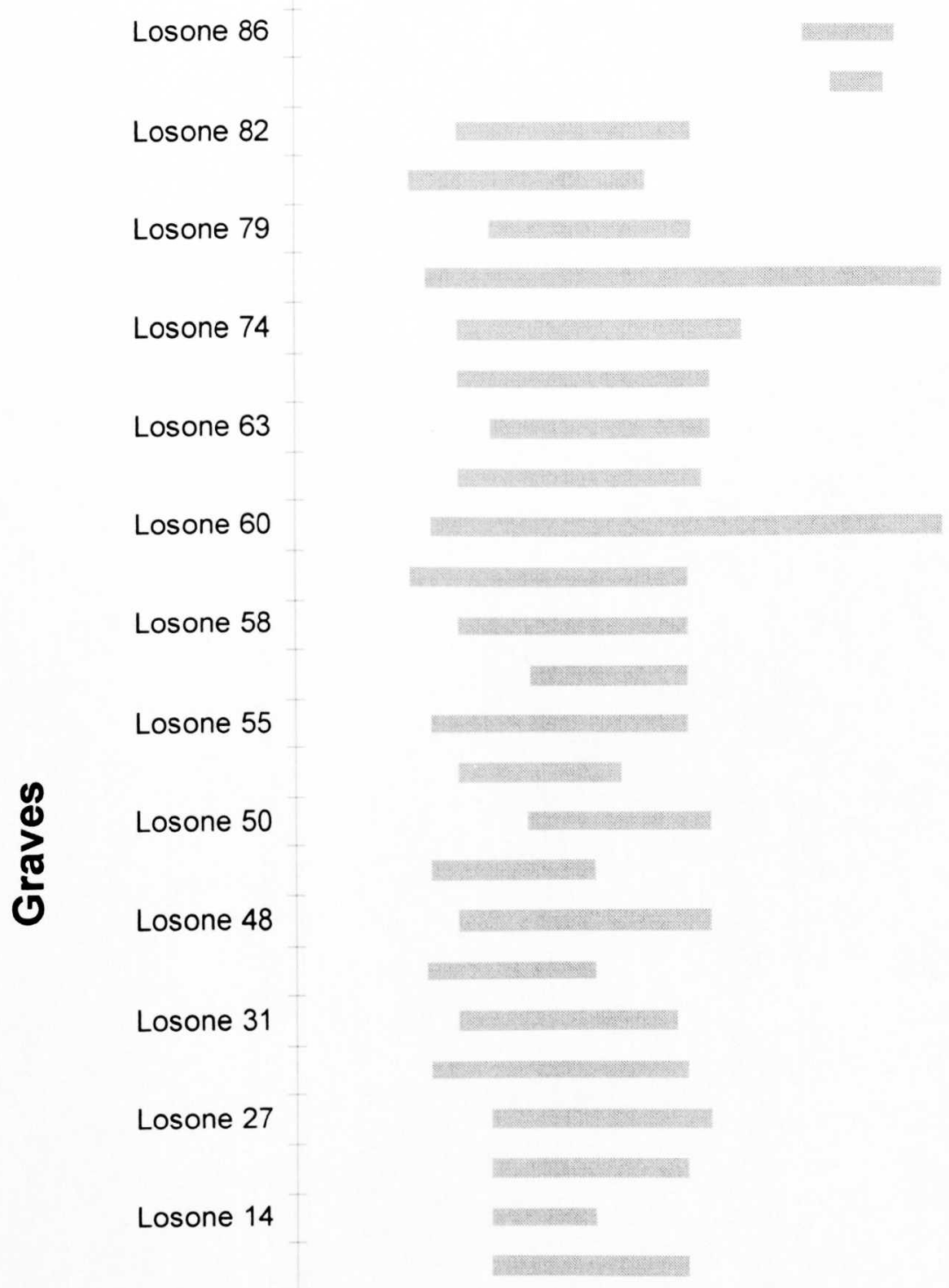

Muralto-Tom. 5

Muralto-Liv. 33

Minusio 12

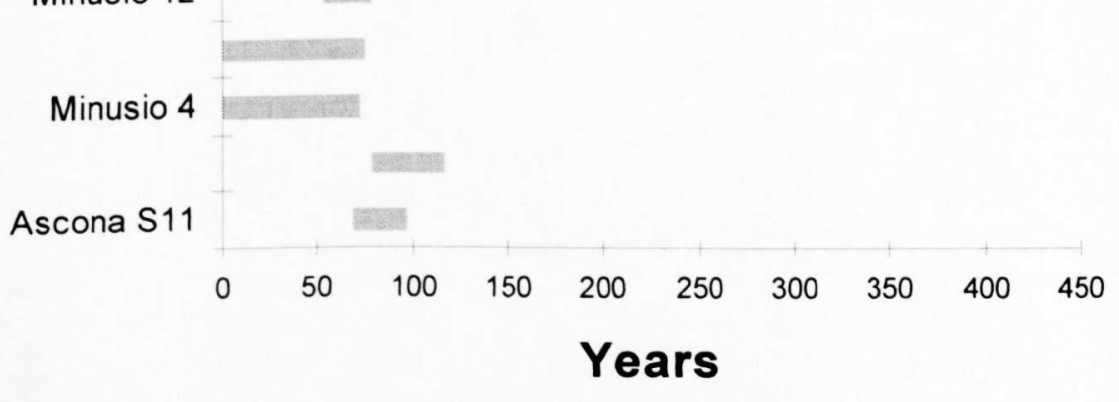

Fig. 3.3. Date-ranges of coins. Intervals. 


\section{Average intervals in years}

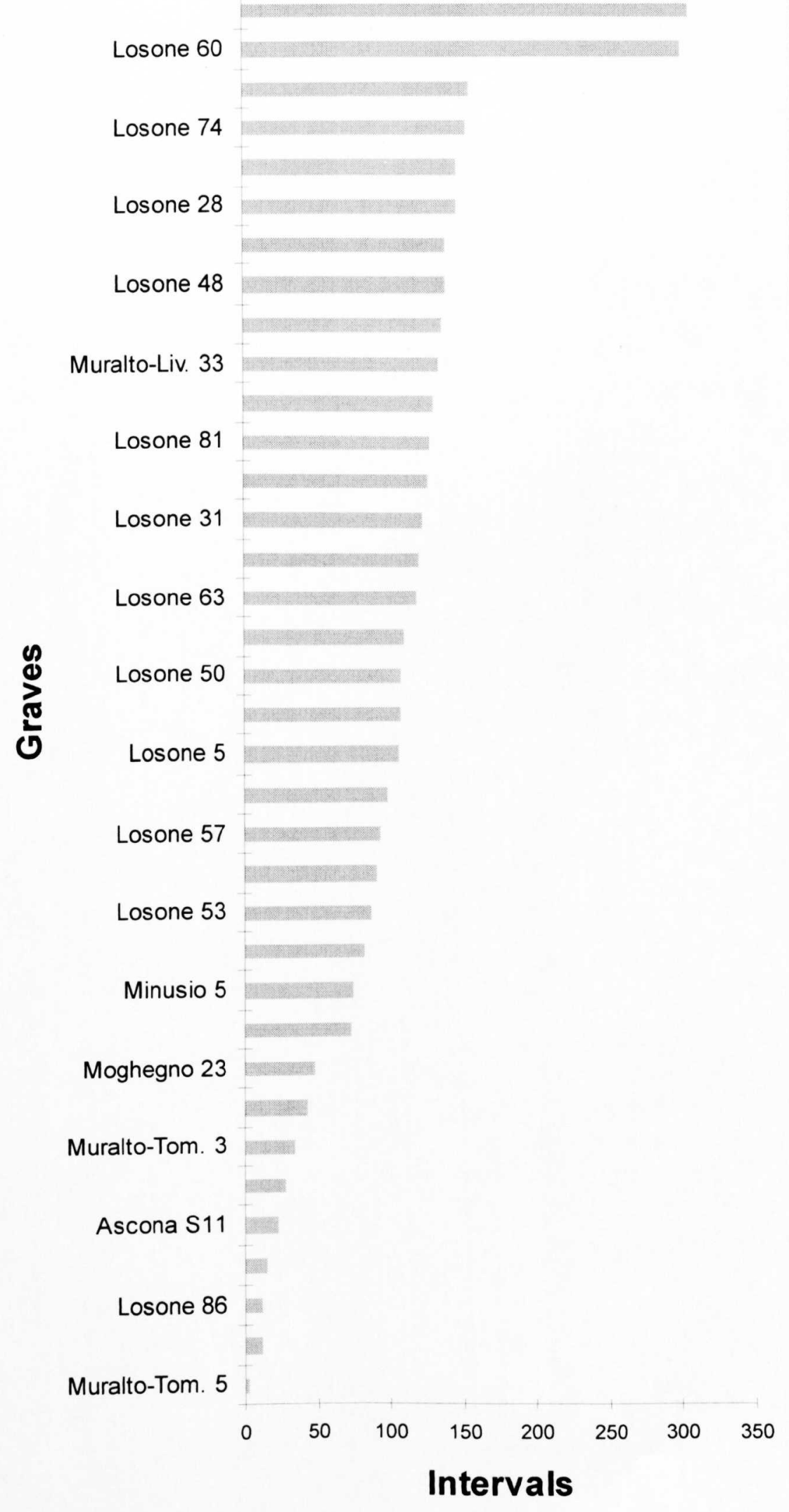

Fig. 3.4. Date-ranges of coins. Average intervals. 
SECTION II : THE MATERIAL 


\section{CHAPTER 4}

\section{The Forms}

\subsection{INTRODUCTION AND METHODOLOGY}

Chapter 4 deals with the typology of the vessels according to their forms. Thin walled and coarse pottery have been divided into eight main groups (Cups, Beakers, Balsamaria, Dishes, Bowls, Jars, Lids, Flagons \& Jugs). Vessels in both thin walled and coarse wares have been listed first, followed by vessels in coarse ware only. In both cases, open forms are followed by closed forms. Each group has been further divided into sub-groups, according to the general features of the vessels (i.e. globular, hemispherical, conical, ovoid, cylindrical body, etc.). Finally, each sub-group consists of several forms, collecting all vessels with similar details. Shape rather than fabric or decoration was the basis for the grouping. The forms, moreover, are not necessarily in chronological order. Each vessel is described with indication of thesis catalogue number, museum inventory number, context, and suggested dating. The dates given in the discussion are those preferred by the author and are discussed in Appendix IV. Full descriptions of the items are in Appendix I. Here the vessels are grouped according to their provenance, in order to avoid losing their context. Although not essential for the attribution to a Form, details of fabric and decoration are mentioned in Chapter 4. Comparanda for each Form are also indicated, together with dating, although these matters will be discussed further in Chapters 7 and 8. 
A minor section of Chapter 4 deals with the possible functions of the vessels, indicating their Latin names, and discusses a few examples of graffiti on coarse pottery. Another section analyses the quantitative presence of thin walled and coarse pottery and its typology in some cemeteries within the study area. 


\subsection{THE FORMS}

\subsubsection{Cups}

The cups found within the study area may be divided into two main groups: raised foot-ring cups and thin walled cups.

\section{Raised foot-ring cups}

Raised foot-ring cups seem to occur instead of drinking vessels of finer ware, which progressively disappeared during the 2nd century AD. At Angera, the presence of raised foot-ring cups within the grave-goods became relevant from the end of the 1st and the beginning of the 2nd century AD (Tomaselli 1985, 461ff.), whereas in Ticino they seem to appear already from the mid-1st century AD.

The study of coarse cups, better than the analysis of other pottery classes, highlights analogies among coarse pottery from Angera, Lomellina, Novara, and the western side of Ticino and Verbano. The manufacture centres of these cups seems to have been local, because their diffusion is limited to a relatively small area during the 2 nd century $A D$.

Raised foot-ring cups in Ticino are characterized by globular or hemispherical body, inturned, out-turned or vertical rounded rim and foot-ring. At Angera, by 
contrast, there occur only types with a globular body and inturned or vertical rounded rim.

\section{Form C1: Cups with globular body and concave base}

Cup $\mathrm{C} 1$ is characterized by a globular body, which becomes rather conical because of a deep depression inside the base. On the outside, a swelling corresponds to this depression.

Examples within the study area may be further divided into two variants according to the rim form:

- Form C1.1: Cup with slightly inturned, rounded rim.

- Form C1.2: Cup with slightly out-turned, short and rounded rim.

\section{Form C1.1}

1 Locarno-Muralto, property Branca, grave 3

2 Moghegno, grave 21, c. AD 160-210

Both cups have beige fabric, hard (3), with medium mica inclusions (size 0.1$0.25 \mathrm{~mm}$ ), and are of J-Ware. The decoration consists of a cordon under the rim and some wide barbotine dots on the shoulder. Cup 2 also has two girth-grooves under the shoulder. Cup 1 comes from a grave with terminus post quem in the second half of the 1 st century AD. It is associated with a sigillata cup and many glass vessels. Cup 2 is also associated with a sigillata cup and a glass vessel, but the date of the grave is $C . A D 160-210$. 
Similar cups also occur at Angera (Maccabruni \& Schifone 1985, 143 pl. 41.9 ; $155-6$ pl. 43.11 ; 179 pl. 45.14 ; 192 pl. 47.5 ; 210 pl. 48.7 ; Tomaselli 1985, 462: Type A; pl. 92A), where they occur from the end of the 1st to mid-2nd century $A D$ and represent the first examples of coarse cups, and at Ghemme, where the example dates to the 2nd century AD (Poletti Ecclesia \& Bonini 1996, XL.27). Their production seems to have been very limited because they do not occur north of the Alps or at Milan.

\section{Form C1.2}

3 Moghegno, grave 23, c. AD 117-50

Form $\mathrm{C} 1.2$ is similar to $\mathrm{C} 1.1$, except for the rim and the decoration. The rim of 3 is short, rounded and out-turned. The cup does not bear any plastic decoration but black slip inside and outside. The fabric is orange-red, medium hard (2), with few mica and sand inclusions (size $0.1-0.25 \mathrm{~mm}$ ). It is of L-Ware. The cup was associated with a sigillata cup, glass and coins dated to the second half of the 1st and the 2 nd century $A D$. The date of the grave is $C$. AD 117-50.

Cups of Form C1.2 do not occur at Angera, where no coarse cup has an outturned rim. 


\section{Form C2: Cups with globular-conical body and rounded rim}

According to the rim, Form C2 may be divided into two variants:

- Form C 2.1: Cup with rounded rim.

- Form C 2.2: Cup with slightly out-turned rim

\section{Form C2.1}

4 Locarno-Muralto, property Branca, grave 4 ; c. AD 50-100

5 Losone-Papögna; cemetery, context unknown

Form C2.1 may be considered a coarse imitation of the sigillata cup Dragendorff Form 40/Conspectus Form 36 (in particular Conspectus Form 36.2.1) with globular-conical body. Both examples, however, show a small depression of the bottom inside, to which corresponds a small swelling on the outside. Form C2.1 may therefore constitute a hybrid form between $\mathrm{C} 1$ with marked depression and protuberance of the bottom, and the sigillata prototype with flat bottom.

The rim of 5 is rather vertical, whereas that of 4 is slightly inturned. A similar slightly inturned rim belongs to a further example of Form C2.1 from grave 57.6 at Airolo-Madrano (Inv. no. 3.57.8; terminus post quem: second half of the 1st century AD). The fabrics of both vessels are of $L-W a r e$. The fabric of 4 is orangered, medium hard to hard (2-3), with medium mica inclusions (size $0.25 \mathrm{~mm}$ ). The only decoration consists of a cordon on the foot-ring. The cup is associated with a sigillata cup. The terminus post quem of the grave is the second half of the 1st century $A D$. A possible date, even if based of a single datable item, is c. AD 50100. The similar cup from Airolo-Madrano is associated with sigillata and glass 
ware and comes from a context (Grave 57.6) with a terminus post quem in the second half of the 1 st century $A D$, but has black slip on inside and outside. Cup 5 has dark red fabric with traces of contact with fire, hard (3) clay, medium mica inclusions (size $0.25 \mathrm{~mm}$ ). The decoration consists of a dark red slip on the outside. The exact context of this cup is unknown.

A vessel similar to 5 occurs at Borgosesia and dates to the 4 th century $A D$ (Brecciaroli Taborelli 1995, $115 \mathrm{pl}$ XXXII.8). At Angera these cups do not bear any slip. They are of Type D (Tomaselli 1985, $466 \mathrm{pl} .92$ : D32) and date to the second half of the 2 nd and first half of the 3rd century AD.

\section{Form C2.2}

6 Locarno-Solduno, property Bonetti, grave Bo2

7 Losone-Papögna; cemetery, context unknown

Form C2.2 consists of a variant of C2.1, with out-turned instead of vertical or slightly inturned rim. 6 has a real out-turned rim, whereas 7 has vertical rim but curved like an out-turned rim.

Cup 6 has red fabric, hard (3), with medium mica inclusions (size $0.25 \mathrm{~mm}$ ). The decoration consists of black slip inside and outside. The cup comes from a grave without datable grave-goods. Cup 7 has dark red to brown fabric, hard (3), with medium mica inclusions (size $0.25 \mathrm{~mm}$ ). Both vessels have fabrics of L-Ware. As by 6 the decoration consists of slip. In this case, however, the slip is dark red and 
on the outside only. This cup also comes from a grave, but the exact context is unknown.

As with cups of Form $\mathrm{C} 1$, the variant with out-turned rim does not occur at Angera. A similar vessel, however, occurs at Greggio (Valsesia) and dates from the end of the 1st and the first half of the 2 nd century AD (Sommo 1989, 43 pl. 4.7).

\section{Form C3: Cups with globular-hemispherical body and rounded rim}

8 Locarno-Muralto, property Ardito, grave C28, c. AD 69-120

9 Locarno-Solduno, property Passetto, grave B3, C. AD 50-100

10 Locarno-Muralto, property Passalli, grave 29, c. AD 50-100

11 Locarno-Muralto, ex-Orselina; cemetery, context unknown

Form C3 has a hemispherical body, very slightly inturned rim, flat bottom and foot-rim. Its direct prototype is the sigillata cup Dragendorff Form 40/ Conspectus Form 36.

Cup 8 still bears a small depression inside and the vertical rim is slightly tapering. The fabric is red, hard (3), with medium mica and sand inclusions (size $0.25 \mathrm{~mm}$ ). The decoration consists of red slip. Cups 9,10 and 11 have slightly inturned rims: the former are rounded, the latter rather triangular in section. Cups 10 and 11 have a girth-groove under the rim, as some examples of sigillata Dragendorff Form 40/Conspectus Form 36 usually do. Cup 10 has a further girth-groove on 
the foot-ring. Its fabric is red, hard (3), with medium mica inclusions (size $0.25 \mathrm{~mm}$ ). The fabrics of both 8 and 10 are of L-Ware. The fabric of 11 is brownbeige with black core, hard (3), with medium mica and crushed quartz inclusions (size $0.25 \mathrm{~mm}$ ), and is of D-Ware. The fabric of 9 is red, hard (3), with medium mica inclusions. Cups 8, 9 and 10 come from contexts dated within c. AD 50-120. The exact context of 11 is unknown.

Form C3 corresponds to Type E at Angera (Lavizzari Pedrazzini 1985b, $362 \mathrm{n}$. 155 ; Tomaselli $1985,466-7$ pl. 92E), dating from the mid-2nd to the first half of the 3rd century $A D$. To the same period belong two vessels from Costa Masnaga-Lecco (Nobile 1994, 217-18 figs. 144.1-2). At Gropello Cairoli, the form occurs already in Tiberian-Claudian times (St 33729 : Arata 1984, 83 pl. IX.4). At Seriate (Bergamo; Ceresa Mori 1980-81, $172-73$ pl. 4.f) and Pioltello (Milan; Ceresa Mori 1986a, 161 fig. 151 no. St 51066) similar vessels come from contexts dated to the 4 th century AD. At Ghemme, an example dates to the 2 nd century AD (Poletti Ecclesia \& Bonini 1996, pl. XXXVIII.1).

\section{Form C4: Cups with hemispherical body, out-turned rim, foot-ring}

Form C4 has wide, out-turned, usually rounded rim. The general form of the cup is more squat and therefore the body is hemispherical.

These cups may be divided into two groups according to the base:

- Form C4.1: Cup with a depression inside and a swelling outside. 
- Form C4.2: Cup without a depression but with a normally curved base.

\section{Form C4.1}

12 Locarno-Muralto, property Liverpool sotto, grave 19, c. $A D 70-120 / 30$

13 Cavigliano, property Monotti, grave 2, c. AD 98-120

14 Losone-Arcegno, grave 16, c. AD 119-40

15 Losone-Arcegno, grave 90, c. AD 98-140

Cups 12 and 13 are very similar. Both have only very slightly out-turned, rounded rims. The fabrics are hard (3), red for 12 or rust-red for 13 , with medium mica inclusions (size $0.25 \mathrm{~mm}$ ). They are of L-Ware. Both have a slip on both sides: black on 13 and dark red to brown on 12. Cup 13 is decorated with a girth-groove under the rim. Both cups from Losone-Arcegno are very similar. The rim is outturned and not as rounded as in the former two cups. The fabrics are red, hard (3), with medium mica inclusions (size $0.25 \mathrm{~mm}$ ). Both cups have a girth-groove under the rim, at the junction with the shoulder, and black slip on the two sides. Another cup, similar to those from Losone-Arcegno, was found at Airolo-Madrano (Inv. no. 3.57.147, no context). All cups come from contexts dated c. AD 70-140.

\section{Form C4.2}

16 Cavigliano, property Monotti, grave 4, c. AD 50-100

17 Cavigliano, property Monotti, grave 5, c. AD 79-100 
All cups have red fabric (rust-red for 18), medium hard to hard (2 to 3 ), with medium mica or few mica and sand inclusions (size $0.25 \mathrm{~mm}$ ). They are of LWare. They are decorated with black slip on inside and outside. Two cups from Cavigliano, 16 and 17, have graffiti on the outside of the bottom (see Chapter 4, Section 4.3.2). The third cup from Cavigliano is fragmentary: the lower half of the body and the foot-ring are missing. It may therefore belong to Form C4.1 rather than C4.2. All cups from Cavigliano belong to contexts dated C. AD 50-100. Another example comes from Airolo-Madrano (Inv. no.3.57.148, no context).

Cups of Form C4 do not occur either at Angera or at Milan. This form seems therefore to be of local origin. The closest parallels to Form C4, in particular C4.2, consist of hemispherical cups with out-turned rounded rim and foot-ring from the Iron Age cemetery at Locarno-Solduno. These cups also have a dark-brown to black slip on the outside. They are associated with mid-La Tène iron brooches and La Tène C1 and C2 bronze brooches (Stöckli 1975, 63 Fig. 59: 'Kopffibeln'). Their contexts (La Tène C1: graves C53; L7; La Tène C2: F5; F6; J14; further La Tène D: E17) date therefore to the 2nd and the 1st century BC. During the La Tène $D$ period the cups with out-turned rim were replaced by cups with vertical and slightly inturned rim. Although there is a gap of some centuries between La Tène and Roman cups with similar features, it is possible to assume that the 
former remained in the local tradition and constituted a sort of 'prototype' for the latter.

\section{Thin walled cups}

Cups with globular body

\section{Form C5: Cups with globular body}

20 Minusio, property Cadra, grave 24

21 Locarno-Muralto, property Liverpool sotto, grave 37, c. AD 37/8-70

22 Locarnese, Catalogue Simonett, context unknown

Form C5 (Ricci 1985, Type 2/214) has globular body, slightly inturned or vertical rim and foot-disc. Its prototypes may be found in Marabini Moeus's Form XXXVI and Mayet's Form XXXVII.

The fabrics are pink to beige, soft and powdery (1), with some mica and sand inclusions (size $0.1-0.25 \mathrm{~mm}$ ). They are of $\mathrm{H}-$ Ware. More sand was applied on the surface of the cups and constitutes the characteristic rough-cast surface. The decoration consists of girth-grooves under the rim $(20 ; 22)$ or a cordon under the rim between two girth-grooves (21). The surfaces of the three cups bear traces of red slip, resembling 'sigillata' red slip, often partly eroded. Only cup 21 belongs to a datable grave, c. AD 37-70. The context of cup 22 is unknown. 
Cups with beige-pink fabrics, rough-cast surface and red slip are known at Angera (Sena Chiesa 1985, 406ff.), but seem to belong to Forms C10 rather than to Form $\mathrm{C} 5$ because of their hemispherical bodies. Globular cups, although they may constitute a variant of hemispherical ones, seem not to have been found at Angera or Milan.

Form C6: Cups with globular body, slightly carination and inturned rim

23 Locarno-Muralto, property Liverpool sotto, grave 20, c. AD 50-100

24 Locarno-Muralto, property Passalli, grave 30, c. AD 70-120

25 Locarno-Muralto, property Passalli, grave 12, c. AD 50-100

Cups 23 and 24 are very similar. The prototypes are Marabini Moeus's Form XXXVI and Mayet's Form XXX/XXXIII. The body is globular and bears a carination at mid-body. The rim is rounded and inturned as is the upper half of the body. The foot-disc is slightly concave. Both fabrics are grey, hard (3), with some mica and many sand inclusions (size $0.25-0.5 \mathrm{~mm}$ ). Cup 25 has grey fabric with some orange patches, medium hard (2), with many mica, sand and quartz inclusions (size $0.25-0.5 \mathrm{~mm}$ ). This kind of surface is the only decoration on the cups of Form C6. All fabrics are of A-Ware. The three cups come from contexts dated c. AD 50-120.

Similar cups seem not to occur at Angera or Milan. The thin walled cup with grey fabric and many sand inclusions appears at Angera (Sena Chiesa 1985, 398ff.), 
but as by the previous Form $\mathrm{C} 5$ does not have globular body. A vessel similar to Form C6 occurs at Legnano (Milan) and dates to the end of the 1st century BC and the beginning of the 1st century AD (Volonté 1996, 185 pl. 35.2 Grave 27).

\section{Form C7: Cups with globular body and inturned rim}

26 Locarno-Muralto, property Liverpool sotto, grave 33, c. AD 36/7-70

27 Locarno-Muralto, property Liverpool sotto, grave 49, c. AD 23-60/70

28 Locarno-Muralto, property Meyster; cemetery, context unknown

29 Losone-Papögna; cemetery, context unknown

These cups have inturned tapering rims, globular bodies with continuous profile, slightly concave foot-discs (Ricci 1985, 287, Type 2/214). Marabini Moeus's Form $X X X V I$ and Mayet's Form XXXV may be considered as prototypes. Their main feature is the decoration: oblique feather-like patterns on the body as a result of indents filled with elements à la barbotine. The rim is usually plain $(26 ; 29)$ or sometimes decorated with a small cordon (27). Cups 28 and 29 are fragmentary but they surely belong to this form.

The fabrics are white-beige $(27)$, beige $(26 ; 29)$ or beige-grey $(28)$. They are soft and powdery (1-2), with medium mica inclusions (size $0.1-0.25 \mathrm{~mm}$ ), and are of $\mathrm{H}$ Ware. The four cups bear traces of dark red to brown or brown to black slip on both sides.

Cups 26 and 27 come from graves dated c. AD 23-70. The exact contexts of the two other cups are unknown. 
At Angera was found a cup similar to 26 , dating from Claudian-Neronian times (Sena Chiesa 1985, 410 pl. 113.2). Other examples come from Linescio (Canton Ticino, upper Valle Maggia; Donati 1981, 16), Gropello Cairoli, and Chur (Sena Chiesa 1985, 410 nos. 120 and 122).

\section{Form C8: Cups with globular-hemispherical body and vertical rim}

30 Locarno-Muralto, property Passalli, grave 3, c. AD 50-100

31 Locarnese, Catalogue Simonett; cemetery, context unknown

32 Locarno-Muralto, property Liverpool sotto, grave 12, c. AD 30-60

Form C8 has a rather hemispherical body, vertical rim, flat or slightly concave foot-disc. Direct prototypes are Marabini Moeus's Form XXXVI and Mayet's Form XXXIII (Mayet 1975, pl. XXXIII.258). Although the form is similar, the three cups belong to two types. Cup 32 has beige fabric, soft and powdery (1) and red slip. The fabric is of $\mathrm{H}$-Ware. The surface is rough-cast because of the application of sand on the outside (size $0.25-0.5 \mathrm{~mm}$ ), but does not reach the rim. Cups 30 and 31 have red, respectively grey fabrics, hard (3). The fabric of 30 is of A-Ware, that of 31 is of G-Ware. The surface is decorated with the many sand and quartz inclusions contained in the clay, but does not bear any slip. The decoration consists of the particular surface and of girth-grooves. Cup 30 bears a girthgroove on the shoulder ; 31 under mid-body, and 32 has two girth-grooves under the rim. Cup 32 comes from a context dated c. AD 30-60; cup 30 from a grave dated c. AD 50-100. 
As with Form C5, this form also has a rather globular instead of hemispherical body and therefore seems not to occur at Angera or Milan. Vessels decorated with applied sand occur at Baden as imports from Lyon and date to the first half of the 1st century AD (Schucany 1999, 179 pl. 96.29). The sand, however, seems to be applied on both outside and inside, on the rim and under the base. Form C8 also occurs at the Magdalensberg, where it becomes common from Tiberian times (Schindler-Kaudelka 1975, 84-7 pl. 13 ; Form 68).

Form C9: Cups with globular body and out-turned rim

33 Ascona, grave 8, c. AD 81-130

The prototypes are Marabini Moeus's Form V and Mayet's Form XLIV. The cup is also similar to Mayet's Form XX, but without handle (Mayet 1975, pl. XXV.192).

The cup has a light grey, soft and powdery (1) fabric with few mica inclusions (size $0.1 \mathrm{~mm}$ ), and is of C-Ware. The decoration consists of two girth-grooves at mid-body, a rouletted band above and one below them. The rouletted bands have been done with two different tools. The cup also has a black slip on both surfaces. This is the only example of Form $\mathrm{C} 9$ from the study area. It comes from a grave dated C. AD 81-130. 
Cups with hemispherical body

Form C10: Cups with hemispherical body and slightly inturned rim

Form $\mathrm{C} 10$ has hemispherical body, slightly inturned rim, flat or slightly concave foot-ring (Ricci 1985, 289-90, Type 2/315; pls. Cll and CLV: suggested production centres in the central and western Po regions and at Aquileia and Emona).

The prototypes are Marabini Moeus's Form XXXVI and Mayet's Form XXXV.

According to the decoration, it may be divided into four groups:

- Form C10.1: Cup with rough-cast surface ;

- Form C10.2: Cup with rouletting and red slip;

- From C10.3: Cup with rouletting and barbotine ;

- Form C10.4: Cup with rouletting.

\section{Form C10.1}

34 Locarno-Muralto, property Liverpool sotto, grave 32, c. AD 41-80

35 Locarno-Muralto, property Liverpool sotto, grave 46, c. AD $22 / 3-70 / 80$

36 Locarno-Muralto, property Liverpool sotto, grave 43, c. AD 40-70

37 Locarnese, Catalogue Simonett, context unknown

The cups bear a rim separated from the body by a girth-groove or a tiny step. The form can go back to central Italian vessels (Marabini Moeus 1973, 194 pl. 35 ; 
Frova 1973-74, pl. 85.10). The fabrics are pink to beige-yellow, soft and powdery (1-2), with many mica, sand and quartz inclusions (size $0.25-0.5 \mathrm{~mm}$ ). They are of $\mathrm{H}$-Ware. The rough-cast outer surface is the result of applied sand. This surface and the smooth inside of the cups bear traces of red $(34 ; 35)$ or brown-black $(36$; 37) slip. Cup 37 also bears two girth-grooves above the foot. Cups 35 and 36 have girth-grooves under the rim. Cups 34,35 and 36 come from graves dated within c. AD 40-80. The exact context of 37 is unknown.

At Angera and Milan these cups occur during Julio-Claudian times and rarely reach the mid-1st century AD (Sena Chiesa 1985, 406ff. pl. 112.4; Ceresa Mori 1991, 42: Forma 1). Two cups occur in Graves 21 and 82 at Ornavasso-Persona, dating from Tiberian-Claudian times (Graue 1974, fig. 23, 2-3). At Legnano, a cup comes from a context dated to Augustan-Tiberian times (Volonté 1996, $189 \mathrm{pl}$. 41.4 Grave 31). North of the Alps, examples dating from Augustan-Tiberian times have been found at Chur (Hochuli-Gysel et al. 1986, 90, 302-3 pl. 21.18), and at the Magdalensberg, dated to C. AD 15-25 (Schindler-Kaudelka 1975, 116-7 pl. 22-23; 176 : Form 115). Other examples occur at Augst (Ettlinger 1949, pl. 22.12), Emona (Petru 1972, pls. $29.6 ; 31.6 ; 42.5 ; 75.7 ; 115.5 ; 158.12$ ), Vindonissa (Ettlinger \& Simonett 1952, fig. 14.4-7 : Form 223), at the Lorenzberg (Ulbert 1965, pl. 13.5) and in Pannonia (von Bonis 1942, pl. 19.59). 
Form $\mathrm{C} 10.2$

38 Moghegno, grave 36, c. AD 34-80

39 Moghegno, grave 37, c. AD 30-80

40 Moghegno, grave 38, c. AD 40-90

Form C10.2 has a slightly squat, hemispherical body and a foot-disc. The walls of cups 38 and 40 are thicker $(2-3 \mathrm{~mm})$ than that of $39(1-2 \mathrm{~mm})$. The fabrics are beige-red, soft and powdery to medium hard (1-2), with medium mica and sand inclusions (size $0.25 \mathrm{~mm}$ ), and are of $\mathrm{H}$-Ware. All cups bear traces of red slip on both sides. The decoration consists of a wide rouletted band that occupies the body, flanked by two groups of girth-grooves. The rim is plain. Cups 38,39 and 40 come from graves dated c. AD 30-90.

The three examples were found in the Roman cemetery of Moghegno, in three graves next to each other and situated in the north-eastern corner of the excavated area, by the cantonal road.

Form C10.2 occurs at Angera and Milan as does Form C10.1. At Ornavasso a cup occurs in grave 23 at Persona, dated to the first half of the 1st century AD (Graue 1974, 170 pl. 56, 4). North of the Alps, cups of form, fabric, surface treatment and decoration similar to C10.2 occur at Chur (Hochuli-Gysel et al. 1986, 302-3 pl. 21.6-8). 


\section{Form $C 10.3$}

41 Minusio, property Cadra, grave 14, c. AD 70-120

42 Losone-Arcegno, grave 21, c. AD 40-70

43 Losone-Papögna; cemetery, context unknown

44 Losone-Papögna; cemetery, context unknown

The fabrics are grey, hard (3), with medium mica inclusions (size $0.1-0.25 \mathrm{~mm}$ ), and are of B-Ware. Cups 41 and 43 have respectively silver grey and black slips on both surfaces.

The decoration consists of girth-grooves and cordons under the rim $(41 ; 44)$ or a simple cordon (43) or a girth-groove (42), barbotine pattern on the shoulder and rouletting on the lower half of the body. The barbotine patterns are in the form of leaves or vine leaves and grapes. Only cups 41 and 42 come from datable contexts: the date for the former is C. AD 70-120, that of the latter is c. AD40-70.

At Angera the association of rouletting and barbotine in the decoration of these cups occurs on vessels from graves dated to Claudian-Neronian times (Sena Chiesa 1985, 404 ; Troso \& Uglietti 1985, 119 pl. 33.1 ; Caporusso et al. 1985b, 275-6 pl. 64.16). The form, as import from northern Italy, occurs at Vindonissa dating c. 10 BC-AD 10 (Meyer-Freuler 1999, 161 pl. 88.13). Form C10.3 also occurs at Turin (Greene 1979, fig. 9.2), at the Magdalensberg dated c. AD 30-40 (Schindler-Kaudelka 1975, 107-10 pl. 20 : Form 102.m). Similar vessels also occur at Emona (Petru 1972, pl. 45.2) and in Pannonia (von Bonis 1942, pl. 20.58-72). 
Form C10.4

45 Locarno-Muralto, property Liverpool sotto, grave 42, c. AD 161-200

46 Minusio, property Cadra, grave 33, c. AD 70-120

The body of Form C10.4 is higher than that of the other variants of Form C10. Both cups have a slightly concave foot-disc. The rims are slightly different; inturned and rounded in 46; very slightly out-turned and triangular in 45 . Both cups have grey fabrics with medium mica inclusions (size $0.1-0.25 \mathrm{~mm}$ ), of BWare. The fabric of 45 is hard (3); that of 46 is medium-hard (2) and the cups bear traces of black slip. The decoration of 46 consists of two groups of girthgrooves under the rim and two rouletted bands on the body. Cup 45 has three groups of cordons on the body and two rouletted bands in between. The context 45 dates C. AD 161-200; that of of 46 c. AD 70-120.

\section{Form C11: Cups with squat, hemispherical body and vertical rim}

47 Locarno-Solduno, property Balli, grave Ba3, c. AD 40-60

48 Losone-Papögna; cemetery, context unknown

49 Losone-Papögna; cemetery, context unknown

Form $\mathrm{C} 11$ has squat, hemispherical body. The rim is vertical and rounded. The foot is a foot-disc. In profile the transition from rim to body is marked by a break. The prototypes are Marabini Moeus's Form XXXVI and Mayet's Form XXXVII. 
The fabrics of 47 and 48 are red, medium hard (2), with some mica inclusions (size $0.1-0.25-0.5 \mathrm{~mm}$ ). They are of $\mathrm{H}$-Ware. Both cups show traces of red slip. Cup 47 is rough-cast with applied sand; the rim is separated from the body by a girth-groove. Cup 48 has a cordon on the rim; the rim is separated from the body by a girth-groove. The body is decorated with barbotine blackberry-like pattern. Cup 49 has grey, medium hard (2) fabric with some mica inclusions (size $0.25 \mathrm{~mm}$ ), of B-Ware. The decoration consists of a cordon under the rim, two rows of barbotine crescents on the shoulder and rouletting on the lower body's half. Only 47 comes from a context with datable grave goods; the date of the grave is C. AD 40-60.

\section{Form C12: Cups with hemispherical body}

Form $\mathrm{C} 12$ has hemispherical body with wide, slightly inturned rim. Its prototype is Marabini Moeus's Form XXXVI. The foot-disc is slightly concave.

The examples of Form $\mathrm{C} 12$ may be divided into two groups:

- Form C12.1: Cup with continuous profile ;

- Form C12.2: Cup with broken profile.

Form C12.1

50 Minusio, property Cadra, grave 33, C. AD 70-120

51 Losone-Papögna; cemetery, context unknown

52 Locarno-Muralto, property Meyster; cemetery, context unknown 
Cups 50 and 51 are very similar. The main feature of this form is the extreme thinness of the wall $(1 \mathrm{~mm})$. The fabrics are light beige, hard (3), with few mica inclusions (size $0.1 \mathrm{~mm}$ ). The fabrics of all vessels of Form C12.1 are of $1-$ Ware. The decoration consists of girth-grooves: cup 50 has two wide grooves on the body; cup 51 has a group of girth-grooves and cordons at mid-body and two grooves above the foot. Cup 52 is a fragment of rim and wall only. Its fabric is beige, medium hard (2), with some mica inclusions. The decoration consists of a small cordon under the rim and barbotine pattern on the body. Only cup 50 comes from a datable context: the date is $c . A D 70-120$.

\section{Form $C 12.2$}

53 Ascona, grave S 14, c. AD 114-50

Cup 53 is very similar in fabric and inclusions to the examples of Form C12.1. The wall is very thin. The fabric is light beige, hard (3), with few mica inclusions (size $0.1 \mathrm{~mm}$ ), and is of I-Ware. The difference to Form C12.1 lies in the profile, which appears as broken because of the decoration. It consists of big indents at mid-body, flanked by two groups of girth-grooves. A further parallel is Marabini Moeus's Form XXVII, in particular because of the broken profile given by the decoration. The latter, however, is a carinated, two-handled cup. The form exists also in glass, as Isings' Form 117, with a more conical body dated to the 4th century AD. It seems not to occur in Canton Ticino. Cup 53 comes from a grave dated C. AD 114-50. 
A similar cup, with smaller indents, was found in the Roman cemetery of Angera dating to Flavian times (Sena Chiesa 1985, 408 pl. 82.27).

\section{Form C13: Cups with low hemispherical body and vertical rim}

Form C13 may be considered as a variant of Form C8. By C13 the rim is wider. Therefore, the general form becomes lower (Ricci 1985, 288-9, Type 2/216: Augustan-Flavian times, and 2/407: Tiberian-Claudian times). The prototypes are Marabini Moeus's Form XXXVI and Mayet's Form XXXIII. At Angera this form seems to occur in Tiberian-Neronian times (Sena Chiesa \& Lavizzari Pedrazzini 1985, pl. 82.2 and 12). At Milan this form falls within 'Forma 2', ranging from Julio-Claudian times to the first quarter of the 2nd century AD (Ceresa Mori 1991, 42). At Ornavasso two cups of Form $\mathrm{C} 13$ with barbotine decoration occur in Grave 23 at Persona, dated to the first half of the 1st century AD (Graue 1974, 170 pl. 56. 3).

According to the decoration it may be divided into four groups:

- Form C13.1: Rough-cast cup.

- Form C 13.2: Rough-cast cup with girth-groove at mid body.

- Form C 13.3: Rough-cast cup with girth-grooves under the rim.

- Form C13.4: Cup with rouletting or other decorations. 


\section{Form C13.1}

54 Locarno-Muralto, property Passalli, grave 6, c. AD 10-60

55 Locarno-Muralto, property Passalli, grave 22, c. AD 20-70

56 Locarno-Muralto, property Passalli, grave 28, c. AD 100-150

57 Locarno-Muralto, ex-Orselina; cemetery, context unknown

58 Locarno-Muralto, property Meyster; cemetery, context unknown

59 Locarno-Muralto, property Meyster; cemetery, context unknown

60 Minusio, property Cadra, grave 4, c. AD 0-30

61 Minusio, property Cadra, grave 5, c. AD 0-30

62 Losone-Papögna; cemetery, context unknown

63 Losone-Papögna; cemetery, context unknown

Cups $54,56,57,58,59,60,61,62$ and 63 have grey, hard (3) fabric with many mica and sand inclusions (size $0.25-0.5 \mathrm{~mm}$ ). These fabrics are of A-Ware. The fabric of 55 is red, hard (3), with many mica and sand inclusions (size 0.25$0.5 \mathrm{~mm}$ ) and is of G-Ware. Except for 62, the only decoration of these cups is the surface with sand and quartz inclusions. Cup 62 also has a small girth-groove under the rim. All examples of Form C13.1 have flat foot-disc. Cup 61 has slightly inturned upper part of the body and rim. Cups 54, 55, 60 and 61 come from contexts dated c. AD 0-70. Also 56 comes from a datable context, c. AD 100-150. 
These vessels occur at Ornavasso (Persona, Grave 112: Graue 1974, $170 \mathrm{pl}$. 76.6 ; c. 15 BC-AD 20), Segusio (Brecciaroli Taborelli 1990, pl. XLIII.226-227, 1st century $A D$ ). Form C13.1 also occurs at the Magdalensberg, where it occurs from c. 25-10 BC and becomes common from Tiberian times (Schindler-Kaudelka 1975, 84-7 pl. 13 ; Form 68).

\section{Form C13.2}

64 Locarno-Muralto, property Passalli, grave 5, c. AD 0-30

65 Locarno-Muralto, property Passalli, grave 21

66 Minusio, property Cadra, grave 4, c. AD 0-30

67 Minusio, property Scascighini, grave 2, C. AD 20-70

68 Minusio, property Cadra, grave 15, c. AD 60-110

Form C13.2 is similar to C13.1, but the decoration of the cups consists of the rough-cast surface and a girth-groove at mid body.

Cups 64 and 65 have beige to red fabrics, hard (3), with many mica and sand inclusions (size $0.25-0.5 \mathrm{~mm}$ ). These fabrics are of G-Ware. Cups 66 and 68 are wider and lower. Cups 66, 67 and 68 have grey and hard (3) fabrics, and roughcast as before. These fabrics are of A-Ware. Cups 64 and 66 come from contexts dated c. AD 10-70; cup 67 was found in a grave with grave-goods dated c. AD 030. The decoration of cup 68 is slightly different from that of the other cups, because the girth-groove is above mid-body. This cup comes from a context dated C. $A D$ 60-110. 
At Ornavasso a cup occurs in Grave 59 at Persona, dated 15 BC-AD 20 (Graue $1974,170 \mathrm{pl}$. 67.2). The form, as import from northern Italy, occurs at Vindonissa dating c. 10 BC-AD 10 (Meyer-Freuler 1999, $161 \mathrm{pl}$. 83.21), and at the Magdalensberg dating from c. $25 \mathrm{BC}$ and becoming common during Tiberian times (Schindler-Kaudelka 1975, 61-64 pl. 7 : Form 28 ; 84-7 pl. 68 : Form 68).

Form C13.3

69 Locarno-Solduno, property Balli, grave Ba3, c. AD 40-60

70 Locarno-Muralto, property Liverpool sotto, grave 35, c. AD 50-100

71 Ascona, grave S18, c. AD 50-100

Cups 69 and 70 have beige fabric, soft to medium hard (1-2), with mica and few sand inclusions (size $0.1-0.25 \mathrm{~mm}$ ). The fabrics are of $\mathrm{H}-\mathrm{Ware}$. The rough-cast surface is the result of the application of sand. The girth-grooves are distributed under the rim, whereas the rough-cast surface occupies the rest of the cup as far as the foot-disc. Both sides bear traces of red slip. Cup 71 has beige-red fabric, hard (3), with many mica and sand inclusions (size $0.25 \mathrm{~mm}$ ), of G-Ware. The decoration consists of the particular surface, a cordon under the rim and light redbrown slip. Grave Ba3 at Locarno-Solduno, where 69 was found, dates C. AD 40$60 ; 70$ and 71 come from graves dated c. AD 50-100. The inventory number of 70 (1936.1088a), however, although written on the vessel, could be wrong. In Simonett's publication $(1941,98)$ a clay balsamarium in Grave 35 at LocarnoMuralto, property Liverpool sotto, corresponds to this number. 
A similar vessel occurs at Gropello Cairoli, where it dates to Tiberian times (St 33727 : Arata 1984, 81 pl. IX.1). Similar cups occur at Augst, from the military site. Their decoration with applied sand, however, seems to reach the rim and be distributed outside and inside the vessels site (Martin-Kilcher \& Fünfschilling 1999, pl. 62.19-21). They were found in the layer corresponding to the leaving of the military settlement and containing material datable to the occupation period $\mathrm{c}$. AD 20/30-50 (Martin-Kilcher \& Fünfschilling 1999, 151).

\section{Form C13.4}

72 Minusio, property Cadra, grave 6, c. AD 40-90

73 Locarno-Muralto, property Märki, grave 4

74 Locarno-Muralto, property Liverpool sotto, grave 26, c. AD 50-80

75 Locarno-Muralto, property Liverpool sotto, grave 48, c. AD 40-80

76 Locarno-Solduno, property Ardito, grave C28, c. AD 69-120

77 Locarno-Solduno, property Balli, grave Ba4, c. AD 50-100

The cups of Form C13.4 have rather low body and wide rim. The fabrics are grey or beige-white, hard (3), with some mica inclusions (size $0.25 \mathrm{~mm}$ ). The fabric of 72 is of A-Ware ; all other, except for 77, are of B-Ware. Each cup bears a different decoration on the body: 72 bears three rows of barbotine dots flanked by two cordons; 73 has girth-grooves; 74 has two cordons with rouletting in between, a rouletted band above the foot and black slip ; 75 shows girth-grooves and cordons with rouletted bands in between; 76 shows two girth-grooves under the rim, rouletting on the body and a shiny, black slip; 77 shows a girth-groove 
and a cordon under the rim, two main rouletted bands on the body and black slip on both surfaces. All examples, except for 76, come from graves dated c. AD 40 100. Cup 76 comes from a context dated C. AD 69-120.

A similar beaker occurs at Asti and dated from mid-1st to the beginning of the 2nd century AD (Zanda \& Preacco Ancona 1994, pl. XLVIII.6). Form C13.4 occurs the Magdalensberg dated from c. AD 20-30 (Schindler-Kaudelka 1975, pl. 17 : Form 84), and at Emona (Petru 1972, pls. $79.11 ; 88.2 ; 147.9 ; 166.16$; 171.1).

Cups with conical body

\section{Form C14: Cups with conical body}

78 Losone-Papögna; cemetery, context unknown

79 Locarno-Muralto, property Meyster; cemetery, context unknown

Form $\mathrm{C} 14$ has conical body and rather vertical rim. The prototype may be Marabini Moeus's Form XXXVII. According to cup 78, the disc-foot is flat. Although they have conical body, 78 and 79 are different. Cup 78 has a very thin wall $(1 \mathrm{~mm})$. The fabrics are white-beige, hard (3), with few mica inclusions (size $0.1 \mathrm{~mm})$, and are of I-Ware. The only decoration is a girth-groove situated on the carination between rim and body. Cup 79 is a fragment of rim and wall. The rim is 
plain. The wall is decorated with small barbotine cells. None of these cups comes from a datable context.

Cups with similar form and fabric and very thin wall occur from Claudian to Hadrianic times. Ricci $(1985,293$, Type $2 / 414)$ suggests a production centre in Baetica (Cadiz).

\section{Form C15: Cups with conical body and high vertical rim}

Its prototypes are Marabini Moeus's Form XXXVI and Mayet's Form XXX.

Form C15 may be further divided into two groups:

- Form C15.1: Cup with rounded shoulder (Ricci 1985, Type 2/347).

- Form C15.2: Cup with inturned shoulder.

\section{Form C15.1}

80 Locarnese, context unknown

81 Cavigliano, property Monotti, grave 4, C. AD 50-100

82 Locarno-Muralto, property Meyster; cemetery, context unknown

83 Locarno-Muralto, property Meyster; cemetery, context unknown

Form $\mathrm{C} 15.1$ has conical body, rounded shoulder, high vertical rim, slightly outturned on the top and foot-disc. The passage from rim to shoulder is marked by a girth groove. Other girth-grooves are distributed on the body. The decoration consists of rouletted bands between the grooves $(80 ; 81)$, barbotine and 
rouletting (82) or girth-grooves only (83). The fabrics are grey, hard (3), with medium mica inclusions (size $0.25 \mathrm{~mm}$ ). They are of B-Ware. Both surfaces show a black slip. Cup 81 comes from a datable contexts: the grave dates c. AD 50100.

Cups of similar form and decoration were found at Angera (Caporusso et al. 1985b, 232-34 pl. 54.1-3) and come from a context dated to Flavian times. The same dating can be suggested for an example from Lurate Caccivio (no context : Butti Ronchetti 1985, pl. XII.5). At Gropello Cairoli, examples similar to 81 date to Tiberian-Claudian times (St 33691 and St 33712 : Arata 1984, 66-67, 73 pl. IV.6 ; 75 pl. VII.1; see also Lamboglia 1950, 34ff.). The same dating is proposed for the examples from the Iberian Peninsula (Mayet 1975, 63-4 no. 230). A cup of this form from Vindonissa dates to the second half of the 1st century AD (Ettlinger \& Simonett 1952, pl. I.21).

\section{Form C15.2}

84 Losone-Papögna; cemetery, context unknown

Form C15.2 has a biconical and flattened body, vertical rim, and flat foot-disc. The transition from rim to body and the carination are marked by girth-grooves. The fabric is grey-black, hard (3), with some mica inclusions (size $0.25 \mathrm{~mm}$ ), and is of B-Ware. Both surfaces show a black slip. On the slip there also appear the fingerprints of the potter. The exact context of the cup is unknown. 
Carinated cups

Form C16: Cups with carination at mid-body, curved wall and high vertical rim

Form $\mathrm{C} 16$ has a relatively high body, a carination at mid-body, a high vertical rim and foot-disc. The lower half of the body is curved. The resulting general form of the cup is therefore rather globular (Ricci 1985, Type 2/237).

The prototypes are Marabini Moeus's Form XXXVI and Mayet's Form XXXIII. At Angera This form occurs in Flavian times (Sena Chiesa \& Lavizzari Pedrazzini 1985, pl. 82.26 and 31).

According to their decoration, these cups have been divided into two groups:

- Form C161: Cup with rouletted decoration.

- Form C16.2: Cup with barbotine and rouletted decoration.

Form C16.1

85 Losone-Arcegno, grave 29, c. AD 50-100

86 Locarno-Muralto, property Liverpool sotto, grave 30

87 Locarno-Muralto, property Liverpool sotto, grave 34, c. AD 81-130

88 Locarnese, Catalogue Simonett, context unknown

89 Locarno-Solduno, via al Passetto, grave B 2, c. AD 50-100

90 Locarno-Solduno, Trench B

The fabrics are grey, hard (3), with few mica inclusions $(0.1-0.25 \mathrm{~mm})$. They are of B-Ware. 
The upper half of the bodies of cups 86 and 88 are decorated with cordons and girth-grooves. The bands between them are rouletted. Cups 85,89 and 90 have girth-grooves and cordons under the rim and rouletting on the body. Cups 85 and 87 also show black slip on both surfaces. Cups 85,87 and 89 come from contexts dated C. AD 50-130.

At Angera, similar cups with rouletting dates to the first half of the 1st century $A D$ (Troso \& Uglietti 1985, 121 pl. 33.8 ; Caporusso et al. 1985b, 234-5 pl. 53.8). Form C16.1 also occurs at the Magdalensberg, dating C. AD 20-30 (SchindlerKaudelka 1975, 98 pl. 18 ; Form 85), at Novaesium (Vegas 1975), at Emona (Plesnicar Gec 1972, pls. $77.10 ; 244.13 ; 191.4$ ), at Vindonissa (Ettlinger \& Simonett 1952, Form 265), and at the Lorenzberg (Ulbert 1965, pl. 13.12).

\section{Form C16.2}

91 Locarno-Muralto, property Branca, grave 4

92 Locarno-Solduno, property Balli, grave Ba9, c. AD 30-70

93 Moghegno, grave 13, c. AD 20-70

The fabrics are grey, medium hard to hard (2-3), with a few mica inclusions (size $0.1-0.25 \mathrm{~mm}$ ). They are of B-Ware. Cup 91 has a girth-groove under the rim ; cups 92 and 93 have a cordon. All cups bear barbotine ivy leaves or vine leaves and grapes on the upper half and rouletting on the lower half of the body. The decoration also includes black slip on both surfaces. The contexts at Solduno and Moghegno date C. AD 20-70. 
A similar cup, decorated with ivy leaves and rouletting, occurs at Angera and dates to Flavian times (Caporusso et al. 1985b, 278-9 pl. 65.19). Form C16.2 occurs at Turin (Greene 1979, fig. 9.2), at the Magdalensberg dated c. AD 30-40 (Schindler-Kaudelka $1975,107-10$ pl. 20 : Form 102.l-m). Similar vessels also occur at Emona (Petru 1972, pl. 45.2) and in Pannonia (von Bonis 1942, pl. 20.58-72).

\section{Form C17: Cups with carination at mid-body, straight wall and high vertical rim}

Form $\mathrm{C} 17$ has rather high body, vertical rounded rim and flat or slightly concave foot-disc. The carination is situated at mid-body. The upper half of the body is vertical, the lower half is straight or only slightly curved (Ricci 1985, 291, Type 2/323). The prototypes are Marabini Moeus's Form XXXVI and Mayet's Form XXXXXXXIII.

According to the decoration, the cups of Form $\mathrm{C} 17$ have been divided into four groups:

- Form C17.1: Plain cup.

- Form C17.2: Cup decorated with girth-grooves.

- Form C17.3: Cup decorated with rouletting.

- Form C17.4: Cup decorated with barbotine elements or barbotine and rouletting. 
Form C17.1

94 Locarno-Solduno, property Balli, grave Ba2, c. AD 50-100

Cup 94 has a grey fabric, hard (3), with many mica and sand inclusions (size $0.25-0.5 \mathrm{~mm})$, and is of A-Ware. The decoration consists of the surface with inclusions. The cup comes from a grave dated c. AD 50-100.

\section{Form C17.2}

$95 \quad$ Locarnese ; context unknown

Cup 95 has a very high upper half of the body. The fabric is white-pink, hard (3), with a few mica inclusions (size $0.1 \mathrm{~mm}$ ), and is of I-Ware. The wall is very thin. The decoration consists of two groups of girth-grooves: on the upper half of the body and on the carination. This cup bear a catalogue number similar to those of the grave-goods excavated by Simonett in Locarnese, but is not mentioned in the publication (Simonett 1941). Site and exact context are therefore unknown.

\section{Form $C 17.3$}

96 Losone-Papögna, grave 5

$97 \quad$ Losone-Papögna, grave 34

98 Ascona, no context

99 Locarno-Solduno, Trenches 1956/58 
Locarno-Solduno, Modern cemetery, grave 58.20 ,

c. AD $70-120$

101 Locarno-Solduno, property Passetto, grave B10, c. AD 40-90

102 Locarno-Muralto, property Liverpool sopra, grave 12, c. AD 80-120

103 Locarno-Muralto, via Scazziga, settlement

104 Locarnese, context unknown

105 Moghegno, grave 7, c. AD 40-90

106 Moghegno, grave 22, c. AD 138-50

The cups of Form C17.3 may be further divided into two groups: cups with black or grey slip and cups without black slip.

To the first group belong cups 102, 104, 105, 106 (with black slip), 97 and 101 (with grey slip). The fabrics are grey or grey to beige. All cups, except for 97 and 101, have hard (3) clay, with low to medium mica inclusions (size $0.1-0.25 \mathrm{~mm}$ ). The other cups have a soft to medium hard (1-2) clay, and the same inclusions as before. Cups 96, 98, 99, 100 and 103 have the same fabric as the other cups, but there is no trace of any slip. Cups 97 and 101 are of D-Ware. All other fabrics are of B-Ware. The decoration consists always of rouletting on the body. Rouletting may be associated with a group of girth-grooves and cordons under the $\operatorname{rim}(98,101,104,105)$, two small cordons (97), a girth-groove just under the rim and another about $1 \mathrm{~cm}$ deeper $(99,102,103,106)$, girth-grooves under the rim and on the body $(99,100)$ or a plain rim with a girth-groove about $1 \mathrm{~cm}$ deeper (96). 
Only a few cups come from datable contexts: c. AD 40-90 for 101 and 105; C. AD 70-120 for 100 and 102; c. AD 138-50 for 106 .

Similar vessels, dated to the 1st century AD, were found at Chur (Hochuli-Gysel et al. 1986, 302-3 pl. 21.14-15), and at Angera dating to Claudian-Neronian times (Caporusso et al. 1985b, 282 pl. 65.10).

\section{Form C17.4}

107 Losone-Arcegno, grave 22

108 Losone-Arcegno, grave 46, c. AD 80-130

109 Losone-Papögna; cemetery, context unknown

All cups have a grey and hard (3) fabric, with medium mica inclusions (size $0.25 \mathrm{~mm}$ ), and bear black slip on both sides. They are of B-Ware. The two cups from Losone-Arcegno show a sharp carination. The vertical upper half of the body is decorated with barbotine comb-like pattern, partly laid one on the top of the other. On cup 108 the barbotine band is flanked by girth-grooves: two under the rim and one over the carination. Cup 107 also bears a girth-groove under the rim; the decoration continues below the barbotine as rouletting. Cup 109 shows girth-grooves and barbotine concentrical crescents on the upper half of the body and a rouletted band under the carination. Only cup 108 comes from a datable context, c. AD 80-130. 
This form occurs at Angera in Claudian-Neronian times (Sena Chiesa \& Lavizzari Pedrazzini 1985, pl. 82.7-9) and at Milan in the first half of the 1st century AD (Ceresa Mori 1991, 42-43, Forma 2/404 ; pl. Cll, suggested production centres in the central and western Po regions). Fragments of a plain cup with profile similar to 108 occur at Lurate Caccivio (no context, suggested dating: mid to second half of the 1st c. AD : Butti Ronchetti 1985, pl. XII.6). Other vessels of Form 17 occur in Piemonte during the 1 st century $A D$ and the first half of the 2 nd century AD at Asti (Zanda - Alessio \& Lavati 1988, 27-8 pl. IX.17), Alba (Filippi 1982, 44 pl. XXXVIII.175), Industria (Bacci Spigo 1979, fig. 2.35), Alessandria (Zanda \& Preacco Ancona 1994, pls. XXXVII.3; XXXVIII.12; XXXIX.1; XLII.4), and Poirino (Filippi 1987, pl. XXX.9). North of the Alps, examples of Form C17.3 occur at Chur (Hochuli-Gysel et al. 1986, 90, 302-3 pl. 21.14-15). The form is one of the best represented in central Transpadana and Canton Ticino during the second half of the 1st century AD (see also Zanda \& Preacco Ancona 1994, 139 ; Greene 1972, 10 fig. 9.6; Maioli 1972-73, 113ff.). Its absence among the material from the Magdalensberg could to confirm the dating from mid-1st century AD (Hochuli-Gysel et al. 1986, 90). 
Form C18: Cups with carination over mid-body, straight wall and high vertical rim

110 Losone-Papögna, grave 5

111 Losone-Papögna; cemetery, context unknown

112 Losone-Papögna; cemetery, context unknown

113 Losone-Arcegno, grave 19, c. AD 85-100

114 Locarno-Muralto, property Liverpool; cemetery, context unknown

115 Locarno-Solduno, via al Passetto, destroyed grave

Direct prototypes of Form C18 are Marabini Moeus's Form XXXVI and Mayet's Form XXX.

Cups 110,112 and 114 have a grey to beige-grey fabric, soft to medium hard (12), with a few mica inclusions (size $0.1-0.25 \mathrm{~mm}$ ). These fabrics are of $\mathrm{C}-\mathrm{Ware}$. The other cups have a grey and hard (3) fabrics with the same inclusions, of BWare. The decoration consists of a girth-groove under the rim and two rouletted bands on the body $(111,112)$, or a group of girth-grooves and cordons under the rim and rouletting on the body $(110,113,115)$ All cups have black slip on both sides. Only cup 113 comes from a datable context, c. AD 85-100.

At Angera this form occurs in Claudian-Flavian times (Sena Chiesa \& Lavizzari Pedrazzini 1985, pl. 82. 9 and 26), at Lurate Caccivio it occurs in graves dated to the second half and to the end of the 1st C. AD (Butti Ronchetti 1985, pls. VI.5; VIII.4), at Alba and Alessandria at the end of the 1st and the beginning of the 2nd 
century AD (Cagnana 1994, 112-3 pl. XXXIII.4 ; Zanda \& Preacco Ancona 1994, $157 \mathrm{pl} . \mathrm{XLI} .1)$.

\section{Form C19: Squat cups with carination and vertical rim}

Form C19 has a wide, vertical rim, a carinated body and a flat or slightly concave foot-disc. The body is rather short and the general form appears squat. The prototypes are Marabini Moeus's Form XXXVI and Mayet's Form XXXIII. According to the decoration, Form C19 may be divided into three groups:

- Form C19.1: Cup with rouletted decoration.

- Form C19.2 Cup with barbotine decoration.

- Form C19.3: Cup with barbotine and rouletted decoration.

\section{Form C19.1}

116 Solduno, via al Passetto, context unknown

117 Locarno-Muralto, property Liverpool sotto, grave 33, c. AD 36-70

118 Locarno-Solduno, Modern cemetery, grave 58.13, c. AD 70-120

119 Losone-Papögna; cemetery, context unknown

120 Losone-Papögna; cemetery, context unknown

121 Moghegno, grave 8, c. AD 85-100

122 Moghegno, grave 32, C. AD 50-100 
Cups $116,120,121$ and 122 have grey fabrics, soft and powdery to medium hard (1-2), with a few mica inclusions (size $0.1-0.25 \mathrm{~mm}$ ). These fabrics are of C-Ware. All these cups show black slip on both surfaces.

Cups 117,118 and 119 have grey and hard (3) fabrics with the same inclusions as before, but no slip. These fabrics are of B-Ware. The decoration consists of girth-grooves and cordons under the rim and rouletting on the body $(116,118$, 122), two cordons under the rim and rouletting (120), one or more girth-grooves under the plain rim and a girth-groove about $1 \mathrm{~cm}$ lower and rouletting $(117,119$, 121).

Cup 117 comes from a grave dated c. AD 36-70;121, 122, 118 come from graves dated C. AD 50-100/20.

Similar cups occur in Piemonte during the 1st century AD at Asti (Zanda - Alessio \& Lavati $1988,27-8$ pl. IX.12; $14 ; 15$; first half of the 1 st century AD), Alba (Filippi 1982, 144 pl. XXXVIII.174), Industria (Bacci Spigo 1979, fig. 2.36-37), and Caselette (Wataghin Cantino - Lanza \& Crosetto 1980, 124 pl. XLV.13).

Form C19.2

123 Maggia; cemetery, context unknown

124 Moghegno, grave 35, c. AD 30-80

Both cups have grey, medium hard (2) fabric, with few mica inclusions (size 0.1$0.25 \mathrm{~mm}$ ), of B-Ware. Cup 123 is decorated with two wide girth-grooves under the rim and a band of barbotine dotted triangles separated by vertical elements over 
the carination. Cup 124 has girth-grooves and cordons under the rim, the same band of dotted triangles separated by crescents and traces of black slip on both surfaces. Only 124 comes from a datable context, c. AD 30-80.

\section{Form C19.3}

125 Locarno-Muralto, property Liverpool sotto, grave 20, c. AD 50-100

126 Locarno-Solduno, property Passetto, grave B1, C. AD 70-120

127 Locarno-Muralto, property Liverpool sotto, grave 26 , c. AD 50-80

128 Minusio, property Cadra, grave 28, c. AD 50-100

129 Locarno-Solduno, Modern cemetery, grave 58.12, c. AD 70-120

The cups have a grey, medium hard $(2: 126,128)$ to hard $(3: 125,127,129)$ fabric, with a few mica inclusions (size $0.1-0.25 \mathrm{~mm}$ ). The fabrics are of B-Ware. All cups bear traces of black slip on both surfaces. Barbotine elements and rouletting are associated in the decoration.

Cups 125 and 127 have two girth-grooves under the rim, a band of spaced barbotine comb-like pattern, other two girth-grooves over the carination and a rouletted band. Cups 126 and 128 have plain rim and a small cordon about $1 \mathrm{~cm}$ deeper. The decoration of 126 consists of big barbotine combs and rouletting on the carination; that of 128 of vertical barbotine elements and rouletting under the carination. Cup 129 has two cordons under the rim, barbotine ivy leaves over the carination and rouletting underneath.

Cups 125, 127 and 128 come from contexts dated C. AD 50-100; 126 and 129 date c. AD 70-120. 
Other similar vessels, decorated with rouletting and barbotine combs, occur at Ornavasso-Persona dated to the first half of the 1st century AD (Graue 1974, 170 pl. 57.4), at Angera dated to Neronian times (Caporusso et al. 1985b, 262-3 pl. 62.12), at Bologna and Portorecanati dated to Tiberian times (Bergamini 1980, pl. XV.267 ; Mercando 1974, 211 fig. 126e).

Form C19 occurs at Cosa in Tiberian-Claudian times (Marabini Moeus 1973, pl. 44.409: 'Alpine product'), and at Angera in Tiberian-Neronian times (Sena Chiesa \& Lavizzari Pedrazzini 1985, pl. 82.3 and 14). It is rare at the Magdalensberg, where it dates C. AD 35-45 (Schindler-Kaudelka 1975, 110-1 pl. 20 : Form 103), and occurs in Pannonia (von Bonis 1942, pl. 19.61).

\section{Form C20: Squat cups with carination and slightly curved rim}

Form $\mathrm{C} 20$ is similar to Form $\mathrm{C} 19$, but the rim is slightly inturned.

The prototypes are Marabini Moeus's Form XXXVI and Mayet's Form XXX. This form occurs at Angera and Gropello Cairoli in Flavian times (Sena Chiesa \& Lavizzari Pedrazzini 1985, pl. 82.26 ; Arata 1984, 79 pl. VIII.2, St 33720).

According to the decoration the cups have been divided into two groups:

- Form C20.1: Cup with rouletted decoration.

- Form C20.2: Cup with barbotine and rouletted decoration. 
Form $\mathrm{C} 20.1$

130 Locarno-Muralto, property Liverpool sopra, grave 8, c. AD 79-100

131 Losone-Papögna; cemetery, context unknown

Cups 130 and 131 have grey, hard (3) fabrics, with few mica inclusions (size 0.1$0.25 \mathrm{~mm}$ ). The fabrics are of B-Ware. The decoration consists of a corrugated rim and rouletting on the body. Cup 131 also bears a shiny black slip on both sides. The terminus post quem for 130 is the first half of the 1 st century AD. The exact context of 131 is unknown.

A similar cup occurs at Lurate Caccivio, from a grave dated to the second half of the 1st c. AD (Butti Ronchetti 1985, pl. III.10). At Alba, this form occurs at the end of the 1st and the beginning of the 2nd century AD (Cagnana 1994, 112-3 pl. XXXIII.5).

\section{Form C20.2}

132 Locarno-Muralto, property Meyster; cemetery, context unknown

133 Locarno-Solduno, Modern cemetery, grave 56.1, c. AD 50-100

Both cups have grey fabric with few mica inclusions (size $0.1-0.25 \mathrm{~mm}$ ), of BWare. The clay of 132 is medium hard (2), that of 133 is hard (3).

The decoration consists of barbotine dotted grapes under the rim (132) or stylized vine leaves and grapes (133) and rouletting under the carination. Cup 132 also 
bears traces of black slip. The only cup from a datable context is 133 , c. AD 50 100.

Cups with cylindrical body

\section{Form C21: Cups with cylindrical body}

134 Minusio, property Cadra, grave 4, c. AD 0-30

135 Minusio, property Cadra, grave 4, c. AD 0-30

136 Minusio, property Cadra, grave 5, c. AD 0-30

The prototype could be Mayet's Form VII (see Ricci 1985, Type 2/240, but without handles):

The three cups of Form C21 come from two graves found at Minusio in the same area. The cups are almost identical in features and dimensions: the body is cylindrical, the foot-disc slightly concave, the rim slightly out-turned and rounded. The fabrics are grey, hard (3), with many mica and sand inclusions (size 01 $0.25 \mathrm{~mm})$, and are of A-Ware. The decoration consists in two cases of a garland of fat barbotine 'berries' on the body: on 136 it is flanked by two rows of dots; on 134 there are only a girth-groove and a row of dots above the garland. Cup 135 shows a garland of dotted elements, flanked by two rows of dots. Both decorative pattern seem to go back to metallic prototypes (Schindler-Kaudelka 1975, 92-6 pl. 16: Form 80). Graves 4 and 5 at Minusio-Cadra date c. AD 0-30. 
Cups with similar form, fabric and decoration occur in Piemonte (Greene 1979, pl. 9.3), at Pollentia, at Emona (Petru 1972, pls. 27.12 ; 110.16) and at the Magdalensberg (Schindler-Kaudelka 1975, 92-5), where they date to c. 25-10 BC. Schindler-Kaudelka (1975, 92-5 pl. 16.80d and 80k) suggests manufacturing centres in the region of Turin because of the frequent presence of these vessels.

\section{Form C22: Cups with indented body}

137 Moghegno, grave 5, c. AD 80-100

138 Losone-Papögna, grave 34

The prototype is Mayet's Form VII.

Form C22 has a cylindrical, indented body and flat foot-disc. The rim is vertical (137) or slightly out-turned (138). The fabrics are beige, hard (3), with few mica inclusions (size $0.1 \mathrm{~mm}$ ), and are of $1-$ Ware. The wall is extremely thin. This form may be connected to the beakers of Form BK29, with the same features. Only 137 comes from a datable context, c. AD 81-100.

This form occurs with a slightly different rim at Angera in Claudian-Neronian times (Sena Chiesa \& Lavizzari Pedrazzini 1985, pl. 82.20). 


\section{Handled cups}

\section{Cups with globular body}

Handled cups occur five times within the study area: three examples are thin walled (cups $139,140,141$ ) and one has a thicker wall and is therefore closer to coarse pottery (cup 142). As it often occurs with beakers, similar forms may occur in both coarse and thin walled variants. The last handled cup (143) belongs to a different form and definitely to coarse pottery.

\section{Form C23: Cups with foot-disc}

139 Ascona, no context

140 Locarno-Solduno, Modern cemetery, grave 80.1

141 Locarno-Muralto, property Passalli, no context

142 Vira Gambarogno, Property Saxer; cemetery, context unknown

The four handled cups are of Marabini Moeus's 1973 Forms L/LI/LXVIII by Marabini Moeus, which she dated to Tiberian-Neronian times: out-turned ( $L$ and LXVIII) or inturned curved rim (LI), globular body and flat foot-disc (see Ricci 1985, Type1/111).

Cups 139 from Ascona and 140 from Locarno-Solduno are very similar. Their form may be traced back to Marabini Moeus's Form LXVIII, with which they share body with lower belly, flared towards the flat foot-disc, and handle reaching mid- 
body. Cup 140, moreover, also shows a cordon on the neck, as Marabini Moeus's Form LXVIII does. Both examples, however, have a sharply out-turned rim closer to Marabini Moeus's Form L rather than Form LXVIII. Cup 141 from LocarnoMuralto also finds close parallels in Marabini Moeus's Form LXVIII, even if the belly is less pronounced and the foot-disc is slightly concave. The slightly inturned rim, however, belongs rather to Marabini Moeus's Form LI. The same may be said of cup 142. The rim, however, is partly missing and it is impossible to determine whether it is closer to Marabini Moeus's Forms L or LI. Thickness of wall and especially fabric allow one to place the cup within the coarse pottery class. Cups 139, 140 and 142 have a hard (3), red-brown fabric with a few and fine mica inclusions (size $0.1 \mathrm{~mm}$ ), of L-Ware. Cup 142 also shows traces of fire. Cup 141 has a hard (3), red- pink fabric with some medium mica inclusions (size $0.25 \mathrm{~mm}$ ), of N-Ware. None of these cups comes from datable contexts.

Cups 139 and 140 are similar to examples from the Roman cemetery at Angera (Facchini et al. 1985, 81 pl. 24.13 ; 110 pl. 31.7 ; Maccabruni \& Schifone 1985, 136-7 pl. 39.3 ; Caporusso et al. 1985, 159 pl. 42.13 ; Sena Chiesa \& Lavizzari Pedrazzini 1985, pl. 83.2-3), dated to Trajanic-Antonine times. 141 is close to another cup from Angera (Sena Chiesa \& Lavizzari Pedrazzini 1985, pl. 83.12) also dated to Trajanic-Hadrianic times. Cup 142 resembles a vessel from Angera dating from the Antonine period (Sena Chiesa \& Lavizzari Pedrazzini 1985, pl. 83.19). 


\section{Form C24 : Cups with flat base}

\section{Locarnese, context unknown}

Cup 143 belongs to the coarse pottery class and is totally different from the former examples. It consists of a globular cup with a wide three-ribbed handle, surmounted by a thumb impression near the rim, slightly out-turned triangular rim and slightly concave base. The fabric is hard (3), beige, with fine to medium mica inclusions (size $0.1-0.25 \mathrm{~mm}$ ). It is of $\mathrm{J}-\mathrm{Ware}$. The surface bears traces of contact with fire. The context is unknown. According to its catalogue number, this cup seems to belong to the grave-goods excavated by Simonett in the Locarno area in 1936 and published in 1941. In Simonett's publication, however, there is no mention of this item.

The form does not find any parallels at Angera.

Handled cups occurred among the grave-goods at Angera during Flavian times or slightly earlier, and replaced the handleless cups as drinking vessels, as beakers Form BK10 did (Sena Chiesa 1985, 417-19). During the 2nd century AD, however, the handled cup became commoner than the beaker (Carandini 1977, 26; Mercando 1974, e.g. Graves 18, 35, 187, 212). At Pompeii, beakers and handled cups appeared together with cups (Carandini 1977, 26). From Trajanic times onwards, the presence of handled cups and beakers became exclusive at Luni (Frova 1977, 373-374, 466, 469) and Ostia (Carandini et al. 1968, 65ff. no. 143; Carandini et al. 1973, 360; Carandini et al. 1977, 333-4) and in northern Italy 
(Ricci 1981, 133). The examples from northern Italy, however, are usually plain, whereas those from Ostia are often sanded or have a combed decoration (Caselette 1977, 28, 30; Beltràn Lloris 1978, 787). 


\subsubsection{Beakers}

Definition : BEAKER is a vessel of suitable size and shape to hold in the hand for drinking (Webster 1976, 9).

The beakers in this work, however, shade off into jars including small ovoid jars.

Beakers with globular body

\section{Form BK1: Beakers with out-turned rim and foot-ring}

144 Locarno-Solduno, property Ceschi, grave K3, c. AD 70-120

This form finds its prototypes in Mayet's Form XL and Marabini Moeus's Form $V$ (Marabini Moeus 1973, 62; from the beginning of the 1st century BC). The only example from the study area comes from Locarno-Solduno. It also represents the only beaker with globular or ovoid body so far known with footring as the central Italian prototypes, instead of flat foot or foot-disc. The fabric is red, hard (3), with few mica inclusions (size $0.1 \mathrm{~mm}$ ), and is of L-Ware. The surface, which shows traces of contact with fire, is decorated with rouletting. The distribution of rouletting on the whole body, except for a narrow band over the foot, resembles that of the earliest example of Form BK10.1, beaker 169 from Locarno-Solduno (c. AD 50-100). Grave K3, from which comes beaker 144 , dates to $C . A D 70-120$. 


\section{Form BK2: Beakers with globular to biconical body}

145 Locarno-Muralto, property Farinelli; cemetery, context unknown

This form occurs only once within the study area. It is roughly similar to Mayet's Form XX, although the latter bears one handle and a more rounded body. The example from Muralto has a very thin wall. The fabric is white as result of a reduced firing and hard (3), and is of I-Ware. It does not show any particular inclusion. The beaker belongs to some grave-goods recovered at the end of last century, whose exact context is today unknown.

\section{Form BK3: Beakers with long neck}

146 Locarno-Muralto, property Passalli, grave 9, c. AD 50-100

147 Locarno-Muralto, property Passalli, grave 9, c. AD 50-100

Form BK3 has an out-turned rim, a long vertical neck, a rounded body and a disc-foot. It is similar to Mayet's Form VIII, which shows a foot-ring (Mayet 1975 , pl. XII.92). This beaker occurs twice only within the study area. Both examples are thin walled and come from property Passalli's grave 9 at Locarno-Muralto. According to the datable grave-goods, the date of this grave falls within $c$. AD 50-100. The decoration consists of three rows of barbotine dots on the belly. By 146 they border upon two girth-grooves; by 147 there is a cordon over the upper row. Beaker 146 also bears a further girth-groove over the belly. The fabrics are beige (146; J-Ware) or red (147; L-Ware), hard (3), 
with few to medium fine mica inclusions (size $0.1 \mathrm{~mm}$ ). Both beakers bear traces of black slip.

Similar beakers have been found at Milan (Guglielmetti et al. 1991, 44: Form 1/205; Caporusso et al. 1991, pl. XII,1) and at Ornavasso (Graue 1974, 260 pl. 69.3: Persona, Grave 90), and date to Augustan and Tiberian times. On the contrary, this form does not occur at Angera. Ricci $(1985,277 \mathrm{pl}$. $L X X X I X .13)$ suggests that these beakers were manufactured in the western Po area.

\section{Form BK4: Beakers with globular body}

Form BK4 has out-turned rim, short vertical neck, onion-shaped body with high shoulder, foot-ring (except for Form BK.4, with foot-disc). It is similar to Mayet's Form XXI, which has more rounded body (Mayet 1975, pl. XXVI.196). These beakers may be divided into three groups according to their profile:

- Form BK4.1: Profile as continuous line from neck to body.

- Form BK4.2: Profile broken between neck and body.

- Form BK4.3: Profile as BK4.1 but with double curved neck.

\section{Form BK4.1}

148 Minusio, property Cadra, grave 13, c. AD 20-70

149 Losone-Arcegno, grave 16, c. AD 119-40 
Beakers 148 and 149 are very similar. The form may be traced back to Mayet's Form XXI, although the examples from Ticino do not show the globular body. Beaker 148 is thin walled, has a medium-hard (2), red fabric with medium mica inclusions (size $0.1-0.25 \mathrm{~mm}$ ), and shows traces of fire. Beaker 149 belongs to the coarse pottery class. Its fabric is red, hard (3), with medium mica inclusions (size $0.25 \mathrm{~mm}$ ), and is of L-Ware. The neck is slightly longer than 148, the rim less flattened, and the foot-ring out-turned instead of inturned. Beaker 148 comes from Cadra's grave 13, at Minusio. The date, suggested according to the datable grave-goods, belongs within C. AD 20-70. A coarse beaker, found in Grave 35 at Ornavasso-Persona, shows similar details as the example from Minusio, such as the flattened rim and the 'inturned' foot-ring (Graue 1974, pl. 59.7). This beaker comes from a grave dated from 50 to 25/15 BC (Graue 1974, 170: 'Zeitgruppe III' and fig. 55). Losone-Arcegno's grave 16, from which comes 149, dates C. AD 119-40.

The form appears during the 1st $\mathrm{c} . A D$ in the Po region. It is attested in the settlement and the cemetery of Angera (Sena Chiesa \& Lavizzari Pedrazzini 1995, pl. 93.13). In the cemetery, however, there occurs a variant of this form (Sena Chiesa \& Lavizzari Pedrazzini 1985, pl. 96.1): the body is more flattened and the rim only slightly out-turned. This beaker dates from Augustan to Neronian times. At Ottobiano (Lomellina) there occur three examples dating from the end of the 1st c. BC to the first half of the 1st c. AD (nos. ST 34332, St 34443 , St 34445 : Vannacci Lunazzi 1986, 53 ; 80-81; pls. IV.4; VIII.4 and VIII.7). At Dorno (Pavia) two examples come from contexts dating from the 1st century BC (Graves 9 and 12 : Antico Gallina 1985, 118, 120 pl. V.8; 143 pl. 
IX.2). Other examples come from Russi (Mazzeo Saracino 1977, 119 fig. 57 no. 566 ; Bergamini 1973, 24 pl. XI.95), Carpigiano (Gervasini Pidatella 1984, 65 pl. XXVI.65), Modena-S. Damaso (Modena 1988, 504 fig. 443.2), Calvatone (Masseroli 1996, 89 tabella 12a figs. 87-88), Ivrea (Brecciaroli Taborelli 1987, 127 pl. XLV no. 343/127).

\section{Form BK4.2}

150 Losone-Arcegno, grave 25

Beaker 150 represents a variant of the former beakers: the rim, triangular, is only slightly out-turned and the foot is like a slightly concave foot-disc rather than a foot-ring. The main difference, however, consists of the profile. The profiles of beakers 148 and 149 are continuous lines from the rim to the foot. The profile of beaker 150 , by contrast, a line broken by the junction neckbody. The beaker from Losone-Arcegno belongs to the coarse pottery. Its fabric is dark-brown to black, hard (3), with medium mica and sand inclusions (size $0.25 \mathrm{~mm}$ ). Grave 25 did not contain any datable grave-good.

Similar examples come from Ornavasso-San Bernardo (Graves 165 and 17: Graue 1974, 241 pls. 19 and 19.8) and Ornavasso-Persona (Grave 33 : Graue 1974, pl. 58.5). Both date to the end of the Republican period (Graue 1974, $217-18 ; 251-2)$. Another example occurs at Gropello Cairoli and date to the end of the 1st c. BC and the beginning of the 1st c. AD (St 33707 : Arata 1984, 73 pl. VI.4). 
Form BK4.3

151 Locarno-Muralto, property Liverpool sotto, grave 12, c. AD 30-60

Beaker 151 seems to represent a variant of Form BK4.1: the neck is still conical, but it consists of two slightly curved halves. The fabric is white, hard (3), with medium mica inclusions (size $0.1 \mathrm{~mm}$ ), and is of $1-$ Ware. The beaker is thin walled. It comes from grave 12 at Muralto- Liverpool sotto, dated c. AD $30-60$.

Form BK5: Beakers with short out-turned rim and flat base

152 Minusio, property Cadra, grave 10, c. AD 10-30

The example from Minusio-Cadra has red fabric, medium hard (2), with medium mica inclusions (size $0.25 \mathrm{~mm}$ ). It is of L-Ware. The date of grave 10 is c. $A D$ 10-30.

This form seem not to occur at Milan, Angera or Ornavasso. Generally, it appears in Comasco, Lomellina, Liguria and Piemonte (Butti Ronchetti 1986, 121 and $n .83 ;$ pl. IV.28) from the second half of the 1 st and the first half of the 2nd century AD. Similar beakers also occur in Central Europe (Geneva : Paunier 1981, no. 793 ; Emona : Plesnicar Gec 1972, pl. 207.23), in particular at the Magdalensberg (Schindler-Kaudelka 1975, 224, pl. 34.5b-c). Beaker 152 is similar to a glass beaker from the Roman cemetery of Moghegno (164.94.169, Grave 23). The form, in glass or glazed ware, occurs again in 
Canton Ticino and Pavia (Maccabruni 1981, 81, nos. 50 and 109), in central and northern Europe (Limburg: Isings 1971, no. 128; Novaesium : Müller 1977, pls. XVI.8, LXVIII.5, LXXV.18), and at Aquileia (Calvi 1968, Forma D).

\section{Form BK6: Beakers with globular to ovoid body}

Form BK6 may be traced back to Marabini Moeus's Form $V$ with ovoid to globular body, out-turned rim and slightly concave foot-disc. The examples of Form BK6 have flat $(153 ; 155 ; 156)$ or slightly concave feet $(154 ; 157)$. All belong to the thin walled ware. Form BK6, except for BK6.1, and its variants BK22 and BK23 also occur at Angera and Milan, where they date to ClaudioNeronian times (Sena Chiesa 1985, 412-13 pl. 82.21-22 ; Ceresa Mori 1991, 47: Ollette puntellate).

According to the decoration, these beakers may be divided into two groups:

- Form BK6.1: Beaker with stylized pine scales;

- Form BK6.2: Beaker with dots.

\section{Form BK6.1}

153 Locarno-Muralto, property Liverpool sotto, grave 12, c. AD 30-60

Beaker 153 is very similar to Marabini Moeus's Form V; it also shows the same out-turned and slightly curved rim. The fabric is grey, medium to hard (23), with medium mica inclusions (size $0.25 \mathrm{~mm}$ ), and is of B-Ware. The decoration consists of two rows of barbotine stylized pine scales on the body and two girth-grooves under the neck. Barbotine pine scales also occur as 
decoration on beakers of Form BK28.1. Beaker 153 comes form a grave dated c. AD 30-60.

Form BK6.1 does not occur at Angera or at Milan. Similar vessels occur at the Magdalensberg, dated c. 25-10 BC, and in central Italy (Schildler-Kaudelka 1975, 49 pl. 4, Forms 12-13; 73 pl. 9 : Form 43, light fabrics).

\section{Form BK6.2}

154 Locarno-Solduno, Modern cemetery, grave 56.2, c. AD 50-100

155 Locarno-Solduno, property Ardito, grave C28, c. AD 69-120

156 Locarno-Solduno, Modern cemetery, grave 58.13, c. AD 70-120

157 Cavigliano, property Monotti, grave 7, c. AD 50-100

All fabrics are beige, medium hard to hard (2-3). Except for 154, all are of $\mathrm{J}$ Ware. Beaker 155 shows traces of contact with fire. Beaker 156 has few mica inclusions (size $0.1 \mathrm{~mm}$ ); beakers 155 and 157 have few to medium mica, sand and crushed quartz inclusions (size $0.1-0.25 \mathrm{~mm}$ ). Beaker 154 has few mica and grog inclusions (size $0.1 \mathrm{~mm}$ ), and is of N-Ware. Beaker 154 has an out-turned rim; the other beakers have only slightly out-turned, rather vertical rim. Beaker 157 has two cordons on the shoulder and barbotine dots on the body. The dots are distributed on five rows. The upper row is situated on the lower cordon. The decoration of the other three beakers consists of a girthgroove or many grooves on the shoulder and barbotine dots on the body. On beakers 156 and 154 the dots are distributed on five, respectively seven rows; on 155 they seem to be in open order. 
At Angera, similar beakers date to Julio-Claudian times, lasting until Flavian times (Sena Chiesa 1985, 412 pl. 113.6-7). Dotted beakers (Forms BK6.2, BK22 and BK23) are distributed in the Po Valley (Mercallo dei Sassi : Frova 1960, fig. 8 ; Valmadrera : Giussani 1936, 26 ; Alpago Novello Ferrerio 1985 : Civici Musei di Villa Mirabello, unpublished) reaching Adria (Dallemulle 1975, Grave 5 no. 10) and Portorecanati (Mercando 1974, Grave 306). They also occur at Haltern (Schönberger 1976, pl. 5: Haltern Form 43B), in the Magdalensberg (Schildler-Kaudelka 1975, Forms 34-35: Augustan times) and in the Iberian Peninsula (Mayet 1975, Form LXV nos.589-590: Flavian times). All examples of Form BK6.2 come from contexts within the period c. AD 50120.

\section{Form BK7: Beakers with very short rim and concave base}

158 Locarno-Muralto, Grande Albergo; cemetery, context unknown

159 Locarno-Muralto, proprerty Märki, grave 2, c. AD 50-80

160 Locarno-Solduno, Modern cemetery, grave 58.19,c. AD 69-120

161 Losone-Papögna; cemetery, context unknown

Form BK7 may be traced back to the globular beakers Mayet's Forms XL and XLIV. Beakers 159 and 160 are very similar in form: the only difference lies in the foot: almost flat by 159 and slightly concave by 160 . Both belong to coarse pottery. The fabrics are red to red-brown and hard (3), and are of L-Ware. 160 shows a fine clay with low mica inclusions (size $0.1 \mathrm{~mm}$ ); 159 is coarser, with medium mica and quartz inclusions (size $0.25 \mathrm{~mm}$ ). The latter bears also 
groups of comb incised lines on the wall. Both beakers come from graves dated within C. AD 50-120. Beaker 158 has a further flaring of the body towards the foot. The fabric is coarse, red and hard (3), with medium mica inclusions (size $0.25 \mathrm{~mm}$ ). The surface is burnished. The beaker did not come from a datable context. Beaker 161 has a slightly different rim in comparison to the former three examples, because it is slightly expanded inside. Also the concave foot is thicker. The fabric is brown-black, hard (3), with medium mica inclusions (size $0.25 \mathrm{~mm}$ ). The surface is decorated with two girth-grooves at mid-body. As 158, also 161 did not come from a well defined context.

Similar beakers occur at Almese (Val di Susa) and date from Flavian times to the 3rd century AD (Gabucci 1996, pls. XXVI Grave 2.1 and Grave 3.1 ; XXVII Grave 4.1 and Grave 6.1 ; XXIX Grave 9.2).

Form BK8: Beakers with inturned rim and concave base

162 Locarno-Solduno, Via al Passetto, grave B 10, c. AD 40-90

163 Losone-Papögna; cemetery, context unknown

Forms Haltern 41a and 41d and Rödgen 25 (Schönberger 1976, pl. 5) are similar to Form BK8, in particular to beaker 162: the rim is inturned and the high shoulder is rounded. In 163 the shoulder is lower and the body shows a slightly tapering towards the foot. Both beakers belong to the coarse ware. The fabrics are beige with black core (162) and black (163) as result of the reduced firing, hard (3), with low to medium mica, sand and granular quartz 
inclusions (size $0.25 \mathrm{~mm}$ ). The surface of 163 is burnished. Only 162 comes from a context dated C. AD 40-90.

Form BK9: Beakers with short out-turned rim and slightly concave base

164 Ascona, grave 2, c. AD 100-150

165 Locarno-Solduno, Trench 1956/S1

166 Locarno-Solduno, property Ardito, grave C28, c. AD 69-120

167 Losone-Arcegno, area B

168 Locarno-Muralto, property Liverpool sotto, grave 2, c. AD 70-120

Form BK9 may be traced back to Marabini Moeus's Form $V$ (Marabini Moeus 1973, 62: from the beginning of the 1st century BC), with out-turned rim, globular body and foot-disc. The examples from Ticino have shorter and more vertical rim and flat or slightly concave foot.

Beaker 164 has globular body. The fabric is beige with traces of contact with fire, medium hard to hard (2-3), with few mica inclusions (size $0.1 \mathrm{~mm}$ ). It is of J-Ware. The decoration consists of a girth-groove on the shoulder. Its context dates C. $A D$ 100-150. Beakers 165 and 168 have a more conical body. The decoration of 165 consists of girth-grooves on the rim and by the neck; 168 has a girth-groove on the shoulder. Beaker 166 is fragmentary: the rim is similar to that of 165 , the body and the foot are missing. The fabrics of these two beakers are red, hard (3), with few mica inclusions (size $0.1 \mathrm{~mm}$ ), and are of L-Ware. Beaker 166 comes from a grave dated C. AD 70-120. The fabric of 168 is white, hard (3), with medium mica, sand and grog inclusions (size 
$0.25 \mathrm{~mm})$. Grave 2 at Muralto-Liverpool sotto dates c. AD 70-120. The four beakers are thin walled. Beaker 167 is coarser. Its body is rounded but is not as wide as by the former beakers. The rim is almost vertical. The general form is close to Form 13 at Angera (Sena Chiesa \& Lavizzari Pedrazzini 1985, pl. 84.13), dated to Trajanic-Hadrianic times. The fabric is beige with traces of contact with fire, hard (3), with medium mica and sand inclusions (size 0.25 $\mathrm{mm}$ ). The context, from which it comes, does not bear any dating evidence.

Similar beakers occur frequently in Piemonte during the 1st and the 2nd century AD at Susa (Brecciaroli Taborelli 1986, 52 pl. XIII 1.5 and 1.6 Grave 1, end of the 2nd-first half of the 3rd century AD), Caselette (Rebaudo Greco 1977, 33ff. Types A6-Jars and B3-Beakers), Salice d'Ulzio (Monginevro; Capello 1941, figs. 24 and 31e), Caraglio (Cuneo ; Molli Boffa 1980, 244-5 pls. LXXIX ; LXXX.h), Alessandria (Zanda \& Preacco Ancona 1994, 158 pl. XLI.3 ; Preacco Ancona 1989, 95 fig. 3.29). 
Beakers with ovoid body

\section{Form BK10: Beakers with out-turned rim and high foot-disc}

The prototypes of Form BK10 are Marabini Moeus's Form VIII (Marabini Moeus 1973, 69: third quarter of the 1st century BC) with short, out-turned rim, ovoid body and foot-disc, and further Mayet's Form XLV (Marabini Moeus $1973,146)$ with inturned rim, ovoid body with maximum diameter in the upper half and foot-ring.

Form BK10 occurs in the study area as coarse pottery only, but with black or dark brown slip and rouletting as decoration.

In Ticino these beakers may be divided into two groups according to the height of the foot:

- Form BK10.1: Foot-disc of about or less than 1/10 the height of the beaker ;

- Form BK10.2: Foot-disc of more than 1/10 the height of the beaker.

\section{Form BK10.1}

169 Locarno-Solduno, property Balli, grave Ba4, c. AD 50-100

170 Locarno-Solduno, Modern cemetery, grave 57.2

Beaker 169 is very close to Marabini Moeus's Form VIII. The body is ovoid and the maximum diameter lies at mid-body. The fabric is rust-red, hard (3), with few mica and sand inclusions (size $0.1 \mathrm{~mm}$ ), and is of L-Ware. The decoration consists of rouletting on the whole body, except for a small area by the foot, and dark brown slip. Similar beakers were found at Angera and date to the Flavian period (Sena Chiesa \& Lavizzari Pedrazzini 1985, pl. 83.1). 
Beaker 169 comes from a grave with terminus post quem at mid-1st century AD. Beaker 170 seems to be a further evolution of Form BK10.1 towards BK10.2. The proportion height of foot/height of beaker is the same as by 169 , but the maximum diameter is situated slightly in the upper half of the body. The beaker comes from a cremation-grave: the fabric is beige-grey, burnt, medium hard (2), with low mica and sand inclusions (size $0.1 \mathrm{~mm}$ ). The decoration consists of a rouletted band on the shoulder. There is no trace of slip, which probably vanished during the cremation. The only datable context is grave $\mathrm{Ba} 4$ at Locarno-Solduno, dated c. AD 50-100.

\section{Form BK10.2}

171 Locarno-Muralto, property Passalli, grave 28, c. AD 100-150

172 Moghegno, grave 25, c. AD 81-100

Beakers 171 and 172 are very similar. The foot is higher than by Form BK10.1, the ovoid body show a tapering towards the foot and the maximum diameter lies in the upper half of the body. The fabrics are red, medium hard (2) to hard (3), with low mica and crushed quartz inclusions (172: size 0.1 $0.25 \mathrm{~mm}$ ) or medium mica inclusions (171: size $0.25 \mathrm{~mm}$ ). They are of L-Ware. The decoration consists in both cases of black slip and an upper and a lower rouletted band on the shoulder, with two girth-grooves in between. Beaker 172 comes from a grave dated C. AD 81-100; 171 from a grave dated C. AD 100150.

These beakers are common at Angera (Maccabruni \& Schifone 1985, $138 \mathrm{pl}$. 39.8 ; $141-2$ pl. 41.7 ; Caporusso et al. $1985 a, 182$ pl. 46.5 ; 218 pl. 48.9 ; pl. 
83.7) from the beginning to mid-2nd century $A D$, when they replaced the rouletted thin walled cup with black or brown slip as drinking vessels (Sena Chiesa 1985, 416-417 : Forma 14). The form occurred as variant of Mayet's Form XLV already in the latest layers at Cosa, sometimes with rouletted decoration (Marabini Moeus 1973, 249-251 nos. 444-8).

The form is widely attested in northern Italy from Augustan times and during the 1st c. AD. Examples occur at Cremona (Cattaneo 1996a, 155 fig. 9), Angera (Sena Chiesa \& Lavizzari Pedrazzini 1995, pl. 44.4), Gropello Cairoli (Fortunati Zuccala 1979, 58 fig. 42), Russi (Bergamini 1973, 24 pl. XI.96), Adria (Dallemulle 1975, 271 fig. 1.10 Grave 5), Budrio (Bologna; Bergamini 1980, 60 pls. XV and LXXIV no. 278), Ivrea (Brecciaroli Taborelli 1987, 133 pl. XLVII no. 434/3).

The examples from Angera and from Ticino seem to represent a late resumption by Cisalpine production centres of forms produced in central Italy during the first half of the 1 st century $A D$. The closeness of morphologic features of the beakers from Angera and from Ticino allowed Sena Chiesa to presume the local production of types spread in the Cisalpine region and frequent during Trajanic-Hadrianic times (Sena Chiesa 1985, 416-17). In the Adriatic area this form is frequent during the 2nd century AD (Mercando 1974, graves $50,59,63,76,115,136)$.

At Angera, beakers from contexts dated to the end of the 1st century AD have beige-grey fabrics, similar to those of the cups. Later examples, however, bear red fabrics with black, dark brown or brown-red slip. Similar beakers were also found in Pannonia, usual trading area for products from the Po region, and in 
the central and western Transalpine provinces (Plesnicar Gec 1972, pl. 6.2528; Müller 1977, 122 no.389.2).

\section{Form BK11: Beakers with narrow body and high foot-disc}

The prototypes to Form BK11 may be found in Marabini Moeus's Forms VIINIII/XXXII (Marabini Moeus 1973, 101), produced in central Italy during the first half of the 1st century $A D$.

The two examples from the study area may be divided into two groups:

- Form BK11.1: Beaker with ovoid body and separated rim;

- Form BK11.2: Beaker with ovoid body and inturned rim.

\section{Form BK11.1}

173 Locarno-Solduno, property Balli, grave Ba6, c. AD 41-80

Beaker 173 has an ovoid body with high belly, flared towards the foot. The foot-disc is low and flat as in the prototypes. The vertical rim, separated from the body, is not curved as in Marabini Moeus's Form VII, but straight. Only the upper end is slightly inturned. The beaker is thin walled. The fabric is grey, hard (3), with few mica inclusions (size $0.1 \mathrm{~mm}$ ), and is of B-Ware. The decoration consists of girth-grooves and rouletted bands on the body. The date of grave $B a 6$ is $C . A D 41-80$.

At Ornavasso-Persona, in Grave 33, was found a similar beaker, which may be considered as half-way between Marabini Moeus's Form VII and the 
example from Locarno-Solduno (Graue 1974, 110-11 fig. 30.49; 170; pl. 58.3): the body already shows the tapering towards the foot, whereas the rim is still curved as in the prototype. Grave 33 at Ornavasso-Persona is dated between 50 and 25/15 BC (Graue 1974, 170: 'Zeitgruppe III'). A further example comes from Grave 162 at Ornavasso-San Bernardo, with terminus post quem dating from early Augustan times (Graue 1974, pl. 36.6). The Form also occur at Emona (Ricci 1985, Type 1/291, 260).

\section{Form BK11.2}

174 Minusio, property Cadra, grave 2, c. AD 40-90

In Form BK11.2 the rim is not separated from the body, but constitutes a continuous line with the body and is inturned. As in Form BK10.2, the foot-disc is higher than by the prototypes and by Form BK11.1. Form BK11.2 is lower than BK11.1, and the maximal width of the beakers lies at mid-body. Beaker 174 is thin walled. The fabric is pink-beige, soft and powdery (1), with traces of black slip, and is of H-Ware. The clay bears some mica inclusions (size 0.1 $0.25 \mathrm{~mm}$ ). The suggested date of grave 2 at Minusio-Cadra is c. AD 40-90. A further example is known from Airolo-Madrano, in the Leventina valley (Cat. no. 3.57.3, Grave 1). Fabric and decoration are coarser. The maximal width of the beaker at mid-body is emphasized and the body is rather biconical. The rim, inturned, is thickened and flattened on the top. The datable grave-goods from the grave (in particular: coin of Commodus, AD 176-92; brooch, Ettlinger Type 52: late 2 nd to 3 rd century $A D$ ) allow one to suggest the date of the grave within $C$. AD 176-220. It is therefore possible to suppose that the beaker 
from Airolo-Madrano may constitute the last phase of the evolution of Form BK11. Vessels with form similar to the example from Airolo-Madrano occur north of the Alps at Laufen-Müschhang, Basel, dating from the end of the 2nd to the 3rd century AD (Martin-Kilcher \& Fünfschilling 1999, 143 fig. 34.9 : Import).

Form BK12: Beakers with out-turned rim, globular to ovoid body and foot-disc

175 Locarno-Solduno, Modern cemetery, grave 56.1, c. AD 50-100

176 Locarno-Muralto, property Märki, grave 5

Form BK12 goes back to Marabini Moeus's Forms V/XXXI (Marabini Moeus 1973, 100: Augustan times). Beaker 175 has an out-turned rim, a short vertical neck, a globular body and a flat foot-disc. The fabric is beige-pink, hard (3), with medium mica inclusions (size $0.25 \mathrm{~mm}$ ). The decoration consists of two cordons on the shoulder. Beaker 176 is higher. It does not have a real neck, but the passage from rim to shoulder is marked by a cordon. The body is rather ovoid. The foot-disc, slightly concave, is pinched out. The fabric is beige, hard (3), with few mica, sand and grog inclusions (size $0.25 \mathrm{~mm}$ ). Both fabrics are of $\mathrm{J}-$ Ware. Both beakers belong to the coarse ware. Only 175 comes from a datable context, dated c. AD 50-100.

North of the Alps a similar form appears at Rödgen and Oberaden, dating from the end of the 1st century BC (Schönberger 1976, pl. 5: Form Rödgen 26B; Form Oberaden 30). 


\section{Form BK13: Beakers with wide rim and foot-disc}

177 Minusio, property Cadra, grave 16, c. AD 15-50

178 Minusio, property Cadra, grave 16, c. AD 15-50

Form BK13 goes back to Marabini Moeus's Form VIII (Marabini Moeus 1973, 69: third quarter of the 1st century $\mathrm{BC}$ ). Both beakers have ovoid body, although by 177 the maximum width of the body is higher than by 178 , and foot-disc. The rim is slightly out-turned and rounded by 178 and is a bead rim by 177 . Both fabrics are grey, hard (3), with medium mica and sand inclusions (size $0.1-0.25 \mathrm{~mm}$ ), and are of B-Ware. The decoration consists of rows of impressed crescents on the body. This decoration type was very common on La Tène jars from Milan (Ceresa Mori 1991, 171; Caporusso et al. 1991, pl. LXXIV, 14) and continued on coarse pottery until late Roman times. Both beakers come from grave 16 at Minusio-Cadra. The date of the grave is C. AD $15-50$.

Form BK14: Beakers with out-turned curved rim and foot-disc

179 Locarno-Muralto, Villa Sciaroni; cemetery, context unknown

180 Losone-Papögna; cemetery, context unknown

181 Locarno-Solduno, property Balli, grave Ba8, c. AD 30-80

Form BK14 goes back to Marabini Moeus's Form VIII (Marabini Moeus 1973, 69: third quarter of the 1st century BC). The body is high, ovoid. The maximum diameter lies on the shoulder. 
Beakers 179 and 180 seem to be similar, although the rim of the former is missing. Beaker 179 has rust-red fabric (L-Ware), hard (3), with medium mica inclusions (size $0.25 \mathrm{~mm}$ ). Beaker 180 has beige-orange fabric, soft (1), with medium mica inclusions (size $0.1 \mathrm{~mm}$ ), of $\mathrm{H}$-Ware. Both are decorated with rouletting on the body and brown slip. Beaker 181 has a flat base instead of the foot-disc. Its fabric is black, hard (3), with medium mica inclusions (size $0.1 \mathrm{~mm})$. Only this beaker comes from a datable context, c. AD 30-80.

Beakers of similar form occur at Angera (Sena Chiesa \& Lavizzari Pedrazzini 1985, pl. 83.1) and date to Flavian times. In these examples, however, the maximum diameter is situated at mid-body. The general form is therefore slightly different. Moreover the decoration consists of rows of dots, as in Form BK6.

\section{Form BK15: Beakers with tall curved rim and tall body}

182 Minusio, property Scascighini, grave 2, c. AD 20-70

The form may be traced back to Marabini Moeus's Form VII (Marabini Moeus 1973, 66: end of the first quarter of the 1st century BC to Augustan times) and, further to Mayet's Forms II-III and Vegas' Form 24 (Vegas 1973, 64: Type 24.3; 65: end of 1 st century BC). This form, spread over the Mediterranean area and the northern provinces, reached Augustan times. Since it does not occur at Haltern, Lorenzberg and Augsburg-Oberhausen, it is possible to date the end of its production in the last decade of the 1st century BC. 
This form occurs only once in the Locarno area. The beaker is characterized by the extreme thinness of the wall. The fabric is beige, hard (3), with few mica inclusions (size $0.1 \mathrm{~mm}$ ). It is of I-Ware. The grave, in which the beaker was found, belongs to the group of earliest Roman graves so far known in Locarnese, dating from c. AD 20-70.

Grave 33 at Ornavasso-Persona (Graue 1974, pl. 58.3) contained a beaker of similar form, but with thicker wall and decorated with plastic spikes and black slip. Further, another beaker comes from grave 147 at Ornavasso-San Bernardo (Graue 1974, pl. 35.2). Both graves date to the period from 50 to 25/15 BC (Graue 1974, 170: 'Zeitgruppe III' and fig. 55). The beakers from Ornavasso still belong to Vegas' Form 24. The form occurs at Legnano from contexts dated to Augustan times (Volonté 1996, 190, pl. 3.2-3 Grave 301).

\section{Form BK16: Beakers with vertical curved rim}

183 Locarno-Solduno, property Pedrotta, grave Pe1, c. AD 0-30

184 Locarno-Muralto, property Liverpool sotto, grave 10, c. AD 30-80

Form BK16 goes back to Marabini Moeus's Forms IVNII (Marabini Moeus 1973, 66), dating from the first half of the 1st century BC, Vegas' Form 24 (Vegas 1973, 64: Type 24,4-5; 65: end of 1st century BC), and Mayet's Form III (Mayet 1975). Both beakers from Ticino are thin walled. Beaker 183 has ovoid body on a slightly concave foot-disc and relatively short rim as Marabini Moeus's Form IV, whereas position and form of the rim are closer to Marabini 
Moeus's Form VII. The fabric is red, hard (3), with few mica inclusions (size $0.1 \mathrm{~mm})$, and is of L-Ware. The decoration consists of a girth-groove on the shoulder. The beaker comes from grave Pe1, dated C. AD 0-30. Beaker 184 is very fragmentary. The rim and the foot-disc, however, allow one to register the beaker within Form BK16. The vertical curved rim continues into a vertical curved 'neck', separated by a girth-groove from the body. The fabric is grey, soft (1), with medium mica inclusions (size $0.1-0.25 \mathrm{~mm}$ ), and is of C-Ware. The grave dates $C . A D 30-80$. The detail of the neck occurs on beakers from the Magdalensberg ('Wellenbecher' Form 9, with light fabric: SchindlerKaudelka 1975, 47 pl. 3.9a-b : 10-0 BC).

Beakers of Form BK16, in particular similar to 183 , do not occur at Angera. They appear at Milan (Guglielmetti et al. 1991, 44-45: Form 1/19; Caporusso et al. 1991, pl. XI,10) and Ornavasso (Graue 1974, 170 : 'Zeitgruppe III', second half of the 1st c. BC-25/15 BC) during late Republican times. At Ottobiano (Lomellina), one example (St 34443) is associated with long-necked jars (i.e. Graue 1974, fig. 30.50), and dated to Augustan times (Vannacci Lunazzi 1986, 90 : Grave 30, pl. 8.3, grey fabric). In Piemonte, these beakers occur in light fabrics, soft or medium hard, and date to mid-1st century AD (Casalborgnone: Zanda - Alessio \& Lavati 1988, 36 pl. XIII.13-17; Ivrea : Brecciaroli Taborelli 1987, pls. XL.490.51; XLV.24.35; XLVII.339.32). The form also occurs at Oberaden (Form 31) and Rödgen (Form 16; Schönberger 1976, pl. 5) during early Imperial times. Form BK16 corresponds to Ricci's Types $1 / 19$ and $1 / 20$ (Ricci $1985,247-8)$. In particular, Type 1/20 occurs at 
Cosa from c. $75 \mathrm{BC}$ and seems to be produced at Aquileia from Augustan times (Ricci 1985, 248).

Form BK16 seems to develop into Form BK15, well represented in northern Italy in Flavian times (Vannacci Lunazzi 1986, $90 \mathrm{n} .74$ for examples).

\section{Form BK17: Beakers with corrugated shoulder}

185 Locarno-Muralto, property Liverpool sotto, grave 23, c. AD 70-120

186 Locarno-Muralto, property Meyster; cemetery, context unknown

Form BK17 recalls the form of jars of La Tène tradition from Milan (Ceresa Mori 1991, 171; Caporusso et al. 1991, pl. LXXIV, 14). They have vertical (185) or out-turned rims (186), conical bodies with maximum width on the shoulder, flat feet or foot-discs. The main feature is the prominent and corrugated shoulder. The fabrics are red and hard (3) and are of L-Ware. Beaker 185 bears some traces of contact with fire and medium mica inclusions (size $0.25 \mathrm{~mm}$ ). Beaker 186 has medium mica and granular quartz inclusions (size $0.25 \mathrm{~mm}$ ). The decoration, impressed or plastic (barbotine) is completed by girth-grooves. Beakers 185 bears impressed fern leaves, surmounted by rosettes and linked with garlands. Beakers 186 has two rows of dots over the rouletted shoulder and impressed pattern on the body such as crescents, circles and cord-like stabs. Only 185 comes from a datable grave. Its date is $\mathrm{C.} A D$ 70-120. 


\section{Form BK18: Beakers with inturned rim concave base}

187 Minusio, property Cadra, grave 26, c. AD 161-210

188 Minusio, property Cadra, grave 14, c. AD 70-120

189 Locarno-Muralto, property Meyster; cemetery, context unknown

Form BK18 seems to be a variant of BK8 with ovoid instead of globular body. As with 162 (Form BK8), beaker 187 has high shoulder, but the inturned rim is distinct. The general form recalls the situla-like jars of La Tène tradition (Guglielmetti et al. 1991, 169ff.; Caporusso et al. 1991, pl. LXXIV, 10-14). 188 has a further tapering towards the foot. 189 is fragmentary and its profile shows a break over the foot. All beakers are coarse. Beaker 187 has a red fabric, hard (3), with medium mica and sand inclusions (size $0.25 \mathrm{~mm}$ ), of LWare. Beaker 188 is dark brown with red core, hard (3), with medium mica inclusions (size $0.25 \mathrm{~mm}$ ). Beaker 189 is pink-beige, medium hard (2) with medium mica inclusions (size $0.25 \mathrm{~mm}$ ). Beaker 187 comes from a grave of the same cemetery, dated c. AD 161-210. Beaker 188 comes from a grave dating from Flavian times, C. AD 70-120.

\section{Form BK19: Beakers with short out-turned rim and flat base}

Form BK19 includes beakers with ovoid bodies and maximum diameter on the shoulders (Ricci 1985, Type 1/364; pl. CLV : suggested production centres in the region of Ravenna). The prototypes are Marabini Moeus's Forms IIINIII (Marabini Moeus 1973, 69: third quarter of the 1st century BC) and Mayet's Form XXXVI (Mayet 1975, pl. LXXX). The examples from Ticino have flat or 
slightly concave feet as Marabini Moeus's Form III. All are thin walled and come from the area called Liverpool sotto at Locarno-Muralto. Moreover, both 191 (BK19.1) and 194 (BK19.3) come from grave 38.

According to the form of the rim, the beakers have been divided into three groups:

- Form BK19.1: Beaker with ovoid body and out-turned rounded rim;

- Form BK19.2: Beaker with ovoid body and rather vertical rim;

- Form BK19.3: Beaker with ovoid body and inturned rim.

\section{Form BK19.1}

190 Locarno-Muralto, property Liverpool sotto, grave 11, C. AD 20-70

191 Locarno-Muralto, property Liverpool sotto, grave 38, c. AD 40-70

192 Locarno-Muralto, property Broggini; cemetery, context unknown

The beaker with ovoid body, out-turned rim and flat foot also occurs twice at Angera, where it dates to Trajanic-Hadrianic times (Sena Chiesa 1985, 41516; pls. 83.5-6; 84.13). The beakers from Angera, however, are slightly different from the examples from Ticino. Whereas the latter have the maximum diameter of the body on the shoulder, by the former it lies at midbody. The general form of the bodies of the beakers from Ticino is therefore more conical. At Angera this form replaced some drinking vessels from the beginning of the 2 nd century AD, as tankards (Form 23) and beakers with high foot-disc (Form BK10) did. Beaker 190 has grey fabric, hard (3), with medium mica inclusions (size $0.25 \mathrm{~mm}$ ). The fabrics of 190 and 192 are of B-Ware. The decoration consists of three rows of barbotine 'combs' on the upper half 
of the body and a girth-groove above them. The grave dates c. AD 20-70. Beaker 191 has pale red fabric with traces of contact with fire, medium hard (2), with medium mica inclusions (size $0.25 \mathrm{~mm}$ ). This fabric is of L-Ware. The body is decorated with diagonal comb incised lines. Grave 38 from MuraltoLiverpool sotto dates c. AD 40-70. Beaker 192 has more prominent shoulder and a tapering toward the foot. The fabric is grey, hard (3), with medium mica inclusions (size $0.25 \mathrm{~mm}$ ). The upper half of the body is decorated by a wide rouletted band, bordered by girth-grooves. The exact context of the beaker is unfortunately unknown. Two examples very close to Form BK19.1, in particular to Beaker 192, occur at Asti and date from mid-1st to the beginning of the 2nd century AD (Zanda \& Preacco Ancona 1994, 171 pls. XLV.8; XLVIII.1).

Form BK19 occurs in both thin walled and coarse wares (see also: Butti Ronchetti 1987a, 82 pl. X.98, from Mariano Comense). These beakers did not occur at Magdalensberg, but appear among the beakers of Flavian times in Pannonia (Plesnicar Gec 1972, pl. 6.1-2). At Cremona, this form is frequently attested; its presence in the kiln in via Platina, with various decoration, allows Cattaneo $(1996 a, 154)$ to suggest a production centre. The form occurs in the whole Po region, as far as Ravenna, where Maioli suggests another production centre (Maioli 1972-73, 115). Form BK19.1-2 also occurs at the Magdalensberg, dating c. 10-0 BC (Schindler-Kaudelka 1975, 91 pl. 15 ; Form 78), and at Novaesium (Vegas 1975, pl. 5.13). 


\section{Form BK19.2}

193 Locarno-Muralto, property Liverpool sotto, grave 43, c. AD 40-70

Form BK19.2 is similar to BK19.1, but the rim is vertical. Beaker 193 has grey, rough-cast fabric, hard (3), with many mica, sand and crushed quartz inclusions (size $0.25 \mathrm{~mm}$ ). This fabric is of A-Ware. The decoration consists of two girth-grooves on the rim and diagonal incised lines on the body. The grave, from which it comes, dates c. AD 40-70.

Similar beakers occur from the beginning of 1 st to the beginning of the 2 nd century AD at Olgiate Comasco (Butti Ronchetti 1986, 118 pl. III.22 : Flavian times), Gropello Cairoli (Pavia : Fortunati Zuccala 1979, 58 fig. 42.2 : first half of the 1st century AD), Albusciago (May 1930, 113 fig. 2), Arsago Seprio (Ferraresi et al. 1987, 172), Legnano (Volonté 1996, 188 pl. 47.15 no context : Augustan-Tiberian times), Nave (Brescia : Passi Pitcher 1987, 52 Grave 6 pl. L.1: Tiberian times), Milan (Bolla 1988, 180 ; Ceresa Mori 1991, 48), and Cremona (Cattaneo 1996a, 154 ; fig. 4 : first half of the 1st century AD).

\section{Form BK19.3}

194 Locarno-Muralto, property Liverpool sotto, grave 38, c. AD 40-70

Beaker 194 has an inturned tapering rim, decorated with two girth-grooves. The fabric is grey, rough-cast and hard (3), with many mica and sand inclusions (size $0.25 \mathrm{~mm}$ ), and is of A-Ware. The decoration on the body 
consists of roughly diagonal incised lines. The beaker comes from grave 38 at Muralto-Liverpool sotto, as beaker 191. The date of the grave is C. AD 40-70.

A vessel of similar form occurs at Vindonissa dating c. AD 0-10 (Meyer-Freuler 1999, 161 pl. 82.10).

\section{Form BK20: Beakers with out-turned curved rim}

195 Locarnese; cemetery, context unknown

196 Locarno-Muralto, property Liverpool sotto, grave 14, c. AD 41-80

Form BK20 goes back to Marabini Moeus's Form III/IV (Marabini Moeus 1973, 58-9: mid- 2nd century BC to early Augustan times). The rim is out-turned but curved as a rim with internal lid seating. The body is ovoid, with the maximum diameter on the shoulder and a tapering towards the foot. The foot is slightly pinched out and concave. The two beakers are very similar. Beaker 195 has brown fabric with traces of contact with fire, medium hard (2), with medium mica inclusions (size $0.25 \mathrm{~mm}$ ). Beaker 196 has red fabric, hard (3), with medium mica inclusions (size $0.25 \mathrm{~mm}$ ), of L-Ware. Both are coarse. The decoration is almost identical: three girth-grooves on the shoulder and three rouletted bands below the girth-grooves. Only 196 comes from a datable context, whose date is C. AD 41-80. 


\section{Form BK21: Beakers with out-turned rim and slightly concave base}

197 Locarno-Muralto, property Liverpool sotto; cemetery, context unknown

198 Losone-Arcegno, grave 26, c. AD 80-100

199 Locarno-Solduno, Modern cemetery, grave 58.12, c. AD 70-120

200 Maggia, property Pozzi; cemetery, context unknown

201 Minusio, property Cadra, grave 11, c. AD 77-100

202 Locarno-Muralto, property Meyster; cemetery, context unknown

203 Locarno-Muralto, property Liverpool sotto, grave 46, c. AD 22/3-70/80

204 Moghegno, grave 35, c. AD 30-80

205 Losone-Arcegno, grave 34, c. AD 86-110

Form BK21 may be traced back to Marabini Moeus's Form V as Form BK6. The maximum width is situated at mid-body, but the beaker is higher. The beakers have foot-rings or foot-discs, usually slightly concave. The rim is outturned; by 202 it is sharply out-turned; by 203,204 and 205 only slightly outturned. All beakers, except for 203 , have beige fabric, hard, with medium mica inclusions (size $0.25 \mathrm{~mm}$ ), and are of J-Ware. 198 and 200 also bear traces of the contact with fire. Beaker 203 has orange fabric, medium hard (2), with few mica inclusions (size $0.1 \mathrm{~mm}$ ), of L-Ware. The decoration consists of barbotine dots, girth-grooves and cordons in various combinations. Beakers 197, 200 and 203 have one to three girth-grooves on the shoulder and rows of dots on the body. Beakers 198, 199, 201, 202 and 204 have one cordon on the neck, corrugated shoulder and dotted body. Beaker 205 has an elongated and corrugated neck and five irregular rows of dots on the body. The number of dotted rows on the body varies from four (197) to twelve (203). The lower third 
of the body above the foot is always plain. Not all beakers come from datable contexts. Beakers 203 and 204 come from graves dated c. AD 22/30-80. The contexts of 198, 199, 201 and 205 date c. AD 70-120.

Similar beakers occur at Legnano, from contexts dated to the mid-second half of the 1st century AD (Volonté 1996, 188 pls. 28.8 Grave 14 and 41.3 Grave 31).

Form BK22: Beakers with tapering towards the foot

Form BK22 represents a variant of Form BK21. Because of the tapering towards the foot, the maximum width is situated now in the upper half of the body. The foot is a foot-disc, usually slightly concave.

According to the form of the body, the beakers have been divided into three groups:

- Form BK22.1: Beaker with ovoid body.

- Form BK22.2: Beaker with globular upper half of the body.

- Form BK22.3: Beaker with high body.

Form BK22.1

206 Losone-Papögna; cemetery, context unknown

207 Locarno-Muralto, property Passalli, grave 37, c. AD 70-120

208 Locarno-Solduno, Modern cemetery, grave 58.15 
The beakers of Form BK22.1 have ovoid bodies and the tapering towards the feet is only outlined. The rims of 206 and 207 are slightly out-turned and short; the former is rather thick. Vessel 208 is a fragment of foot and wall only. The fabrics are beige, hard (3), with few to medium mica inclusions (size 0.1$0.25 \mathrm{~mm})$, and is of J-Ware. The decoration consists of cordons on neck and shoulder and rows of barbotine dots on the body. Only 207 comes from a datable context: the grave dates to $\mathrm{C}$. AD 70-120.

\section{Form BK22.2}

209 Locarno-Solduno, property Balli, grave Ba8, c. AD 30-80

210 Losone-Papögna; cemetery, context unknown

211 Locarno-Muralto, property Liverpool sotto, grave 35, c. AD 50-100

212 Locarno-Muralto, property Liverpool sotto, grave 10, c. AD 30-80

These beakers have globular upper half of the body and pronounced tapering towards the slightly concave foot, that gives the impression to be slightly pinched out. The rim is sharply out-turned (209), out-turned and thickened (210) or rather vertical $(211 ; 212)$. The fabrics are pink-white $(209,1-W a r e)$ or orange (210), beige (211; J-Ware) and grey (212). All beakers, except for 210 , have hard (3) fabrics, with low to medium mica inclusions (size $0.1-0.25 \mathrm{~mm}$ ). Beaker 210 has soft and powdery fabric (1), with the same inclusions as the former. Beaker 212 has two girth-grooves under the neck and dots on the body. The decoration of the other three examples consists of a cordon on the neck, corrugated shoulder and eight to nine rows of dots on the body. Beaker 211 also has another girth-groove below the dotted surface. Beakers 209 and 
212 come from contexts dating from c. AD 30-80. Beaker 211 comes from a grave dated c. AD 50-100. The exact context of 210 is unknown.

\section{Form BK22.3}

213 Locarno-Muralto, property Liverpool sopra, grave 7, c. AD 70-120

214 Minusio, property Cadra, grave 12, c. AD 73-100

The beakers of Form BK22.3 have higher body but the tapering towards the foot is still evident. The rim is out-turned and the foot is a slightly concave footdisc. By 214 the disc is very wide. The fabrics are beige, medium hard to hard (2-3), with medium mica inclusions (size $0.1-0.25 \mathrm{~mm}$ ), and are of J-Ware. The decoration of 213 consists of a cordon on the neck, corrugated shoulder, barbotine dots and another girth-groove under the dots. It is the only example within Forms BK6, BK21 and BK22 with the dotted surface limited to the centre of the body. Beaker 214 has two girth-grooves on neck and shoulder, followed by a wide cordon and seven rows of dots. Both examples come from contexts dated c. AD 70-100/120.

\section{Form BK23: Beakers with barrel-shaped body}

215 Locarno-Solduno, property Balli, grave Ba9, c. AD 30-70

216 Locarno-Muralto, property Branca, grave 2, c. AD 20-70

217 Locarno-Muralto, property Liverpool sotto, grave 32, c. AD 41-80

218 Locarno-Solduno, property Balli, grave Ba6, c. AD 41-80

219 Minusio, property Cadra, grave 33, c. AD 70-120 
220 Locarno-Muralto, property Liverpool sotto, grave 49, c. AD 23-60/70

221 Locarno-Muralto, property Liverpool sotto, grave 37, c. AD 37/8-70

222 Locarno-Muralto, property Liverpool sotto, grave 48, c. AD 40-80

Form BK23 represents another variant of Form BK21. The rim, short and outturned, is very wide. Therefore the body assumes the form of a barrel. Beakers 215,216 and 217 have a concave rim, that shows a sort of internal lid seating. The foot is a slightly concave foot-disc or a very low foot-ring. The decoration consists of a cordon between two girth-grooves on the neck, corrugated shoulder and five to ten rows of barbotine dots on the body. Only 220 has a plain neck. Excepts for 220 and 222, the fabrics are beige, medium hard to hard (2-3), with low to medium mica inclusions (size $0.1-0.25 \mathrm{~mm}$ ). They are of J-Ware. In 219 also occur sand and crushed quartz as inclusions (size $0.25 \mathrm{~mm}$ ). Beaker 222 has white and hard (3) fabric (I-Ware) with traces of contact with fire. Beaker 220 has red and medium to hard fabric (2-3), of LWare. All fabrics show medium mica inclusions (size $0.1-0.25 \mathrm{~mm}$ ). The date of the contexts from which come the beaker ranges from the first half to the second half of the 1st century AD: c. AD 30-70 for 215; 216, 220 and 221 ; c. $A D 40-80$ for 217, 218 and 222; C. AD 70-120, for 219. 


\section{Form BK24: Beakers with lugs}

Form BK24 may be traced back to Marabini Moeus's Form XI with ovoid body. The form occurs at Cosa from c. $25 \mathrm{BC}$ and at Syracuse from the end of the 2nd and the 1st century BC (Ricci 1985, 274, Type 1/156).

As with $\mathrm{BK} 30.1$, the foot of the examples from Ticino is flat or slightly concave and not a foot-disc. Within the form there are distinguishable two variants:

- Form BK24.1 : Beakers with rounded or inturned rim

- Form BK24.2 : Beakers with out-turned rim

Form BK24.1

223 Locarno-Muralto, property Meyster; cemetery, context unknown

224 Locarnese, Catalogue Simonett; cemetery, context unknown

Beakers 223 and 224 have ovoid body. The inturned rims belong to the curved walls. The feet are flat or slightly concave. The fabrics are beige, hard (3), with medium mica inclusions (size $0.25 \mathrm{~mm}$ ). They are of J-Ware. Beaker 223 does not have any grips. It was recovered from a grave in property Meyster at Muralto, whose context is unknown. It is decorated with two girthgroove on the upper half of the body. Beaker 224 has grips and is decorated with girth-grooves between the grips and under the rim. It bears a catalogue number similar to the items excavated by Simonett in Locarnese, but it does not appear in the publication (Simonett 1941). Therefore, it is impossible to define and date its context. 
A beaker similar to 223 , but without decoration, was found at Angera and dated to Flavian to Hadrianic times (Sena Chiesa \& Lavizzari Pedrazzini 1985, pl. 96.18).

Form BK24.2

225 Locarno-Solduno, Trench 1956/S3

226 Locarno-Muralto, property Branca, grave 4

Beakers 225 and 226 have ovoid bodies, short and slightly out-turned rounded rims, lugs and flat feet. Beaker 225 is decorated with a girth-groove between the lugs, 226 is plain. The fabrics are beige, hard (3), with medium mica, sand and quartz (size $0.25 \mathrm{~mm}$ ). They are of J-Ware. No beakers come from a datable context.

This form occurs once at Angera, without grips, and dates to ClaudianNeronian times (Caporusso et al. 1985b, pl. 72; Sena Chiesa 1985, 411; pls. 82.18 and 84.7$)$. 
Beakers with conical body

\section{Form BK25: Beakers with foot-disc}

227 Losone-Arcegno, grave 68

228 Losone-Papögna; cemetery, context unknown

The prototypes of Form BK25 may be traced back to Marabini Moeus's Form XI (Marabini Moeus 1973, 73: third quarter of the 1st century BC) and Mayet's Form XXXVI.

Both beakers are thin walled. They have conical body with vertical or slightly inturned rim. Beaker 227 has a foot-disc; by 228 the foot is missing. The fabric of 228 is rust-red, hard (3), with medium mica inclusions (size $0.25 \mathrm{~mm}$ ), and is of L-Ware. The decoration consists of grey-green slip and a net of vertical and horizontal incised lines on the body. Beaker 227 has orange fabric, soft to medium hard (1-2), with medium mica inclusions (size $0.25 \mathrm{~mm}$ ). The body is decorated with rouletting and a girth-groove over the foot. The beaker comes from grave 88 at Losone-Arcegno, with terminus post quem in the first half of the 1 st century AD.

A vessel almost identical to 228 occurs at Lugone (Salò) and dates to C. AD 40-50 (Grave 172: Massa et al. 1997, 92). Beakers with this form and decoration occur in northern Italy mainly in the eastern and Adriatic regions during c. 25 BC-AD 25 (Ricci 1985, Type 1/69). They also appear at the Magdalensberg, in hard and grey fabrics, dating from c. AD 20-30 (SchindlerKaudelka 1975, 103 pl. 18), at Emona (Petru 1972, pls. 85.10; 95.18 ; 
150.25), and in Pannonia (von Bonis 1942, pl. 19.14). Beaker 228 does not come from a datable context. Beakers similar to 227 occur at Angera and at the Magdalensberg and date to Tiberian times (Sena Chiesa 1985, $411 \mathrm{pl}$. 82.5).

\section{Form BK26: Beakers with flat base}

This form (Ricci 1985, Type 1/159) finds its closest parallels in Marabini Moeus's Form XII, with conical body, slightly out-turned rim and flat foot. It is dated to the third quarter of the 1st century BC (Marabini Moeus 1973, 74). In general, the Form occurs at Cosa, Lyon, Pollentia, Oberaden and Vetera with different fabrics, and dates to Augustan times (Ricci 1985, 275 Type 1/159; Marabini Moeus 1975, 74 ).

This form developed in Ticino into two variants:

- Form BK26.1: Beaker with bell-shaped body;

- Form BK26.2: Beaker with conical body and two side grips.

Form BK26.1

229 Locarno-Solduno, Modern cemetery, grave 58.17, c. AD 77/8-100

230 Locarno-Solduno, Modern cemetery, grave 58.18, c. AD 81-130

231 Locarno-Solduno, Modern cemetery, grave 58.19, c. AD 69-120

In comparison with the prototype Marabini Moeus's Form XII, Form BK26.1 has curved wall, that gives to the body the shape of a bell. All three examples show slightly concave feet. In 230 and 231 the rim is out-turned and tapering. 
Beaker 229 , on the contrary, has a vertical rounded rim. The decoration consists always of girth-grooves: one at mid-body for 229; two on the upper body's half for 230 , and three distributed on the whole body for 231 . All beakers are thin walled. The fabrics are hard (3), with a few mica inclusions (size $0.1 \mathrm{~mm}$ ). They are of J-Ware. The firing was oxidized and the clay varies from beige to beige-red. Although there have been found so far only three examples, Form BK26.1 occurs only at Locarno-Solduno and only in the graves group situated to the north of the cemetery. All graves 58.17, 58.18 and 58.19 belong within $\mathrm{C} . \mathrm{AD} 70-130$.

The form does not occur at Ornavasso or at Milan. A beaker with similar form but wider rim occur at Angera and dates to mid-1st century AD (Caporusso et al. $1985 \mathrm{~b}, 272 \mathrm{pl}$. 64.10). The presence of this form in the area of Verbano only allows one to suppose a regionally limited production (Saccardo 1985b, 485; pl. 96.17), whose centre still needs to be defined.

\section{Form BK26.2}

232 Minusio, proprerty Cadra, grave 11, c. AD 77/8-100

233 Moghegno, grave 32, c. AD 50-100

234 Ascona, grave S 23, c. AD 80-130

Form BK26.2 is closer to Marabini Moeus's Form XII than Form BK26.1, because of the conical body. The rim is straight and tapering; the foot may be flat $(232 ; 234)$ or slightly concave $(233)$. Further parallels to Form BK26.2 are Vegas' Form 28 from Pollentia and Cavaillon (Vegas 1973, 72; fig. 23, Type 
28), dated to the second half of the 1st century BC, and Form Oberaden $37 a$ (Schönberger 1976, pl. 5), dating from Augustan times.

Characteristic of Form BK26.2 are the two projecting elongated lugs applied to the upper half of the body and linked by a girth-groove. All beakers BK26.2 are coarse. The fabrics are hard (3). Beaker 232 has a beige-yellow fabric with medium mica inclusions (size $0.1-0.25 \mathrm{~mm}$ ). Beaker 233 has a pink and coarser fabric with mica, sand and crushed quartz inclusions (size $0.25 \mathrm{~mm}$ ). Beaker 234 has beige-orange clay, hard (3), with medium mica and sand inclusions (size $0.25 \mathrm{~mm}$ ). In comparison to the other two beakers, the wall is relatively thick $(5-6 \mathrm{~mm})$. The three graves, which contained the beakers, belong within the period $c . A D 50-130$.

Both Forms BK26.1 and BK26.2 seem to be limited to the Verbano area and to date c. AD 50-130.

\section{Form BK27: Beakers with carinated shoulder}

235 Locarno-Muralto, property Liverpool sotto, grave 33, c. AD 36/7-70

Beaker 235 has out-turned expanded rounded rim, high shoulder with carination, conical body with straight wall and concave foot. The fabric is beige-pink, hard (3), with medium mica, sand, crushed quartz and grog inclusions (size $0.25-0.5 \mathrm{~mm}$ ). It is of $\mathrm{N}$-Ware. The decoration consists of a girth-groove on the rim, the corrugated shoulder with ridges impressed on the 
cordons and eight rows of barbotine dots on the body. The date of the context is c. $A D$ 36-70.

A beaker of similar form occurs at Olgiate Comasco from a Flavian context (Butti Ronchetti 1986, 117 pl.III.21).

Beakers with cylindrical body

\section{Form BK28: Beakers with foot-disc}

Form BK28 (Ricci 1985, Type 1/161) represents the cylindrical beaker with the diameter of the rim larger or as wide as the foot, and shaper carination of the body over the foot and foot-disc. The form may be traced back to Marabini Moeus's Form XXXXXXXIII and Mayet's Form XII, dated to Augustan times. Further parallels are Rödgen Form 24 (Schönberger 1976, pl. 5) and Vegas' Forms 29 (Forms BK28.1 and BK28.2) and 32 (Form BK28.3) (Vegas 1973, 73: Type 29 and Type 32; 74; 77-78), also dated to the Augustan period. Other examples in sigillata are Forms Oberaden 12, Rödgen 9 and Haltern 16 (Schönberger 1976, pl. 3).

Form BK28 occurs at Angera with a rouletted beaker (form : Variant BK28.2) from a context dated to Flavian times (St 78085 : Sena Chiesa \& Lavizzari Pedrazzini 1985, pls. 53.2 and 82.34). Although the form seems to be rather rare in Lombardy, some examples have been found at Milan (Guglielmetti et al. 1991, 45; Caporusso et al. 1991, pls. XII, 12-13; XIII, 1; Bolla 1988, 178 pl. CXXVI 3, 25/70; Ceresa Mori 1986b, 137 pl. 56.f) and in northern Italy (Bolla 
1988,178 n. 431; Treggiari 1986-87, Form 19). Other parallels to this Form occur at Portorecanati (Grave 3, 1st century AD : Butti Ronchetti 1986, 117 n. 67), the Magdalensberg (c. AD 30-40 : Schindler-Kaudelka 1975, pl. 18.91) and Emona (Plesnicar Gec 1972, pl. 85 Grave 327; Petru 1972, pl. 12.15 Grave 16).

The examples from Ticino can be divided into three groups:

- Form BK28.1: Cylindrical beaker with barbotine stylized pine scales.

- Form BK28.2: Cylindrical beaker with high carination.

- Form BK28.3: Cylindrical beaker with slightly conical wall.

\section{Form BK28.1}

236 Locarno-Muralto, Canovacce; cemetery, context unknown

237 Losone-Papögna; cemetery, context unknown

238 Minusio, property Cadra, grave 15, c. AD 60-110

The form of BK28.1 goes back to Mayet's Form XII (Mayet 1975, pl. XXII.167). The form also occurs at Cosa (Ricci 1985, 275, Form 1/161). The peculiarity of Form BK28.1 consists of the decoration: three to four rows of barbotine stylized pine scales are applied on the body. All examples are thin walled. Beaker 236 has vertical wall and rim, very low carination and slightly concave foot-disc. The two other beakers from Ticino bear a higher carination over the foot-disc and are wider. Beaker 237 has vertical rounded rim, whereas 238 has slightly out-turned rounded rim. Both have grey fabric, hard (3), with medium mica inclusions (size $0.25 \mathrm{~mm}$ ), and are of B-Ware. The only example from a datable context is 238 . The date of the grave is $c$. AD 60-110. 
Beaker 236 is very similar to the examples from Milan (Caporusso et al. 1991, pl. XII, 12; Bolla 1988, 178 pl. CXXVI 3, 25/70; Ceresa Mori 1986b, 137 pl. 56.f), Angera (Favaro 1995, 87 no. 84380), Olgiate Comasco (from a Flavian context: Butti Ronchetti 1986, 117 pl. III.20), and to one beaker from Magdalensberg (Schindler-Kaudelka 1975, pl. 1.2e). The fabric is red, hard (3), with medium mica inclusions (size $0.25 \mathrm{~mm}$ ), and is of L-Ware.

\section{Form BK28.2}

239 Minusio-Cadogno; cemetery, context unknown

240 Minusio, property Cadra, grave 19, c. AD 70-120

Form BK28.2 is characterized by a relatively high carination of the body over the foot-disc. This form does not occur at Milan. Both examples from Ticino are thin walled. Beaker 240 has vertical wall and tapering rim. The decoration consists of some girth-grooves and red slip on the body. The fabric is pale red, soft and powdery (1), with medium mica inclusions (size $0.1-0.25 \mathrm{~mm}$ ). It is of H-Ware. Beaker 239 also has vertical, but slightly higher wall, and slightly outturned, rounded rim as 238 (Form BK28.1). The decoration consists of barbotine leaves and grapes at mid-body, rouletting over the foot and black slip. The fabric is grey, medium hard (2), with medium mica inclusions (size $0.25 \mathrm{~mm}$ ), and is of B-Ware. Beaker 240 is the only example from a datable context. The date of the grave is $C . A D 70-120$. 


\section{Form BK28.3}

241 Locarno-Muralto, property Märki, grave 2, c. AD 50-80

242 Locarno-Muralto, property Liverpool sotto, grave 1

243 Locarno-Muralto, Via Scazziga; house, context unknown

Form BK28.3 has a low carination over the foot-disc and slightly conical body. All beakers are thin walled. The rim is vertical and tapering. Two examples $(242 ; 243)$ are decorated with a group of two or three girth-grooves on the shoulder. The fabrics are white $(241 ; 242)$ or black $(243 ; B-W a r e)$ as result of reduced firing, although the latter may be the result of a fire which destroyed the house. The clay is hard (3), with medium mica and sand inclusions (size 0.1-0.25mm). Beaker 241 comes from a grave dated C. AD 50-80.

Similar beakers have been found at Milan (Caporusso et al. 1991, pl. XII 13).

\section{Form BK29: Beakers with indented wall}

244 Locarno-Muralto, property Passalli, grave 15, c. AD 0-50

245 Losone-Papögna; cemetery, context unknown

The prototypes of Form BK29 (Ricci 1985, 262, Type 1/85) could be Mayet's Form VINII (Mayet 1975, pl. XI.84 and 88 : second half of the 1st century BC), and further Marabini Moeus's Form LXIX, although they have more cylindrical body as the examples from Ticino. The beakers are characterized by extremely thin wall and the presence of indents. The rim is out-turned, the foot 
slightly concave (244) or a foot-disc (245). Beaker 244 has dark beige fabric, hard (3), with medium mica and sand inclusions (size $0.1 \mathrm{~mm}$ ). It is of J-Ware. Grave 15 from Muralto-Passalli dates c. AD 0-50. Beaker 245 has red-brown fabric, hard (3), with few mica inclusions (size $0.1 \mathrm{~mm}$ ). It is of L-Ware. Rim and body are decorated with groups of girth-grooves. The exact context, from which comes the beaker, is unknown.

These beakers occur at Angera (Sena Chiesa 1985, 411; pls. 82.20; 84.9). In central Italy they appear from Tiberian-Claudian times (Marabini Moeus 1973, 238-239 no. 434; Beltràn Lloris 1978, Form 691; Carandini 1977, 27) and belong to the commonest forms in Imperial times. North of the Alps these beakers are very common from Neronian times to the end of the 2 nd century AD (Plesnicar Gec 1972, pl. 6; Grünenwald 1979, pl. 22; Ettlinger \& Simonett 1952, pl. 12.243-245; Heukemes 1964, 96 pl. 26.6). The fabric is usually beige, very fine and hard. Sena Chiesa $(1985,411)$ hypotizes a transalpine production, whose centres were situated probably in Noricum. Form BK29 is rather rare in the area north of Po. Examples are known from Ticino, Angera (Sena Chiesa \& Lavizzari Padrazzini 1985, pl. 58.3-78531), Piemonte and Novara (Sena Chiesa 1985, 411-12 n. 127).

\section{Form BK30: Beakers with cylindrical to ovoid body and flat foot}

Form BK30 goes back to Marabini Moeus's Forms XI/XXXV (Marabini Moeus 1973, 73 ; 274), and Mayet's Form XIV (Mayet 1975, 52 pl. XXIII.172-173). 
It can be divided into three groups:

- Form BK30.1: Beaker with wide rim, without lugs;

- Form Bk30.2: Coarse beaker with cylindrical to ovoid body and lugs;

- Form BK30.3: Coarse beaker with cylindrical body and lugs

Form BK 30.1

246 Losone-Arcegno, grave 1

247 Losone-Arcegno, grave 7

248 Locarno-Solduno, property Balli, grave Ba 5

249 Losone-Papögna; cemetery, context unknown

Form BK30.1 could be traced back to Marabini Moeus's Form XI from central Italy, dated to the third quarter of the 1st century $B C$ and considered as 'Roman exploitation of an indigenous shape of the Iron Age' and Form XXXV with concave base (Marabini Moeus 1973,$73 ; 274$ ), Mayet's Form XIV dated to Augustan times (Mayet 1975, 52) and Beltràn Lloris' Forms 6 and 8 from the Mediterranean area. The main difference between these prototypes and the examples from Ticino lies in the foot: the former bear foot-discs, the latter slightly concave or flat feet. At Angera, these beakers, although occurring as coarse ware only, always have foot-discs (Sena Chiesa \& Lavizzari Pedrazzini 1985, pl. 82.5). Beakers 246 and 247, both from Losone-Arcegno, are very similar. The body is slightly ovoid, the bead rim flattened on the top. Both are thin walled. The fabrics are orange, medium hard (2), with medium mica inclusions (size $0.25 \mathrm{~mm}$ ). The decoration of 246 is plastic, with rows of barbotine spikes on the whole body. Beaker 247 is decorated with girth- 
grooves on the lower half of the body. Both beakers come from graves without any datable item. The only chronological evidence may eventually be given by examples from Angera, dating from Tiberian times. Beaker 248, although of rather fine fabric, occurs as coarse ware. In comparison to the examples from Losone-Arcegno, the body is less ovoid because of the wider foot. As before, the bead rim is flattened on the top. The fabric is beige-orange, hard (3), with few mica inclusions (size $0.1 \mathrm{~mm}$ ). The progressive straightening of the wall is evident in 249 , from Losone-Papögna, with vertical tapering rim. Its fabric is coarse, pink, medium hard (2), with medium sand and mica inclusions (size $0.25 \mathrm{~mm})$. Both beakers from Locarno-Solduno and Losone-Papögna are decorated with a girth-groove on the upper half of the body. A further prototype for these beakers is now Mayet's Form XIV. None of them bear any dating evidence.

Similar beakers, in particular 247, 248 and 249, occur at Olgiate Comasco in contexts dating from Flavian times (Butti Ronchetti 1986, 119 pl. III.23) and at Legnano from Augustan-Tiberian times Nolonté 1996, 185ff. pl. 3.1 Grave 301). Beakers of similar form occur in central Italy and Lyon, where they were produced (Ricci 1985, 274, Type 1/158).

\section{Form $B K 30.2$}

250 Locarno-Muralto, property Liverpool sotto, grave 14, c. AD 41-80

251 Minusio, property Cadra, grave 31, c. AD 54-100

252 Locarnese, Archivio di Stato, context unknown

253 Locarnese, Archivio di Stato, context unknown 
Form BK30.2 represents a variant of BK30.1, in particular of the coarser examples. The general prototypes are still Marabini Moeus's Form XI and Beltràn Lloris' Forms 6 and 8 . The change consists of the presence of two lugs in the upper half of the body, linked by one or more girth-grooves. All examples of Form BK30.2 and BK30.3 found so far in Ticino belong to coarse pottery.

Form BK30.2 has a cylindrical to ovoid body: the wall is straight from the rim to mid-body and becomes slightly curved from mid-body to the foot. The rim is vertical, tapering or rounded; the foot is slightly concave or flat. Beaker 251 and 253 are quite high because of the relationship between diameter of rim and foot, and height. Beakers 250 and 252, on the contrary, are rather squat, and resemble in the proportions Form BK30.3. The fabrics are red, beige or brown, medium hard (2) to hard (3), with medium mica or mica and sand inclusions (size $0.25 \mathrm{~mm}$ ). The fabric of 250 is of L-Ware. The fabrics of 251, 253 and 254 are of J-Ware. On the surface, except for 253 , they bear traces of contact with fire. The fragment 254 comes from a cremation grave. The fabric is therefore black, burnt, soft and powdery (1). Only beakers 250 and 251 come from datable contexts: the date of the graves ranges within $c . A D$ 40-100.

Form BK30.2 occurs in the cemetery of Angera, dating from ClaudianNeronian times (Caporusso et al. 1985b, 253-4 pl. 61.10). 


\section{Form $B K 30.3$}

255 Minusio, property Cadra, grave 5, c. AD 0-30

256 Minusio, property Cadra, grave 5, c. AD 0-30

257 Locarnese, context unknown

258 Locarnese, context unknown

Form BK30.3 has a cylindrical body with straight wall. As with Form BK30.2, the rim is tapering or rounded, the foot may be flat or slightly concave, and the two handmade grips are linked by a girth-groove (except for 257). The fabrics are red to beige-pink, medium to hard (3), with medium mica inclusions (size $0.25 \mathrm{~mm}$ ). The fabric of 255 is of $\mathrm{J}-\mathrm{Ware}$. Two beakers bear traces of contact with fire $(255 ; 258)$. Two examples only come from datable contexts: both belonged to the grave-goods of grave 5 at Minusio-Cadra, dated c. AD 0-30.

A similar beaker from Angera is dated to Claudian-Neronian times (Caporusso et al. $1985 \mathrm{~b}, 253-4$ pls. $61.10 ; 82.19)$.

Form BK30.3 is common for vessels in Lavez-rock, which are frequent in Roman cemeteries of the Locarno area and continue into Medieval times, reaching the 19th century.

The frequency of coarse beakers with lugs in the cemeteries of Locarnese, and respectively their scarcity at Angera and absence further south, e.g. at Milan, allow one to suppose a locally developed and produced form. Form BK30.3, in particular, shows the same features of Lavez vessels, typical for the pre-alpine regions as far as Como from Roman times onwards. It is 
therefore possible to suggest, that Form BK30.3 constituted a copy of Lavez beakers, probably cheaper and more useful as drinking vessels because of its reduced weight.

\section{Form BK31: Beakers with vertical wall}

259 Locarno-Muralto, property Passalli, grave 23

Beaker 259 has a hemispherical lower half of the body and a vertical wall with tapering rim. The fabric is red, rough-cast, hard (3), with many mica and sand inclusions (size $0.25 \mathrm{~mm}$ ). It is of G-Ware. The beaker is thin walled and decorated with a girth-groove at mid-body. Beaker 259 comes from grave 23 at Muralto-Passalli, which did not contain any datable grave-goods.

A beaker, similar to 259 but with foot-ring, occurs at Ottobiano (Lomellina) in a context dated c. 15 BC-AD 20 (Grave 27 : Vannacci Lunazzi 1986, 90 pl. 8.10). The form seems not to occur at Milan or Angera. 


\subsubsection{Balsamaria}

Definition: BALSAMARIUM is a small, narrow-necked vessel, thought to have been used for ointment or perfume (Webster 1976, 11).

Balsamaria with ovoid body

This form is rare in the graves of the Locarno region. There have been found only four complete balsamaria and three fragments of rim or body and foot, further divided into two groups: with flat base and with foot-disc.

\section{Form BS1 : Balsamaria with flat base}

260 Locarno-Muralto, property Liverpool sopra, grave 7, c. AD 70-120

261 Locarno-Muralto, property Liverpool sotto, grave 24, c. AD 50-100

262 Locarno-Muralto, property Liverpool sotto; cemetery

263 Locarno-Muralto, property Liverpool sotto, grave 35, c. AD 50-100

264 Locarno-Solduno, Via Passetto, grave B1, c. AD 70-120

265 Locarno-Muralto, property Meyster, grave 37

Six vessels may be taken back to Form Haltern 31(Schönberger 1976, pl. 7). In particular, 261 and 262 from Locarno-Muralto and 264 from LocarnoSolduno: the vertical rim, thickened and flattened on the top, is separated from the neck by a girth-groove, the neck is slightly conical, the body is ovoid and the foot flat. Balsamarium 260 from Locarno-Muralto is a variant of Form 
Haltern 31 because of the rim, vertical tapering instead of thickened and flattened. Vessel 265 is a fragment of rim and neck and also comes from Locarno-Muralto. The rim is out-turned and flattened on the top. Even if the body is missing, it is possible to assume that this balsamarium is a further variant of Form Haltern 31. Finally, 263 is a fragment of body and foot. Rim and neck are missing. It is therefore impossible to define if it belongs to Form Haltern 31 or to a variant. The fabrics are red or orange-red, medium-hard (2) and slightly powdery, with few to medium mica inclusions (size $0.1-0.25 \mathrm{~mm}$ ). Only 263 has beige-pink clay. On the inside it shows traces of black slip, completely vanished on the outside.

A balsamarium with a rim similar to 265 occurs at Ottobiano (Lomellina), from a context dated to Augustan-Tiberian times (St 34338: Vannacci Lunazzi 1986, 56-7 pl. V.3). This form occurs at Luni from the end of the 1st century BC to Tiberian times (Rossignani 1973-74, 355). Chronologically, the balsamaria of Form BS1 come from contexts dated C. AD 50-100 and AD 70120.

\section{Form BS2 : Balsamaria with foot-disc}

266 Locarno-Muralto, property Liverpool; cemetery, context unknown

Balsamarium 266 was found at Locarno-Muralto in the same area as 260, 261 and 262, and corresponds to a variant of Form Haltern 30-Oberaden Form 28Friedberg Form 22 (Schönberger 1976, pl. 7; Caporusso et al. 1991, pl. 72, 4- 
5). Form Haltern 30 shows a vertical thickened rim, flattened on the top, a long neck, an ellipsoidal body, a high foot-disc. The example from Canton Ticino is fragmentary. The foot, however, is not flat but concave and constitutes a variant. Form Haltern 30 shows a fabric similar to that of Haltern 31 (redorange with med. mica incl.) in Ticino, but the clay is harder (3).

A balsamarium of similar form, although with slightly different foot, occurs at Nuvoleto (Brescia). It belongs to the group dated between the 1st century BC and mid-1st century AD (Rossi 1988, 53-4). This form occurs at Luni during the 1st century BC and Augustan-Tiberian times (Rossignani 1973-74, 355).

No balsamaria have been found in the cemetery of Angera and these forms do not find any parallels in glass vessels with the same function. Some examples, however, come from Milan (Guglielmetti et al. 1991, 167-168). Here, by contrast of Ticino, there were found more examples of Form Haltern 30 than of Form Haltern 31. The fabrics are similar to those from Ticino, with few mica inclusions. The balsamaria from Milan, however, bear on rim, neck and inside a wash, consisting of clay. This never appears in Ticino. At Milan the balsamaria belong to Augustan and 1st century AD contexts. The contexts dating from the 1st century $A D$, however, contained many later materials. It is therefore difficult to say if the form at Milan really continued to the 1st century AD. 


\subsubsection{Dishes}

Definition: DISH is a shallow vessel having a height less than a third but greater than a seventh of its diameter (Webster 1976, 9).

\section{Dishes with inturned or out-turned rim}

Rim rounded in section

Form D1: Dishes with inturned and slightly expanded rounded rim

267 Locarno-Muralto, property Passalli, grave 27

268 Losone-Arcegno, grave 5, c. AD 231-50

269 Losone-Arcegno, grave 12, c. AD 180-200

270 Losone-Arcegno, grave 57, c. AD 235-50

271 Losone-Arcegno, grave 57, c. AD 235-50

272 Losone-Arcegno, grave 59, c. AD 222-50

273 Losone-Arcegno, grave 62, c. AD 183-230

274 Losone-Arcegno, grave 63, c. AD 244-60

275 Ascona, grave S15, c. AD 200-250

Form D1 has an inturned rounded rim, a rounded shoulder, a deep body with straight wall and a slightly concave or flat foot. Only 274 has a concave foot. The 
fabrics are red (271, L-Ware), red-brown (268, 269, M-Ware), beige-brown (274), beige-red (275) and grey-black to black (267, D-Ware ; 270, E-Ware), and hard (3). Dishes 267 and 268 have some mica, sand, granular and crushed quartz inclusions (size $0.25-1 \mathrm{~mm}$ ); the other examples have some mica (size $0.25 \mathrm{~mm}$ ) only. All dishes show traces of contact with fire on the outside and on the rim. The outer surface of the foot was made rough by application of sand, crushed and granular quartz. Only two dishes $(267 ; 274)$ show a smooth surface. Dish 275 is associated to lid 678 of Form L2. All examples from datable context fall within the last quarter of the $2 \mathrm{nd}$ and the first half of the 3rd century AD. Dishes 269 and 273 have come from contexts dated c. AD 180-230; 275 comes from a grave dated C. AD 200-50. Dishes 268, 270, 271 and 274 belong to graves dated c. $A D 230-50$.

This form is widely attested in Lombardy, often in late Roman contexts. At Angera similar dishes date to the 2nd century AD (Facchini et al. 1985, 77 pl. $23.17 ; 105$ pl. 29.11 ; 110 pl. 31.8 ; Caporusso et al. 1985a, 163 pl. 43.2), but always have flat foot. At Salò (Massa et al. 1997, $112 \mathrm{pl}$. XXXIV.2) this form occurs during the 2nd century AD ( $23 \%$ of examples) and becomes very common during the 4 th century $A D(13 \%$ of examples between the second half of the 3rd and the 4th century $A D ; 60 \%$ during the 4 th century $A D$ ). Other examples come from Milan (Guglielmetti et al. 1991, 224 pl. Cll.3-5), Cremona (Bolla 1985, 202 pl. IV.10), Bergamo and its region (Fortunati Zuccala 1986, 129 fig. 127 ; Sapelli 1981, 170 fig. 10), Brescia and its region (Massa 1988, 92 pl. Xll.1-2 ; Massa 1982 ; Massa 
$1986,43 \mathrm{pl}$. I). North of the Alps similar vessels occur during the second half of the 2nd century AD (von Gose 1950, 40 pl. 45.467).

\section{Form D2: Dishes with inturned rim and tapering}

276 Minusio, property Cadra, grave 1, c. AD 180-230

277 Losone-Arcegno, grave 79, c. AD 236-50

278 Losone-Papögna; cemetery, context unknown

279 Losone-Papögna; cemetery, context unknown

Form D2 has an inturned rim, a high body with tapering towards the foot, a flat or slightly concave foot. The rim of 276 is different from the others and consists of a very expanded rounded rim on rather thin shoulder. The fabrics are red ( $M$ Ware : 278,279$)$ to red-brown $(276$, L-Ware) or dark brown to black $(277, \mathrm{E}-$ Ware), and hard (3). Dish 279 has mica, sand and quartz inclusions (size $0.5 \mathrm{~mm}$ ); the others have mica inclusions (size $0.25 \mathrm{~mm}$ ). Except for 278 , all examples show traces of contact with fire on the outside and on the rim. Only 276 and 277 show the rough surface under the foot. They are also the only dishes from datable contexts: the graves date C. AD 180-230 (No. 276) and C. AD 23650 (No. 277).

This form occurs at Angera (Sena Chiesa \& Lavizzari Pedrazzini 1985, pl. 92.6 ; Compostella $1995 \mathrm{a}, 137-38 \mathrm{pl} .55 .4-5)$, where it dates from the 2 nd to the 4 th century AD. Similar vessels appeared at Garlasco (Pavia; Vannacci Lunazzi 
1981, 103 pl.5.3) and Bergamo (Tremel 1967-69, pl. I.1) during the 2nd and 3rd century AD, at Milan (Caporusso et al. 1991, pl. 7.8) during the 3rd to 5th century $A D$, at Luni (Frova 1977, $648 \mathrm{pl}$. 335.2) during the 4th and 5th century $A D$, and north of the Alps from the 2nd to the 5th century AD (Hochuli Gysel 1986, $323 \mathrm{pl}$. 31.17 ; Grünenwald 1979, 63-64 pls. 57.9 ; 58.1-2 ; von Gose 1950, pl. 45.467 ; Hayes 1972, 200 ; Dyson 1976, 139).

\section{Form D3: Dishes with inturned rounded rim}

Form D3 has an inturned and rounded rim, but not expanded. The shoulder is rounded, the foot flat or slightly concave.

According to the wall, two groups have been distinguished:

- Form D3.1: Dish with slightly curved wall;

- Form D3.2: Dish with straight wall.

Form D3.1

280 Locarno-Muralto, property Passalli, grave 28, c. AD 100-150

281 Locarno-Solduno, San Carlo, grave 76.2, c. AD 200-250

Form D3.1 has a slightly curved wall. The body is rather low, rather cylindrical by 280 and conical by 281 . The fabrics are red (280) or red-brown (281), hard (3), with some mica inclusions (size $0.25 \mathrm{~mm}$ ). Both are of L-Ware. Dish 280 has traces of fire and a decoration under the base (outside), consisting in concentrical circles. Dish 281 has the rough surface under the foot. Dishes 280 and 281 come 
from datable contexts. The suggested dated of the graves are c. AD 100-150 (No. 280) and C. AD 200-250 (No. 281).

A dish very similar to 281 occurs at Angera dating from Flavian-Trajanic times (Sena Chiesa \& Lavizzari Pedrazzini 1985, pl. 92.4), whereas 282 is rather close to a later dish with straight wall, dating from Antonine times (Sena Chiesa \& Lavizzari Pedrazzini 1985, pl. 92.10).

Form D3.2

282 Losone-Arcegno, grave 55, c. AD 235-50

Form D3.2 has a higher and more conical body than D3.1. The foot is narrower, the wall straighter. The fabric is brown, hard (3), with mica and sand inclusions (size $0.25 \mathrm{~mm}$ ), and is of D-Ware. The outside and the rim show traces of contact with fire. The outer surface of the foot is made rough. The graves dated $C$. AD 235-50.

A similar dish occurs at Legnano and dates generally to the 1st-2nd century $A D$ (Binaghi 1990, 221-2). 


\section{Form D4: Dishes with out-turned rim and flat base}

283 Locarno-Muralto, property Branca, grave 4, c. AD 0-30

Dish 283 has an out-turned rim, slightly flattened on the top, a conical body with straight wall and a flat foot. The fabric is grey and shows black patches from the contact with fire, hard (3), with mica and sand inclusions (size $0.25 \mathrm{~mm}$ ), and is of $D-W a r e$. The date of the grave is C. AD 0-30.

This form seems not to occur at Angera. It appears at Molteno (Lecco; Nobile 1994, 224-25 fig. 150.7), Seriate-Bergamo dated to the 2nd century AD (Ceresa Mori 1980-81, 166 Grave A pl. 2.c), Erba (Nobile 1992, 53 pl. 12 cat. 13.5), and Milan from the end of the 3rd and the 4th century AD (Mariotti 1990, 156 scheda 2b.5a).

\section{Form D5: Dishes with out-turned rim and convex base}

284 Losone-Papögna; cemetery, context unknown

Dish 284 has an out-turned rim, a cylindrical body and a convex foot. The fabric is grey to black with traces of contact with fire, hard (3), with some mica inclusions (size $0.25 \mathrm{~mm}$ ), and is of E-Ware. The surface of the dish is burnished. The exact context of the dish is unknown.

Similar vessels seem to be more frequent in central-eastern Lombardy. They occur at Milan (Ceresa Mori 1986, pl. 76.h), in Roman graves from Erba and Molteno (Como), at Mariano Comense (first half of the2nd century AD : Butti 
Ronchetti 1987a, 94 pl. IX.85, from a building), from Bergamo (Tremel 1967-69, 283-4), Seriate and Ghisalba, from Calvatone (Cremona) and Budrio (Bologna). The grave at Erba has a terminus post quem at the end of the 2nd century AD (Nobile 1992, 20-21, n.s 14-15; 53 n. 13.5; 57 n. 16.3). The examples from Budrio date to the 1st and the 2nd century AD (Bergamini 1980, 105). This form does not occur in the Varese-Angera region, where the dishes have inturned or vertical rim and usually flat foot (Sena Chiesa \& Lavizzari Pedrazzini 1985, pl. 92). The examples from the Como and Bergamo regions, however, have coarser fabrics than the dish from Locarno-Muralto, with many inclusions also of considerable size and with vesicular surface. This form is the commonest at Pompeii as cooking dish (Annecchino 1977, 108).

Rim triangular in section

\section{Form D6: Dishes with inturned triangular rim}

Form D6 has an inturned, expanded triangular rim. According to the sharpness of the shoulder, this form may be divided into:

- Form D6.1: Dish with angular shoulder;

- Form D6.2: Dish with rounded shoulder. 
Form D6.1

285 Minusio, property Cadra, grave 1, c. AD 180-230

286 Losone-Arcegno, grave 53, c. AD 193-210

287 Losone-Papögna; cemetery, context unknown

Form D6.1 has an inturned triangular rim, a pointed shoulder, a conical body with straight wall, and a slightly concave foot. The body, in comparison with D6.2, is relatively low. The fabrics are red (M-Ware : 285,287 ) or beige (286), hard (3). Dish 285 has mica inclusions (size $0.25 \mathrm{~mm}$ ); 286 has mica and sand inclusions (size $0.25-0.5 \mathrm{~mm}$ ); 287 has mica, sand and quartz inclusions (size $0.25 \mathrm{~mm}$ ). Only 285 and 286 bear traces of contact with fire, whereas all examples has the outer surface of the foot rough because of the application of sand and quartz. Both dishes from datable contexts, 285 and 286 , belong to graves dated C. AD 180/90-230.

Similar dishes occur at Angera dating from Antonine times (Maccabruni \& Schifone 1985, 134 pl. 38.6 ; 143-4 pl. 41.12; Sena Chiesa \& Lavizzari Pedrazzini 1985, pl. 92.13). A dish of Form D6.1 was found at Airolo-Madrano, associated with a disc-brooch, three brooches of type Misox, and four coins dated to the 2nd century AD (Trajan, Antoninus Pius, Faustina). 
Form D6.2

288 Losone-Arcegno, grave 59, c. AD 222-50

289 Losone-Papögna; cemetery, context unknown

290 Losone-Papögna; cemetery, context unknown

Form D6.2 is higher than D6.1 and the wall of two examples $(288,290)$ shows a slight tapering towards the foot. The shoulder is rounded, the foot slightly concave. The fabrics are red to beige, but only medium hard (2). Dish 290 has mica, sand and quartz inclusions (size $0.25 \mathrm{~mm}$ ); the other two only mica inclusions (size $0.25 \mathrm{~mm}$ ). Only 290 bears traces of contact with fire; only 288 and 289 have the outer surface of the foot made rough. Dish 288 comes from a grave dated c. AD 222-50.

A similar dish occurs at Angera dating from Antonine times (Sena Chiesa \& Lavizzari Pedrazzini 1985, pl. 92.10).

Form D7: Dishes with inturned rim at a sharp angle

291 Losone-Arcegno, grave 48, c. AD 244-60

292 Losone-Arcegno, grave 61, c. AD 243-60

293 Losone-Arcegno, grave 63, c. AD 244-60

294 Locarno-Solduno, property San Carlo, grave 76.3, c. AD 200-250 
Form D7 has a low body. The wall is straight, the rim sharply inturned and the shoulder triangular. The foot is flat or slightly concave. Dishes 291, 292 and 294 are very similar. The body is wide and low. The fabrics are red, hard (3), with few mica inclusions (size $0.25 \mathrm{~mm}$ ). They are of K-Ware. The decoration consists of red slip, similar to African Terra Sigillata slip, on the inside and the rim, and a rouletted circle inside on the base for the two examples from Losone-Arcegno, two roughly rouletted circles for the dish from Solduno. Dish 293 is smaller and its foot is flat. Fabric and slip are the same as the former dishes, the mica inclusions are smaller and rarer (size $0.1 \mathrm{~mm}$ ). This dish does not bear the rouletted circle. Grave 76.3 from Locarno-Solduno is dated c. AD 200-250. The three graves from Losone-Arcegno date c. AD 240-60.

This form occurs once at Angera dating from Antonine-Severian times (Tomaselli 1985, 460: Type D, no. SC. 72001 , pls. 73.6 and 92.17), at Milan in contexts from the end of the 1st to the 4th century AD (De Vanna 1991, 131: Tipo 11; Caporusso et al. 1991, pl. 52, 3-4), at Lurate Caccivio (no context: Butti Ronchetti 1985, pl. XIX.12), at Bergamo (Tremel 1967-69, 284), at Luni dated to the 4th-5th century AD (Cavalieri Manasse 1977, 601; 619: Group 28; pl. 269.18), at Portorecanati dated to Trajanic times (Mercando 1974, pl. 136 figs. 219a and 220), It also appears in the Rhine area, dated to the second half of the 4th century AD (von Gose 1950, 41; pl. 45.474-475), at Carnutum (Grünenwald 1979, pls. 24 ; 57), at Conimbriga dated to the 5th century AD (Alarcâo 1975, pl. 30.67), in Aquitania (Santrot 1979, 58), and at Novaesium dated to the first half of the 4th century AD (Müller 1977, Grave $1268 ;$ pl. 388.6). 


\section{Dishes with straight or slightly inturned wall}

Rim rounded in section

Form D8: Dishes with expanded rounded rim and curved wall

295 Losone-Arcegno, zone B

296 Losone-Arcegno, grave 60, c. AD 256-70

297 Losone-Arcegno, grave 66, c. AD 244-90

298 Losone-Arcegno, grave 75, c. AD 383-400

299 Losone-Papögna; cemetery, context unknown

300 Losone-Papögna; cemetery, context unknown

Form D8 has an expanded rounded rim on slightly thinner wall and a conical body with curved wall. The feet of the examples from Losone-Arcegno and of 299 are slightly concave to concave. Dish 300 has flat foot. Dishes 295, 296 (E-Ware) and 300 have dark beige to brown fabrics, hard (3), with traces of contact with fire on the outside and the rim. Dishes 296 and 300 have mica inclusions (size $0.25 \mathrm{~mm}$ ); 295 has mica and sand inclusions (size 0.25mm). Dishes 297, 298 and 299 have orange fabrics, hard (3). Dish 298 bears black patches on the outside as result of the contact with fire, mica inclusions (size $0.25 \mathrm{~mm}$ ) and the rough surface on the outside of the foot. Dish 297 has mica, sand, crushed quartz and grog inclusions (size $0.25-0.7 \mathrm{~mm}$ ). Its fabric is of $\mathrm{N}$-Ware. Dish 299 has some 
mica and sand inclusions (size $0.25 \mathrm{~mm}$ ). Dishes 296 and 297 come from graves dated c. AD 250-90; dish 298 from a grave dated C. AD 383-400.

This form occurs at Angera in Hadrianic-Antonine times (Sena Chiesa \& Lavizzari Pedrazzini 1985, pl. 92.9).

Form D9: Dishes with slightly expanded rounded rim and slightly curved wall

301 Losone-Papögna; cemetery, context unknown

302 Ascona, no context

303 Locarno-Muralto, Grande Albergo; cemetery, context unknown

304 Locarno-Muralto, via Scazziga, settlement

Form D9 is similar to Form D8, but the rim is only slightly expanded, the foot is wider, the wall straighter and therefore the body less conical. The fabrics are beige (301), brown (302) and beige-orange (303; 304), and are all hard (3). All dishes, except for 303 , show traces of contact with fire on the outside. The inclusions are mica and sand (size $0.25 \mathrm{~mm}$ ) for 301 and 302, and mica, sand, quartz and grog (size $0.25-0.5 \mathrm{~mm}$ ) for 303 and 304 (both N-Ware). Dishes 302 and 303 also bear a rough surface under the foot. Some wear on the rim of 304 , which is missing of the foot, allows one to suppose the use of the vessel as a lid. None of these examples comes from a datable context. 
This form occurs at Angera during the second half of the 2nd century AD (Troso \& Uglietti 1985, 116 pl. 32.3). North of the Alps, it dates to the end of the 2 nd and the 3rd century AD (von Gose 1950, pls. $16.224 ; 46.479$ ).

\section{Form D10: Dishes with rounded rim and curved wall}

305 Losone-Arcegno, grave 81, c. AD 193-220

306 Locarno-Muralto, property Meyster; cemetery, context unknown

Form D10 has a rounded and slightly inturned rim as result of the curved wall. The body is rather low, the foot flat or slightly concave. The fabric of 305 is red, hard (3), with many mica, sand, crushed quartz and grog inclusions. The dish has a rough surface on the outside of the foot. Dish 306 has grey-black fabric with traces of contact with fire, medium hard (2), with some mica inclusions, of EWare. The dish from Losone-Arcegno comes from a grave dated C. AD 193-220. Form D10 is similar to D8, except for the rim, which is not expanded and the body, which is usually lower.

This form occurs at Angera and Gropello Cairoli from Flavian times to the beginning of the 2nd century AD (Lavizzari Pedrazzini 1980, 220, pls. 7.1-7 and 18.6-9 ; Arata 1984, 83-3 pl. IX 5-6 St 33731 and St 33730). Similar vessels appear at Conimbriga during Claudian-Trajanic times (Alarcao 1975, pl. XIC 382384), at Novaesium between the last quarter of the 1st and the first quarter of the 
2nd century AD (Vegas 1975, pls. 46-48), and from the pre-Flavian fort at Usk (Greene 1973, 36-7 fig. 2.24).

\section{Form D11 : Dishes with conical body and girth-groove under the rim}

307 Losone-Papögna; cemetery, context unknown

308 Losone-Arcegno, grave 62, c. AD 183-230

309 Losone-Arcegno, grave 74, c. AD 253-70

310 Losone-Arcegno, grave 75, c. AD 383-400

311 Losone-Arcegno, grave 85, c. AD 351-70

312 Minusio, property Cadra, grave 26, c. AD 161-210

Form D11 has an expanded rounded, slightly inturned rim, a rather high conical body with curved wall and a slightly concave to concave foot. Only 311 has a slightly convex foot. The main feature of this form is a girth-groove on the wall just under the rim. In some examples $(308 ; 309 ; 310 ; 312)$ the wall under this groove is slightly prominent, to make it safer when used as a lid. The fabrics are hard (3), beige-pink (307), brown-red (309), orange (310), burnt black (308; 311 , E-Ware), or red $(312, M-W a r e)$, with some mica or mica and sand inclusions (size $0.25 \mathrm{~mm}$ ). All dishes, except for 307 and 312 show traces of contact with fire on outside and rim. Moreover, all examples have the outer surface of the foot made rough. The contexts ranges from the second half of the 2 nd century $A D$ (c. $A D$ 160-230; Nos. 308 and 312) to the second half of the 3rd century AD (c. $A D$ 
253-70; No. 309) and the second half (c. AD 340-90; No. 311) or the end of the 4th century $A D$ (No. 310).

At Angera dishes of similar Form belong to Type B and occur in HadrianicAntonine times (Sena Chiesa \& Lavizzari Pedrazzini 1985, pl. 92.9). At Almese (Val di Susa), this form occurs at the beginning of the 4th century AD (Gabucci 1996, pl. XXVIII Grave 8.1).

Form D12 : Dishes with lugs

313 Losone-Papögna; cemetery, context unknown

314 Losone-Arcegno, grave 55, c. AD 235-50

315 Losone-Arcegno, grave 58, c. AD 231-50

316 Losone-Arcegno, grave 81, c. AD 193-220

317 Locarno-Muralto, Grande Albergo; cemetery, context unknown

Form D12 has a rounded rim, a conical body with more or less curved wall, two lugs under the rim, a flat or concave foot. All dishes, except for 317 , have slightly inturned rim. The rim of 317 is rather vertical. The fabrics are hard (3), red to redbrown (L-Ware: $314 ; 315 ; 316$ ) or brown-beige to beige $(313 ; 317$ ). All bear traces of contact with fire on outside and rim. The inclusions are mica (size $0.25 \mathrm{~mm}$ ) for 315,316 and 317 ; mica and sand (size $0.25 \mathrm{~mm}$ ) for 313 and 314 . The dishes from Losone-Arcegno have a rough surface under the foot. Only the 
examples from Losone-Arcegno come from datable contexts, dated C. AD 190250.

Dishes with lugs occur in the cemetery of Angera only twice (Tomaselli 1985, 461: Type F, pl. 92.19; Bertolone 1947, 31 pl. 1.8). They date to AntonineSeverian times and, more generally, to the 2 nd century AD.

Form D13: Dishes with rounded rim, low body and slightly pinched out foot

318 Losone-Papögna; cemetery, context unknown

319 Losone-Papögna; cemetery, context unknown

320 Losone-Papögna; cemetery, context unknown

Form D13 has a rounded rim and low body, which shows a tapering towards the foot. The feet are slightly concave. The three examples come from LosonePapögna; unfortunately their exact contexts are unknown. Dishes 319 and 320 are very similar. The fabrics are red, medium hard (2) to hard (3), with mica and sand inclusions (size $0.25 \mathrm{~mm}$ ). Some black patches on the outside are traces of contact with fire. Both dishes bear traces of red slip inside, very worn. Dish 319 also has two concentrical circles on the base (inside). Dish 318 has more expanded rim and less tapered wall. The fabric is red with traces on contact with fire on the outside, hard (3), with some mica (size $0.25 \mathrm{~mm}$ ) inclusions. Inside the dish, the junction between wall and foot is marked by a small groove. All fabrics are of K-Ware. 
This form occurs at Angera in Trajanic-Hadrianic times (Facchini et al. 1985, 101 pl. 28.8 ; Maccabruni \& Schifone 1985, 130-1 pl. 37.7 ; Sena Chiesa \& Lavizzari Pedrazzini 1985, pl. 92.14), but without any slip. At Alba, it appears at the end of the 1 st and the beginning of the 2nd century AD (Cagnana 1994, $114 \mathrm{pl}$. XXXIII.11).

\section{Form D14: Dishes with tapering rim and curved wall}

321 Losone-Arcegno, zone B

Dish 321 has a tapering rim, a curved wall and a flat foot. The fabric is red, medium hard (2), with some mica inclusions (size $0.25 \mathrm{~mm}$ ). It is of K-Ware. The inside and the rim are covered with red slip, similar to sigillata red slip. The exact context of the dish is unknown. 


\section{Rim triangular in section}

\section{Form D15: Dishes with rounded rim and curved wall}

Form D15 is similar to D8, except for the rim (not expanded) and the body (lower).

According to the rim, two groups can be distinguished:

- Form D 15.1: Dish with triangular rim;

- Form D15.2: Dish with rim with 'pointed' inside.

Form D15.1

322 Losone-Arcegno, grave 63, c. AD 244-60

323 Losone-Arcegno, grave 67, c. AD 222-70

324 Locarno-Muralto, property Passalli, grave 31

The rim of Form D15.1 is triangular in section, with the highest point situated on the inside of the rim. Dishes 323 and 324 have rather low bodies and slightly concave feet, whereas 322 is higher and has flat foot. Dish 322 has very fine fabric, hard (3) and orange red, similar to the African Terra Sigillata ware. The inclusions are few, and consist of mica (size $0.1 \mathrm{~mm}$ ). Dish 323 has hard (3), brown-red fabric with contact with fire on the outside and the rim, and some mica inclusions (size $0.25 \mathrm{~mm}$ ). Dish 324 has hard (3), grey fabric with contact with fire, and mica, sand, granular and crushed quartz inclusions (size $0.25-1 \mathrm{~mm}$ ). This fabric is of D-Ware. Both dishes bear the rough surface on the outside of the foot. 
The dishes from Arcegno come from datable contexts, both from graves dated c. $A D$ 220-70.

\section{Form $D 15.2$}

325 Losone-Arcegno, grave 49, c. AD 179-200

Dish 325 has a high body with straight wall and a nearly flat foot. The rim is triangular in section, but the highest point is on the outside of the rim and a 'corner' constitutes a sort of overbang inside the wall, slightly under the rim. The fabric is red, with some black patches due to the fire, hard (3), with mica and sand inclusions (size $0.25 \mathrm{~mm}$ ). It is of M-Ware. The context is dated c. AD 179200.

\section{Summary}

The dishes found in the Locarno region, although belonging to different forms, have as general feature the inturned or vertical rim. The few exceptions consists of Form D4 and D5, with out-turned rim.

Most of these dishes show traces of contact with fire on the outside and the rim. This element gives two kinds of information: it indicates that these vessels were mainly used for cooking and that grave-goods of this type consisted of vessels already used and not produced for funerary purpose only. 
A considerable number of dishes shows a rough surface on the outside of the flat or concave foot. This surface was obtained by spreading sand and quartz. The reason of this feature may be explained by the need of a non-slippery surface or of insulation between the dish and the surfaces of contact, avoiding a breaking due to the difference of temperature, rather than with manufacture techniques. This rough surface also occur on jars and bowls and at Angera and Como. The fabrics of the dishes from the Locarnese are hard and contain few and small inclusions. On the contrary, at Angera and Como the fabrics are rough, sometimes porous and contain inclusions of bigger dimensions (Tomaselli 1985, 456; Nobile 1992,$53 ; 57)$.

Except for Form D4, from a context with terminus post quem in the second half of the 1 st century $A D$, the date of the dishes ranges from the end of the 2 nd to mid4th century $A D$, with a considerable group between the end of the 2 nd and the first half of the 3rd century AD. At Angera, dishes occur as grave-goods from the end of the 1st century $A D$, but become frequent during the 2 nd century $A D$ and last until mid-3rd century AD (Tomaselli 1985, 453ff.). A chronological evolution according to the rim has been traced by Lavizzari Pedrazzini $(1980,205 \mathrm{ff}$.). Before the second half of the 1st century $A D$, the rim is strongly inturned and the wall curved. During the 2 nd century $A D$, the wall becomes straighter and the rim only slightly inturned. As at Angera, also in Ticino the coarse dish occurred as grave-goods instead of sigillata dishes or their local imitation, but never as imitations of sigillata forms. Lamboglia, in his appendix to the translation of Simonett's 'Tessiner Gräberfelder' (1941), mentions imitations of sigillata dishes in coarser ware during the second half of the 1st century AD (Lamboglia 1967-71, 
224; 226). The mentioned examples 'Mur. P. 1' and 'Mur. B. 1', however, are respectively a black slip dish and a local imitation of a sigillata dish in fine ware with red slip.

Dishes in the Locarno area are frequent in both cemeteries of Losone, Arcegno and Papögna, but very scarcely represented in the other sites. In particular, almost all forms occur in the cemetery of Losone-Arcegno, dating from the end of the 2 nd to mid-4th century AD. It is not clear if this feature is due to the presence of later graves or to a funerary habit typical for the area of Losone. Another peculiarity of the cemetery of Losone-Arcegno is the presence of coins in almost all graves, including a relative frequency of coin hoards. The cemetery of Moghegno, north of Losone, does not show the same features and the content of its graves is, on the contrary, closer to that of the cemeteries by the lake. The analysis of the other classes of pottery, found within the study area, may provide further information about funerary uses.

In the cemetery of Angera, raised foot-ring cups of coarser fabric and dishes occur in contexts from mid-2nd to mid-3rd century AD, and are usually associated (Tomaselli 1985, 452). Within the study area, on the contrary, only grave 4 at Muralto-Branca shows the association of a raised foot-ring cup and a dish among its grave-goods. All other examples of cups and dishes occur in different graves. The examples from Losone-Papögna could constitute an exception, but the exact contexts of the grave-goods are unknown.

Coarse dishes, moreover, seem to replace sigillata dishes of Dragendorf's Form 17 from the end of the 1st century AD in the cemetery of Angera. This feature, however, does seem to be a constant. Except for Losone-Arcegno, this form is 
uncommon in the cemeteries within the study area and does not occur in the cemetery at Mariano Comense (Butti Ronchetti 1987a, 93).

It is interesting to find at Losone of 'ceramica a vernice rossa interna', characterized by a thick red or red-brown slip inside, with the double function of making the wall waterproof and non-sticking. This pottery was produced in central Italy from the 3rd century $\mathrm{BC}$; other manufacturing centres appeared later in northern Italy and along the Germanic Limes. At Milan, 'ceramica a vernice rossa interna' occurred in layers dating from the 1st century BC to the 3rd-4th centuries AD. Stratigraphical reliability and parallels with other pottery types, however, seem to restrict this date from the second half of the 1st century $B C$ to the second half of the 1st century AD (De Vanna 1991, 129). The few examples from Losone come from contexts dating from the 3rd century $A D$; the variant with inturned rim is in fact the later one, and in central Italy dates to the second half of the 1st century AD (Goudineau 1970, 185). 


\subsubsection{Bowls}

Definition: BOWL is a vessel having a height more than one third but not greater than its diameter (Webster 1976, 9).

\section{Bowls with globular or hemispherical body}

\section{Form B1: Bowls with bead rim and vertical neck}

Form B1 has a slightly out-turned bead rim, a vertical neck, a conical body with curved wall, a flat base or a foot-disc. According to the rim, two groups can be distinguished:

- Form B1.1: Bowl with slightly out-turned bead rim.

- Form B1.2: Bowl with out-turned bead rim with a sharp angle.

\section{Form B1.1}

326 Locarno-Muralto, Via Scazziga; house, context unknown

327 Locarno-Muralto, Via Scazziga; house, context unknown

The two bowls from Muralto are fragmentary. The rims are slightly out-turned ; the bases are foot-discs. The walls are partly missing, but the bodies can be reconstructed as conical ones with curved walls. Bowl 326 has beige-pink fabric, hard (3), with some mica inclusions (size $0.25 \mathrm{~mm}$ ). Bowl 327 has grey fabric due to the reduced firing, hard (3), also with mica and some granular quartz inclusions (size $0.25 \mathrm{~mm}$ ), of D-Ware. Both bear a girth groove as 
decoration: 326 on the shoulder, 327 at the junction between neck and body. None of them comes from a datable context.

\section{Form B1.2}

328 Locarno-Solduno, Trench 1956/N3

Form B1.2 is similar to B1.1, but the rim ends in a sharp angle over the neck. Bowl 328 has lower body, conical and with straight wall; the base is flat. The fabric is red, hard (3), with mica, crushed and granular quartz inclusions (size $0.25 \mathrm{~mm}$ ). It is of M-Ware. The bowl is decorated with a flat cordon on the shoulder. It comes from a datable context: the terminus post quem is the 2 nd century AD.

Form B1 occurs at Angera and dates to Trajanic-Hadrianic times (Sena Chiesa \& Lavizzari Pedrazzini 1985, pl. 93.10).

Form B2: Bowls with out-turned rim, triangular in section, and vertical neck

329 Locarno-Muralto, Via Scazziga; house, context unknown

330 Locarno-Muralto, property Meyster; cemetery, context unknown

Form B2 has triangular rim. Rim and neck are not separated and therefore are both slightly out-turned. The two examples are different. Bowl 329, although fragmentary, has a foot-ring. The fabric is beige, medium to hard (2-3), with some mica inclusions (size $0.25 \mathrm{~mm}$ ). The vessel is decorated with a girthgroove under the neck. Bowl 330 has a conical body with curved wall, and a 
slightly concave and pinched out foot. The fabric is brown with black areas due to the contact with fire, medium hard (2), with some mica and sand inclusions (size $0.25-0.5 \mathrm{~mm}$ ). None of these bowls comes from a datable context.

Form B2 occurs at Angera and dates to Flavian times (Sena Chiesa \& Lavizzari Pedrazzini 1985, pl. 93.6).

Form B3: Bowls with very slightly out-turned, short rim

331 Losone-Arcegno, grave 8, c. AD 194-210

332 Losone-Arcegno, grave 27, c. AD 244-60

333 Locarno-Muralto, property Passalli, grave 2

Form B3 has a slightly out-turned, rounded rim. The body is conical: 331 has curved wall ; 332 and 333 have straight wall. The feet are flat (332) or slightly concave $(331 ; 333)$.

Bowl 331 has brown-red fabric, medium hard (2), with mica and sand inclusions (size $0.25 \mathrm{~mm}$ ). The surface shows traces of contact with fire. Bowl 332 has beige fabric, hard (3), with mica inclusions (size $0.25 \mathrm{~mm}$ ). Bowl 333 also has beige fabric, medium hard (2), with mica inclusions (size 0.1 $0.25 \mathrm{~mm}$ ). It also shows traces of contact with fire on the outside. The bowls from Losone come from datable contexts: C. AD 194-210 for 331 and $C$. AD $244-60$ for 332 . 
Form B3 occurs at Angera and dates to Flavian times (Sena Chiesa \& Lavizzari Pedrazzini 1985, pl. 93.3).

\section{Form B4: Bowls with out-turned triangular rim, internal lid seating and vertical neck \\ 334 Losone-Arcegno, grave 16, c. AD 119-40}

Form B4 has a concave internal lid seating. As result, the rim ends in a vertical segment and is triangular in section. Rim and body are separated by a vertical neck. Bowl 334 has wide flat foot and body with curved wall. Because of the width of the foot, the body is hemispherical rather than conical. The fabric is beige-red, hard (2), with mica and sand inclusions (size $0.25 \mathrm{~mm}$ ). The outer surface shows contact with fire; under the foot, the surface was made rough. The bowl comes from a grave dated $C$. AD 119-40.

Fragments of rim of Form B4 occur at Milan and date from the second half of the 1st century $B C$ to the first half of the 1st century $A D$ (Guglielmetti et al. 1991, 178-80: Tipo 32 ; Caporusso et al. 1991, pl. 82.1-2). 
Form B5: Bowls with out-turned triangular rim and internal lid seating, without neck

335 Locarno-Solduno, Modern cemetery, grave 1958.20, c. AD 70-120

336 Ascona, grave 6

Form B5 has a concave internal lid seating as with Forms B4 and B25, but does not have the vertical neck. The rim joins the body at a sharp angle. Form B5 has a conical body with curved wall. The feet are flat or slightly concave. The two examples have slightly different rim: rather vertical by 335 ; more elongated and out-turned by 336 . Bowl 335 has dark beige fabric, hard (3), with some mica inclusions (size $0.25 \mathrm{~mm}$ ). Bowl 336 has brown fabric, hard (3), with mica and sand inclusions (size $0.25 \mathrm{~mm}$ ). Both show traces of contact with fire on the outside and have the outer surface of the foot made rough. The bowl from Solduno comes from a context dated c. AD 70-120.

A fragment of rim of Form B5 occurs at Milan and dates from the second half of the 1st century BC to the first half of the 1st century AD (Guglielmetti et al. 1991, 178-80: Tipo 32 ; Caporusso et al. 1991, pl. 82.3). Other examples of this form come from Olgiate Comasco and date to the 1st century AD (Butti Ronchetti 1986, 126-127 pl. VI.41-41). Generally, the form of the body belongs to Type A of Lavizzari Pedrazzini (1980) and seem not to continue beyond the 2 nd century AD. This type is mainly attested in Canton Ticino and Lombardy, at Como (Maggi 1982, 192), Angera (Lavizzari Pedrazzini 1980, 222-3 ; Saccardo 1985a, 471ff.), Legnano (Croci 1996, pl. 48.26 no context) and Arsago Seprio (Ferraresi et al. 1987, 110 pl. XXVI fig. 49.b 


\section{Form B6: Bowls with inturned rim}

Form B6 has an inturned rim, decorated by a wide reeding. The rim may belong to the wall or be separated. Two groups can be distinguished:

- Form B6.1: Bowl with hemispherical body and lugs.

- Form B6.2: Bowl with conical body.

\section{Form B6.1}

337 Minusio, property Cadra, grave 33, c. AD 70-120

338 Tenero, grave 41, c. AD 70-120

339 Locarno-Muralto, Grande Albergo, grave 2

340 Locarno-Muralto, via Scazziga; house, context unknown

Form B6.1 has a hemispherical body with slightly concave foot. The rim is inturned and decorated by a reeding as wide as the rim itself. It belongs to the wall by 337 , is slightly separated from the wall by 338 and 339 , and becomes more horizontal by 340 . Form B6.1 also shows two lugs on the shoulder. Bowl 337 has pale red fabric, medium to hard (2-3), with mica, sand, crushed and granular quartz inclusions (size $0.25-0.5 \mathrm{~mm}$ ). The fabric is of $M-W a r e$. Bowl 340 has beige-pink fabric, hard (3), with mica, sand and crushed quartz inclusions (size $0.25 \mathrm{~mm}$ ). Both show traces of contact with fire. Bowl 338 has pink fabric, medium hard (2), with mica and sand inclusions. Bowl 339 has beige fabric, medium hard (2), with mica and sand inclusions (size 0.25 $0.5 \mathrm{~mm}$ ). Only 337 and 338 come from datable contexts: both date c. AD 70120. 
Similar vessels come from Olgiate Comasco and date to the 1st century $A D$ (Butti Ronchetti 1986, $127 \mathrm{pl}$. VIl.44) and from the Magdalensberg, dating c. AD 40-45 (Schildler-Kaudelka 1975, Form 141).

\section{Form B6.2}

341 Locarno-Solduno, Modern cemetery, grave $\mathbf{5 7 . 2}$

342 Locarno-Solduno, property Bonetti, grave Bo2

343 Locarno-Muralto, property Meyster; cemetery, context unknown

Form B6.2 has an inturned rim with reeding, but conical body with straight wall. Bowl 341 has flat foot. Bowl 342 is a fragment of rim and wall. Form B6.2 seems not to have any lug, but both examples are fragmentary. In particular, 341 is missing of part of the shoulder. Comparing the position of the lugs by Form B6.1, however, it seems that there were not present. Both examples show traces of contact with fire. Bowl 341 has beige fabric, medium hard (2), with mica, sand, crushed and granular quartz inclusions (size $0.25-0.5 \mathrm{~mm}$ ). It also has the outer surface of the foot made rough. Bowl 342 has dark brown fabric, hard (3), with mica, sand and crushed quartz inclusions (size $0.25 \mathrm{~mm}$ ). Bowl 343 has beige-red fabric, hard (3), with mica and sand inclusions (size $0.25 \mathrm{~mm}$ ). None of these bowls comes from datable contexts.

Form B6.2 occurs at Milan and dates to the 4th century AD (Caporusso et al. 1991, pl. 97.1-2; Guglielmetti et al. 1991, 193-4: Tipo 87). 


\section{Form B7: Bowls with horizontal rim}

344 Losone-Papögna; cemetery, context unknown

345 Losone-Papögna; cemetery, context unknown

346 Losone-Papögna; cemetery, context unknown

347 Losone-Papögna, grave 38

Form $\mathrm{B} 7$ has an almost horizontal rim with reeding and a conical body. Bowls 344 and 345 are similar in the form of the rims. The former, however, has rather globular, high body and slightly pinched out, concave foot; the latter has conical body with straight wall and slightly concave foot similar to a foot-ring. Bowl 344 has beige-pink fabric, hard (3), with mica, sand, granular and crushed quartz inclusions (size $0.25-0.5 \mathrm{~mm}$ ). Bowl 345 has red fabric, medium hard (2), with mica and granular quartz inclusions (size $0.25 \mathrm{~mm}$ ). The outer surface is black because of the contact with fire. The body of 346 is similar to that of 344 . The rim is rather expanded rounded, but still bears the reeding on the upper side. The fabric is orange, medium hard (2), with mica inclusions (size $0.25 \mathrm{~mm}$ ). Bowl 347 has a conical body with straight wall and a slightly concave foot. The rim is slightly oblique, with the external corner higher than the internal. It also shows two girth-grooves under the rim. The fabric is beigeorange, hard (3), with mica and sand inclusions (size $0.25 \mathrm{~mm}$ ). The outer surface is grey-black because of the contact with fire. None of these bowls comes from datable contexts. 


\section{Form B8: Bowls with triangular rim}

348 Locarno-Muralto, via Scazziga; house, context unknown

349 Locarno-Muralto, via Scazziga; house, context unknown

Form B8 has a conical body with curved wall. The rim is vertical, triangular in section. Bowl 348 has a flat foot, 349 has a foot-ring. The outer surface of both feet is made rough by application of sand and quartz. The fabrics are brown-red, hard (3), with some mica inclusions (size $0.25 \mathrm{~mm}$ ). Bowl 349 has the inside black because of the contact with fire. Both bowls are fragmentary. Their exact context is unknown and no date is possible.

Form B8 occurs at Milan (Caporusso et al. 1991, pl. 90.12; Guglielmetti et al. 1991, 195: Tipo 10) and dates to the end of the 1st century BC and the beginning of the 1st century $A D$.

\section{Form B9: Varia: small bowls}

Form B9 groups small bowls of different types:

- Form B9.1: Bowls with out-turned rim.

- Form B9.2: Varia.

Form B9.1

350 Gambarogno-Vairano; cemetery, context unknown

351 Gambarogno-Vairano; cemetery, context unknown 
The two bowls are very similar: out-turned, triangular rims, conical bodies, slightly concave feet, decoration on the shoulders. Bowl 350 has a straight wall and a high out-turned rim; the shoulder is relatively high. Bowl 351 has a bead-like rim on a high inturned neck; the wall is curved; the shoulder is lower and less prominent. Both show a decoration on the shoulder, consisting of a wavy combing. The fabrics are identical: pink-orange, medium to hard (2-3), with mica, sand and quartz (size $0.25-0.5 \mathrm{~mm}$ ). Both show traces of contact with fire on the outside and have the outer surface of the foot made rough. Their exact contexts are unknown.

\section{Form $B 9.2$}

352 Cavigliano, property Monotti, grave 7, c. AD 50-100

353 Minusio; cemetery, context unknown

The two bowls are different in form and fabric. Bowl 352 has a very short, inturned and rounded rim. The body is ellipsoidal; the foot is a flat foot-disc. Its fabric is red-brown, hard (3), with mica, sand, granular and crushed quartz, and grog (size $0.25-0.5 \mathrm{~mm}$ ), and is of M-Ware. The outer surface of the foot was made rough. The bowl comes from a grave dated c. AD 50-100. Bowl 353 has a bead rim, a very short neck, a conical body with straight wall and a flat foot. The neck is decorated with two girth-grooves, the shoulder with a row of oblique stabbed lines. The prominent shoulder also holds two lugs. The fabric is grey to brown, hard (3), with mica and crushed quartz inclusions (size 0.25$0.5 \mathrm{~mm})$, and is of D-Ware. The exact context of this bowl is unknown. 
A vessel with a rim similar to 352 occurs at Milan, where the bowl has more rounded body and the examples date from the 1st century BC onwards (Caporusso et al. 1991, pl. 89.15: Tipo 85).

\section{Form B10: Large bowls with triangular rim}

354 Locarno-Muralto, property Liverpool sopra, grave 4, c. AD 70-120

Bowl 354 has a vertical, expanded triangular rim, a short vertical neck, a globular flattened body, and a slightly concave foot. The fabric is pink-red, hard (3), with mica and sand inclusions (size $0.25-1 \mathrm{~mm}$ ). The outer surface show traces of contact with fire. The bowl comes from a grave dated c. AD 70120.

A similar bowl occurs at Angera and dates to Claudio-Neronian times (Troso \& Uglietti 1985, 118-9 pl. 32.11 ; Sena Chiesa \& Lavizzari Pedrazzini 1985, pl. 93.1).

Form B11: Large bowls with rounded rim

355 Locarno-Muralto, property Liverpool sotto, grave 8, c. AD 70-120

Bowl 355 has a vertical, expanded rounded rim, an ovoid body and a flat foot. The shoulder is decorated with a row of obliquely incised lines. The fabric is brown-black, hard (3), with mica inclusions (size $0.25-0.5 \mathrm{~mm}$ ). The surface 
show traces of contact with fire. The bowl comes from a grave dated c. AD 70120.

\section{Bowls with conical body}

Bowls with low conical body

\section{Form B12: Bowls with bead rim and vertical neck}

Form B12 has a slightly out-turned bead rim, a vertical neck, a conical body with curved wall, a flat foot or foot-disc. According to the rim, two groups can be distinguished:

- Form B12.1: Bowl with slightly out-turned bead rim.

- Form B12.2: Bowl with out-turned bead rim with a sharp angle.

Form B12.1

356 Locarno-Solduno, Trench 1956/N3

357 Locarno-Solduno, Modern cemetery, grave 1958.17, c. AD 77/8-100

358 Minusio, property Cadra, grave 31, c. AD 54-100

The two bowls from Solduno are very similar. The example from Minusio has a slightly different rim, more elongated rather bead-shaped. All have flat feet. The fabrics are hard (3); 356 is red, with mica, sand and crushed quartz inclusions (size $0.25 \mathrm{~mm}$; M-Ware), 357 is dark brown, with mica and sand inclusions (size $0.25 \mathrm{~mm}$ ) and 358 is grey, with mica and sand inclusions (size 
$0.25 \mathrm{~mm}$ ), and is of D-Ware. Bowls 356 and 358 show traces of contact with fire. Bowls 357 and 358 have the outer surface of the flat foot made rough by application of sand and quartz. This element occurs often also by other forms, such as jars and dishes. It function is mainly to avoid the vessel sliding. The decoration consists of one or more girth-grooves on the neck or by the junction between neck and rim. Only two vessels, 357 and 358, come from datable contexts, c. AD 54-100.

\section{Form B12.2}

359 Locarno-Muralto, property Liverpool sotto, grave 1

Form B12.2 is similar to B12.1, but the rim ends in a sharp angle over the neck. Bowl 359 has a high body with curved wall and a flat base. It has redbrown fabric, hard (3), with mica, sand and crushed quartz inclusions (size $0.25 \mathrm{~mm})$, and is of M-Ware. It shows traces of contact with fire. The vessel does not come from a datable context.

Form B12 occurs at Angera and dates from mid-1st century AD to TrajanicHadrianic times (Caporusso et al. 1985b, 237 pl. 56.3; Sena Chiesa \& Lavizzari Pedrazzini 1985, pl. 93.10 ; Lavizzari Pedrazzini 1980, Tipo A). At Ottobiano (Lomellina) it occurs in Grave 37, dated c. 15 BC-AD 20 (St 34465 : Vannacci Lunazzi 1986, 79 ; pl. IX.11). At Olgiate Comasco it appears during the 1st century AD (Butti Ronchetti 1986, 126 pl. VI.40). At Legnano, it occurs from Augustan times to mid-1st century AD (Croci 1996, 203-4; 209 n. 20 pl. 36.9 Grave 27 ; pl. 48.26 , no context). 


\section{Form B13: Bowls with out-turned rim, triangular in section}

360 Locarno-Solduno, property Ceschi, grave K3, c. AD 70-120

361 Locarno-Solduno, Modern cemetery, grave 56.2, c. AD 50-100

362 Locarno-Solduno, Modern cemetery, grave 58.15

363 Locarno-Muralto, Via Scazziga; house, context unknown

364 Losone-Arcegno, area B

365 Locarno-Solduno, property Passetto, grave B10, c. AD 40-90

366 Locarno-Solduno, property Boccadoro, grave J25, c. AD 70-120

Form B13 has an out-turned rim, triangular in section, a conical body with curved (e.g. 362) or straight (e.g. 364) wall and a flat or slightly concave foot. Only one example, 363, has a foot-disc. Two bowls from Solduno (361 and 362) show a slightly break in the profile at the junction between neck and body. The bowl from Losone has a slightly different rim, the body is higher and the foot is slightly concave. The fabrics are different. Those of the bowls from Solduno contain some mica and sand inclusions (size $0.25 \mathrm{~mm}$ ) and are medium hard (2) or medium hard to hard (2-3): 362 is beige-pink and shows traces of contact with fire; 361 is red, but both surfaces are burnt and black; 360 and 365 are beige and do not show contact with fire; 366 is grey with traces of contact with fire. Bowl 363 has beige-brown fabric, the inside and the rim being black because of contact with fire, hard (3), with some mica and crushed quartz inclusions (size $0.25 \mathrm{~mm}$ ). Bowl 364 has orange fabric, hard (3), with many mica, sand and crushed quartz inclusions (size $0.25 \mathrm{~mm}$ ). Only 360 and 362 bear a decoration: two narrow cordons on the neck for the 
former, a girth-groove under the neck for the latter. The bowls 360, 361 and 365 from Solduno come from contexts datable c. AD 50-120.

\section{Form B14: Bowl with out-turned rim, triangular in section, and vertical neck}

Form B14 is similar to B13, but the rim is separated from the body by a vertical neck.

According to rim and neck, two groups have been distinguished:

- Form B14.1: Bowl with out-turned rim and vertical neck.

- Form B14.2: Bowl out-turned rim, vertical neck and internal lid seating.

Form B14.1

367 Losone-Papögna; cemetery, context unknown

368 Losone-Papögna; cemetery, context unknown

369 Locarno-Solduno, Modern cemetery, grave 1958.16, c. AD 70-120

370 Locarno-Solduno, property Ceschi, grave K6, c. AD 70-120

371 Locarno-Muralto, Via Scazziga; house, context unknown

Form B14.1 has an out-turned, triangular rim, a vertical neck, a conical body with curved wall and a flat foot. Only 371 has a foot-disc. The three element rim, neck, body - are clearly separated. Except for 369, all examples show traces of contact with fire or are fully burnt. The fabrics vary: 367 (D-Ware) and 368 (E-Ware) are black, medium hard to hard (2-3), with mica and sand, and respectively mica inclusions (size $0.25 \mathrm{~mm}$ ); 369 and 370 have beige fabric, hard (3) and medium hard (2), with many mica and sand inclusions 
(size $0.25-0.5 \mathrm{~mm}$ ). They also have a rough outer side of the foot by application of sand. The decoration consists of a girth-groove: at mid-body by 368 ; under the neck by 371 and 370 . Only 370 and 369 come from datable contexts, c. AD 70-120.

\section{Form B14.2}

372 Locarno-Muralto, Grande Albergo; cemetery, context unknown

Form B14.2 has an out-turned triangular rim and a vertical neck as with B14.1. It also shows an internal lid seating. The body is conical with rather straight wall. The foot is slightly concave. Its fabric is red-beige, hard (3), with mica, crushed quartz and grog inclusions (size $0.25 \mathrm{~mm}$ ). Its exact context is unknown.

Form B14 occurs at Angera and dates to Flavian times (Sena Chiesa \& Lavizzari Pedrazzini 1985, pl. 93.6).

Form B15: Bowls with out-turned, rounded rim, set at a sharper angle with the body

373 Losone-Arcegno, grave 12, c. AD 180-200

374 Losone-Arcegno, grave 14, c. AD 161-80

375 Locarno-Muralto, property Liverpool sopra, grave 5, c. AD 70-120

376 Locarno-Muralto, property Liverpool sotto, grave 14, c. AD 41-80

377 Locarno-Muralto, property Passalli, grave 17 
Locarnese, context unknown

379 Locarno-Muralto, Grande Albergo; cemetery, context unknown

380 Losone-Papögna; cemetery, context unknown

381 Losone-Papögna; cemetery, context unknown

Form B15 is very similar to B31: the difference consists of the angle between rim and body, wide in B31, sharper but still rounded in B15. Some bowls of Form B15 also show a sort of 'step' between neck and shoulder. As in Form B31, the body of these vessels is conical with slightly curved or straight wall. The foot is always flat, except for 374 , slightly convex, and 379 , slightly concave and slightly pinched out. The fabrics vary. Some vessels show traces of contact with fire on one or both surfaces: 374, 375 (L-Ware), 377, 379 (FWare), 380, 381 (M-Ware). Bowls 374 and 375 have red fabrics, hard (3), with mica and sand inclusions (size $0.25 \mathrm{~mm}$ ). Bowl 377, fragmentary, has a grey fabric, hard (3), with mica and sand inclusions (size $0.25-0.5 \mathrm{~mm}$ ), of D-Ware; 379 has a beige-white fabric, soft to medium hard (1-2), with mica and sand inclusions (size $0.25 \mathrm{~mm}$ ); 381 has a red fabric, strongly burnt on both sides and turned to black, hard (3), with mica, sand and quartz inclusions (size 0.25$0.5 \mathrm{~mm}) ; 380$ has beige-red fabric, grey on the rim, hard (3), with mica and sand inclusions (size $0.25 \mathrm{~mm}$ ). The other bowls did not come in contact with fire. Bowl 373 has a brown-red fabric, hard (3), with many mica, sand and crushed quartz inclusions (size $0.25 \mathrm{~mm}$ ). Bowl 376, fragmentary, has an orange fabric, medium to hard (2-3), with mica inclusions (size $0.25 \mathrm{~mm}$ ). The fabric is of N-Ware. Bowl 378 has a brown-black fabric with red core, hard (3), with mica and crushed and granular quartz (size 0.25mm). Bowls 373,374 , 
$375,376,378$ and 380 have the outer surfaces of the feet made rough by application of sand and quartz to avoid sliding. Only three bowls are decorated: 373 and 381 with a girth-groove under the neck; 379 with a row of nail indentations in the same position. Bowls $373,374,375$ and 376 come from datable contexts: C. AD 41-80 for 376; c. AD 70-120 for 375; c. AD 160200 for 373 and 374 .

At Angera, Form B15 dates to Antonine times (Maccabruni \& Schifone 1985, 136-7 pl. 39.5).

Form B16: Bowls with out-turned, triangular rim, set at a sharper angle with the body

382 Losone-Arcegno, grave 9, c. AD 161-80

383 Losone-Arcegno, grave 15, c. AD 98-140

384 Moghegno, grave 23, c. AD 117-50

385 Minusio, property Cadra, grave 12, c. AD 73-100

386 Locarno-Muralto, Grande Albergo; cemetery, context unknown

Form B16 is similar to B15. The difference consists of the rim, triangular instead of rounded. Bowl 385 has a conical body with rounded wall and a flat foot. Also 383 has flat foot, but the conical body has straight wall. Bowls 382 , 384 and 386 have slightly concave and slightly pinched out foot. All vessels show traces of contact with fire. Bowl 382 has a red fabric, hard (3), with mica, sand and crushed quartz inclusions (size $0.25 \mathrm{~mm}$ ). Bowl 383 has a black fabric, hard (3), with mica and sand inclusions (size $0.25 \mathrm{~mm}$ ), of D-Ware. 
Bowl 384 has a beige-grey fabric, hard 83 ), with mica, sand and crushed quartz inclusions (size $0.5-1 \mathrm{~mm}$ ). Bowl 385 has a beige fabric, hard (3), with mica, sand and crushed quartz inclusions (size $0.25 \mathrm{~mm}$ ). The fabric of 386 is dark beige, hard (3), with mica and sand inclusions (size $0.25 \mathrm{~mm}$ ). Bowls 382 , 383 and 384 have the outer surface of the foot made rough by application of sand and quartz. The only decorated bowl is 383 , with a corrugated shoulder. Except for 386, the other vessels come from datable contexts: c. AD 73-100 for 385 ; c. AD $100-150$ for 383 and 384 ; c. AD $160-90$ for 382 .

This form occurs at Angera in Flavian times (Caporusso et al. 1985a, $171 \mathrm{pl}$. 43.10).

Form B17: Bowls with out-turned, elongated rim, and vertical neck 387 Losone-Arcegno, grave 32, c. AD 180-230

388 Ascona, grave 10, c. AD 103-50

Form B17 has an out-turned and elongated rim, rather triangular in section, a vertical neck, and low, almost hemispherical body. Bowl 387 has a curved wall and a slightly concave foot; 388 has a slightly pinched out, flat foot. The fabric of 387 is dark beige, hard (3), with some mica inclusions (size $0.25 \mathrm{~mm}$ ). Bowl 388 has a red fabric, hard (3), with many mica, sand, granular quartz and grog inclusions (size $0.25 \mathrm{~mm}$ ), of $\mathrm{N}$-Ware. Both bowls show traces of contact with fire and have the outer surface of the foot made rough with sand and quartz. 
Only the bowl from Losone is decorated with a girth-groove under the neck. The context of 388 dates C. AD 103-50; that of 387, c. AD 180-230.

\author{
Form B18: Bowls with out-turned, elongated rim, and break over \\ the body \\ 389 Locarno-Solduno, property Ardito, grave C3, C. AD 70/80-120/30 \\ 390 Locarno-Solduno, property Passetto, grave B1, c. AD 70-120 \\ 391 Ascona, grave 9, c. AD 112-50
}

Form B18 has an out-turned, elongated and expanded rounded rim. The passage from neck to shoulder is highlighted by a 'step'. The body is conical with curved wall, the foot is flat or slightly concave (390). Bowls 390 and 391 show traces of contact with fire and have the outer surface of the foot made rough. Bowl 389 has a grey fabric, soft to medium hard (1-2), with mica and sand inclusions (size $0.25 \mathrm{~mm}$ ), of F-Ware. Bowl 390 has a red-brown fabric (L-Ware), 391 has a black fabric with pink core (D-Ware). Both fabrics are hard (3) and contain mica and sand inclusions (size $0.25 \mathrm{~mm}$ ). Both bowls from Solduno come from contexts dated c. AD 70-120; bowl 391 comes from a context dated c. AD 112-50.

Form B18 occurs at Angera and dates to the end of the 1st and the beginning of the 2 nd century AD (Troso \& Uglietti 1985, 120 pl. 33.6). A similar vessels was found at Lurate Caccivio, in a grave dating from the mid-1st century AD (Butti Ronchetti 1985, pl. V.15). 


\section{Form B19: Bowls with out-turned, expanded rounded rim and continuous profile}

Form B19 has an out-turned and elongated, expanded rounded rim as with B18, but the profile is continuous. The conical body is relatively high. According to rim and wall, three groups can be distinguished:

- Form B19.1: Bowl with elongated rim and curved wall.

- Form B19.2: Bowl with shorter expanded rounded rim and slightly pinched out foot.

- Form B19.3: Bowl with cavetto rim and body with high shoulder.

\section{Form B19.1}

392 Locarno-Solduno, property Balli, grave Ba2, c. AD 50-100

393 Locarno-Solduno, property Bonetti, grave Bo2

394 Losone-Arcegno, grave 79, c. AD 236-50

Bowl 392 has a red-brown fabric, hard (3), with mica, sand and grog inclusions (size $0.25 \mathrm{~mm}$ ), of $\mathrm{N}$-Ware. The wall is curved and the foot is flat. Bowl 393, fragmentary, has a beige-pink fabric with orange patches, hard (3) clay, mica and sand inclusions (size $0.25 \mathrm{~mm}$ ). Its wall is curved, but the foot is slightly concave. Bowl 394 has red-orange fabric, hard (3), with mica and sand inclusions (size $0.25 \mathrm{~mm}$ ), of L-Ware. The wall is straight, the foot flat and slightly pinched out. Bowls 392 and 394 have the outer surface of the foot made rough. None of bowls of Form B19.1 show traces of contact with fire. Bowl 393 is decorated with a girth-groove on the shoulder. Bowls 392 and 394 come from datable contexts: C. AD 50-110 for 392 and c. AD 236-50 for 394 . 
Form B19.1 occurs at Angera and Varese, and dates to Flavian times and the end of the 2nd century AD (Facchini et al. 1985, 73 pl. 23.6 ; Caporusso et al. 1985a, 168 pl. 44.6 ; Sena Chiesa \& Lavizzari Pedrazzini 1985, pl. 93.11).

Form B19.2

395 Cavigliano, property Cavalli, grave 3, c. AD 174-200

396 Locarno-Muralto, property Meyster ; cemetery, context unknown

The bowl from Cavigliano has a slightly concave foot. The fabric is rust-red, medium hard (2), with mica and crushed quartz inclusions. The bowl from Muralto consists of a fragment of rim. The fabric is beige-white on the outside and red-grey on the inside, medium hard (2), with mica and sand inclusions (size $0.25 \mathrm{~mm}$ ). Both vessels show traces of contact with fire.

Only the bowl from Cavigliano comes from a datable context, c. AD 174-200.

\section{Form B19.3}

397 Locarno-Muralto, property Liverpool sotto, grave 47

Bowl 397 is a big vessel. The body has high shoulder and slightly concave wall, the foot is flat. The bowl is decorated under the neck with two girthgrooves. The fabric is grey, hard (3), with mica, sand, granular and crushed quartz, and grog (size $0.25-1 \mathrm{~mm}$ ). It is of D-Ware. The vessel shows traces of contact with fire and has the outer surface of the foot made rough by application of sand and quartz. Grave 47 at Locarno-Muralto, property Liverpool sotto, did not contain any datable grave-goods. 


\section{Form B20: Bowls with sharply out-turned, expanded rounded rim}

398 Locarno-Muralto, property Biffoni; cemetery, context unknown

399 Locarno-Muralto, via Scazziga; house, context unknown

400 Locarno-Muralto, via Scazziga; house, context unknown

Form B20 has sharply out-turned rims, rounded by 399 , expanded rounded by 398 and 400 . The necks are vertical $(398)$ or inturned $(399 ; 400)$. The transition from neck to body is highlighted by a 'step'. All bowls have conical bodies with straight walls. The feet vary: 398 has a flat foot; 399 has a slightly concave foot-disc; 400 has a foot-ring. The surfaces of bowls 398 and 400 show traces of contact with fire. Bowl 398 has a beige-pink fabric on the outside, black on the inside, soft (1), with mica, sand, crushed and granular quartz (size $0.25-1 \mathrm{~mm}$ ). This vessel comes from a cremation. Bowl 399 does not show contact with fire. Its fabric is red-beige, hard (3), with mica, crushed quartz and grog inclusions (size $0.25 \mathrm{~mm}$ ). It is of $\mathrm{N}$-Ware. Bowl 400 has a grey fabric on the outside, brown on the inside, hard (3), with mica and crushed quartz inclusions (size $0.25 \mathrm{~mm}$ ). The vessel bears as decoration a girth-groove under the neck. None of these vessels comes from a datable context.

\section{Form B21: Bowls with short out-turned rim and low body}

401 Locarno-Muralto, property Branca, grave 1, c. AD 41-80

402 Locarno-Muralto, property Liverpool sotto, grave 1

403 Losone-Papögna; cemetery, context unknown 
404 Losone-Papögna; cemetery, context unknown

405 Losone-Papögna; cemetery, context unknown

406 Losone-Papögna; cemetery, context unknown

Form B21 has a short out-turned and rounded rim, sometimes slightly expanded. The conical body is low and has a slightly curved or straight wall. The foot is flat. Two bowls, 403 and 404, have continuous profiles; the other vessels show a tiny 'step' under the neck. The bowls from Losone-Papögna show traces of contact with fire. Bowls 404 (M-Ware) and 405 have respectively red and black fabrics, hard (3), with mica, sand, granular and crushed quartz inclusions (size $0.25-05$ ). Bowls 403 and 406 have respectively black-brown and beige fabrics, hard (3), with mica and sand inclusions. The fabrics of 403 and 405 are of D-Ware. Bowl 401 has a pale red fabric, hard (3), with mica and crushed and granular quartz inclusions (size $0.25 \mathrm{~mm}$ ), of LWare. Bowl 402 has a grey-white fabric due to the reduced firing, soft (1), with mica, sand, crushed and granular quartz inclusions (size $0.25-0.5 \mathrm{~mm}$ ), of FWare. Two vessels, 401 and 406, have the outer surface of the foot made rough by application of sand and quartz. Only 401 comes from a datable context, c. AD 41-80.

Form B21 occurs at Angera during the first half of the 2 nd century $A D$ (Facchini et al. 1985, 83 pl. 25.88; Maccabruni \& Schifone 1985, 138 pl. 39.9 ; Caporusso et al. 1985a, 183 pl. 46.6). It appears at Legnano, dating from Augustan times to mid-1st century $A D$ and possibly also reaching the 2nd century AD (Croci 1996, 203-4; 209 n. 20 pl. 39.9 Grave 28 ; Binaghi 
1990, 221-2), and at Arsago Seprio, dating from the beginning of the 2nd century AD (Ferraresi et al. 1987, 108 pl. XXVI fig. 49.a Grave 99).

\section{Form B22: Bowls with slightly out-turned, high rim}

407 Locarno-Muralto, property Liverpool sotto, grave 18, c. AD 80-130

408 Minusio, property Cadra, grave 7, c. AD 70-120

Form B22 has a slightly expanded, rounded rim, only slightly out-turned. The body is conical with curved wall. The foot is flat, slightly pinched out in 408 . Both bowls are decorated with a cordon under the neck. Bowl 408 is associated to lid 693 (Form L7).

Bowl 407 has a dark beige fabric, hard (3), with traces of contact with fire; 408 has a pink-beige fabric with black core, medium hard (2), and has the outer surface of the foot made rough. Both fabrics have mica, sand, granular and crushed quartz, and grog inclusions (size $0.25-1 \mathrm{~mm}$ ) and are of N-Ware. Grave 7 at Minusio-Cadra contained both bowl 408 and lid 693 (Form L6), described by Simonett as 'Urnendeckel' ('bowl's/jar's lid': Simonett 1941, 126). The grave was a cremation and both vessels consisted of fragments only. It is therefore impossible to define the real association between bowl and lid. Both bowls come from contexts dated c. AD 70-130. 


\section{Form B23: Bowls with slightly out-turned, short and straight rim}

Form B23 has a short, very slightly out-turned rim, expanded rounded or triangular. The body is conical with curved wall, the foot is slightly concave. Two groups can be distinguished from the rim form:

- Form B23.1: Slightly out-turned, expanded rounded rim.

- Form B23.2: Slightly out-turned, expanded triangular rim.

\section{Form B23.1}

409 Locarno-Solduno, property Ardito, grave C28, c. AD 69-120

410 Locarno-Solduno, property Balli, grave Ba4, c. AD 50-100

Bowl 409 has an expanded rounded rim. The fabric is beige, burnt black on the outside, grey on the inside, hard (3), with mica and sand inclusions (size $0.25 \mathrm{~mm}$ ). Bowl 410 also has an expanded rounded rim, but the expansion is limited to the end. The fabric is red-brown, hard (3), with mica inclusions (size $0.25 \mathrm{~mm}$ ), and is of L-Ware. The surfaces are black because of the contact with fire. The two bowls come from contexts dated c. AD 50-120.

Form B23.1 occurs at Angera and dates to Trajanic-Hadrianic times (Saccardo 1985a, 471 pl. 93.8) and at Olgiate Comasco (Butti Ronchetti 1986, $126 \mathrm{pl}$. VI.39). The cylindrical neck occurs on bowls during the 1 st and the beginning of the 2nd c. AD (Lavizzari Pedrazzini 1980, 222). 


\section{Form B23.2}

411 Locarno-Muralto, via Scazziga; house, context unknown

412 Locarno-Solduno, Modern cemetery, grave 58.13, c. AD 70-120

Bowl 411 has an expanded triangular rim. The fabric is beige-grey, hard (3), with some mica inclusions (size $0.25 \mathrm{~mm}$ ). Bowl 412 has a rounded rim with a sort of 'flange', that makes the rim triangular in profile. The fabric is brown, medium hard (2), with mica, sand and granular quartz (size $0.25 \mathrm{~mm}$ ). Both surfaces show traces of contact with fire. Only this bowl comes from a datable context, c. AD 70-120.

\section{Form B24: Bowls with slightly out-turned rim, narrower than the body}

413 Locarno-Solduno, Modern cemetery, grave 58.19, c. AD 69-120

414 Minusio, property Cadra, grave 14, c. AD 70-120

415 Locarno-Muralto, property Passalli, grave 34

416 Locarno-Muralto, property Liverpool sotto, grave 1

417 Locarno-Muralto, property Liverpool sopra, grave 10, c. AD 37-80

Form B24 has a slightly out-turned, usually rounded rim. Only 414 has a triangular rim. The rim is less wide than the maximum diameter of the bowl. The body is conical with curved wall. The base is flat. Bowls 413,416 and 417 show traces of contact with fire. Bowl 413 has a brown fabric, hard (3), with some mica inclusions (size $0.25 \mathrm{~mm}$ ). Bowl 414 has a beige-white fabric, hard (3), with mica and sand inclusions (size $0.25-0.5 \mathrm{~mm}$ ). Bowl 415 has white 
fabric on the outside, red on the inside, hard (3), with many mica, sand, crushed and granular quartz inclusions (size $0.25-1 \mathrm{~mm}$ ). This fabric is of $M-$ Ware. Bowl 416 has red fabric, hard (3), with mica and sand inclusions (size 0.25-0.5mm), of L-Ware. Bowl 417 has a pink-red fabric, hard (3), with mica, sand and granular quartz inclusions (size $0.25 \mathrm{~mm}$ ). Bowls 415 and 416 have the outer surface of the foot made rough. Some bowls are decorated: 413 has two girth-grooves on the neck; 415 has two lugs on the shoulder; 416 has a cordon under the neck. Except for 415 and 416, the other bowls come from datable contexts: c. AD 37-80 for 417; c. AD 70-120 for 413 and 414 .

Form B24, in particular 416 and 417, occurs at Milan (Guglielmetti et al. 1991, 183-4: Tipo 45; Caporusso et al. 1991, pl. 84.6-9) and Nave (Bessi Trevale 1987, 194-200), dating from Augustan-Tiberian times onwards. At Legnano, a vessel dates to late Tiberian-Claudian times (Croci 1996, pl. 44.6 Grave 35). It occurs at Angera as material with no context (Sena Chiesa \& Lavizzari Pedrazzini 1985, pl. 76.3).

Form B25: Bowls with out-turned rim, internal lid seating, vertical neck 418 Minusio, property Cadra, grave 24

419 Locarno-Muralto, Villa Liverpool sotto, grave 21, c. AD 125/6-150

420 Cavigliano, property Cavalli, grave 3, c. AD 176-200

Form B25 has an out-turned, rounded rim, which is as wide as the maximum diameter of the bowl. The rim has an internal lid seating, rather flat. Between 
rim and body there is a vertical neck. The bodies of two examples, 418 and 419, are conical with straight wall. The bowl from Cavigliano has more globular body with high shoulder and tapering towards the foot. The feet are flat or slightly concave. Although bowls 418 and 419 have similar features, the three vessels are different. Bowl 418 has short rim and very short neck. The fabric is red, hard (3), with mica, sand and crushed quartz inclusions (size $0.25-1 \mathrm{~mm})$, and is of M-Ware. The outer surface of the foot is made rough by application of sand and quartz. Bowl 419 has higher body than 418 . Its fabric is beige-white due to the reduced firing, soft to medium hard (1-2), and contains mica and sand inclusions (size $0.25 \mathrm{~mm}$ ), and is of F-Ware. Both vessels show traces of the contact with fire. Only 419 is decorated with a girthgroove under the neck. Bowls 418 and 419 show contacts with fire on the surfaces. Bowl 418 has a red fabric, hard (3), with mica, sand and crushed quartz inclusions (size $0.25-1 \mathrm{~mm}$ ). The outer surface of the foot is made rough. Bowl 419 has a beige-white fabric, soft to medium hard (1-2), with mica and sand inclusions (size $0.25 \mathrm{~mm}$ ). The bowl from Cavigliano has a pink fabric, medium hard (2), with mica, sand and crushed quartz inclusions (size $0.25 \mathrm{~mm})$. This bowl come from a grave dated C. AD 176-200. 


\section{Form B26: Bowls with out-turned triangular rim, internal lid}

\section{seating and vertical neck}

Form B26 has a concave internal lid seating. As result, the rim ends in a vertical segment and is triangular in section. Rim and body are separated by a vertical neck. According to the body, two groups can be distinguished:

- Form B26.1: Bowl with conical body and curved wall.

- Form B26.2: Bowl with conical body and straight wall.

\section{Form B26.1}

421 Locarno-Solduno, Trench 1956/S1

422 Locarno-Solduno, Modern cemetery, grave 58.18, c. AD 81-130

423 Losone-Arcegno, grave 34, c. AD 86-110

424 Ascona, grave 9, c. AD 112-50

425 Locarno-Muralto, property Passalli, grave 37, c. AD 70-120

426 Locarno-Muralto, property Meyster; cemetery, context unknown

Form B26.1 has a conical body with a curved wall. Inside the group, two further groups can be distinguished: bowls with wide foot and bowls with narrow foot.

Bowls 421, 422, 424 and 425 belong to the first group. Except for 424, with slightly concave foot, the other have flat feet. Bowls 421, 422 and 425 show traces of contact with fire: the outer surface is often completely burnt. Bowl 421 has a black fabric, medium to hard (2-3), with mica and sand inclusions (size $0.25 \mathrm{~mm}$ ), and is of D-Ware. Bowl 422 has a red-brown fabric, hard (3), with mica, sand, granular and crushed quartz inclusions (size $0.25 \mathrm{~mm}$ ), of $\mathrm{M}$ Ware. Bowl 424 has a beige fabric with black core, medium to hard (2-3), with 
mica and sand inclusions. Bowl 425 has a beige fabric on the inside, hard (3), with mica, sand, crushed and granular quartz and grog (size $0.25 \mathrm{~mm}$ ). Its fabric is of N-Ware. Bowls 424 and 425 have the outer surface of the foot made rough. Bowls 423 and 426 have narrower feet, slightly concave in the former, and flat in the latter. Both show traces of fire. Bowl 423 has a beigepink fabric, hard (3), with mica and sand inclusions (size $0.25 \mathrm{~mm}$ ); 426 has a red-brown fabric, hard (3), with some mica inclusions (size $0.25 \mathrm{~mm}$ ), of LWare. Except for 421 and 426, the bowls come from contexts dated C. AD 70150.

Form B26.2

427 Locarno-Muralto, property Branca, grave 1, c. AD 41-80

428 Locarno-Muralto, property Märki, grave 3

429 Losone-Papögna; cemetery, context unknown

Form B26.2 has a conical body with straight wall. Bowls 427 and 428 have slightly pinched out feet, flat in the former and slightly concave and rather a foot-disc in the latter. Bowl 427 has a pale red fabric, medium hard (2), with mica, sand and crushed quartz inclusions (size $0.25 \mathrm{~mm}$ ). Bowl 428 has a red fabric, hard (3), with the same inclusions (size $0.25-0.5 \mathrm{~mm}$ ), of M-Ware. Bowl 429 has a flat foot. Its fabric is beige, hard (3), with mica and sand inclusions (size $0.25 \mathrm{~mm}$ ). The outer surface of the foot was made rough. All bowls show traces of contact with fire. Only 427 comes from a datable context, c. AD 4180. 
A similar vessel occurs at Legnano (Milan) from Augustan times to mid-1st century AD (Croci 1996, 203-4 ; 207 no. 20 pl. 28.11 Grave 4). Fragments of rim of Form B26 occur at Milan and date from the second half of the 1st century BC to the first half of the 1st century AD (Caporusso et al. 1991, pl. 82.1-2; Guglielmetti et al. 1991, 178-80: Tipo 32).

\section{Form B27: Bowls with out-turned triangular rim and internal lid seating, without neck \\ 430 Locarno-Muralto, property Branca, grave 4 \\ 431 Minusio, property Cadra, grave 11, c. AD 77/8-100 \\ 432 Locarno-Muralto; cemetery, context unknown}

Form B27 has a concave internal lid seating as with Forms B25 and B26, but does not have a vertical neck. The rim joins the body at a sharp angle. The wall of Form B27 is straight. The foot is a slightly concave foot-disc by 430 , and flat and slightly pinched out by 431 and 432 . Bowl 430 has a beige fabric, medium to hard (2-3), with mica and sand inclusions (size $0.25 \mathrm{~mm}$ ). Bowl 431 has a pink fabric, hard (3), with mica, sand and crushed quartz inclusions (size $0.25 \mathrm{~mm}$ ). Bowl 432 has a brown fabric, medium hard (2), with mica, sand and granular quartz inclusions (size $0.25 \mathrm{~mm}$ ). All bowls show contact with fire; 432 also has the outer surface of the foot made rough. Bowl 431 is decorated with an incised wavy line on the shoulder. It comes from a context dated C. AD 77100. The exact context of 432 is unknown. 
Form B27 occurs at Angera dating from Flavian times (Sena Chiesa \& Lavizzari Pedrazzini 1985, pl. 93.5), and at Legnano dating from Augustan times to the end of the 1st century AD (Croci 1996, 203-4; 209 n. 20 pls. 17.5 Grave 3 and 38.8 Grave 28).

\section{Form B28: Castor boxes}

433 Minusio, property Cadra, grave 5, c. AD 0-30

The castor box consists of two parts: a bowl (433) and its lid (687). The bowl has a slightly inturned, straight rim, a conical and flattened body with slightly curved wall, and a flat foot. The lid, recorded as Form L6, has a slightly outturned straight rim, flattened at the end, as 'pendant' to the rim of the bowl. The body is conical with straight wall; the hold is disc-shaped. The fabric is red, medium to hard (2-3), with some mica inclusions (size $0.25 \mathrm{~mm}$ ). This example is the only one found in Ticino. It comes from a context dated c. AD $0-30$. 
Bowls with high conical body

\section{Form B29: Bowl with out-turned rim, triangular in section}

434 Locarno-Solduno, Modern cemetery, grave 57.1

435 Cavigliano, property Cavalli, grave 3, c. AD 174-200

436 Moghegno, grave 3, c. AD 117-50

Form B29 has an out-turned rim, triangular in section, and a conical body. The bowl from Moghegno show a slightly break in the profile at the junction between neck and body. 434, 435 and 436 have high bodies; the former has also straight wall.

The fabrics are different. Bowl 434 has a grey to black fabric due to the contact with fire, hard (3), with mica and sand inclusions (size $0.25 \mathrm{~mm}$ ). The outer surface of the foot is made rough. Bowl 435 has a beige fabric, hard (3), with some mica and sand inclusions (size $0.25 \mathrm{~mm}$ ). The surface shows traces of contact with fire. Bowl 436 has a grey fabric with traces of contact with fire, hard (3), with many mica, sand, crushed quartz and grog inclusions (0.5$1 \mathrm{~mm})$, and is of D-Ware. Bowl 434 is decorated with a girth-groove under the neck. The bowl from Moghegno comes from a grave dated c. AD 117-50; bowl 435 from a grave dated C. AD 174-200. 
Form B30: Bowl with out-turned rim, triangular in section, and vertical neck

437 Locarno-Muralto, property Meyster; cemetery, context unknown

438 Locarno-Muralto, property Passalli, grave 23

Form B30 has an out-turned, triangular rim, a vertical neck, a conical body with curved wall and a flat foot. The three element - rim, neck, body - are clearly separated. Bowl 437 has a beige to dark beige fabric, medium to hard (2-3), with mica inclusions (size $0.25 \mathrm{~mm}$ ). Bowl 438 has a higher body. The fabric is dark red, hard (3), with mica, sand and crushed quartz inclusions (size $0.25-0.5 \mathrm{~mm}$ ), and is of M-Ware. The outer surface of the foot is rough. The rim shows traces of contact with fire. None of them comes from a datable context.

Form B30 occurs at Angera and dates to Flavian times (Sena Chiesa \& Lavizzari Pedrazzini 1985, pl. 93.6).

Form B31: Bowls with out-turned, rounded rim

439 Losone-Arcegno, grave 74, c. AD 253-70

440 Losone-Arcegno, grave 76, c. AD 163-80

441 Losone-Arcegno, grave 93, c. AD 173-200

442 Losone-Papögna; cemetery, context unknown

443 Locarno-Muralto, property Liverpool sopra, grave 14, c. AD 100-130

444 Locarno-Muralto, property Meyster; cemetery, context unknown 
Form B31 has an out-turned and rounded rim, which curves outwards from the shoulder with a wide angle. The profile does not have any break between rim and body. The body is conical with slightly curved or straight wall. The foot is flat or slightly concave. 441 has a slightly pinched out foot. Except for 440 , all bowls show more or less expanded traces of contact with fire. Bowls 439 and 442 (E-Ware) have black fabrics, hard (3), with mica and sand, and respectively mica inclusions (size $0.25 \mathrm{~mm}$ ). Bowl 440 has a red fabric, hard (3), with some mica and sand inclusions (size $0.25 \mathrm{~mm}$ ); 441 has a red-brown fabric, hard (3), with mica and sand inclusions (size $0.25 \mathrm{~mm}$ ) The fabrics of both vessels are of L-Ware. Bowl 443 has a beige fabric, hard (3), with some mica inclusions (size $0.25 \mathrm{~mm}$ ); its has the outer surface of the foot made rough by application of sand and quartz. Bowl 444 has a brown fabric, hard (3), with mica, sand and crushed quartz inclusions (size $0.25 \mathrm{~mm}$ ), of D-Ware. Only 441 is decorated with two girth-grooves under the neck and on the shoulder. Four vessels come from datable contexts: c. AD 100-130 for 443; c. AD $160-200$ for 440 and 441 ; c. AD $250-70$ for 439 . These bowls seem therefore to range from the beginning of the $2 \mathrm{nd}$ to the second half of the $3 \mathrm{rd}$ century $A D$. 


\section{Form B32: Bowls with out-turned, elongated rim, and vertical neck}

445 Losone-Arcegno, grave 81, c. AD 193-220

Form B32 has an out-turned and elongated rim, rather triangular in section, and a vertical neck. The body is high, similar to a jar: the diameter the rim is only slightly more than its height. Bowl 445 has a slightly pinched out flat foot. Its fabric is beige-pink, hard (3), with some mica inclusions (size $0.25 \mathrm{~mm}$ ). The outer surface is burnished and, under the foot, made rough by application of sand and quartz. The date of the grave is C. AD 193-220.

\section{Form B33: Bowls with high out-turned rim and high body}

Form B33 has a high out-turned rim and high body. According to rim and profile, three groups can be distinguished:

- Form B33.1: Bowl with rounded rim and continuous profile.

- Form B33.2: Bowl with expanded rounded rim and break under the neck.

- Form B33.3: Bowl with triangular rim and continuous profile.

\section{Form B33.1}

446 Locarno-Solduno, San Carlo, grave 76.3, c. AD 200-250

447 Losone-Papögna; cemetery, context unknown

Both vessels have flat feet and conical bodies: 446 has a straight wall, 447 has a curved wall. The former has a red fabric, medium to hard (2-3), with mica and sand inclusions (size $0.25 \mathrm{~mm}$ ), of L-Ware. Although the profile is 
continuous, the bowl shows a thin girth-groove under the neck. The latter has a red fabric with thin black core, medium hard (2), with mica, sand and grog inclusions (size $0.25 \mathrm{~mm}$ ), of $\mathrm{N}$-Ware. It does not bear any trace of contact with fire. Only the example from Solduno comes from a datable context, c. AD 200-250.

Form B33.2

448 Losone-Arcegno, grave 67, c. AD 222-70

449 Losone-Arcegno, grave 42

Form B33.2 has an expanded rounded rim. The neck narrows by the junction with the conical body and breaks the line of the profile. The wall is straight, the foot is slightly concave. Bowl 448 has an orange fabric, hard (3), with mica and sand inclusions (size $0.25 \mathrm{~mm}$ ). Bowl 449 has a rust-red fabric, hard (3), with mica and sand inclusions (size $0.25 \mathrm{~mm}$ ), of L-Ware. The outside and the rim show traces of contact with fire. The outer side of the foot is made rough by application of sand and quartz. Only 448 comes from a datable context, c. AD 222-70.

Form B33.3

450 Losone-Arcegno, grave 20, c. AD 235-50

451 Losone-Arcegno, grave 48, c. AD 244-60

452 Ascona, grave 2, c. AD 100-150 
Form B33.3 is similar to B33.1, except for the rim which is triangular. The two bowls from Losone have high, conical bodies with straight walls. Bowl 450 also has a slightly pinched out foot. The feet are flat or slightly concave. Bowl 452 has a more flattened body with slightly curved wall. Bowls 451 and 452 show contact with fire. Bowl 450 has beige-pink fabric, medium hard (2), with mica, sand and grog inclusions (size $0.25 \mathrm{~mm}$ ). The fabric is of $\mathrm{N}$-Ware. The body is decorated with seven girth-grooves ranging from under the neck to mid-body. Bowl 451 has a brown fabric, hard (3), with mica inclusions (size $0.25 \mathrm{~mm}$ ). Bowl 452 has a beige fabric, black on the outside, hard (3), with mica and sand inclusions (size $0.25 \mathrm{~mm}$ ), of D-Ware. The three vessels have the outer surface of the foot made rough. All vessels come from datable contexts: c. AD 100-150 for 452; c. AD 235-60 for the bowls from Losone.

\section{Form B34: Bowls with vertical rim and internal lid seating}

Form B34 has a vertical rim, a small internal lid seating and a high body. According to rim and wall, two groups can be distinguished:

- Form B34.1: Bowl with rounded rim and straight wall.

- Form B34.2: Bowl with triangular rim and curved wall.

\section{Form B34.1}

453 Locarno-Solduno, Modern cemetery, grave 57.4

454 Minusio, property Cadra, grave 8, c. AD 50-80 
Bowl 453 has a flat foot. The fabric is beige, medium hard (2), with mica and sand inclusions (size $0.25 \mathrm{~mm}$ ). Bowl 454 is a fragment of rim. The fabric is beige, hard (3), with some mica inclusions (size 0.25-0.5). Both show traces of contact with fire. Bowl 454 comes from a datable context, c. AD 50-80.

Form B34.1 occurs at Milan and dates from the second half of the 1st century $B C$ to the first half of the 1st century AD (Caporusso et al. 1991, pl. 81.13-14; Guglielmetti et al. 1991, 179-80: Tipo 32).

\section{Form B34.2}

455 Losone-Arcegno, grave 85, c. AD 351-70

Bowl 455 has a vertical rim, triangular in section. The internal lid seating is wider. The body has a slightly curved wall, the foot is slightly concave. It is decorated with an irregular girth-groove on the shoulder. The fabric is dark brown, hard (3), with mica and sand inclusions (size $0.25 \mathrm{~mm}$ ). The outside show traces of contact with fire; the outer surface of the foot is made rough. The bowl comes from a grave dated c. AD 351-70.

Form B34.2 occurs at Milan and dates to the end of the 5th and the 6th century AD (Caporusso et al. 1991, pl. 100.16; Guglielmetti et al. 1991, 220: Tipo 21). This example finds parallels dating from the same period at Castelseprio (Brogiolo \& Lusuardi Siena 1980, 481-2 figs. 11.3 and 12.1). In Ticino this form occurs at Stabio-Vignetto, in late Roman graves dating from the 4th century: 1937.344 in Grave $34,1937.426$ in Grave 39, 1937.459 in 
Grave 41, 1937.483 in Grave 43, and 1937.490 in Grave 48 (Simonett 1941, 200-7). They are associated to 4th century glass and glazed ware. It is noticeable that Form B34.2 follows in the evolution Form B34.1, dating from late Republican and early Imperial times.

Form B35: Large bowls with inturned rim

456 Minusio, property Cadra, grave 1, c. AD 180-230

Bowl 456 has an inturned, straight and slightly expanded rim, a conical body with straight wall, and a slightly concave foot. The fabric is pink-beige, medium to hard (2-3), with mica, sand and crushed quartz inclusions (size 0.25$0.5 \mathrm{~mm})$. The outer surface of the foot was made rough. The bowl comes from a grave dated C. AD 180-230. 


\subsubsection{Jars}

Definition: JAR is a vessel with a constriction at the neck whose width is usually less than its height (Webster 1976, 10).

\section{Jars with ovoid body}

Jars with out-turned rounded rim

\section{Form J1: Jars with out-turned rounded rim}

Form J1 has an ovoid body with flat or slightly concave foot. The rim is outturned, rounded and shows the same width from the junction with the neck to its end.

According to the rim, two groups can be distinguished:

- Form J1.1: Jar with elongated rim.

- Form J1.2: Jar with short rim.

Form $\mathrm{J1.1}$

457 Losone-Papögna; cemetery, context unknown

458 Losone-Papögna; cemetery, context unknown

459 Losone-Papögna; cemetery, context unknown

460 Losone-Papögna; cemetery, context unknown

461 Losone-Papögna; cemetery, context unknown 
462 Losone-Papögna, grave 42

463 Losone-Papögna, grave 38

464 Losone-Papögna, grave 22

465 Locarno-Muralto, property Passalli, grave 14, c. AD 20-70

466 Locarno-Muralto, property Passalli, grave 24, c. AD 14-60/70

467 Locarno-Muralto, property Liverpool sotto, grave 15, c. AD 70-120

468 Locarno-Muralto, property Liverpool sopra, grave 11, c. AD 20-70

469 Minusio, property Cadra, grave 26, c. AD 161-210

470 Locarno-Muralto, property Passalli, grave 39, c. AD 70-120

471 Minusio, property Cadra, grave 25

472 Locarno-Muralto, property Märki, grave 10

473 Locarno-Muralto, property Liverpool sotto, grave 37, c. AD 37/8-70

474 Locarno-Muralto, property Meyster; cemetery, context unknown

475 Locarno-Muralto, property Meyster; cemetery, context unknown

476 Ascona, no context

477 Cavigliano, property Cavalli, grave 2, C. AD 176-200

478 Locarno-Solduno, Modern cemetery, grave 57.4

479 Losone-Arcegno, grave 23, c. AD 80/1-130

480 Losone-Arcegno, grave 33, c. AD $167-90$

481 Moghegno, grave 9, c. AD 20-70

482 Moghegno, grave 19, c. AD 157/8-200

483 Moghegno, grave 36, c. AD 34-80

Form $\mathrm{J} 1.1$ has a relatively elongated rim. The profile is continuous or shows a tiny 'step' on the shoulder. Among the examples of Form J1.1 some variants 
can be distinguished: with a high shoulder and a rather straight wall (e.g. 478), with a curved wall and a relatively wide base (e.g. 476) or a narrow base (e.g. 458), and with a rim narrower than the shoulder (e.g. 479). Nevertheless, it is reasonable to consider all these differences as variants within the general Form $\mathrm{J1.1}$, instead of divide these jars into groups. Jars have been grouped according to their fabrics, in particular according to their inclusions, because of the relatively high number of examples in comparison to other forms.

\section{A) Fabrics with mica inclusions.}

Fabrics with medium mica inclusions (size $0.25 \mathrm{~mm}$ ) are medium hard (2) to hard (3), beige to beige-orange, orange. Jars $459,462,474$ and 475 show wide traces of contact with fire. Two jars, 458 and 479 (E-Ware), are inside and outside burnt black; 479 also has the outer surface of the foot made rough by application of sand and quartz. Jars 464 and 465 have beige-orange and red fabrics, without any trace of contact with fire; also 465 has the outer surface of the foot made rough. The fabric of 465 is of L-Ware.

B) Fabrics with mica and sand inclusions.

Fabrics with medium mica and sand inclusions (size $0.25 \mathrm{~mm}$ ) are medium hard (2) to hard (3), and orange to orange-red, beige or beige-yellow, light brown. Jars $457,468,478$ and 482 show traces of contact with fire. Jars 461 , 468,478 and 482 also have the outer surface of the foot made rough. Jars 470 and 480 (D-Ware) have black surfaces due to the direct contact with fire. Jar 463 has an orange fabric, hard (3) and rough cast, with many mica and 
sand inclusions inside the clay (size $0.25-0.5 \mathrm{~mm}$ ) and the outer surface of the foot made rough. This jar does not show any trace of contact with fire.

C) Fabrics with mica, sand, quartz and sometimes grog inclusions.

Fabrics with mica, sand and quartz inclusions (size $0.25 \mathrm{~mm}$ and $0.25-0.5 \mathrm{~mm}$ ) are medium hard (2) to hard (3), red to red-pink, beige, brown. The fabric of 467 also contain some grog inclusions (size $0.25-1 \mathrm{~mm}$ ) and is of N-Ware. This jar has beige fabric, without any trace of contact with fire. Jars $470,471,472$ (D-Ware), 473, 476, 477 and 481 show traces of contact with fire; 471 and 481 have the outer surface of the foot made rough. Jars 460,466 and 469 do not have any trace of contact with fire. Jar 483 shows a different surface treatment. The fabric is orange, hard (3), with many mica, sand and crushed quartz inclusions of considerable size (size $0.5-1.5 \mathrm{~mm}$ ). The outer surface show traces of a red slip, now almost vanished, and of contact with fire.

The decoration, where there is one, consists usually of girth-grooves. Jars $471,480,478$ and 483 have a girth-groove under the necks; $461,462,473$ and 474 have two separated girth-grooves under the necks and on the shoulders; 463 and 466 have a corrugated segment of wall under the necks. Jar 476 has a cordon under the neck instead of the girth-groove. Not all examples come from datable contexts: the date range within the 1st and the 2nd century $A D$. Jars $465,466,468,473,481$ and 483 come from contexts dated c. AD 20-80. Jars 467,470 and 479 come from graves dated C. AD 70120/30. Jars 469, 477, 480 and 482 come from contexts dated c. AD 160-210. 
Form J1.1 with wide conical body (e.g. 467) occurs at Angera dating from Claudian-Neronian to Trajanic-Hadrianic times (Sena Chiesa \& Lavizzari Pedrazzini 1985, pl. 94.3 ; Maccabruni \& Schifone 1985, 138 pl. 39.10). Jar 458 finds a parallel in the form at Milan, Monte Barro and Castelseprio, dating to the 5th and 6th century AD (Guglielmetti et al. 1991, 219: Tipo 17; Caporusso et al. 1991, pl. 100.7; Brogiolo \& Lusuardi Siena 1980, fig. 15.2).

Form $J 1.2$

484 Locarnese, context unknown

485 Locarno-Muralto, property Liverpool sotto, grave 47

486 Minusio, property Cadra, grave 21

487 Locarno-Muralto, via Scazziga; house, context unknown

488 Locarno-Muralto, via Scazziga; house, context unknown

489 Locarno-Muralto, via Scazziga; house, context unknown

490 Locarno-Muralto, via Scazziga; house, context unknown

491 Locarno-Muralto, via Scazziga; house, context unknown

Form $\mathrm{J} 1.2$ has a short rounded rim. Only two examples are complete and show a continuous profile (Nos. 484,485 ). The body is ovoid with maximum width at mid-body (No. 484) or in the upper half (No. 485). The base is flat. Jar 486 has a grey-pink fabric, hard (3), with the same inclusions (size $0.25-1 \mathrm{~mm}$ ), and the outer surface of the foot made rough. Jars 487 and 488 have beige to grey, and respectively brown to beige fabrics, hard (3), with mica and sand inclusions (size $0.25 \mathrm{~mm}$ ). Jars 490 (M-Ware) and 491 have red or orange fabrics, medium hard to hard (2-3), with mica, sand and crushed quartz 
inclusions (size $0.25 \mathrm{~mm}$ ). All show traces of contact with fire on the outside. Jar 484 has a beige fabric, soft (1), with mica and granular quartz inclusions (size $0.25-0.5 \mathrm{~mm}$ ). This jar is the only one with a decoration, that consists of a girth-groove on the shoulder. Jars 489 ( $\mathrm{N}$-Ware) and 485 have beige, and respectively pink fabrics, hard (3), with mica, sand, quartz and grog inclusions (size $0.25-1 \mathrm{~mm}$ ). Jar 485 has the outer surface of the foot made rough. None of these vessels comes from a datable context.

Form J1.2 occurs at Milan, Monte Barro and Castelseprio, and dates to the 5th and the 6th century AD (Guglielmetti et al. 1991, 218: Tipo 15 variante 2; Caporusso et al. 1991, pl. 100.3; Brogiolo \& Lusuardi Siena 1980, figs. 13.4, 14.1-2), or to late Medieval times (Guglielmetti et al. 1991, 241: Tipo 2; Caporusso et al. 1991, pl. 111.8).

Form J2: Jars with out-turned rounded rim and vertical neck

492 Losone-Papögna

493 Losone-Papögna

494 Losone-Papögna

495 Ascona, grave 8, c. AD 81-130

496 Losone-Arcegno, grave 57, c. AD 235-50

497 Losone-Arcegno, grave 61, c. AD 243-60

498 Losone-Arcegno, grave 62, c. AD 183-230

499 Moghegno, grave 31, c. AD 80-130 
Form $\mathrm{J} 2$ is similar to Form $\mathrm{J} 1$, but there is a vertical neck between the outturned rim and the body. The body is ovoid with slightly concave wall, ending in a slightly pinched out foot (flat or slightly concave; i.e. 496), or with a curved wall and a slightly concave foot (e.g. 495). Except for jar 495, all examples of Form J2 come from Losone (four from Arcegno, one from Papögna).

A) Fabrics with sand inclusions.

Only jar 497 has a fabric with some mica inclusions (size $0.25 \mathrm{~mm}$ ). It is hard (3), dark beige in the inside, black on the outside because of the contact with fire. This jar is decorated with a segment of corrugated wall under the neck.

B) Fabrics with mica and sand inclusions.

All other jars have medium hard (2) to hard (3) fabrics, red to beige, with some mica and sand inclusions (size $0.25 \mathrm{~mm}$ ). Jars 492 and 495 (L-Ware) show traces of contact with fire; 498 is completely burnt and therefore black. Jar 496 does not show the contact with fire. These jars have the outer surface of the foot made rough. Only 492 has a decoration, that consists of two separated girth-grooves under the neck.

C) Fabrics with mica, sand and quartz inclusions.

Jar 493 has a beige fabric with traces of contact with fire; 494 has a greyblack fabric and also shows the contact with fire, and is of D-Ware. This vessel is decorated with a girth-groove under the neck. Jar 499 has a beige fabric, hard (3), with mica, sand and crushed quartz inclusions (size 0.1- 
$0.25 \mathrm{~mm})$. The surface is burnished and shows traces of contact with fire. The outer surface of the flat foot is made rough.

Except for 492, all jars come from datable contexts: C. AD 80-130 for 495 and 499; c. AD 183-230 for 498; c. AD 235-60 for 496 and 497.

Form J3: Jars with bead rim and vertical neck

500 Losone-Papögna, grave 21

501 Locarnese, context unknown

502 Locarno-Muralto, property Märki, grave 6, c. AD 101/2-140

503 Locarno-Muralto, property Märki, grave 6, c. AD 101/2-140

504 Minusio, property Cadra, grave 20, c. AD 81-130

505 Locarno-Muralto, property Liverpool sotto, grave 37, c. AD 37/8-70

506 Locarno-Muralto, Via Scazziga; house, context unknown

507 Losone-Arcegno, grave 17, c. AD 50-100

508 Losone-Arcegno, grave 49, c. AD 179-200

509 Losone-Arcegno, grave 96, c. AD 161/2-200

510 Moghegno, grave 4, c. AD 149-200

511 Moghegno, pit 6/2

512 Moghegno, grave 22, c. AD 138-50

Form J3 has an ovoid body with a high shoulder and a narrow foot (e.g. 508) or a lower shoulder and a wider foot (e.g. 507). The rim ends in a rounded bead and is separated from the body by a vertical neck. The foot is flat or 
slightly concave. The fabrics are beige to pink, orange and grey, hard (3), with mica, mica and sand or mica, sand and quartz inclusions.

A) Fabrics with mica inclusions.

The fabrics of jars 501, 507 and 509 contain some mica inclusions (size 0.25$0.5 \mathrm{~mm})$. Jar 501 has a beige fabric with traces of contact with fire. Jar 507 has a orange fabric and the outer surface of the foot is made rough. Jar 509 has a beige-orange fabric; the foot is missing. Only 509 is decorated with three separated girth-grooves under the neck.

B) Fabrics with mica and sand inclusions.

Jars 500, 506, 508 and 512 have fabrics with some mica and sand inclusions (size $0.1-0.25 \mathrm{~mm}$ ). The fabrics are beige, except for 500 (D-Ware), which is burnt black and has a brown core and 506, which is grey without traces of contact with fire. Jar 512 shows traces of contact with fire. This vessel, and 508 , have the outer surface of the foot made rough. Jar 512 is decorated with a girth-groove under the neck; 508 has two separated girth-grooves in the same position.

C) Fabrics with mica, sand and quartz inclusions.

Jars 502, 503 and 511 have fabrics with medium mica, sand and quartz inclusions (size $0.25-0.5 \mathrm{~mm}$ ). The fabrics of jars 505 and 510 contain bigger inclusions (size $0.5-1.5 \mathrm{~mm}$ ). The fabrics are beige or beige-pink. All jars show traces of contact with fire. Jars 510 and 511 have the outer surface of the foot made rough; 502 is plain; the feet of the other two jars are missing. Jar 502 is 
decorated with two girth-grooves under the neck; 503 has a corrugated segment of neck at the junction with the body. Jar 504 has a red fabric, medium hard (2), with mica, sand, quartz and grog inclusions (size $0.25 \mathrm{~mm}$ ), of $\mathrm{N}$-Ware. The outer surface of the foot is made rough.

Some jars come from datable contexts: c. AD 37-70 for 505; c. AD 50-150 for $502,503,507,504$ and 164.94.15; c. AD 150-200 for 508, 509 and 510 .

Form J4: Jars with elongated out-turned rim and vertical neck

513 Losone-Papögna; cemetery, context unknown

514 Losone-Papögna; cemetery, context unknown

515 Locarno-Muralto, via Scazziga; house, context unknown

516 Losone-Arcegno, grave 30, c. AD 80/1-100

517 Moghegno, grave 30, c. AD 98-130

Form $\mathrm{J} 4$ has an ovoid body with a flat base. Only one example, 513, has slightly concave foot. The rim is out-turned and elongated, rounded (No. 516), slightly expanded rounded (Nos. 513,515 ) or rectangular in section (Nos. 514, 517). A short neck separates the rim from the body. The neck is vertical by 514,516 and 517 , straight and slightly inturned by the other two jars. Jar 513 has a beige-yellow fabric, medium hard to hard (2-3), with mica and sand inclusions (size $0.25 \mathrm{~mm}$ ). The outer surface of the foot is made rough. Jar 514 has a beige fabric, medium hard (2), with mica and sand inclusions. The surface shows traces of contact with fire. Jar 515 has a red-brown fabric, hard 
(3), with mica, sand, granular quartz and grog inclusions (size $0.25 \mathrm{~mm}$ ), of $\mathrm{M}$ Ware. Jar 517 has an orange fabric, hard (3), with many mica, sand, granular quartz and grog inclusions (size $0.5-1 \mathrm{~mm}$ ). Jars 514 and 517 have the outer surface of the feet made rough by application of sand and quartz. Jars 517 and 516 are decorated with a girth-groove under the necks. Jar 516 has a beige fabric, medium hard (2), with black patches on the outside. The inclusions consist of some mica and grog (size $0.25 \mathrm{~mm}$ ). The fabrics of 516 and 517 are of $\mathrm{N}-$ Ware. Only three jars come from datable contexts, C. AD 80130.

\section{Form J5: Jars with cavetto rim}

518 Ascona, grave S1, c. AD 70-120

Jar 518 has an ovoid body and a flat base. The rim forms a concave quarterround profile. Its fabric is brown, hard (3), with mica and sand inclusions (size $0.25 \mathrm{~mm})$. The surface shows traces of contact with fire. The outer surface of the foot is made rough. This jar comes from a grave dated c. AD 70-120.

\section{Form J6: Jars with out-turned expanded rounded rim}

Form $\mathrm{J} 6$ has an expanded rounded rim, an ovoid body, and a flat or concave foot. According to the form of body and rim, three groups can be distinguished:

- Form J6.1: Jar with ovoid to conical body. 
- Form J6.2: Jar with ovoid body.

- Form J6.3: Jar with ovoid body and high shoulder.

Form J6.1

519 Losone-Papögna; cemetery, context unknown

520 Cavigliano, property Monotti, grave 3

521 Locarno-Muralto, via Scazziga; house, context unknown

522 Locarno-Muralto, via Scazziga; house, context unknown

523 Locarno-Muralto, via Scazziga; house, context unknown

524 Locarno-Muralto, via Scazziga; house, context unknown

525 Locarno-Muralto, property Meyster; cemetery, context unknown

526 Locarno-Solduno, Modern cemetery, grave 57.7

527 Locarno-Solduno, Modern cemetery, grave 57.9, c. AD 179-230

528 Losone-Arcegno, grave 9, c. AD 161-80

529 Losone-Arcegno, grave 53, c. AD 193-210

530 Losone-Arcegno, grave 58, c. AD 231-50

Form J6.1 has a relatively narrow foot and a wide rim. The maximum width lies on the shoulder. The body is therefore ovoid but with conical form. The foot is concave (e.g. 528) or slightly concave (e.g. 529). Some jars, however, are fragmentary and their bases are missing. It is therefore possible that among this group there exist also jars with flat bases. Jars 521 (L-Ware) and 524 (E-Ware) have red, respectively black fabrics, hard (3), with the same inclusions. The outer surface of 521 is burnished. Jars 525 and 530 have beige-orange fabrics, hard (3), with some mica inclusions (size $0.25 \mathrm{~mm}$ ). Jars 
526, 527 (M-Ware), 528 (L-Ware) and 529 have red, orange and beige fabrics, hard (3), with some mica and sand inclusions (size $0.25 \mathrm{~mm}$ ). Only 526 has a medium hard fabric (2). Jar 527 also has the outer surface of the foot made rough. Jars 520 ( $M-W a r e), 523$ have respectively rust-red and beige fabrics, medium hard to hard (2-3), with some mica and crushed quartz inclusions (size. $0.25 \mathrm{~mm}$ ). Jar 522 has a beige-grey fabric, hard (3), with mica, sand, granular and crushed quartz inclusions (size. $0.25 \mathrm{~mm}$ ). It is the only example of Form J6.1 with traces of contact with fire (except for 524 with black fabric due to the reduced firing). The decoration of these jars consists of girthgrooves. Jars 526, 527 and 529 have a girth-groove under the necks; 520 has two girth-grooves under the neck; 528 has segment of corrugated wall under the neck above the shoulder. Only few vessels of Form J6.1 come from datable contexts: $527,528,529$ and 530 . The dates of the graves range within c. AD 161-250.

This form occurs at Angera, but with no context (Sena Chiesa \& Lavizzari Pedrazzini 1985, pl. 76.2).

Form J6.2

531 Losone-Papögna; cemetery, context unknown

532 Locarno-Muralto, property Meyster; cemetery, context unknown

533 Locarno-Muralto, property Meyster; cemetery, context unknown

534 Locarno-Muralto, via Scazziga; house, context unknown

535 Locarno-Muralto, via Scazziga; house, context unknown

536 Cavigliano, property Cavalli, grave 4, c. AD 186-210 
Form J6.2 has an ovoid body. The maximum width is at mid-body. The foot is slightly concave (e.g. 533) or flat (e.g. 531). Jar 537 has a more vertical rim, a slightly flattened body and a wide, slightly concave foot.

Jar 531 has a red fabric, hard (3), with mica and sand inclusions (size $0.25 \mathrm{~mm}$ ), of L-Ware. The outer surface of the base is made rough. Jars 519 , 532 and 533 (M-Ware) have beige to beige-pink fabrics, medium hard to hard (2-3), with mica and crushed quartz inclusions (size $0.25 \mathrm{~mm}$ ). Jar 534 has a beige, hard (3), with some mica inclusions (size $0.25 \mathrm{~mm}$ ). It shows traces of contact with fire on the inside. Jar 535 has a red fabric, medium hard (2), with the same inclusions. The outer surface shows traces of contact with fire. Jar 537 has a beige-pink fabric, hard (3), with some mica inclusions (size $0.25 \mathrm{~mm}$ ). The outer surface of the foot is made rough. The decoration consists of one (No. 533) or two girth grooves (Nos. 519,$532 ; 535 ; 536$ ) under the necks. Only 536 and 537 come from datable contexts: the dates of the graves is c. AD 186-250.

Form $J 6.3$

538 Locarno-Solduno, Trench 1956/S2

Form J6.3 has an ovoid body with relatively wide foot. The shoulder is high and the maximum width is set at the shoulder. The base is flat. Jar 538 has a red fabric, hard (3), with some mica, sand and crushed quartz inclusions (size 
$0.25 \mathrm{~mm}$ ). The fabric is of M-Ware. The decoration consists of two girthgrooves under the neck. This example does not come from a datable context.

Form J6.3 has a parallel at Angera dating from Trajanic-Hadrianic times (Sena Chiesa \& Lavizzari Pedrazzini 1985, pl. 94.4).

\section{Form J7: Jar with slightly out-turned expanded rounded rim}

Form $\mathrm{J} 7$ has a slightly out-turned, expanded rounded rim, an ovoid body, and a flat, slightly concave foot or foot-disc.

According to body and foot, three groups can be distinguished:

- Form J7.1: Jar with ovoid body.

- Form J7.2: Jar with ovoid/globular body.

- Form J7.3: Jar with conical body.

Form $J 7.1$

539 Losone-Papögna; cemetery, context unknown

540 Locarno-Muralto, property Passalli, grave 15, c. AD 0-50

541 Minusio, property Cadra, grave 8, c. AD 50-80

542 Locarno-Muralto, property Liverpool sotto, grave 18, c. AD 80-130

543 Locarno-Muralto, property Passalli, grave 18

544 Locarno-Muralto, property Liverpool sopra, grave 5, c. AD 70-120

545 Locarno-Muralto, via Scazziga; house, context unknown

546 Locarno-Muralto, via Scazziga; house, context unknown

547 Locarno-Muralto, via Scazziga; house, context unknown 
Form $\mathrm{J} 7.1$ has an ovoid, relatively narrow and high body. The maximum width is at mid-body or on the low shoulder. The form of the body varies in detail in the different examples. The base is flat or slightly concave. Only 545 has a foot-disc. Jars 541 and 547 have beige, and respectively rust-red fabrics, hard (3), with some mica inclusions (size $0.25-0.5 \mathrm{~mm}$ ). Both vessels show traces of contact with fire on the outside. The fabrics of 539 and 547 are of L-Ware. Jar 541 also has the outer surface of the base made rough. Jars 539,542 and 544 (M-Ware) have respectively red, beige and red-orange fabrics, hard (3), with mica and sand inclusions (size $0.25 \mathrm{~mm}$ ). The surface of 542 shows some red areas, whereas that of 539 shows traces of contact with fire. The outer surface of the feet of these three vessels is made rough.

Jars 540 (M-Ware) and 543 have red-beige and beige-pink fabrics, hard (3), with mica, sand, crushed and granular quartz inclusions (size $0.25-0.5 \mathrm{~mm}$ and $0.25-1 \mathrm{~mm}$ ). Jars 545 and 546 (M-Ware) have beige-pink and red fabrics, hard (3), with mica and quartz inclusions (size $0.25 \mathrm{~mm}$ ). The former bears traces of contact with fire. The decoration of Form J7.1 consists of girth-grooves: one by 539 and 543 ; two separated by 542,545 and 546 . Four vessels come from datable contexts: c. AD 0-50 for 540; c. AD 50-80 for 541; c. AD 70-130 for 542 and 544.

Form $\mathbf{J 7 . 2}$

548 Locarnese, context unknown

549 Locarno-Muralto, property Passalli, grave 15, c. AD 0-50

550 Locarno-Muralto, property Meyster; cemetery, context unknown 
Form J7.2 has a wide, slightly flattened body. The maximum width is between mid-body and the shoulder. The base is slightly concave. Jar 548 has a red fabric, hard (3), with mica and crushed quartz inclusions (size $0.25 \mathrm{~mm}$ ), of $\mathrm{M}$ Ware. The surface on the shoulder is burnished. Jar 550 has a red fabric, medium hard (2), with mica and sand inclusions (size $0.25 \mathrm{~mm}$ ). Jar 549 has a beige fabric, hard (3), with mica and sand inclusions (size $0.1-0.25 \mathrm{~mm}$ ). The surface shows traces of contact with fire. This jar is decorated with a cordon under the neck, between two girth-grooves. It is the only vessel from a datable context coming from Grave 15 at Muralto, property Passalli, as with jar 540 (Form J7.1). The date of the grave is C. AD 0-50.

\section{Form J7.3}

551 Losone-Papögna; cemetery, context unknown 552 Losone-Papögna, grave 45

Form J7.3 has a conical body with a high and wide shoulder and a straight wall. The foot is flat. The fabric of 551 is red-pink, medium hard to hard (2-3), with mica and sand inclusions (size $0.25 \mathrm{~mm}$ ), and is of L-Ware. The outer surface of the base is made rough. Jar $\mathbf{5 5 2}$ has more pronounced shoulder. Its fabric is dark beige, black on the outside because of the contact with fire, medium hard to hard (2-3), with mica and sand inclusions (size $0.25 \mathrm{~mm}$ ). None of these jars comes from a datable context. 


\section{Form J8: Jars with out-turned rim with internal bevel}

Form $\mathrm{J} 8$ has an ovoid body and a flat or slightly concave foot. The rim is outturned and shows an internal bevel.

According to the rim, two groups can be distinguished:

- Form J8.1: Jar with rim triangular in section.

- Form J8.2: Jar with rim hemispherical in section.

Form $\mathrm{J} 8.1$

553 Losone-Papögna; cemetery, context unknown

554 Locarno-Muralto, via Scazziga; house, context unknown

Jar 553 is complete. The rim is out-turned, triangular in section and with an internal bevel. The body is ovoid, the base is flat. The fabric is red, medium hard to hard (2-3), with some mica and sand inclusions (size $0.25 \mathrm{~mm}$ ), and is of L-Ware. The outer surface of the base is made rough.

Jar 554 is a fragment of rim. The out-turned rim is separated from the body by a vertical neck. The fabric is red with traces of contact with fire, hard (3), with mica, sand and granular quartz inclusions (size $0.25 \mathrm{~mm}$ ). It is of $M-W a r e$. None of these vessels comes from a datable context.

A similar vessel was found at Lurate Caccivio (no context: Butti Ronchetti 1985, pl. XV.16). 
Form J8.2

555 Locarno-Muralto, via Scazziga; house, context unknown

556 Losone-Arcegno, grave 63, c. AD 244-60

557 Moghegno, grave 12, c. AD 81-120

558 Moghegno, grave 18, c. AD 95/6-130

559 Losone-Papögna; cemetery, context unknown

Form J8.2 has an ovoid body, and a flat or slightly concave foot. The rim is hemispherical in section. Jars 555 and 556 have rather wide and high rims. Jars 557, 558 and 559 have narrow and short rims. Jar 555 has an orange fabric, hard (3), with some mica inclusions (size $0.25 \mathrm{~mm}$ ). The outside shows traces of contact with fire. Jar 556 has a beige-pink fabric, hard (3), with mica and sand inclusions (size $0.25 \mathrm{~mm}$ ). Jar 557 has a beige-grey fabric with traces of contact with fire, medium hard (2), also with mica and sand inclusions (size $0.1-0.25 \mathrm{~mm}$ ). Jar 558 has a grey-pink fabric, hard (3), with mica, sand and crushed quartz inclusions (size $0.25-0.5 \mathrm{~mm}$ ). The outer surface of the feet of both is made rough. Jar 559 has a beige fabric, medium hard (2), with mica and sand inclusions (size $0.25 \mathrm{~mm}$ ). Only jars 556 and 557 are decorated under the neck: the former with two girth-grooves, the latter with one. The two jars from Moghegno and that from Losone come from datable contexts: c. AD 81-130 for 557 and 558, and c. AD 244-60 for 556 . 
Form J9: Jars with short out-turned rim

560 Losone-Papögna; cemetery, context unknown

561 Losone-Papögna; cemetery, context unknown

562 Locarno-Muralto, property Liverpool sotto, grave 17, c. AD 70-120

563 Locarno-Muralto, property Meyster; cemetery, context unknown

564 Cavigliano, property Monotti, grave 5, c. AD 79-100

565 Locarno-Muralto, via Scazziga; house, context unknown

566 Ascona, grave 7, c. AD 70-120/30

567 Losone-Arcegno, grave 15, c. AD 98-140

Form J9 has an ovoid body, a short and out-turned rounded rim, and a flat foot. The rims are different in detail: some are straight (e.g. 561), others are slightly curved (e.g. 564). These jars have usually wide feet and wide rims. Only 564 has slightly flattened and therefore more globular body and rather narrow rim. Jars 563 (E-Ware) and 565 have light grey, and respectively beige fabrics, medium hard to hard (2-3), with some mica inclusions (size $0.25 \mathrm{~mm}$ ). Both show traces of contact with fire. Jar 563 has the outer surface of the foot made rough and bears a sort of cordon on the neck. Jar 565 is decorated with a girth-groove on the outer side of the rim, which makes it 'bifid' in section, and two separated girth-grooves under the neck. Jars 560, 561 and 564 have fabrics with some mica and sand inclusions (size $0.25 \mathrm{~mm}$ ). Jar 560 has a beige fabric, hard (3), with traces of contact with fire. Jar 560 is decorated with a girth-groove under the neck. Jars 561 (L-Ware) and 564 have red and medium hard (2), and respectively beige-pink and medium hard to hard (2-3) fabrics, and the outer surface is made rough. Jar 567 has a beige-pink fabric, 
hard (3), with many mica and sand inclusions (size $0.25 \mathrm{~mm}$ ). The outer surface of the foot is made rough. Jars 562 and 566 have some mica, sand, quartz and grog inclusions (size $0.25-1 \mathrm{~mm}$ ). Jar 562 has a beige fabric, hard (3), and has the outer surface of the foot made rough. Jar 566 has an orangefabric, soft (1). It is decorated with a cordon on the outside of the rim. Jars $562,564,566$ and 567 come from datable contexts: the dates of the graves range within $\mathrm{c.} A D$ 70-140.

Form J9 finds some parallels at Angera dating from Trajanic-Hadrianic times (Sena Chiesa \& Lavizzari Pedrazzini 1985, pl. 94. 6-7). A vessel, very similar to 566 , occurs at Olgiate Comasco from a context dated between the end of the 1st and the beginning of the 2nd century AD (Butti Ronchetti 1986, $127 \mathrm{pl}$. VII.43). This form corresponds to Lavizzari Pedrazzini's (1980) Type B ; contemporary to Type A (Bowls) at the beginning, but reaching the 3rd and the 4th century AD (Lavizzari Pedrazzini 1980, 224ff.).

Jars with out-turned rim triangular or rectangular in section

Form J10: Jars with bead rim, triangular in section, and vertical neck 568 Locarno-Muralto, property Märki; cemetery, context unknown

569 Locarno-Solduno, 1956/58 no context

570 Losone-Arcegno, grave 47, c. AD 141-60

571 Moghegno, grave 21, c. AD 160-210

572 Moghegno, grave 23, c. AD 117-50

573 Moghegno, grave 25, c. AD 81-100 
Form $\mathrm{J} 10$ has an ovoid body with flat or slightly concave foot. The bead rim is triangular in section and is separated from the body by a vertical neck. Although these jars have common features, they show in detail some differences. These details, however, do not seem to be of enough relevance, to ascribe these vessels to different forms. Jar $\mathbf{5 7 0}$ has a slightly pinched out and slightly concave foot. Its rim is a real bead rim, triangular in section, high and narrow. The fabric is beige-pink, hard (3), with many mica and sand inclusions (size $0.25 \mathrm{~mm}$ ), which make the surface similar to a rough-cast one. The outer surface of the foot is also made rough. The decoration consists of two separated girth-grooves under the neck. Jars 568 and 571 are very similar. The bodies are slightly flattened, the feet are concave. The rims are low and wide, almost 'hemispherical' in section. Jar 568 has a beige fabric, medium hard (2), with some mica inclusions (size $0.25 \mathrm{~mm}$ ). Jar 571 has a beige-pink fabric, hard (3), with some mica, sand and crushed quartz inclusions (size $0.1-0.5 \mathrm{~mm}$ ). Both vessels are decorated with a girth-groove under the neck. Jar 572 has a slightly pinched out very slightly concave foot. The triangular rim is pointed, the neck is short and slightly curved. Inside the rim there is a sort of lid seating. The fabric is beige-grey, hard (3), with few mica, sand and crushed quartz inclusions (size $0.1-1 \mathrm{~mm}$ ). The surface shows traces of contact with fire. The vessel is decorated with a girth-groove under the rim. Jar 573 has a flat foot; the triangular rim is more rounded and slightly elongated; the neck is curved. Inside the rim there is a lid seating. The fabric is beige-orange, medium hard (2), with many mica, sand and crushed quartz inclusions (size $0.25-1.5 \mathrm{~mm}$ ). The outer surface of the foot is made rough. The vessel is decorated with a girth-groove under the rim. Jar 569 has a 
triangular and elongated rim. The neck is not vertical but straight and slightly out-turned. The foot is slightly concave. The fabric is beige, medium hard to hard (2-3), with mica and sand inclusions (size $0.25 \mathrm{~mm}$ ). The outer surface of the foot is made rough. Only the jars from Moghegno and that from Losone come from datable contexts. The graves date within the period c. AD 80-210.

\section{Form J11: Jars with straight out-turned rim, rectangular in section}

574 Locarno-Muralto, property Passalli, grave 2

575 Losone-Arcegno, grave 8, c. AD 194-210

576 Losone-Arcegno, grave 16, c. AD 119-40

577 Losone-Arcegno, grave 60, c. AD 383-400

578 Moghegno, grave 29, c. AD 70-120

579 Locarno-Muralto, via Scazziga; house, context unknown

Form $\mathrm{J} 11$ has an ovoid body with a flat or slightly concave foot. The rim is straight, out-turned and rectangular in section. Jars 575 and 578 are similar. The rims, however, has different thickness: the former is thinner, the latter thicker. Jars 575 and 578 have orange, respectively beige-pink fabrics, medium hard (2), with mica, sand and crushed quartz inclusions (size 0.1 $0.25 \mathrm{~mm})$. The outer surface of the feet is made rough. Jar 575 is decorated with two separated girth-grooves under the neck. Jar 574 has a thick and more out-turned rim. The fabric is beige-pink, medium hard (2), with some mica and sand inclusions (size $0.25 \mathrm{~mm}$ ). Jars 576 and 577 have high rims. The fabrics are beige, hard (3), with mica and sand inclusions (size $0.25 \mathrm{~mm}$ ). 
The outer surfaces are black because of the contact with fire. The outside of the foot of 576 is made rough. The jars are decorated with a girth-groove under the necks. Jar 579 is a fragment of a rim, slightly out-turned, and flattened on the top. The fabric is beige-pink, hard (3), with some mica inclusions (size $0.25 \mathrm{~mm}$ ). This fragment shows a band of stabbed decoration on the shoulder. The jars from Moghegno and Losone come from datable contexts: c. AD $70-140$ for 576 and 578 ; c. AD 194-210 for 575 ; c. AD 383400 for 577 .

Form J11 occurs at Angera dating from Claudian-Neronian times (Maccabruni \& Schifone 1985, 139 pl. 40.1 ; Sena Chiesa \& Lavizzari Pedrazzini 1985, pl. 94.2).

\section{Form J12: Jars with out-turned triangular rim}

580 Cavigliano, casa sindaco

581 Locarno-Solduno, Modern cemetery, grave 58.16, c. $A D 70-120$

582 Losone-Arcegno, grave 29, c. AD 50-100

583 Losone-Arcegno, grave 82, c. AD 236-50

584 Losone-Arcegno, grave 90, c. AD 98-140

585 Moghegno, grave 1, c. AD 161-200

586 Moghegno, grave 13, c. AD 20-70

587 Locarno-Muralto, via Scazziga; house, context unknown

588 Locarno-Muralto, via Scazziga; house, context unknown 
Form $\mathrm{J} 12$ is similar to Form $\mathrm{J} 11$ : the body is ovoid, the base is flat or slightly concave. The rim is out-turned and triangular in section, but is curved instead of straight. Jars $581,582,583$ and 589 have the rims set at wide angle on the bodies. Jar 581 has a pink fabric with orange areas, hard (3), with some mica inclusions. The outer surface of the foot is made rough. Jar 582 has a beige fabric, hard (3), with mica and sand inclusions (size $0.25 \mathrm{~mm}$ ). Jar 583 has a red-orange fabric, medium hard (2), with some mica inclusions (size $0.25 \mathrm{~mm}$ ). Both jars show traces of contact with fire on the surfaces and have the outer surface of the feet made rough. Jar 589 has a red, hard (3) fabric with medium mica and sand inclusions (size $0.25 \mathrm{~mm}$ ). Except for the latter, the other vessels are decorated with girth-grooves: one under the neck and one on the shoulder for 582; one under the neck for 581 and 583 . Jars 580,584 and 585 have the rims set at a sharper angle. Jar 580 has a pink fabric, hard (3), with mica and sand inclusions (size $0.25-0.5 \mathrm{~mm}$ ). The surface is burnished. Jar 584 has a beige fabric, hard (3), with some mica inclusions (size $0.25 \mathrm{~mm}$ ). Both jars have the outer surface of the feet made rough. Jar 585 has a dark grey fabric due to the contact with fire, hard (3), with mica and sand inclusions (size $0.25 \mathrm{~mm}$ ), of D-Ware. Jar 586 has a slightly flattened body with wide foot. The rim is curved, rounded on the inside and pointed on the outside. It has a beige-pink fabric, hard (3), with mica, sand and crushed quartz inclusions (size $0.25-1.5 \mathrm{~mm})$. The jar shows traces of the contact with fire and has the outer surface of the foot made rough. Jars 587 and 588 are fragments of rims only. The former has a beige-brown, the latter a brown-red fabric, hard (3), with 
some mica and sand inclusions (size $0.25 \mathrm{~mm}$ ). Jar 588 shows traces of contact with fire on the outside. Except for the jars from Cavigliano and Muralto-via Scazziga, whose exact context is unknown, all other vessels come from datable contexts, ranging from the first half of the 1st to the first half of the 3rd century $A D$. The dates of the graves are $C$. AD 20-70 for 586; C. AD 50-140 for 581,582 and $584 ;$ c. AD $70-120$ for 589 ; C. AD 161-200 for 585 ; c. AD 236-50 for 583 .

Form J13: Jars with out-turned expanded triangular rim at a sharp angle According to the body, two groups can be distinguished:

- Form J13.1: Jar with conical body.

- Form J13.2: Jar with ovoid body.

Form $\mathbf{J 1 3 . 1}$

590 Losone-Papögna, grave 26

591 Losone-Arcegno, grave 14, c. AD 161-90

592 Losone-Arcegno, grave 55, c. AD 235-50

593 Losone-Arcegno, grave 75, c. AD 383-400

594 Locarno-Muralto, via Scazziga; house, context unknown

Form J13.1 has a wide and conical body with a flat or slightly concave, narrow foot. The rim is out-turned, rounded on the top and pointed on the outside. It is set at a rather sharp angle on the body. The fabrics are beige to red, and hard (3). Jar 590 has a beige fabric with some mica inclusions (size $0.25 \mathrm{~mm}$ ). Jar 
594 has the same inclusions and a red fabric, and is of L-Ware. The outside of this vessel shows traces of contact with fire. Jars 591 and 592 (N-Ware) have beige-pink, and respectively orange-pink fabrics, with mica and sand inclusions (size $0.25 \mathrm{~mm}$ ). Jar 593 has a pale orange fabric, and mica, sand and grog inclusions (size $0.25 \mathrm{~mm}$ ). This jar and 591 have the outer surface of the feet made rough. The decoration consists of girth-grooves: one under the neck by 590,593 and 594 , two separated under the neck by 592 , and a corrugated segment of wall under the neck by 591. All jars from Losone come from datable contexts: C. AD $181-90$ for 591 ; c. $A D 235-50$ for 592 and c. $A D$ 383-400 for 593.

Form $J 13.2$

595 Losone-Papögna; cemetery, context unknown

Form J13.2 has an ovoid instead of a conical body. Jar 595 has a slightly pinched out and a concave foot. The rim is out-turned at a sharp angle. The fabric is beige, medium hard to hard (2-3), with mica, sand and quartz inclusions (size $0.25 \mathrm{~mm}$ ). The jar is decorated with a girth-groove under the neck. The exact context of this vessel is unknown.

\section{Form J14: Jars with out-turned expanded triangular rim at a wide angle} Form J14 has an out-turned, expanded triangular rim. It is rounded on the top and pointed on the outside. This rim is therefore similar to that of Form J13, except that here it is set at a wider angle on the body. 
According to the form of the body, three groups can be distinguished:

- Form J14.1: Jar with conical body.

- Form J14.2: Jar with ovoid body.

- Form J14.3: Jar with ovoid body and high shoulder.

Form $J 14.1$

596 Losone-Arcegno, grave 4, c. AD 154-80

597 Losone-Arcegno, grave 66, c. AD 244-90

598 Gerra Gambarogno-Vairano; cemetery, context unknown

Form J14.1 has a slightly flattened and conical body. The foot is flat or slightly concave. Both jars from Losone have a slightly pinched-out feet. Jar 596 has an orange fabric, hard (3), with many mica and sand inclusions (size $0.25 \mathrm{~mm}$ ). Jar 597 has a red to dark brown fabric, hard (3), with some mica inclusions (size $0.25 \mathrm{~mm}$ ). The outside shows traces of contact with fire. Jar 598 has a beige fabric, medium hard to hard (2-3), with mica, sand and quartz inclusions (size $0.25 \mathrm{~mm}$ ). The outside has black patches due to the contact with fire. The outer surface of the foot is made rough. None of these vessels is decorated. The two jars from Losone come from datable contexts: c. AD $154-80$ for 596 and c. AD 244-90 for 597.

Form $\mathbf{J 1 4 . 2}$

599 Losone-Papögna; cemetery, context unknown

600 Losone-Papögna, grave 42

601 Losone-Arcegno, grave 76, c. AD 163-80 
Form J14.2 has an ovoid body with the maximum diameter in the upper half of the body. The foot is flat or concave. Jar 599 has an orange fabric, medium hard to hard (2-3), with mica and crushed quartz inclusions (size $0.25 \mathrm{~mm}$ ). Jar 600 has a light brown fabric, also medium hard to hard (2-3), with mica and sand inclusions (size $0.25 \mathrm{~mm}$ ). It has the outer surface of the foot made rough. Jar 601 has a red-orange fabric, hard (3), with mica and sand inclusions (size $0.25 \mathrm{~mm}$ ), of L-Ware. Jar 602 has a body similar to Form J14.1. The rim is out-turned and expanded but is shorter than the other examples. The fabric is beige-pink, hard (3), with mica, sand and crushed quartz inclusions (size $0.25-0.5 \mathrm{~mm}$ ). The jars from Losone are decorated with a girth-groove under the neck. The jar from Moghegno is plain. Two jars come from datable contexts: c. AD 85/6-100 for 602 and c. AD 163-80 for 601 .

Form J14.3

603 Losone-Arcegno, grave 79, c. AD 236-50

Form J14.3 has an ovoid body with the maximum width at mid-body. The foot is flat. Jar 603 has a beige-pink fabric, medium hard (2), with some mica inclusions (size $0.25 \mathrm{~mm}$ ). The date of the grave is C. AD 236-50. 


\section{Form J15: Jars with out-turned expanded rim, triangular in section}

604 Minusio, property Cadra, grave 7, c. AD 70-120

605 Cavigliano, property Monotti, grave 3

$606^{\prime}$. Locarno-Muralto, via Scazziga

607 Locarno-Muralto, via Scazziga

608 Ascona, grave 3, c. AD 70-120/30

609 Ascona, grave 5, c. AD 40-100

610 Losone-Arcegno, grave 24, c. AD 210-30

611 Moghegno, grave 7, c. AD 40-90

612 Moghegno, grave 10, c. AD 180-200

Form $\mathrm{J} 15$ has an out-turned, expanded triangular rim as Forms $\mathrm{J} 13$ and $\mathrm{J} 14$. The difference consists of the detail of the rim: in Form J15 it is triangular in section with pointed top and outside, in Form $\mathrm{J} 13$ and $\mathrm{J} 14$ the rim is rounded on the top and pointed on the outside only.

The body is ovoid, the foot is flat or slightly concave. All jars belonging to Form $\mathrm{J} 15$ are slightly different in body and rim: $604,609,610$ and 612 have high but not the same rims; the others have shorter rims, also always different. The body may be ovoid with maximum width in the upper half (e.g. 609) or at midbody (e.g. 610). Jars 610 and 612 are similar: the bodies are rather flattened, the feet are slightly concave. The rim of 610 is more out-turned than that of 612 , which is rather vertical. They have beige fabrics, hard (3), with some mica inclusions (size $0.25 \mathrm{~mm} ; 610$ ) or few mica, sand and crushed quartz inclusions (size $0.1-0.25 \mathrm{~mm} ; 612$ ). Both show traces of contact with fire. Jar 612 is decorated with a girth-groove under the neck. The outer surface of the 
foot of 610 is made rough. Jars 605,606 and 611 are similar: the rims are shorter and thicker. Jar 611 has an orange fabric, hard (3), with few mica, sand, crushed quartz and grog inclusions (size $0.5-1 \mathrm{~mm}$ ). Jar 604 has a beige fabric with orange areas, hard (3), with mica, sand, crushed quartz and grog inclusions (size $0.25-0.5 \mathrm{~mm}$ ). The fabrics of both 604 and 611 are of N-Ware. Jar 605 has a black fabric with some orange areas, hard (3), with mica, sand and crushed quartz inclusions (size $0.25 \mathrm{~mm}$ ). This jar and the former show traces of contact with fire. Jar 606 has a beige-grey fabric, hard (3), with some mica inclusions (size $0.25 \mathrm{~mm}$ ). Jar 607 has a dark red fabric on the outside, grey on the inside and red core, hard (3), with mica, sand and crushed quartz inclusions (size $0.25 \mathrm{~mm}$ ). It is of M-Ware. The vessel is decorated with two separated girth-grooves under the neck. Jar 608 has a brown-red fabric, medium hard to hard (2-3), with mica and sand inclusions (size $0.25 \mathrm{~mm}$ ). Jar 609 has a brown fabric, hard (3), with mica and sand inclusions (size $0.25 \mathrm{~mm}$ ). It shows traces of contact with fire. Jars 604 and 609 have the outer surface of the foot made rough. Some vessels come from datable contexts: c. $A D$ 40-100 for 609 and 611; c. AD 70-120/30 for 604 and 608; C. AD 180-200 for $612 ;$ c. AD 210-30 for 610 . 


\section{Form J16: Jars with narrow rim}

613 Locarno-Muralto, property Meyster; cemetery, context unknown

614 Locarno-Muralto, via Scazziga; house, context unknown

Form $\mathrm{J} 16$ has a relatively narrow, out-turned rim, triangular in section. The two examples are fragments of rims only. It is therefore impossible to define the form of bodies and feet. Jar 613 has a red fabric, medium hard (2), with some mica inclusions (size $0.25 \mathrm{~mm}$ ). Jar 614 has a beige-orange fabric, medium hard to hard (2-3), with mica, granular and crushed quartz inclusions (size $0.25 \mathrm{~mm}$ ). This jar also has a girth-groove over the shoulder as decoration. None of these vessels comes from a datable context.

\section{Form J17: Jar with out-turned triangular rim}

615 Minusio, property Cadra, grave 13, c. AD 20-70

616 Locarno-Muralto, via Scazziga; house, context unknown

617 Losone-Arcegno, grave 57, c. AD 50-100

Form $\mathrm{J} 17$ has an out-turned rim, triangular in section. Jar 615 has an ovoid body with high shoulder and slightly concave foot. The rim is relatively high and is very pointed on top and outside. Its fabric is grey, soft (1), with some mica, sand, granular quartz inclusions and inclusions of organic material (size $0.25 \mathrm{~mm}$ ), and is of F-Ware. Jar 616 , although fragmentary, is similar. The fabric is black, medium hard to hard (2-3), with some mica, sand and quartz inclusions (size $0.25 \mathrm{~mm}$ ). It is of D-Ware. Both jars shows traces of contact 
with fire. Jar 615 comes from a datable context, c. AD 20-70. Jar 617 has an ovoid to globular body, a very short rim and a slightly pinched out flat foot. The fabric is grey-brown, hard (3), with mica and sand inclusions (size $0.25 \mathrm{~mm}$ ).

\section{Form J18: Jars with large bead rim and foot-disc}

618 Locarno-Muralto, via Scazziga; house, context unknown

Jar 618 is a fragment with out-turned, expanded rounded rim and foot-disc. The wall is missing. It is decorated with a girth-groove under the rim. The fabric is beige, with pink core, soft and powdery (1), with mica and granular quartz inclusions (size $0.25 \mathrm{~mm}$ ). The jar comes from the Roman house at Muralto-via Scazziga. Its exact context is unknown.

Jars with rim with internal lid seating

\section{Form J19: Jars with out-turned expanded rounded rim \\ 619 Locarno-Muralto, property Liverpool sotto, grave 1 \\ 620 Locarno-Solduno, Modern cemetery, grave 80.1}

Form $\mathrm{J} 19$ has an expanded rounded rim with internal lid seating, a high shoulder, an ovoid body, and a flat or concave foot. Jar 620 also has a slightly pinched out foot. Its fabric is brown, hard (3), with mica and sand inclusions (size $0.25 \mathrm{~mm}$ ). Jar 619 has a grey fabric, soft to medium hard (1-2), with mica, 
sand and crushed quartz inclusions (size $0.25 \mathrm{~mm}$ ), and is of F-Ware. Both show traces of contact with fire. Jar 620 has the outer surface of the foot made rough. No examples come from a datable context.

Form J20: Jars with out-turned rim with internal lid seating

Form $\mathbf{J} 20$ has an out-turned rim, triangular in section, with an internal lid seating. The foot is slightly concave or flat. According to the presence or absence of vertical neck and the form of the body, three groups can be distinguished:

- Form J20.1: Jar with ovoid body, without neck.

- Form J20.2: Jar with ovoid body and vertical neck.

- Form J20.3: Jar with ovoid/ rounded body and vertical neck.

Form J20.1

621 Ascona, grave 10, c. AD 103-50

622 Moghegno, grave 16

623 Moghegno, grave 24, c. AD 50-100

624 Locarno-Muralto, property Passalli, grave 7

625 Locarno-Muralto, property Meyster, context unknown, cemetery

Form J20.1 has a wide rim, an ovoid body with high shoulder, and a narrow flat or slightly concave foot. Jar 621 has a brown fabric, medium hard to hard (2-3), with some mica and sand inclusions. Jars 622 and 623 have beigeorange, and respectively beige-yellow fabrics, hard (3), with mica, sand and 
crushed quartz inclusions (size $0.1-0.5 \mathrm{~mm}$ ). All vessels show traces of contact with fire on the outside. Jars 621 and 622 have the outer surface of the feet made rough. Jar 622 is also decorated with a girth-groove over the shoulder. Jar 624 has an ovoid body and a flat foot. The slightly out-turned, curved rim is similar to a lid seating. Its fabric is pink, medium hard (2), with some mica inclusions (size $0.1-0.25 \mathrm{~mm}$ ). Jar 625 has an ovoid body and a slightly concave foot. The rim is vertical, triangular in section and shows an internal lid seating. The fabric is beige-brown, hard (3), with some mica inclusions (size $0.25 \mathrm{~mm})$. The surface shows traces of contact with fire. The exact context is unknown. Two vessels come from datable contexts: c. AD 50-100 for 623, and c. $A D 103-50$ for 621 .

Form $\mathrm{J} 20.2$

626 Minusio, property Cadra, grave 19, c. AD 70-120

627 Minusio, property Cadra, grave 23, c. AD 50-100

628 Locarno-Muralto, property Meyster; cemetery, context unknown

629 Locarno-Muralto, property Meyster; cemetery, context unknown

630 Cavigliano, property Monotti, grave 6, c. AD 79-100

631 Losone-Arcegno, grave 46, c. AD 80/1-130

632 Moghegno, grave 2, c. AD 70-120

633 Moghegno, grave 33, c. AD 167-90

Form $\mathrm{J} 20.2$ is similar to $\mathrm{J} 20.1$, but the rim is separated from the body by a vertical neck. The foot is sometimes slightly pinched out. Jars 628 and 629 
have brown-red fabrics, hard (3), with some mica inclusions (size $0.25 \mathrm{~mm}$ ). Both show the contact with fire on the outside.

Jar 631 has a beige-pink fabric, hard (2), with mica and sand inclusions (size $0.25 \mathrm{~mm}$ ). This vessel is decorated with a small cordon and a girth-groove under the neck. The other jars, except for 626 , have fabrics with mica, sand and crushed quartz inclusions (crushed and granular quartz inclusions by 627). Jar 627 has an orange fabric, hard (3) and inclusions of size $0.25-1 \mathrm{~mm}$. Jar 632 has an orange-brown fabric, hard (3), and inclusions of size 0.25 $0.5 \mathrm{~mm}$. Both jars shows traces of contact with fire. Jar 630 has a red fabric, medium hard to hard (2-3), also with inclusions of size $0.25-0.5 \mathrm{~mm}$, of $M$ Ware. This jar and 632 have the outer surface of the feet made rough. Jar 633 has a beige fabric, hard (3), with inclusions of size $0.1-1 \mathrm{~mm}$. The jar is decorated with a girth-groove under the neck.

Jar 626 has a beige-pink fabric, hard (3), with mica, sand, granular and crushed quartz, and grog inclusions (size $0.25-1 \mathrm{~mm}$ ), of $\mathrm{N}$-Ware. The outside shows traces of contact with fire. The outer surface of the foot is made rough. Except for the two jars from Muralto, property Meyster, the other vessels come from datable contexts: c. AD 50-130 for $626,627,630,6310$ and 632 ; C. AD $167-90$ for 633.

Form $\mathbf{J} 20.3$

634 Cavigliano, property Monotti, grave 4, c. AD 50-100

635 Cavigliano, property Monotti, grave 7, c. AD 50-100

636 Losone-Arcegno, grave 18, c. AD 86-110

637 Losone-Arcegno, grave 19, c. AD 85-100 
Form J20.3 has an ovoid body with curved wall, whose maximum width is at mid-body. The rim is separated from the body by a vertical neck, less pronounced by the two examples from Cavigliano. The foot is slightly concave or flat, by 634 slightly pinched out. Jar 634 has a beige-red fabric, hard (3), with some mica inclusions (size $0.25 \mathrm{~mm}$ ). The outer surface shows traces of contact with fire. Jar 636 also contains some mica inclusions (size $0.25 \mathrm{~mm}$ ). Its fabric is black because of the contact with fire, and medium hard (2). It is of E-Ware. The outer surface of the foot is made rough. Jar 635 has a dark grey to black fabric, burnt, hard (3), with some mica and sand inclusions (size $0.25 \mathrm{~mm})$, of D-Ware. Jar 638 has a light brown fabric, medium hard (2), with the same inclusions (size $0.1-0.25 \mathrm{~mm}$ ). Jar 637 has a beige to brown fabric, hard (3), with many mica and sand inclusions (size $0.25 \mathrm{~mm}$ ). All the three jars have the outer surface of the feet made rough. All jars come from contexts dated C. AD 50-120.

A similar vessel occurs at Angera with no context (Sena Chiesa \& Lavizzari Pedrazzini 1985, pl. 73.1).

Form J21: Jars with short collar

639 Locarno-Muralto, property Fivian; cemetery, context unknown

640 Minusio, property Cadra, grave 27

641 Gerra Gambarogno-Vairano; cemetery, context unknown 
642 Locarno-Muralto, via Scazziga; house, context unknown

643 Locarno-Muralto, via Scazziga; house, context unknown

644 Locarno-Muralto, via Scazziga; house, context unknown

645 Losone-Arcegno, grave 80, c. AD 306-50

Form J21 has a short collar with internal lid seating, an ovoid to rather globular body and a slightly concave or flat foot. The jars grouped as Form J21 are almost all different because of details of rim and body. Nevertheless, they show common features and belong therefore to the same form. Jar 639 has a high, ovoid body. The rim is pointed on the top and is narrower than the body, whose maximum width is in the upper half. The foot is flat. The fabric is red, medium hard (2), with some mica inclusions (size $0.25 \mathrm{~mm}$ ). The surface shows traces of contact with fire. The outer surface of the foot is made rough. The rims of jars 640,641 and 642 are similar: they are rounded, as wide as the maximum width of the body or slightly wider. The bodies of these jars are different: that of 640 looks flattened because of the wide foot, that of 641 rather ovoid because of the narrow foot. Jar 642 is a fragment of rim only. Jar 640 has a pale red fabric, hard (3), with mica, sand, crushed quartz and grog inclusions (size $0.25-1 \mathrm{~mm}$ ). This fabric is of $\mathrm{N}$-Ware. The surface shows traces of contact with fire. Jar 641 has a beige fabric, black on the outside because of the strong contact with fire, hard (3), with mica, sand and crushed quartz inclusions (size $0.25-0.5 \mathrm{~mm}$ ). This jar is decorated with two girthgrooves over the shoulder. Both jars have the outer surface of the feet made rough. The fragment 642 has a beige-pink fabric, black on the inside, hard (3), with some mica inclusions (size $0.25 \mathrm{~mm}$ ). Jars 643 and 644 are also similar: 
the collars are triangular in section and do not bear the internal lid seating. Jar 643 has a pink fabric inside, grey to black because of the fire on the outside, hard (3), with mica, sand and quartz inclusions (size $0.25-0.5 \mathrm{~mm}$ ). Jar 644 has a beige fabric, black on the outside, hard (3), with some mica inclusions (size $0.25 \mathrm{~mm})$. Both jars are fragmentary: according to 643 , however, they seem to have rather high ovoid body. Jar 645 has a rather flattened, 'biconical' body. The rim is wide, the foot is relatively narrow. The fabric is beige-pink, hard (3), with mica and sand inclusions (size $0.25 \mathrm{~mm}$ ). The outside shows traces of contact with fire. The outer surface of the foot is made rough. It is the only vessel of Form $\mathrm{J} 21$ from a datable context: c. AD 306-50.

Form J21 seems to occur in particular in western Lombardy and eastern Piemonte. Some examples of Form $\mathrm{J} 21$ find parallels at Milan: 640 is similar to Type 32, dating from the second half of the 1 st century $B C$ to the first half of the 1st century AD (Guglielmetti et al. 1991, 179; 180: Type 32; Caporusso et al. 1991, pl. 81.14). Jars 643 and 644 are similar to Type 21 from Milan and occur at Castelseprio, dating from the end of the 5th and the 6th century AD (Guglielmetti et al. 1991, 119-220: Type 21; Caporusso et al. 1991, pls. 45.23 and 100.16; Brogiolo \& Lusuardi Siena 1980, $481-482$ figs. 11.3, 12.1). At Angera and in the region of Varese, the Form appears from the 3rd to mid-5th century AD (Tassinari 1995, 104-5 ; Type 1) ; an example from Sesto Calende dates to the 4th century AD (Pozzi 1988, 75 fig. 69 St 55725). Form J21 also occurs at Lurate Caccivio (no context: Butti Ronchetti 1985, pl. XV.17) and appears frequently in late Roman contexts in Piemonte (Borgosesia, 3rd to 4th 
century AD, Brecciaroli Taborelli 1995, $113 ; 117$ pls. XXXII.1-2 and $4 ;$ XL.1 and 3-4).

Form $\mathrm{J} 21$ is also relatively frequent in the Roman cemetery at Stabio-Vignetto (Canton Ticino, Sottoceneri). Four examples occur in the same number of graves: 1937.426 in Grave 39, 1937.459 in Grave 41, 1937.483 in Grave 43, and 1937.490 in Grave 48 (Simonett 1941, 202-7). All graves are inhumations 'alla cappuccina', with a saddle roof made with flat tiles. The grave-goods of Stabio-Vignetto consist usually of few coarse pottery and iron tools, or even only a single coarse vessel. Italian sigillata is rare and occurs in few graves only. In general, according to the few datable grave goods, the cemetery of Stabio-Vignetto seems to be a rather late one. In fact the dating ranges from the 2 nd to the 4 th century AD. Among the jars of Form J21 at Stabio, only 1937.426 comes from a datable context. Grave 39 has a terminus post quem in the 4th century $A D$, according to the only datable grave-good: a glass beaker of Ising's Form 106c. This jar is very similar to 643 and 644 from Muralto-Via Scazziga. Two other jars from Stabio also resemble jars from Locarnese: 1937.459 to 640 and 1937.483 to 645 . Jar 1937.490 belongs to the same Form, but the rim is higher and vertical, instead of triangular in section. Other jars from Ticino were found at Cimo (Sottoceneri), and date to the 4th-5th century AD (Donati 1971, 9 pls. 5.1 and 6.1).

Similar vessels, but with a light red wash on the outer surface, occur at Segusio during Augustan-Tiberian times (Brecciaroli Taborelli 1990, 86 pls. XXXVII 128; XLI.197 : see 641 and respectively 645). 
Jars with horizontal rim

Form J22: Jars with horizontal rim

646 Locarno-Muralto, property Fivian; cemetery, context unknown

647 Locarno-Muralto, via Scazziga; house, context unknown

648 Locarno-Muralto, via Scazziga; house, context unknown

649 Locarno-Muralto, via Scazziga; house, context unknown

650 Locarno-Muralto, via Scazziga; house, context unknown

Form J22 has a horizontal rim, triangular in section. Jar 646 is complete: the body is ovoid, the foot is flat. Jar 650 has a rim rather hemispherical in section. The other examples are fragments of rims only. Jar 649 has a slightly curved wall; it is therefore possible to assume an ovoid body. The fragments of walls of 647 and 650 are rather straight. Jar 648 seems to have a rim narrower than the maximum width of the body, but the fragment is not big enough to allow one to understand the whole profile of the vessel. All fabrics are beige, except for 650 . Jar 650 has a pink to orange fabric, hard (3), with some mica and crushed quartz inclusions (size $0.25 \mathrm{~mm}$ ). Jars 646 and 648 have medium hard to hard (2-3) fabrics, with some mica inclusions (size $0.25 \mathrm{~mm})$. Jars 647 and 649 also have medium hard to hard (2-3) fabrics, but with mica and sand inclusions (size $0.25 \mathrm{~mm}$ ). Both show on the outside traces of contact with fire. Jar 649 also has combed decoration on the wall. None of these vessels come from a datable context. 
This form occurs in the cemetery of Angera dating from Flavian-Hadrianic times (Sena Chiesa \& Lavizzari Pedrazzini 1985, pl. 94.5), and at Milan, where it dates to the end of the 1st century $B C$ and the beginning of the 1st century AD (Guglielmetti et al. 1991, 95: Tipo 10; Caporusso et al. 1991, pl. 90.12). In the settlement of Angera, vessels of similar form but coarser fabric and traces of fire occur from mid-3rd to the end of the 6th century AD (Tassinari 1995, 130-1, Type 2 pl. 54.2). Other examples occur at Ghisalba (Bergamo) from the 3rd to mid-4th century AD (Sapelli 1981, 169 nos. 8-9 ; 196 fig. 5-8-9), Milan during the 5th century AD (Guglielmetti et al. 1991, 222 ; Caporusso et al. 1991, pl. 101.3), and Pieve Manerba (Brescia) from the 4th to the 6th century AD (Massa 1982, 282-3 fig. 29 Group 2a). This type seems to occur in eastern Piemonte and western Lombardy during late Roman times, in particular from settlements. A vessel of form similar to 649 occurs in fact at Monferrera (Valsesia), dating from the 5th-6th century AD (Brecciaroli Taborelli 1995, 125 pl. XXII.4).

\section{Jars with barrel-shaped body}

\section{Form J23: Jars with vertical or bead rim}

651 Locarno-Muralto, property Liverpool sopra, grave 8, c. AD 79-100

652 Locarno-Muralto, property Meyster; cemetery, context unknown

653 Losone-Papögna; cemetery, context unknown 
Form $\mathrm{J} 23$ has an ovoid body, an inturned rim and a slightly concave or flat foot. The rim is rounded and plain $(651,652)$ or expanded, rather triangular in section (653). All jars are decorated with a girth-groove on the shoulder. Jars 651 and 653 have two lugs on the shoulders and the girth-groove in between. The general form is similar to Form BK24 (e.g. 224), in particular jar 651. The other two examples have different rims. Jars 651 and 653 have beige-pink, and respectively dark beige fabrics, medium hard (2), with some mica inclusions (size $0.25 \mathrm{~mm}$ ). Jar 652 has a red fabric, hard (3), with mica and sand inclusions (size $0.25 \mathrm{~mm}$ ), of M-Ware. This jar has the outer surface of the foot made rough. Only 651 comes from a datable context, c. AD 79-100.

\section{Form J24: Jars with collar}

654 Locarno-Muralto, ex-Orselina; cemetery, context unknown

655 Locarnese, context unknown

656 Minusio, property Scascighini, grave 3, c. AD 0-30

657 Locarno-Muralto, via Scazziga; house, context unknown

658 Losone-Arcegno, grave 60, c. AD $384-400$

Form J24 has a short collar, triangular in section, sometimes with an internal lid seating. The rim is separated from the body by a high, slightly inturned neck. The body is barrel-shaped; the foot-disc is slightly concave. The decoration of these jars consists of a band of combed wavy lines on the bellies, and girth-grooves over and below the band. Sometimes the girthgrooves over the feet appear as corrugated wall. The fabrics are red to orange 
and the outer surfaces do not show traces of contact with fire. Jar 654 has a red fabric, soft and powdery (1), with some mica and sand inclusions (size 0.1$0.25 \mathrm{~mm})$. Jar 656 has an orange fabric, medium hard to hard (2-3), with some mica inclusions (size $0.25 \mathrm{~mm}$ ). Jar 655 has a red-orange fabric, hard (3), with mica and sand inclusions (size $0.25 .0 .5 \mathrm{~mm}$ ). Jar 658 has a red to brown fabric, hard (3), with few mica and sand inclusions (size $0.1-0.25 \mathrm{~mm}$ ). The fabrics of both vessels are of L-Ware. Jar 657 is a fragment of wall with wavy combed decoration only. Two jars come from datable contexts: c. AD 0-30 for 656 and $c$. $A D 384-400$ for 658 . The jar from Losone-Arcegno is probably residual.

Form J24, or its prototype, occurs at Ornavasso-San Bernardo (Graue 1974, pl. 35 , Graves 123, 147, 152), where it dates C. 50-25/15 BC (Graue 1974, 170: 'Zeitgruppe III').

\section{Form J25: Jars with vertical rounded rim}

659 Locarno-Muralto, via Scazziga; house, context unknown

Jar 659 is a fragment with vertical, rounded, slightly inturned rim and a sort of cordon underneath. Body and foot are missing. The fabric is orange, medium hard (2), with some mica inclusions. On the inside, there are traces of contact with fire. The jar comes from the Roman house at Muralto-via Scazziga. Its exact context is unknown. 
Form J26: Jars with vertical or bead rim

660 Minusio, property Cadra, grave 14, c. AD 70-120

661 Losone-Arcegno, grave 22

662 Locarno-Muralto, property Liverpool sopra, grave 4, c. AD 70-120

Form J26 has a cylindrical body with slightly curved wall and a slightly concave or flat foot. The rim is very slightly inturned, slightly expanded rounded (No. 660) or much expanded rounded (Nos. 661, 662). The general form, in particular 660, is similar to Form BK30.1 (e.g. Beaker 249). Jar 660 has a dark brown to black fabric, hard (3), with mica, sand, granular and crushed quartz inclusions (size $9.25-1 \mathrm{~mm}$ ). Jar 661 has a different, expanded rounded rim. Jar 662 is rather similar to Form BK30.3, because of the two lugs, but is also has an expanded rounded rim as 661 . Jar 661 has a dark beige fabric, hard (3), with mica and sand inclusions (size $0.25 \mathrm{~mm}$ ). Jar 662 has a red fabric, hard (3), with some mica inclusions (size $0.1-0.25 \mathrm{~mm}$ ), of LWare. Both show traces of contact with fire and have the outer surface of the foot made rough. All jars are decorated with a girth-groove on the shoulder; by 662 the girth-groove is situated between the lugs.

Two jars, 660 and 662, come from datable contexts, c. AD 70-120. Some examples of beakers of similar Form BK30.2 come from contexts with terminus post quem in the second half of the 1st century AD. 
As a jar, this form does not occur at Angera. It occurs at Milan, where it dates to the 1st and 2nd century AD (Guglielmetti et al. 1991, 157-8: Tipo 7; Caporusso et al. 1991, pl. 64.19). The example from Milan is similar to 661 .

\section{Form J27: Jars with internal lid seating \\ 663 Locarno-Muralto, via Scazziga; house, context unknown}

Jar 663 is a fragment with slightly out-turned, rounded rim, with internal lid seating. According to the fragment of wall, the body was cylindrical and decorated with two girth-grooves. The fabric is orange, hard (3), with some mica inclusions (size $0.25 \mathrm{~mm}$ ). The jar comes from the Roman house at Muralto-via Scazziga. Its exact context is unknown.

\section{Jars with globular body}

\section{Form J28: Jar with short vertical rim}

664 Ascona, grave 1, c. AD 80-130

665 Tenero, grave 68, c. AD 71-120

Form $\mathrm{J} 28$ has a globular body and a short, vertical and rounded rim. The two jars are different and belong to a same form only because of these general features. Jar 664 has a globular to conical body with a high shoulder, a vertical rounded rim, narrower than the shoulder, and a slightly pinched out flat foot. 
The body is decorated with a girth-groove on the shoulder. The fabric is beige, medium hard to hard (2-3), with some mica and sand inclusions (size $0.25 \mathrm{~mm}$ ). The surface shows traces of contact with fire and the outer surface of the foot is made rough. Jar 665 has a globular body, a carinated shoulder, and a slightly concave foot. The rounded rim is slightly out-turned and narrower than the maximum width of the vessel, set at mid-body. The fabric is beige, black on the outside because of the contact with fire, medium hard (2), with some mica inclusions (size $0.25 \mathrm{~mm}$ ). Both jars come from contexts dated c. $A D 70-130$.

A vessel, similar to 665, but handmade, was found at Arsago Seprio (Varese) and dated to the end of La Tène (St 48170 : Tassinari 1986, 162 and note 17 ; pls. VIII.2 and XII.2).

\section{Form J29: Jars with out-turned rim with internal lid seating}

Form $\mathrm{J} 29$ has an out-turned rim, triangular in section, with an internal lid seating. The foot is slightly concave or flat. According to the presence or absence of vertical neck, two groups can be distinguished:

- Form J29.1: Jar with globular body, without neck.

- Form J29.2: Jar with globular body and vertical neck.

Form $\mathbf{J} 29.1$

666 Locarno-Solduno, Modern cemetery, grave 58.15

667 Moghegno, grave 34, c. AD 71-120 
Form J29.1 has a slightly flattened body with a curved wall. The foot is slightly concave or flat. The fabrics are beige to beige-orange and hard (3). Jar 666 has mica and sand inclusions (size $0.25 \mathrm{~mm}$ ). It is decorated with a small cordon on the neck. The two jars from Moghegno have fabrics with mica, sand and crushed quartz inclusions (size $0.25-0.5 \mathrm{~mm}$ ). Both have the outer surface of the feet made rough. The two jars from Moghegno come from contexts dated c. AD 70-150.

This form occurs at Angera dating from Claudian-Neronian times (Sena Chiesa \& Lavizzari Pedrazzini 1985, pl. 94.1).

Form $\mathbf{J} 29.2$

669 Moghegno, grave 15, c. AD 71-120

Form J29.2 is similar to Form J29.1, but the rounded rim is separated from the body by a vertical neck. The foot is slightly concave. Jar 669 has a beige fabric on the outside and an orange one on the inside, medium hard (2), with some mica and sand inclusions (size $0.1 \mathrm{~mm}$ ). The surface shows traces of contact with fire. The jar is decorated with a girth-groove on the shoulder. It comes from a grave dated c. AD 71-120. 


\section{Handled jars}

\section{Form J30: Jars with ovoid body}

670 Locarno-Muralto, property Passalli, by grave 10

671 Locarno-Muralto, property Liverpool sopra, grave 2

672 Locarno-Muralto, property Meyster; cemetery, context unknown

Form J30 has an out-turned rim, an ovoid body, two elongated handles, and a flat or slightly concave foot. The three examples belong to the same form because of their general features, but are different in detail. Jars 670 and 671 have bifid out-turned rims with internal bevels and three-ribbed handles. Jar 670 is complete and its body has the maximum width in the lower half. The fabric is red, hard (3), with some mica and sand inclusions (size $0.25-0.5 \mathrm{~mm}$ ), and is of L-Ware. The outer surface of the foot is made rough. Jar 671 is fragmentary and the rim is only slightly made bifid by a girth-groove; its fabric is beige with a wide grey core, hard (3), with mica, sand, granular and crushed quartz inclusions (size $0.25-1 \mathrm{~mm}$ ). Jar 672 (E-Ware) consists of fragments of two six-ribbed handles. According to the fragment of wall, the body was ovoid. This vessel was relatively small in comparison to the other handled jars, and probably had the size of a cup. Its fabric is grey with wide black areas on the outside as result of the contact with fire, hard (3), with some mica inclusions (size $0.1 \mathrm{~mm}$ ). No examples come from datable contexts.

Form J30 occurs at Angera, where the example is similar to 670 and dates to Flavian times (Sena Chiesa \& Lavizzari Pedrazzini 1985, pl. 95.1). 


\section{Form J31: Jars with globular body}

673 Locarno-Muralto, property Märki; cemetery, context unknown

Form J31 has a short and vertical collar with an internal lid seating, a biconical to globular body, two pointed handles, triangular in section, and a slightly concave foot. The handles are two-ribbed. The fabric is beige-pink, medium hard (2), with mica and grog inclusions (size $0.25-1 \mathrm{~mm}$ ). It is of $\mathrm{N}$-Ware. The outer surface of the foot is made rough. The exact context of this jar is unknown.

Similar vessels, slightly taller, occur at Legnano (Milan) dating from AugustanTiberian times (Cattaneo 1996b, pl. 12.4), and at Angera dating from the 2nd century AD (Troso \& Uglietti 1985, 115 pl. 31.9).

\section{Form J32: Jars with conical body \\ 674 Locarno-Muralto, property Meyster; cemetery, context unknown}

675 Locarno-Muralto, via Scazziga; house, context unknown

Jars 674 and 675 are respectively fragments of jars and handles, and a fragment of handle only. Both vessels have a circular handle, instead of an elongated one, but also are different. Because of their poor conservation, it is not possible to define if these vessels had one or two handles. Jar 674 has a short, out-turned, rounded rim, ovoid body with high shoulder, and tapering towards the flat foot. The ring-handle is circular in cross-section. Its fabric is 
beige-pink, medium hard (2), with some mica inclusions (size $0.25 \mathrm{~mm}$ ). The surface is burnished. Jar 675 consists of a fragment of ring-handle. The crosssection is irregularly oval. The fabric is orange. hard (3), with some mica inclusions (size $0.25 \mathrm{~mm}$ ). None of these vessels comes from a datable context.

No parallels for these jars have been found. 